\title{
Field perceptions of the Vision Initiative for Children's preschool vision screening training model
}

\author{
P. Kay Nottingham Chaplin \\ West Virginia University
}

Follow this and additional works at: https://researchrepository.wvu.edu/etd

\section{Recommended Citation}

Nottingham Chaplin, P. Kay, "Field perceptions of the Vision Initiative for Children's preschool vision screening training model" (2006). Graduate Theses, Dissertations, and Problem Reports. 4252.

https://researchrepository.wvu.edu/etd/4252

This Dissertation is protected by copyright and/or related rights. It has been brought to you by the The Research Repository @ WVU with permission from the rights-holder(s). You are free to use this Dissertation in any way that is permitted by the copyright and related rights legislation that applies to your use. For other uses you must obtain permission from the rights-holder(s) directly, unless additional rights are indicated by a Creative Commons license in the record and/ or on the work itself. This Dissertation has been accepted for inclusion in WVU Graduate Theses, Dissertations, and Problem Reports collection by an authorized administrator of The Research Repository @ WVU.

For more information, please contact researchrepository@mail.wvu.edu. 
Field Perceptions of the

Vision Initiative for Children's

Preschool Vision Screening Training Model

P. Kay Nottingham Chaplin

Dissertation submitted to the College of Human Resources and Education

at West Virginia University

in partial fulfillment of the requirements for the degree of

Doctor of Education

in

Special Education

Elizabeth A. Dooley, Ed.D. Chair

Geoffrey E. Bradford, M.D.

Barbara L. Ludlow, Ed.D.

Barbara G. Warash, Ed.D.

Jaci Webb-Dempsey, Ph.D.

Department of Educational Theory and Practice

Morgantown, West Virginia

2006

Keywords: preschool vision screening, program evaluation, training

Copyright 2006 P. Kay Nottingham Chaplin 


\author{
Abstract \\ Field Perceptions of the Vision Initiative for Children's \\ Preschool Vision Screening Training Model \\ P. Kay Nottingham Chaplin
}

Because lay vision screeners rarely receive formal training in how to screen vision and because older children were seen in clinic with vision disorders that should have been detected earlier through vision screening, a pediatric ophthalmologist and the researcher created the Vision Initiative for Children (VIC) in 2001 as a statewide program of the West Virginia University Eye Institute. VIC has trained, equipped, and provided ongoing support to lay individuals who are mandated or want to screen preschoolers' vision. This program evaluation study explored, from the perspective of Head Start personnel, whether VIC prepares Head Start personnel to screen preschoolers' vision and whether participants encountered screening experiences that were not discussed during VIC's workshop. Forty-seven participants, representing 8 of the state's 24 Head Start grantees, completed an evaluation at the end of each workshop; 27 completed a postworkshop evaluation after screening vision. The workshop evaluation captured perceptions of the instructional content and delivery system, the instructor's skills in teaching and delivering the content, and the logistical arrangements. The postworkshop evaluation captured perceptions of the workshop after screening vision. This study also explored whether participants learned new vision screening knowledge, as measured by the difference between pretest and posttest scores administered at the workshop; whether they maintained knowledge, as measured by the difference in scores between the workshop posttest and a 3-month posttest; and which of VIC's job aids they preferred. Results yielded positive perceptions and indicated that participants learned and maintained a significant amount of knowledge, regardless of education. Participants preferred a flowchart (96\%) and handout packet (92\%) over a web site (15\%) as job aids for transferring learning from the workshop to the workplace. Results indicated that $44 \%$ of participants encountered no vision screening experiences that were not discussed during the workshop; 56\% encountered distracting screening environments, uncooperative younger children, and concerns that pediatricians, in follow-up exams, reported vision was "good" although children failed vision screening. Additionally, $92 \%$ of participants reported that animated Microsoft PowerPoint slides enhanced their learning, 96\% reported that receiving instructor feedback during practice enhanced their learning, $100 \%$ reported that practicing tests were necessary parts of a vision screening workshop, and $98 \%$ reported that an instructor's modeling and demonstration of tests were necessary parts of a vision screening workshop. 


\section{Acknowledgements}

I wish to thank my committee members for their assistance and continuous support and encouragement in navigating and completing this process. Second, I wish to thank the West Virginia University Libraries personnel for their phenomenal research system and assistance. Conducting the literature review without this system would have been quite arduous. Third, I thank the Head Start participants who gave their time to fulfill activities for this study. I also want to thank Dr. D. J. Hendricks, who patiently provided guidance on statistics. Finally, I wish to thank my family members for their patience, support, and understanding. 


\section{Table of Contents}

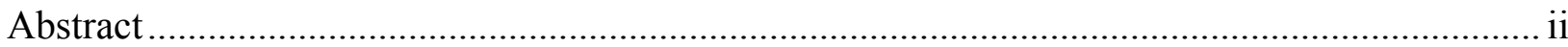

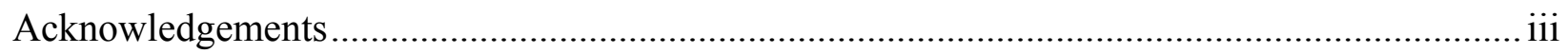

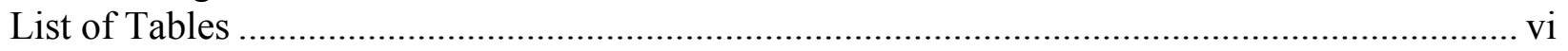

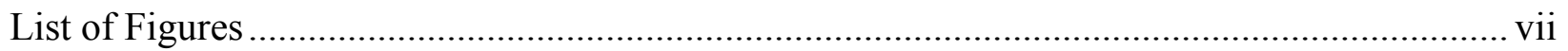

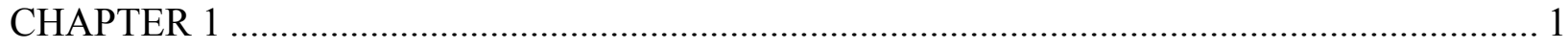

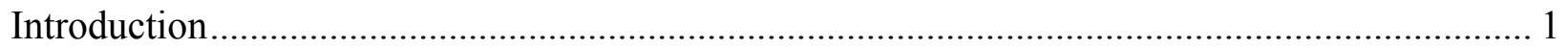

Overview of the Research Problem ..................................................................................... 2

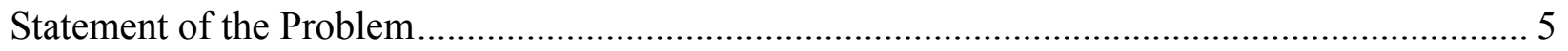

Research Questions ...................................................................................................... 5

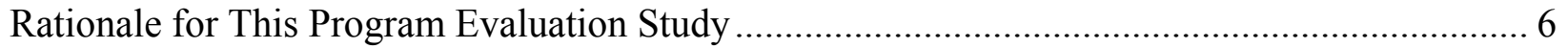

Contribution of the Program Evaluation Study to the Field of Preschool Vision Screening ........ 7

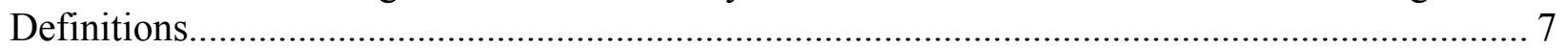

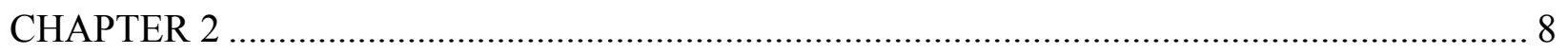

Literature Review......................................................................................................... 9

Vision Initiative for Children's Preschool Vision Screening Model ...................................... 10

Previous Vision Initiative for Children's Studies ................................................................ 12

Pilot Study of the Vision Initiative for Children's Preschool Vision Screening Model.............. 13

Seven Tenets of the Rational for This Program Evaluation Study ......................................... 14

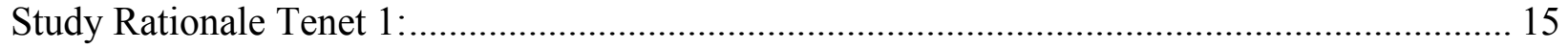

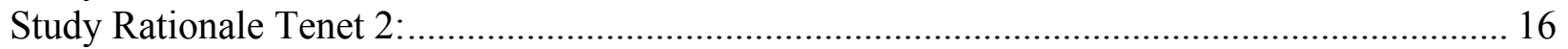

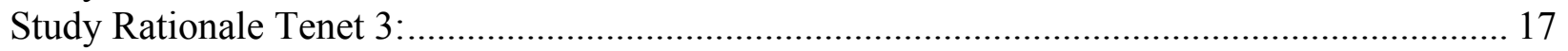

Common Early Childhood Vision Disorders.................................................................... 18

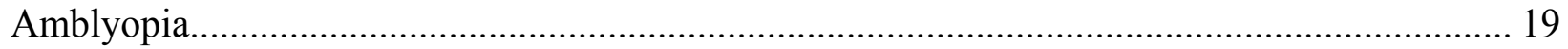

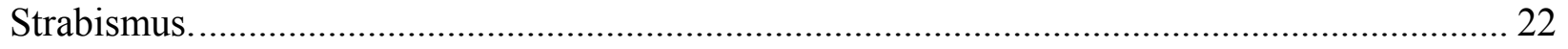

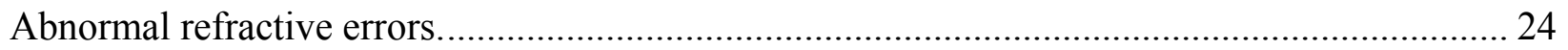

Quality of life issues associated with early childhood vision disorders .................................. 25

Costs associated with undetected early childhood vision disorders ...................................... 26

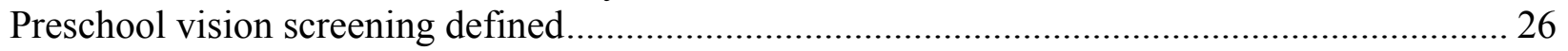

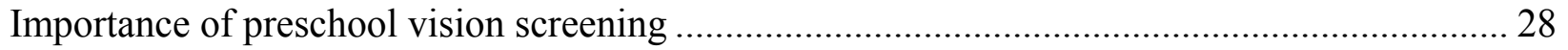

State and federal Mandates or Guidelines to Screen Vision of Preschoolers ............................ 32

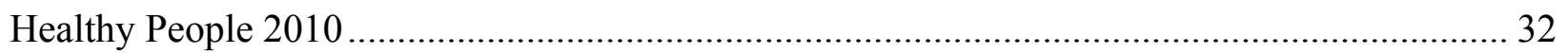

United States Preventive Services Task Force................................................................... 32

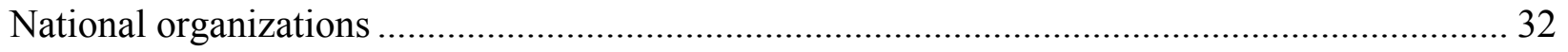

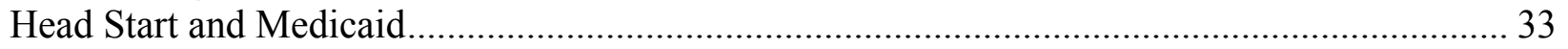

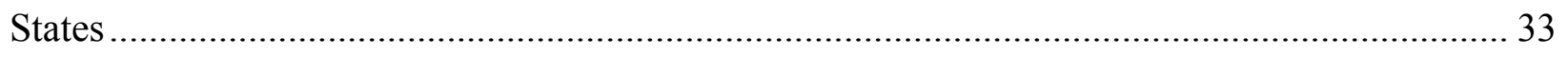

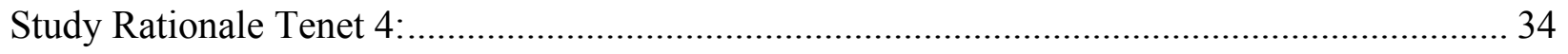

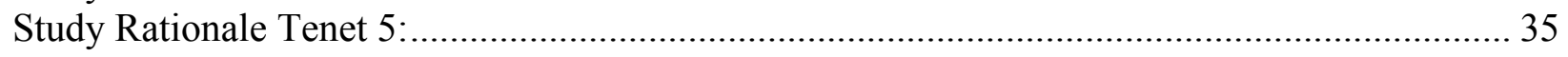

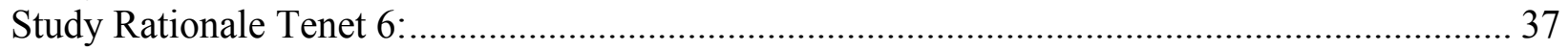

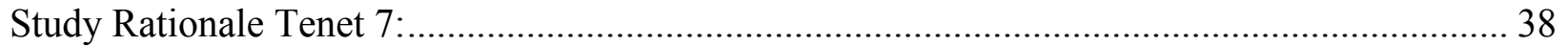

Literature Supporting the Eight Guiding Principles ........................................................ 39

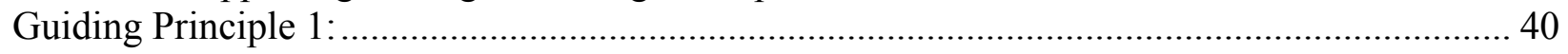

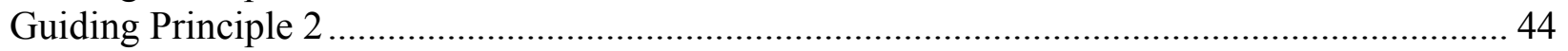

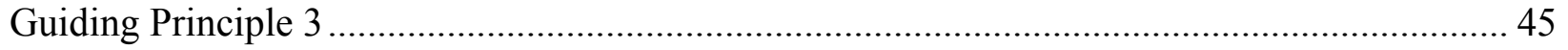

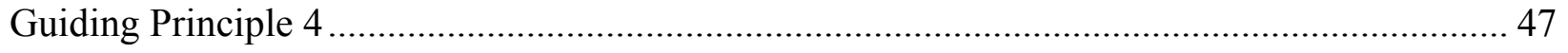




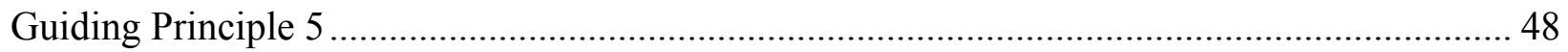

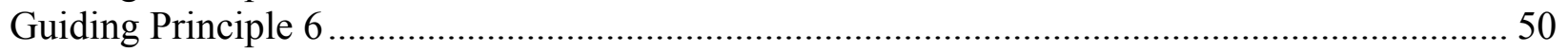

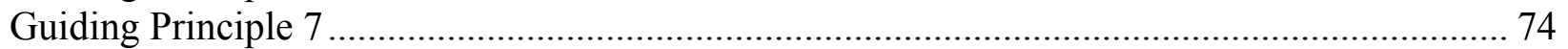

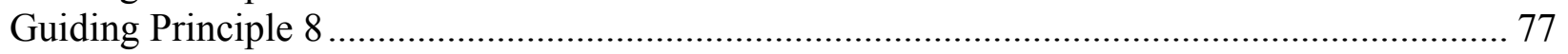

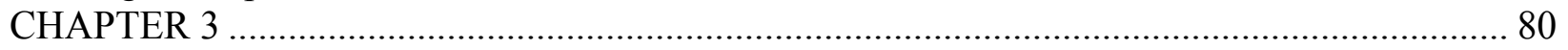

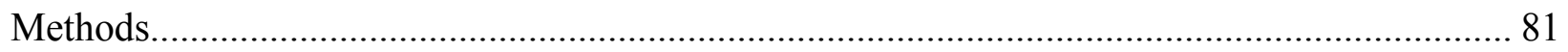

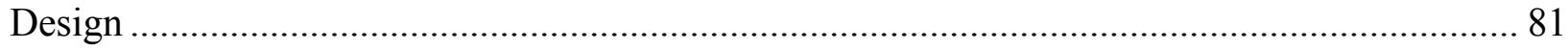

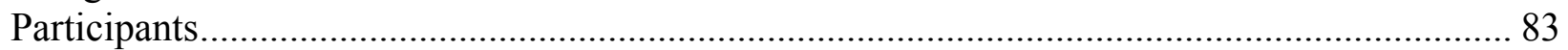

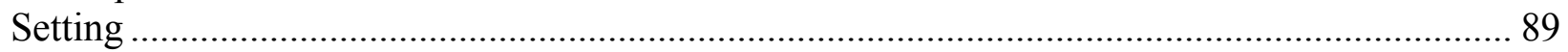

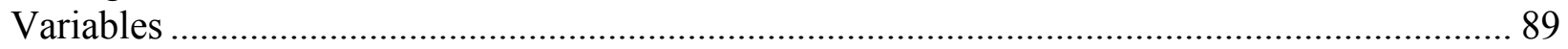

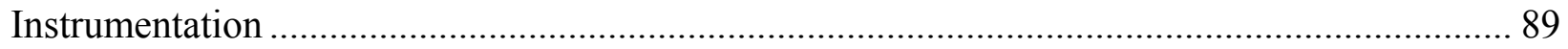

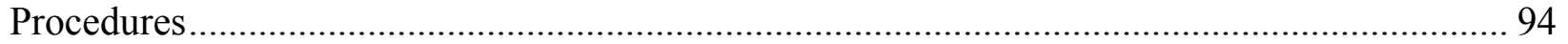

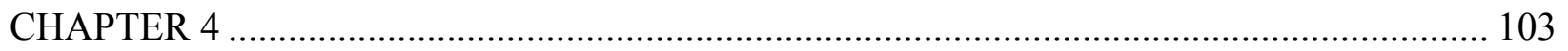

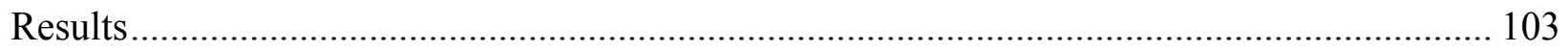

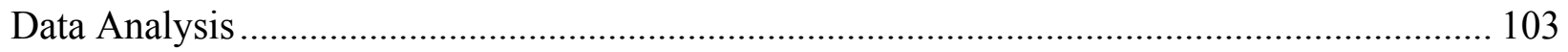

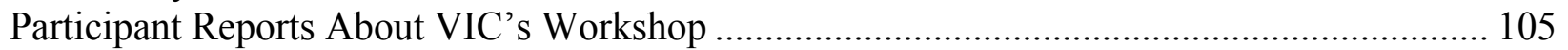

Participant Reports About VIC's Workshop After Screening Vision ......................................... 120

Effectiveness of Workshop in Preparing Participants to Screen Vision.................................... 120

Did Participants Learn New Preschool Vision Screening Knowledge at VIC's Workshop?..... 121

Did Participants Maintain Knowledge Learned at VIC's Workshop?....................................... 123

Job Aids Participants Reported Using to Transfer Knowledge From the Workshop to Practice 125 Events Occurring During Vision Screening That Were Not Discussed in VIC's Workshop..... 128

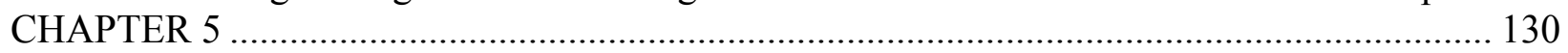

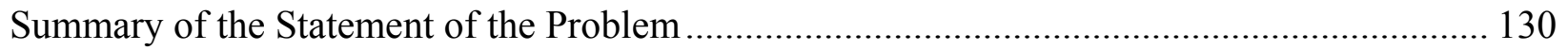

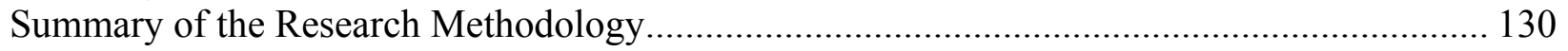

Conclusion of Research Findings ................................................................................. 131

Relationship of Findings Regarding the Purpose of the Study to Previous Research ................ 132

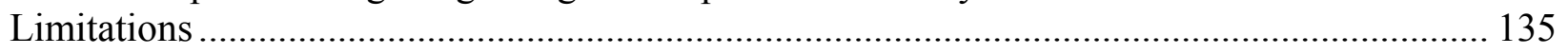

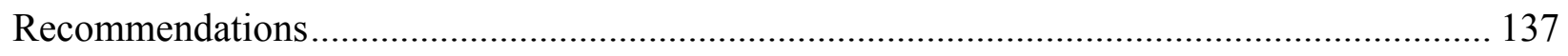

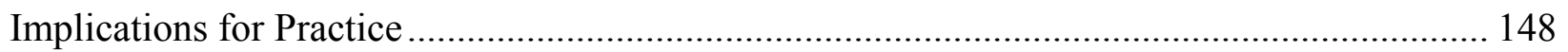

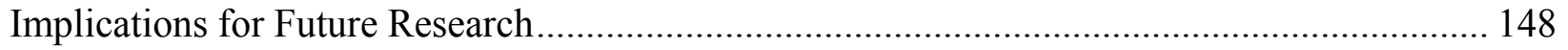

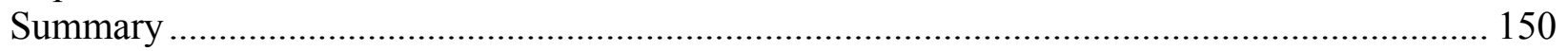

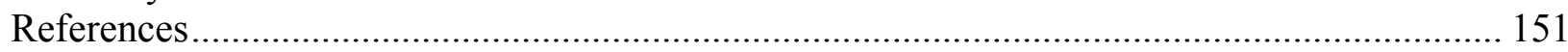

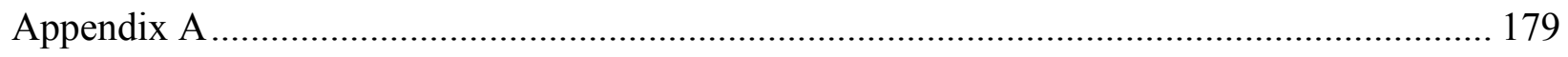

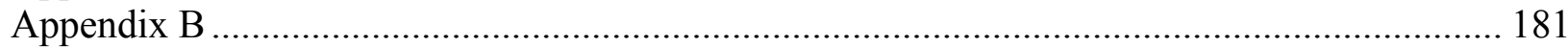

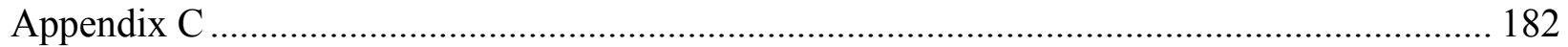

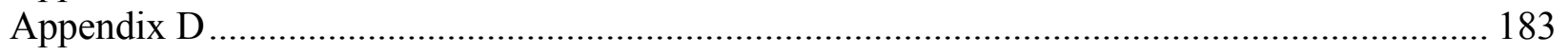

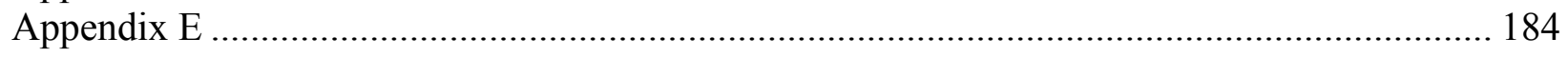

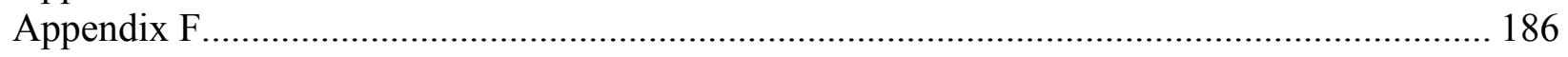

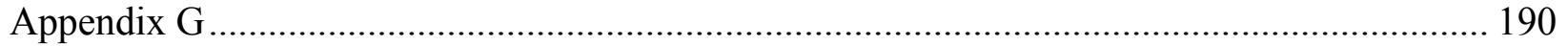

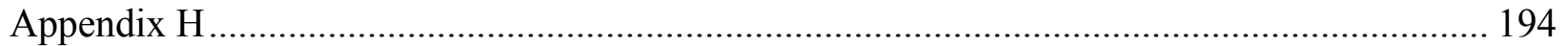

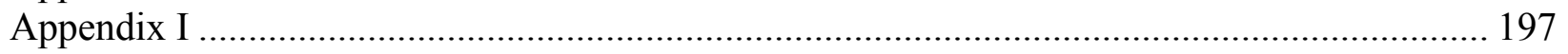

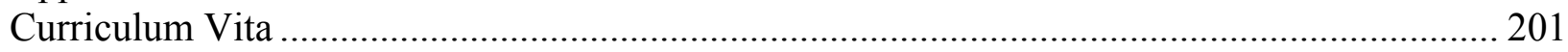




\section{List of Tables}

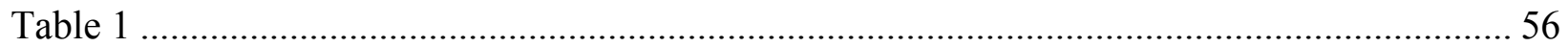

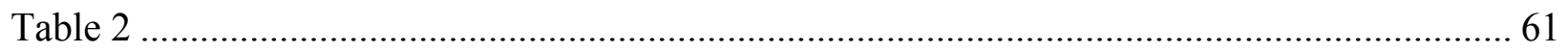

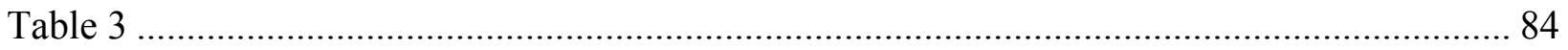

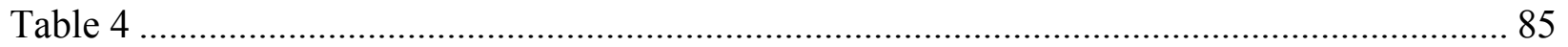

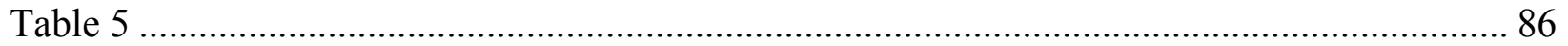

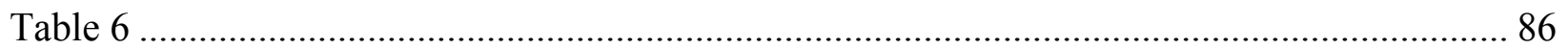

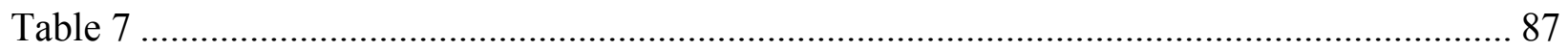

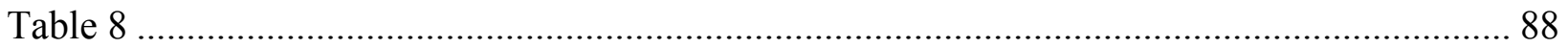

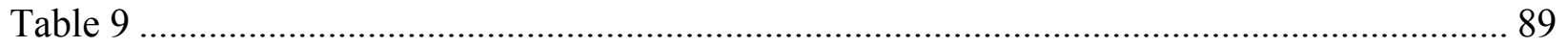

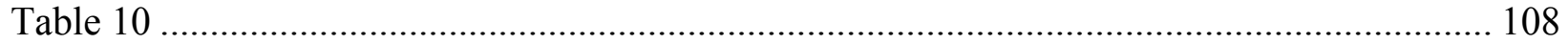

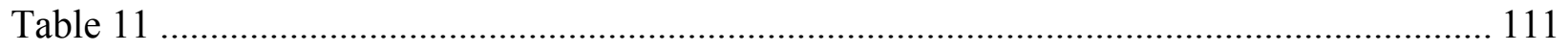

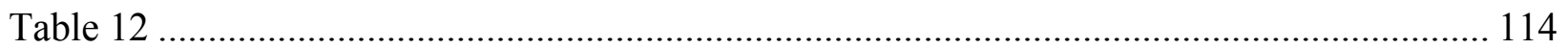

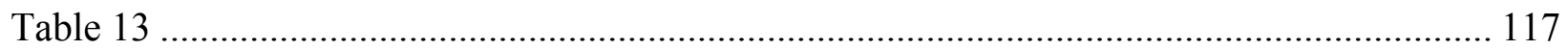

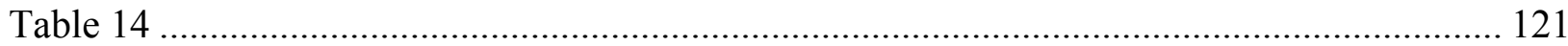

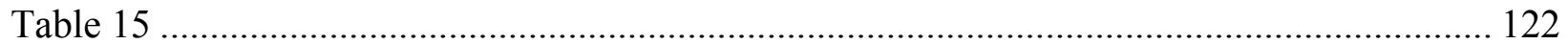

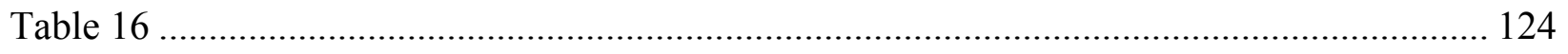

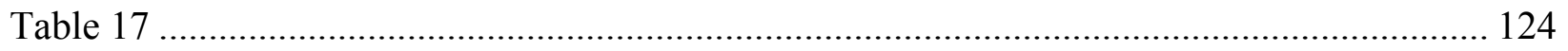

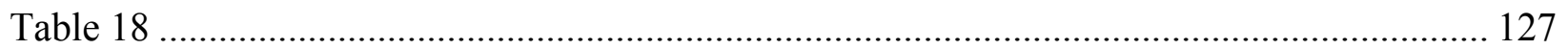

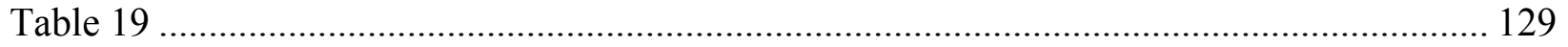




\section{List of Figures}

Figure 1. Frequency of 47 participants' tallied responses as scores for 17 items in the Instructional Content and Delivery subscale of the Workshop Evaluation administered at the end of each workshop. Tallied responses fluctuated from a low of 50 to the possible score of 63. 107

Figure 2. Frequency of 47 participants' tallied responses as scores for 15 items in the Instructor Skills subscale of the Workshop Evaluation administered at the end of each workshop. Tallied responses fluctuated from a low of 24 to the possible score of 45 . 110

Figure 3. Frequency of 45 participants' tallied responses as scores for 5 items in the Logistical Arrangements subscale of the Workshop Evaluation administered at the end of each workshop. Tallied responses fluctuated from a low of 3 to the possible score of 15. 


\section{CHAPTER 1}

\section{Introduction}

Many instructors who train lay people to screen vision possess content expertise but lack training in how to help adults learn. Many early care and education and primary care medical practice professionals are mandated to screen vision of preschoolers as a function of their job responsibilities. Five years of experience training adults to screen vision through the West Virginia University Vision Initiative for Children's (VIC) preschool vision screening training model suggests that many of these professionals receive only informal training in preschool vision screening tests and methodology. For example, oftentimes these professionals receive a vision screening test manual prior to screening children's vision, but no formal instruction or demonstration on how to use screening tests. Yet, these professionals are commonly the frontline personnel tasked with identifying potential common vision disorders that occur in up to 1 in 10 or 1 in 20 young children, disorders that can lead to permanent vision impairment if these vision problems are not detected and treated early.

Common, treatable, yet often undiagnosed, pediatric eye disorders result in an unnecessarily high prevalence of permanent vision loss in young children. Common causes of visual impairment in young children include amblyopia (lazy eye) and its risk factors and refractive errors (nearsightedness, farsightedness, and astigmatism) disassociated with amblyopia. Amblyogenic risk factors include strabismus (eye misalignment), anisometropia (a large difference in refractive power between the two eyes), cataract (lens opacity), and ptosis (drooping eyelid).

Research suggests that visual impairment caused by refractive error, amblyopia, strabismus, and astigmatism affects $5 \%$ to $10 \%$ of preschoolers (Calonge, 2004). These common vision disorders that can lead to permanent vision impairment if they are not detected and treated early, preferably before a child reaches age 4 (Simon \& Kaw, 2001a; Wasserman, Croft, \& Brotherton, 1992).

If left undetected and uncorrected, strabismus and highly abnormal refractive errors can lead to amblyopia, which has been defined as a central nervous system phenomenon where the brain fails to process visual cues accurately when a young child is unable to form a clear visual image in one or both eyes (Bacal, Rousta, \& Hertle, 1999). Amblyopia, considered a public health concern (Brooks, 1996), has also been defined as poor vision from lack of use and 
uncorrectable with prescription glasses (Calhoun, n.d.), vision loss as a result of inadequate visual stimulation during development of the brain's visual pathways (Teplin, 1995), and reduced visual acuity in the absence of organic disease, which cannot be improved by eye glasses alone (Snowdon \& Stewart-Brown, 1997). Any condition that affects normal visual development can cause amblyopia, such as strabismus, abnormal refractive errors, and cataract (National Eye Institute, 2005).

Amblyopia has been reported as the prevalent cause of visual impairment in childhood (Bacal \& Hertle, 1998; Bacal et al., 1999; National Eye Institute, 2005; The Pediatric Eye Disease Investigator Group, 2002), the most common cause for vision loss in individuals under age 40 (Brooks, 1996), and the predominant cause of impaired vision among adults 25 to 74 years of age (Ganley \& Roberts, 1983; Krueger \& Ederer, 1984). Additionally, when compared with the general population, individuals with amblyopia are at a higher risk of becoming blind (Kemper, Harris, Lieu, Homer, \& Whitener, 2004; Tommila \& Tarkkanen, 1981). For example, Tommila and Tarkkanen reported that school-aged children and adults with amblyopia, when compared to individuals in the general population, are more likely to lose vision in the better eye as a result of trauma and disease.

While preschool children generally can function using one eye when vision in the other eye is severely reduced (Dubowy, 2005), some researchers and eye care professionals have linked vision problems in young children with behavioral risk, delayed early childhood development, an interference in academic performance, and social development problems, such as low self-esteem (e.g., see Bane \& Beauchamp, 2001; Johnson, Nottingham, Stratton, \& Zaba, 1996; Käsmann-Kellner \& Ruprecht, 2000; Koller, 2002; Koller \& Goldberg, 2000; Romano, 1990; Yawn, Lydick, Epstein, \& Jacobsen, 1996).

Community-based preschool vision screening is one approach to detecting vision disorders in young children. Routine vision screening with simple, age- and developmentally appropriate tests can identify vision problems early, before irreversible damage is done (Bacal et al., 1999).

\section{Overview of the Research Problem}

Passage of Public Law 99-457, the federal law requiring a statement regarding health status, including vision, when determining eligibility for early intervention services, led to mandatory vision screening for children entering Head Start (Ciner et al, 1998). Head Start has a 
federal mandate to screen vision or collect vision screening results from children's primary care physicians within 45 days of a child's enrollment (Head Start Program Performance and Other Regulations, 2001) Head Start's Program Performance Standards neither dictates particular pedagogy for teaching personnel to screen nor provides guidelines regarding screening tests to use.

To illustrate the vast number of children requiring vision screening, during the 2002-2003 Head Start program year, Head Start nationally served 909,608 children. Of that number, 87\% ( $n$ $=791,359)$ were aged 3 and 4. Eighty-nine percent of the children were enrolled in health insurance programs; yet, $83 \%$ of the $89 \%$ with health insurance were enrolled in Medicaid's Early and Periodic Screening, Diagnosis and Treatment (EPSDT) program or a state sponsored child health insurance program (Head Start Program Fact Sheet, 2005). EPSDT is Medicaid's comprehensive and preventive child health program for individuals from birth to age 21 . The EPSDT component of the federal Medicaid program does not contain an explicit requirement to screen vision. However, an assumption exists that vision screening is part of a child's general health screening (C. Ruff, personal communication, July 30, 2004).

Head Start Program Performance Standards present Head Start personnel the option of screening vision or obtaining vision screening results from other entities, such as Medicaid's EPSDT program (Head Start Program Performance and Other Regulations, 2002). However, relying on screening results from primary care medical practices can be problematic. For example, various studies, including a VIC-initiated study, found that preschool vision screening in the primary care medical practice setting is inconsistent and that 3-year-old children are screened less often than 4-year-old children, who are screened less often than 5-year-old children (American Academy of Pediatrics, n.d.; Bradford, Nottingham Chaplin, \& Odom, 2003; Campbell \& Charney, 1991; Marcinak \& Werntz Yount, 1995; Wall et al., 2002; Wasserman et al., 1992). Further, another study conducted with family practice and pediatric physicians and residents at West Virginia University suggested that many primary care physicians appear to be unaware of current methods for preschool vision screening and would like better training in this area (Bradford, Wadia, \& Nottingham Chaplin, 2004).

In an article frequently cited in the preschool vision screening literature, Simons (1996) reported that working with young children is challenging and, regardless of the test modality used to detect vision disorders in young children, test performance is dependant on adequate 
training in test administration. Simons further stated that because diverse individuals screen vision, "there is a clear need for some means of assuring that a screener has the necessary expertise to use a given test effectively" (p. 22).

Other experts in the preschool vision screening field have postulated that (a) oftentimes individuals in community settings, as a result of insufficient training, will modify screening protocols, which may significantly reduce the detection of amblyopia (Marsh-Tootle, 1998); (b) thorough and careful training is required for screening personnel to consistently use vision screening tests and methods to maintain a screening program's integrity (Shoemaker, 1998), (c) extensive didactic and hands-on instruction by experienced trainers enhance the performance of screening tests (The Vision in Preschoolers Study Group, 2004), and (d) repeated training sessions through videotaped or computerized training material may promote a more lasting impact than a single workshop on screening frequency (Hered \& Rothstein, 2003).

The necessity for preschool vision screening training and follow-up was recently highlighted in two national studies (Hartmann et al., 2006; The Vision in Preschoolers Study Group, 2004) and one state study (Hered \& Rothstein, 2003). Both national studies suggested the need for extensive and didactic preschool vision screening training. Neither study explicitly prescribed training content nor how best to deliver the content to lay individuals. In the state study, Hered \& Rothstein recommended videotaped or computerized training programs to supplement a single workshop training format for primary care physicians. This study did not describe what the training materials should include.

A literature review revealed a plethora of material regarding principles of "good" teaching methods but none that linked these principles to preschool vision screening. The literature review produced only one published article that included a description of program evaluation activities for a vision screening program, but the program evaluation focused on an adult vision screening program (Shoemaker, 1997). The literature review also produced a poster session that included language about modifying a preschool vision screening training program as a result of Head Start parent responses to an end-of-workshop evaluation; however, the results were neither explicitly discussed in the poster nor published (B. Moore, personal communication, December 8, 2005). Moreover, this literature review failed to unearth material specifically linking good teaching methods or principles of practice to workshops for training heterogeneous individuals to screen the vision of preschoolers. To facilitate this critical missing linkage, the 
literature review for this study brings together the preschool vision screening literature and the educational and professional development and training literature.

\section{Statement of the Problem}

The lack of research regarding preschool vision screening training programs suggests that a research-based training model does not exist, thus creating the need for a model to emerge. Because lay vision screeners rarely receive formal training in how to screen vision and because older children were seen in a pediatric eye clinic with vision disorders that should have been detected earlier through vision screening, a pediatric ophthalmologist, Geoffrey Bradford, MD, and the researcher created the Vision Initiative for Children (VIC) in 2000 as a statewide outreach program of the West Virginia University Eye Institute. VIC trains, equips, and provides ongoing support to lay individuals who are mandated, or have a desire, to screen the vision of children ages 3, 4, and 5. Through VIC's model, lay individuals participate in interactive, faceto-face workshops and receive age-appropriate screening tests and ongoing support. VIC has trained more than 1,000 individuals; its database holds nearly 15,000 vision screening events. Trained individuals include Head Start employees, school health nurses, primary care practice nurses, pediatricians, and child care providers. VIC currently partners with lay screeners in West Virginia, but plans to expand its program to Head Start programs in other states. The purpose of this study was to explore, from the perspective of Head Start personnel, whether the Vision Initiative for Children prepares Head Start personnel to screen the vision of preschoolers and whether Head Start participants encounter screening experiences that were not discussed during VIC's workshop.

\section{Research Questions}

To explore VIC from the perspective of Head Start personnel, this program evaluation study attempted to answer six research questions. Five of the 6 research questions include a total of 12 subquestions:

1. What do participants report about VIC's workshop?

a. Across all participants, what do participants report about the instructional content and delivery system of VIC's preschool vision screening workshop?

(1) Is there a significant difference in means on participants scores in instructional content and delivery system due to education? 
b. Across all participants, what do participants report about the workshop instructor's teaching skills?

(1) Is there a significant difference in means on participant scores in instructor skills due to education?

c. Across all participants, what do participants report about the logistical arrangements of VIC's preschool vision screening workshop?

(1) Is there a significant difference in means on participant scores in logistical arrangements due to education?

2. What do participants report about VIC's workshop after they screen vision?

a. Across all participants, do participants report that the overall workshop was effective in preparing them to screen vision?

b. Across all participants, what additional support do participants report they need from VIC to screen the vision of preschoolers?

3. Do participants learn new preschool vision screening knowledge at VIC's workshop?

a. Is there a significant difference in means on participants' scores between the pretest and posttest?

b. Is there a significant difference in means on participants' scores between the pretest and posttest due to education?

4. Do participants maintain knowledge learned at VIC's workshop?

a. Is there a significant difference in means on participants' scores between the workshop posttest and the 3-month posttest?

b. Is there a significant difference in means on participants' scores between the workshop posttest and the 3-most posttest due to education?

5. What job aids do participants report using to transfer learned knowledge from the workshop to practice?

6. What occurred during preschool vision screening that was not discussed in VIC's workshop?

\section{Rationale for This Program Evaluation Study}

The rationale for this program evaluation study included seven tenets:

1. Head Start personnel are mandated to screen vision, yet Head Start Program Performance Standards do not describe how Head Start personnel should be formally trained to screen vision. 
2. Head Start personnel may obtain vision screening results from primary care physicians, yet studies suggest that primary care physicians inconsistently screen vision of children ages 3 and 4 .

3. An unnecessarily high number of preschool-aged children have vision disorders that can be detected and treated as a consequence of vision screening.

4. Lay screeners in community settings, when insufficiently trained, will oftentimes modify screening protocols, which may significantly reduce the detection of amblyopia.

5. Various preschool vision screening experts have suggested that vision screening training programs will help ensure accurate and reliable implementation of vision screening tests used by lay individuals in community settings.

6. No empirically studied training model currently appears to exist for training lay individuals to screen the vision of preschoolers.

7. A linkage appears to be nonexistent between preschool vision screening literature calling for training and educational and professional development literature describing how to teach and what workshops should entail.

Contribution of the Program Evaluation Study to the Field of Preschool Vision Screening

Results of this program evaluation study will help demonstrate whether one faction of lay screeners, Head Start participants, believes the Vision Initiative for Children's Preschool Vision Screening Model prepares them to screen the vision of preschoolers. If this vision screening training model prepares lay screeners to screen the vision of preschoolers, VIC's model may provide instructors and curriculum designers with essential knowledge for effectively helping adults learn to screen the vision of children ages 3,4 , and 5 .

\section{Definitions}

All definitions were described in Chapter 2 after they were introduced. 


\section{CHAPTER 2}

\section{Review of the Literature}

The purpose of this study was to explore, from the perspective of Head Start personnel, whether the Vision Initiative for Children (VIC) prepares Head Start personnel to screen the vision of preschoolers and whether Head Start participants encounter screening experiences that were not discussed during VIC's workshop. This West Virginia University Institutional Review Board-approved program evaluation study attempted to answer six research questions, which included a total of 12 subquestions:

1. What do participants report about VIC's workshop?

a. Across all participants, what do participants report about the instructional content and delivery system of VIC's preschool vision screening workshop?

(1) Is there a significant difference in means on participants' scores in instructional content and delivery system due to education?

b. Across all participants, what do participants report about the workshop instructor's teaching skills?

(1) Is there a significant difference in means on participants' scores in instructor skills due to education?

c. Across all participants, what do participants report about the logistical arrangements of VIC's preschool vision screening workshop?

(1) Is there a significant difference in means on participants' scores in logistical arrangements due to education?

2. What do participants report about VIC's workshop after they screen vision?

a. Across all participants, do participants report that the overall workshop was effective in preparing them to screen vision?

b. Across all participants, what additional support do participants report they need from VIC to screen the vision of preschoolers?

3. Do participants learn new preschool vision screening knowledge at VIC's workshop?

a. Is there a significant difference in means on participants' scores between the pretest and posttest?

b. Is there a significant difference in means on participants' scores between the pretest and posttest due to education? 
4. Do participants maintain knowledge learned at VIC's workshop?

a. Is there a significant difference in means on participants' scores between the workshop posttest and the 3-month posttest?

b. Is there a significant difference in means on participants' scores between the workshop posttest and the 3-most posttest due to education?

5. What job aids do participants report using to transfer learned knowledge from the workshop to practice?

6. What occurred during preschool vision screening that was not discussed in VIC's workshop? (See Appendix A for WVU Institutional Board Approval document.)

\section{Literature Review}

The intent of this literature review was to describe literature supporting the seven tenets of the rationale for this program evaluation study, as well as literature pertaining to training lay individuals to screen the vision of preschoolers. However, no studies or articles surfaced pertaining specifically to training adult lay individuals to screen vision. Instead, numerous principles of practice emerged regarding general characteristics of effective teaching and training, as well as characteristics of adult learning. Similar to Guskey's (2003) analysis of characteristics for effective professional development, no single list for either teaching and training characteristics or adult learner characteristics surfaced in general, or to teaching lay people to screen vision in particular. Guskey, after analyzing 13 different lists of effective professional development characteristics published in the $1990 \mathrm{~s}$, concluded that to assume a single list of characteristics for effective professional development would ever emerge may be unreasonable. Hence, the researcher compiled the principles of effective practice into a list of key features that appear relevant for preschool vision screening training workshops. The researcher named this list: "Eight Guiding Principles for Effective Preschool Vision Screening Training." Additionally, the researcher compiled various adult learner characteristics into a list and named this list "17 Assumptions Regarding Adult Learners as They Pertain to Preschool Vision Screening Training," which preschool vision screening instructors could follow as guidelines when developing training programs. Consequently, this review also provides literature supporting the researcher's Eight Guiding Principles, as well as the 17 Assumptions Regarding Adult Learners. 
This literature review included a variety of resources: online and paper-based descriptive and empirical research journal articles, online library databases, resource books, dissertations, conference papers and posters, proceedings papers, and governmental and other web sites regarding adult learners, preschool vision screening, ophthalmology, continuing medical education, training, program planning, and early intervention special education. The framework for this literature review includes six primary topics:

1. A description of the Vision Initiative for Children's Preschool Vision Screening Model.

2. A description of the pilot study that led to this program evaluation study.

3. A description of the seven tenets of the rationale for this study.

4. Literature supporting the rationale tenets.

5. A description of the Eight Guiding Principles for Effective Preschool Vision Screening Training, which the researcher created as a result of the literature review for this study.

6. Literature supporting the Eight Guiding Principles.

\section{Vision Initiative for Children's Preschool Vision Screening Model}

The Vision Initiative for Children (VIC) was created in June 2000 with grant funding from the Claude Worthington Benedum Foundation as an 8-county pilot project to address the unnecessarily high prevalence of permanent vision loss in young children as a result of common, treatable, yet often undiagnosed, pediatric eye disorders, such as amblyopia (lazy eye) and strabismus (crossed eyes). VIC addressed this need by:

1. Facilitating opportunities for preschool vision screening with age-appropriate tests and procedures for the more than 40,000 children aged 3 and 4 in the state (West Virginia Department of Health and Human Resources [WVDHHR], 2004).

2. Educating parents, health care professionals, and members of the early care and education community regarding common early childhood vision disorders.

3. Educating parents, health care professionals, and members of the early care and education community about the impact of effectively conducting appropriate preschool vision screening on improving long-term vision potential in children with these disorders.

VIC facilitates opportunities for preschool vision screening with age-appropriate tests, recommended by various national entities, and procedures by conducting hands-on, interactive, face-to-face training workshops and providing vision screening kits to individuals of the medical 
and early care and education communities. For purposes of this dissertation, the researcher relies on a definition of workshop supplied by Bitpipe, Inc. (www.bitpipe.com), an online network of information-technology and business web sites: "Educational seminars or series of meetings emphasizing interaction and exchange of information among a small number of participants" (http://www.bitpipe.com/tlist/Workshops.html). Birman, Desimone, Porter and Garet (2000) found that workshops are effective in enhancing knowledge and skills if workshops meet certain criteria, such as focusing on specific content and permitting opportunities for active engagement in the learning activity.

VIC's didactic training workshop relies on lecture supported by PowerPoint slides, modeling and demonstration of tests, hands-on practice of tests, feedback regarding test practice, and job aids to assist with transferring learning from the workshop to the workplace. Vision screening kits (see Appendix B for vision screening kit photograph) initially included two ageappropriate tests - the Lea Symbols ${ }^{\text {TM }}$ Flipchart (see Appendix C for Flipchart photograph) and the Random Dot E (see Appendix D for photograph of Random Dot E test and photograph of adult screening child with Random Dot E) — and WVU Institutional Review Board-approved documentation to capture the results of each child screened, as well as other material, such as a training manual. The current vision screening kit includes one test, the Lea Symbols ${ }^{\mathrm{TM}}$ Flipchart, instead of two tests. VIC modified a standard Lea Symbols ${ }^{\mathrm{TM}}$ pediatric wall eye chart into a hand-held Flipchart for ease of use by lay screeners in the field. The Flipchart measures visual acuity at a 10-foot distance. Visual acuity has been defined as how well a child sees a standardized symbol at a standardized distance (Brown, 1975) and "a measure of the smallest retinal formed image that can be distinguished by the human eye" (Jan, Freeman, \& Scott, 1977, p. 11). The Flipchart is designed to detect common pediatric vision disorders, such as amblyopia (lazy eye), as well as abnormal vision from strabismus (misaligned eyes), abnormal refractive errors (farsightedness, nearsightedness, and astigmatism), and other eye diseases.

VIC educates health care professionals and members of the early care and education community regarding common early childhood vision disorders during workshops and via a public web site for parents, health care professionals, and members of the early care and education community, and a password-protected Screener Support web site for workshop trainees. VIC educates parents through its public web site and with the WVU IRB-approved vision screening results documentation. Additionally, VIC educates parents, health care 
professionals, and members of the early care and education community through presentations at local meetings and state conferences.

Through these web public and secure websites and local and state conferences, VIC educates parents, health care professionals, and members of the early care and education community regarding the impact of effectively conducting appropriate preschool vision screening on improving long-term vision potential in children with these disorders. For example, information about the importance of preschool vision screening and the importance of attending a follow-up, comprehensive eye exam after failed vision screening is available to parents on VIC public web site, is distributed to trainees during the workshop, and is made available on the secure web site.

Because no other vision screening training model exists in the state and individuals outside the 8 counties expressed an interest in wanting to partner with VIC to screen preschoolers, the program quickly expanded beyond the original 8 counties. To date, VIC has trained more than 1,000 individuals through 87 workshops. Currently, nearly 15,000 screening events are housed in VIC's database.

\section{Previous Vision Initiative for Children's Studies}

Since 2000, VIC has participated in one national study (American Academy of Pediatrics, 2005; Hartmann et al., 2006), conducted four local and statewide pilot studies, and was selected in January 2006 to serve as one of two pilot sites to launch a national See By Three program. The four pilot studies include:

1. A statewide study of preschool vision screening practices in primary care settings in West Virginia (Bradford, Nottingham Chaplin, \& Odom, 2003)

2. A study of the modified Lea Symbols ${ }^{\mathrm{TM}}$ Flipchart to determine how this test compares with the standard Lea Symbols ${ }^{\mathrm{TM}}$ pediatric eye chart used in the pediatrics clinic of the WVU Eye Institute (Bradford, Nottingham Chaplin, Odom, \& Schwartz, 2003).

3. An exploration of knowledge regarding preschool vision screening from the perspective of pediatric and family physician professors and residents (Bradford et al., 2004).

4. An evaluation of VIC's workshop from 468 participants (Nottingham Chaplin, 2003). This evaluation served as a pilot to the current study. 


\section{Pilot Study of the Vision Initiative for Children's Preschool Vision Screening Model}

Following the launching of VIC's first workshop in September 2001, ongoing adjustment and revision in content and delivery occurred over time as a result of the researcher's personal cumulative training experience and participant responses to workshop evaluations. As a pilot to the current study, VIC formally researched workshop evaluations during December 2003 and January 2004 through a consumer-oriented program evaluation approach (Worthen et al., 1997) designed to understand perceptions of the workshop from the perspective of consumers (trainees). In the pilot study, VIC analyzed responses to all evaluation forms $(N=468)$ completed at the end of each of 43 workshops conducted between September 2001 and October 2003. Additionally, VIC employed a purposive sampling method (Worthen et al, 1997) to survey screeners who received training and screened children between July 2003 and October 2003. Twenty screeners matched the survey criteria.

From responses to the 468 completed participant workshop evaluations and 8 returned mail questionnaires, VIC created an action plan to implement suggestions and modified the workshop based on the participant suggestions. Modifications included the following nine changes or additions to the workshop:

1. Reducing the training time from 6 hours to 2.5 to 3.5 hours, depending on the size of the training group.

2. Filming and providing a video of vision screening that is available on VIC's passwordprotected web site.

3. Editing PowerPoint slides to permit less lecture time and more time for hands-on practice of tests.

4. Conducting "reality checks" during the workshop to ensure consensus on the presentation pace.

5. Providing PowerPoint slides that illustrate how objects appear to individuals with various vision disorders.

6. Providing a break after the first hour of the workshop.

7. Creating and providing a 1-page Vision Screening At-A-Glance Flow Chart, a job aid that screeners can refer to when screening vision of preschoolers.

8. Removing pictures on slides that illustrate surgical procedures. 
9. Eliminating content that did not pertain specifically to vision screening, such as eye anatomy and typical and atypical vision development.

As a result of changes or additions to the workshop format, VIC's Preschool Vision Screening Model includes three primary components: (a) providing a face-to-face, interactive, hands-on workshop; (b) distributing age- and developmentally appropriate tests in vision screening kits; and (c) providing three job aids to help transfer learning from the workshop to practice. Three job aids used in this study included a: (a) handout packet, (b) Vision Screening At-A-Glance Flowchart, and (c) password-protected web site. A goal of this study was to evaluate VIC's workshop after implementing changes from the pilot study.

\section{Seven Tenets of the Rational for This Program Evaluation Study}

The rationale for this program evaluation study included seven tenets:

1. Head Start personnel are mandated to screen vision, yet Head Start Program Performance Standards do not describe how Head Start personnel should be formally trained to screen vision.

2. Head Start personnel may obtain vision screening results from primary care physicians, yet studies suggest that primary care physicians inconsistently screen vision of children ages 3 and 4 .

3. An unnecessarily high number of preschool-aged children have vision disorders that can be detected and treated as a consequence of vision screening.

4. Lay screeners in community settings, when insufficiently trained, will oftentimes modify screening protocols, which may significantly reduce the detection of amblyopia.

5. Various preschool vision screening experts have suggested that vision screening training programs will help ensure accurate and reliable implementation of vision screening tests used by lay individuals in community settings.

6. No empirically studied training model currently appears to exist for training lay individuals to screen the vision of preschoolers.

7. A linkage appears to be nonexistent between preschool vision screening literature calling for training and educational and professional development literature describing how to teach and what workshops should entail. 


\section{Study Rationale Tenet 1:}

Head Start Personnel Are Mandated to Screen Vision, Yet Head Start Program Performance Standards

\section{Do Not Describe How Head Start Personnel Should Be Formally Trained to Screen Vision}

Passage of Public Law 99-457, the federal law requiring a statement regarding health status, including vision, when determining eligibility for early intervention services, led to mandatory vision screening for children entering Head Start (Ciner et al, 1998). The federal Head Start program is administered by the Head Start Bureau; the Administration on Children, Youth and Families; Administration for Children and Families; Department of Health and Human Services. Head Start has served 22 million children since its inception in 1965 as a federal program designed to help break the cycle of poverty by serving preschool-aged children of low-income families (Head Start Program Fact Sheet, 2005). Head Start provides a comprehensive child development program to meet the emotional, social, health, nutritional, and psychological needs of children ages 3, 4, and 5 with an overarching goal of helping prepare children for school. Vision screening is part of meeting the health needs of children.

During the 2003-2004 Head Start program year, Head Start served 905,851 children, of which $34 \%$ were age 3 and 52\% were age 4, which translates to more than 779,000 children participating in vision screening in Fiscal Year 2004 alone. The remaining children were under age 3 or age 5 and older. Ninety-one percent of Head Start children enrolled in Fiscal Year 2004 had health insurance; $83 \%$ of the $91 \%$ with health insurance were enrolled in Medicaid's Early and Periodic Screening, Diagnostic, and Treatment (EPSDT) program or a state-sponsored health insurance program (Head Start Program Fact Sheet, 2005).

Head Start programs are required to adhere to Program Performance Standards. One standard states that within 45 calendar days of a child's enrollment in Head Start, grantee and delegate agencies are required to either perform age appropriate screening procedures, including vision, or acquire screening results from other entities, such as children's EPSDT providers, to identify children who require more formal assessments to receive the benefit of intervention, such as vision aids. The Program Performance Standards, however, neither specify strategies, instruments, or techniques to use nor describe how Head Start personnel should be trained to perform vision screening (Head Start Program Performance and Other Regulations, 2001). 


\section{Study Rationale Tenet 2: \\ Head Start Personnel May Obtain Vision Screening Results From Primary Care Physicians, Yet Studies Suggest That Primary Care Physicians Inconsistently Screen Vision of Children Ages 3 and 4}

Head Start Program Performance Standards present Head Start personnel the option of screening vision or obtaining vision screening results from other entities, such as Medicaid's EPSDT program (Head Start Program Performance and Other Regulations, 2002). However, relying on screening results from primary care medical practices can be problematic because various studies found that preschool vision screening in the primary care medical practice setting is inconsistent and that 3-year-old children are screened less often than 4-year-old children, who are screened less often than 5-year-old children (American Academy of Pediatrics, n.d.; Bradford, Nottingham Chapin, \& Odom, 2003; Campbell \& Charney, 1991; Marcinak \& Werntz Yount, 1995; Wall et al., 2002; Wasserman et al., 1992). For example, Crowley, Baines, and Pellico (2005) reported that only $25 \%$ of 181 children in their study received vision screening from their primary care provider.

Although Campbell and Charney (1991) found that earlier diagnosis of amblyopia has been associated with adhering to preschool vision screening authoritative guidelines from national entities, such as the American Academy of Pediatrics, a gap exists between guidelines and practice. For example, Wall et al. found that more than $60 \%$ of pediatricians do not begin visual acuity screening at age 3 and about $20 \%$ do not begin vision screening until a child is age 5. Another example involves results from a periodic survey conducted by the American Academy of Pediatrics (n.d.), which indicated that while the majority of 1,137 pediatricians selfreported that they routinely test for visual acuity in children ages 4 to 6 , only one-third reported screening vision of patients at age 3 .

Another problem pertaining to collect vision screening results from many primary care providers involves the lack of specific training in vision screening. Although physicians are encouraged to include vision screening as a critical component of early well-child exams (Broderick, 1998), basic primary care skills, such as vision screening, are typically not included in medical training (Szumlas, 2002). Supporting Szumlas, a study conducted with family practice and pediatric physicians and residents at West Virginia University suggested that many primary care physicians appear to be unaware of current methods for preschool vision screening, but would welcome better training in this area (Bradford et al, 2004). 
Results of various studies have identified at least 12 barriers to preschool vision screening in the primary care setting:

1. Insufficient vision screening training (Bradford, Nottingham Chaplin \& Odom, 2003; Bradford et al., 2004; Hered \& Rothstein, 2003).

2. Difficulty of screening uncooperative young children (Bradford, Nottingham Chaplin \& Odom, 2003; Foster \& Gilbert, 1997; Giangiacomo \& Morey, 2005; Gundersen, 1955;

Kemper, 2004; Kemper et al., 2004; Simon \& Kaw, 2001b; Simons, 1996).

3. Children too young for screening (Bradford, Nottingham Chaplin \& Odom, 2003, Marcinak \& Werntz Yount, 1995; Wasserman et al., 1992).

4. Insufficient practical knowledge in preliterate vision screening tests and techniques (Bradford, Wadia \& Nottingham Chaplin, 2004, Hered \& Rothstein, 2003).

5. Lack of experience with vision screening tests (Kemper, 2004).

6. Insufficient office space (Bradford, Nottingham Chaplin \& Odom, 2003).

7. Inadequate time (Bradford et al., 2003; Marcinak \& Werntz Yount, 1995).

8. A high number of false positives associated with vision screening (Kemper, 2004).

9. Confusion regarding screening methodology (Foster \& Gilbert, 1997; Hartmann et al., 2000).

10. Confusion regarding inconsistent guidelines from various organizations for screening and referral (Hartmann et al., 2000).

11. Inadequate reimbursement for vision screening (Bradford et al., 2004).

12. Screening done at school (Marcinak \& Werntz Yount, 1995).

Finally, when compared to screening conducted by primary care physicians, communitybased school screening programs, such as Head Start, are more likely to detect amblyopia in young children (Campbell \& Charney, 1991).

\section{Study Rationale Tenet 3:}

\section{An Unnecessarily High Number of Preschool-Aged Children Have Vision Disorders} That Can Be Detected and Treated as a Consequence of Vision Screening

Metaphorically, the human eye is similar to a manual-focus camera. The camera lens focuses an image on the film. The cornea and internal lens of the eye focuses an image on the retina. An image captured on film is not a photograph until the film is mailed or transported to a processing center, where images captured on film are developed into photographs. Similarly, one does not "see" the image on the retina. Light rays reflected off objects are converted to nerve 
impulses, which are transported via the optic nerve to the occipital cortex, the visual area in the back of the brain, where the image from one eye is fused with the image from the other eye. Thus, vision occurs at the brain level when the brain "develops" a picture from the images captured on the retina (Simon \& Calhoun, 1998). The brain must fuse, or integrate, focused images from each eye into a single image for normal vision development to occur (DeRespinis, 2001; Mills, 1999). Interference of a focused, fusible image during the first decade of a child's life can interrupt normal vision development and cause permanent vision loss (Crowley et al., 2005; DeRespinis, 2001; Olitsky, Nelson, \& Brooks, 2002; McManaway (n.d.); Mills 1999).

The preschool vision screening literature suggests that an unnecessarily high prevalence of vision loss exists in young children as a result of common, preventable, treatable, yet often undetected, undiagnosed pediatric vision disorders. For example, Calonge (2004) reported that as many as 1 in 10 or 20 (5\% to 10\%) preschool-aged children experience undetected vision disorders. Children with undetected and untreated vision problems can grow into adults with visual impairment. In the United States, 1 of the 10 most frequent causes of disability in adults aged 18 and older is impaired vision (Verbrugge \& Patrick, 1995).

Preventive measures for permanent visual impairment include early detection and prompt treatment (Campbell \& Charney, 1991; Wu \& Hunter, 2006), which produce better vision outcomes when vision disorders are detected and treated at a young age (McManaway, n.d.; Giangiacomo \& Morey, 2005; Jakobsson, Kvarnström, Abrahamsson, Bjernbrink-Hörnblad, \& Sunnqvist, 2002; Simon and Kaw, 2001a). Many children with vision problems can achieve improved vision if their problems are "diagnosed in a timely manner" (Centers for Disease Control [CDC], 2005, p. 428). Therefore, visual acuity screening to detect vision disorders should begin before children reach age 4 (Simon and Kaw, 2001a). Despite recommendations for visual acuity testing around the age of 3 , only $36 \%$ of children aged 5 and under received vision screening in 2002 (Healthy Vision 2010, n.d.).

\section{Common Early Childhood Vision Disorders}

The most common pediatric vision disorders targeted for vision screening are amblyopia (lazy eye), strabismus (crossed eyes or eye misalignment), refractive error (nearsightedness and farsightedness), and astigmatism (Calonge, 2004; Hartmann, 1998; Snowdon \& Stewart-Brown, 1997). These common pediatric vision disorders affect $5 \%$ to $10 \%$ of all preschoolers (Calonge, 2004), which translates to 617,400 children ages 3, 4, and 5 in the United States alone using the 
more conservative 5\% statistic. This number, 617,400 , was derived by multiplying the number of live births in 2004, 4,116,000, by 5\% and multiplying that number by 3 to account for three age groups: 3, 4, and 5. Thus, based on 4,116,000 live births in the United States in 2004 (USDHHS, National Vital Statistics Reports, 2005), 617,400 children ages 3, 4, and 5 possess these vision disorders. Additional amblyogenic factors to be detected through vision screening, but not included in the vision disorders impacting $5 \%$ to $10 \%$ of preschoolers, include ptosis and any media opacity, such as cataract (Kerr \& Arnold, 2004).

Vision impairment, considered a serious health problem (Lennerstrand, Jakobsson, \& Kvarnström, 1995), has been associated with various developmental delays and disabilities, as well as various syndromes and the need for special education, vocation, and social services (Healthy People, 28. Vision and Hearing, n.d.). To discuss all developmental disabilities and syndromes in which vision disorders may be linked exceeds the scope of this dissertation. However, a few examples are provided. Reduced visual acuity and amblyopia have been associated with prematurity, low birth weight, multiple handicaps, and developmental delay (Bacal \& Hertle, 1998; Brooks, 1996; Dobson, 1998; O’Connor et al., 2004). Additionally, amblyopia, the risk of amblyopia, and strabismus have been associated with children who have hydrocephalus, especially children who experienced shunt revision (Altintas, Etus, Etus, Ceylan, \& Caglar, 2005). Strabismus has been associated with prematurity; perinatal hypoxia; cerebral palsy; and chromosomal abnormalities, such as Down syndrome, cri du chat syndrome, and Trisomy 13 (Teplin, 1995). Refractive error and strabismus tend to be more prevalent in children with cerebral palsy, mental retardation, Down syndrome, and Fragile X syndrome (Orel-Bixler, 1999). Visual disorders, including amblyopia, strabismus, and refractive disorders, are common in children with mental impairments, especially teenage and young adults (Chang, Shih, Tseng, Cheng, \& Teng, 2005). Amblyopia-inducing risk factors have been associated with children whose mothers used cigarettes, alcohol, or drugs during pregnancy (Dobson, 1998). Finally, a group of researchers in Finland reported that children with motor impairment tend to have varying vision problems, which oftentimes is undetected and, thus, not included in, or addressed as, part of their Individualized Education Plans (Kiviranta et al, 2006).

Amblyopia. Amblyopia (am-blee-O-pee-ah), also known as "lazy eye," has been defined as a central nervous system phenomenon where the brain fails to process visual cues accurately when a young child is unable to form a clear visual image in one or both eyes (Bacal et al., 
1999); poor vision from lack of use and uncorrectable with prescription glasses (Calhoun, n.d.); vision loss as a result of inadequate visual stimulation during development of the brain's visual pathways (Teplin, 1995); and reduced visual acuity in the absence of organic disease, which cannot be improved by eye glasses alone (Snowdon \& Stewart-Brown, 1997). Any condition that affects normal visual development can cause amblyopia, such as strabismus, abnormal refractive errors, and cataract (National Eye Institute, 2005). Researchers suspect amblyopia "is caused by anomalous wiring of the eye's central connections in the brain" (Horton, 2001, p. 46), a phenomenon confirmed in experiments where newborn kittens' eyelids were sutured together (e.g., see Wiesel \& Hubel, 1965). Horton further noted that amblyopia develops only in younger children when the visual system is still developing and vulnerable to the consequences of sensory deprivation.

Although amblyopia is considered a public health concern (Brooks, 1996), prevalence rates tend to depend on the age of the study population. The incidence rate of amblyopia in young children ranges from as low as $1.6 \%$ (Simons, 2005) to 3\% (Kemper et al., 2004; Thompson, Woodruff, Hiscox, Strong, \& Minshull, 1991; Webber \& Wood, 2005), and as high as 5\% (Preslan \& Novak, 1996). Prevalence increases for the medically underserved population (Simons, 2005).

The incidence rate for amblyopia among the general population ranges between $2 \%$ and 5\% (Day, 1997b), although Kemper et al. (2004) more recently reported a rate of 2.9\% to 3.9\% for school-aged children and adults. Amblyopia has been reported as the prevalent cause of visual impairment in childhood (Bacal \& Hertle, 1998; Bacal et al., 1999; National Eye Institute, 2005; The Pediatric Eye Disease Investigator Group, 2002), the most common cause for vision loss in individuals under age 40 (Brooks, 1996), and the predominant cause of impaired vision among adults 25 to 74 years of age (Ganley \& Roberts, 1983; Krueger \& Ederer, 1984).

With early detection and treatment, amblyopia is treatable, or reversible, until a child is about 8 or 10 years of age (Bacal \& Wilson, 2000; Simon \& Kaw, 2001b; Snowdon \& StewartBrown, 1997; Wu \& Hunter, 2006). Wu and Hunter reported finding no compelling evidence for successful amblyopia treatment after age 10 although Epelbaum, Milleret, Buisseret, and Dufier (1993) found that treatment for strabismic amblyopia decreased with age and was successful until age 12. While experts do not always agree on the ceiling age for successful treatment, most to agree that without early detection and treatment, incurable, lifelong visual deficits can occur 
(Fulton, 1992; Rubin \& Nelson, 1993). Additionally, the degree of amblyopia will be more profound the longer amblyopia remains undetected and untreated (Webber \& Wood, 2005). Lack of knowledge and public awareness regarding amblyopia and the necessity of timely detection and treatment is the predominant cause for the significant vision loss associated with amblyopia (Menon, Chaudhuri, Saxena, Gill, and Sachdev (2005).

Amblyopia may adversely affect activities requiring depth perception, as well as longterm educational pursuits, educational performance, and sporting ability, although high quality data to quantitatively access the loss of utility appears to be nonexistent (Kemper, 2004; Snowdon \& Stewart-Brown, 1997). Additionally, some degree of emotional distress has been associated with wearing adhesive patches over the non-amblyopic eye to stimulate vision development in the amblyopic eye, which is typically part of active treatment for amblyopia (Hrisos, Clarke, \& Wright, 2004).

While preschool children generally can function, and learn, using one healthy eye when vision in the other eye is severely reduced (Dubowy, 2005; Koller \& Goldberg, 2000), some researchers have linked vision problems with young children who are at risk for academic, behavioral, and social development problems, such as those who have low self-esteem as a result of experiencing ridicule for their misaligned eyes or for wearing patches (Johnson et al., 1996; Käsmann-Kellner \& Ruprecht, 2000; Koller \& Goldberg, 2000; Romano, 1990).

Despite results of various studies, debate exists in the literature regarding whether amblyopia specifically affects school performance. For example, Snowdon \& Stewart-Brown stated that children with amblyopia may achieve good acuity in the unaffected eye, suggesting that educational attainment may not be an issue. Rose (1998), however, stated that children who experience vision problems are in danger of losing effective vision in one or both eyes that could result in diminished ability to process visual material they need to learn in school.

Although children with amblyopia may be able to continue educational pursuits by relying on the healthy eye and adults may experience problems in some life activities, such as racquet sports, driving, or jobs requiring near vision or fine-motor coordination, the overarching concern with amblyopia is the risk for visual handicap if vision is lost in the better eye. When compared with the general population, individuals with amblyopia are at a higher risk of becoming blind (Kemper et al., 2004; Tommila \& Tarkkanen, 1981). Tommila and Tarkkanen reported that school-aged children and adults with amblyopia, when compared to individuals in 
the general population, are more likely to lose vision in the better eye as a result of trauma and disease. Levels of trauma included (a) accident at work, (b) sport or play injury, and (c) a blow from a violent act. Levels of disease included (a) tumor, (b) uveitis (inflammation of the uvea or the middle layer of the eye that includes the iris [colored part of the eye]), (c) vascular occlusion, (d) glaucoma (increased pressure within the eyeball that can damage the optic disk [an area of the retina where the optic nerve enters the eye]), (e) intraocular hemorrhage, and (f) retinal detachment. The authors defined loss of vision as (a) enucleation (removal of the eyeball), (b) permanent poor acuity in the healthy eye, and (c) impending blindness in the healthy eye. (Definitions are from Medline Plus, a service of the U. S. National Library of Medicine and the National Institutes of Health [http://www.nlm.nih.gov/medlineplus/aboutmedlineplus.html].)

Accidents at work led the list of Tommila and Tarkkanen's (1981) vision loss causes. Tommila and Tarkkanen maintained that this finding raised implications for sustained employment regarding adults with amblyopia. Vereecken and Brabant (1984) found that accidents were the leading cause of loss of vision in the good eye for males younger than age 30 and illness was the primary cause for both males and females older than 50 years. Illness included glaucoma, macular degeneration (gradual loss of central vision), and retinal detachment. Vereecken and Brabant defined loss of vision as enucleation or loss of sight. MacEwen, Baines, and Desai (1999) discovered that 2\% of 415 children admitted to a hospital with ocular trauma in Scotland over a 1-year period were visually impaired in the injured eye as a result of the injury.

Chua and Mitchell (2004) found that individuals with amblyopia were three times more likely to experience vision loss in their better seeing eye when compared to individuals without amblyopia. Finally, Rahi, Logan, Timms, Russell-Eggitt, and Taylor (2002) found that individuals with amblyopia possessed a lifetime risk of $1.2 \%$ to $3 \%$ for serious vision loss in the better eye. The authors defined serious vision loss as socially significant visual impairment, severe visual impairment, or visual impairment or blindness. Rahi et al. stated that for older adults, "avoidance of visual impairment even for a limited period would still confer tangible benefits" (p. 601) and, thus, "effective treatment of amblyopia during childhood - to achieve a good level of functional vision in the amblyopia eye - remains a potentially valuable strategy against incapacitating vision loss later in life" (p. 601). 
Strabismus. For normal vision to occur, both eyes need to look in the same direction at the same time (Strabismus, 1998). Strabismus (stra-BIZ-muss), which is also oftentimes called lazy eye or squint, occurs when the two eyes are misaligned (Rubin, 2001; Snowdon \& StewartBrown, 1997) and often leads to a preference for using only one eye. This preference can result in "preferential development of visual pathway connections between the preferred eye and the brain, leading to reduced acuity in the nonpreferred eye" (Bacal \& Wilson, 2000, p. 49). When eyes are misaligned, the brain suppresses the deviating eye to avoid double vision (Calhoun, n.d.). This consistent suppression in strabismus is a major cause of amblyopia (Calhoun, n.d.).

Strabismus occurs when one of the six eye muscles controlling eye movement is weaker than the corresponding muscle in the other eye and the eyes are not held in alignment with each other, allowing one eye to drift or move separately from the other eye (Rose, 1998). Manifest strabismus or tropia - a disturbance of coordination of the extraocular muscles of the eyes retained on monocular and binocular viewing - affects up to $3.7 \%$ of the civilian noninstitutionalized population between the ages of 1 and 74 in the United States; and latent strabismus or phoria - a tendency for one eye to deviate and look at a different image than the other eye looks at when binocular viewing is interrupted - affects an estimated $16 \%$ of the civilian noninstitutionalized population ages 1-74 in the United States (Roberts, 1978).

Strabismus should be detected and treated early not only because strabismus can be treated more effectively in the younger child, but also because "[b]inocular alignment provides better depth and general perception, which is important for the child's overall development (Romano, 1990, p. 360). Properly aligned eyes help a child to feel "normal" like other children, which is key to achieving positive self-esteem, especially when the appearance of the eyes is often the first impression one makes in social relationships (Romano, 1990). Thus, the cosmetic appearance of misaligned eyes may interfere with social and psychological development (Michaelides \& Moore, 2004).

Properly aligned eyes has been associated with increased performance on developmental testing. For example, results of one study demonstrated that infants (mean age 7.6 months), whose eyes were aligned surgically, performed significantly better postoperatively on fine motor developmental testing and visual functions of directed reaching and grasping when compared to an age-matched control group (Rogers, Chazan, Fellows, \& Tsou, 1982). Additionally, the presence of a functionally relevant reading impairment in reading speed has been associated with 
children diagnosed with microstrabismic (decreased depth perception with eyes that appear straight) amblyopia (Stifter, Burggasser, Hirmann, Thaler, \& Radner, 2005).

Amblyopia and strabismus can be asymptomatic and include subtle signs and symptoms that parents and physicians may overlook unless the eye misalignment is severe enough to be noticed (Romano, 1990). Preschool vision screening can detect these vision disorders.

Abnormal refractive errors. A refractive error occurs when parallel light rays, reflected from an object, enter the eye and fail to focus directly on the retina, causing a blurred image (Snowdon \& Stewart-Brown, 1997). Refractive errors of concern in young children involve hyperopia, myopia, astigmatism, and anisometropia, especially when these refractive errors are sufficiently abnormal to result in amblyopia (Tongue, 1987). Refractive errors, as a group, have been called the most common vision disorders in children and occur in $20 \%$ of children by age 16 (American Family Physician, 1994).

Hyperopia, or farsightedness, typically occurs when the axial length of the eye is short and parallel light rays coming into the eye strike the retina before coming to a sharp focus (Jensen, 1997; Simon \& Calhoun, 1998; Tongue, 1987). With myopia, or nearsightedness, the eye is elongated and parallel light rays come into sharp focus in front of the retina (Simon \& Calhoun, 1998). Myopia has been found in $2 \%$ of children entering $1^{\text {st }}$ grade (Jensen, 1997). With astigmatism, parallel light rays coming into the eye do not focus in one point of the retina; instead the light rays focus on different points of the retina, causing blurring at both near and far distances (Simon \& Calhoun, 1998; Tongue, 1987). Anisometropia is a difference in refractive error between the two eyes (Jensen, 1997; Snowdon \& Stewart-Brown, 1997), where one eye can be nearsighted while the other eye is farsighted.

Typically, prescription eyeglasses will focus the light rays onto the retina. However, if amblyopia has resulted from the abnormal refractive error, additional treatment - usually occlusion of the nonamblyogenic eye - is also often necessary. The ability to bring an individual's visual acuity to 20/20 with corrective lenses tends to increase with annual family income, suggesting that families in lower socioeconomic classes experience more difficulty in achieving 20/20 vision with corrective lenses (Roberts, 1978). Newacheck, Jameson, and Halfon (1994) found that children from low-income families were less likely to have adequate refraction than children from high-income families. Roberts also reported that African Americans tend to experience less refractive potential and poorer usual visual acuity than Caucasians. 
Refractive errors, particularly anisometropia and hyperopia, can strain eye muscle balance and lead to strabismus and amblyopia (Jensen, 1997; Snowdon \& Stewart-Brown, 1997). Refractive errors dissociated with amblyopia, although correctable regardless of the age when detected, may interfere with learning and other daily activities (Kemper et al., 2004). If left undetected and uncorrected, strabismus and abnormal refractive errors can lead to amblyopia (Tongue, 1987). Strabismus and amblyopia can be effectively treated when detected early; however, both are frequently undetected until irreparable damage occurs (Rose, 1998).

\section{Quality of life issues associated with early childhood vision disorders}

Romano (1990) stated that "[n]o other paired organ in the human body is as important as the eyes to well-being of a human" (p. 360). Merriam-Webster's Collegiate Dictionary defines well-being as "the state of being happy, healthy, or prosperous" (Mish, 2003, p. 1421). Romano further stated:

Unilateral vision loss negates the natural symmetry of human existence. . . Two good eyes provide better vision than one by compensating for the blind spot in each eye, by providing a larger visual field, and by offsetting or canceling minor imperfections in the optical system of one eye or both. (p. 360)

Healthy People 2010 (n.d.) reported:

Among the five senses, people depend on vision and hearing to provide the primary cues for conducting the basic activities of daily life. At the most basic level, vision and hearing permit people to navigate and to stay oriented within their environment. These senses provide the portals for language, whether spoken, signed, or read. They are critical to most work and recreation and allow people to interact more fully. For these reasons, vision and hearing are defining elements of the quality of life. (p. 2)

Two studies identified psychosocial effects of amblyopia and strabismus. Packwood, Cruz, Rychwalski, and Keech (1999) found that psychosocial difficulties related to amblyopia affected an individual's self-image, work, school, and friendships. Satterfield, Keltner, and Morrison (1994) found that psychosocial difficulties related to possessing socially noticeable strabismus affected an individual's self-image, ability to secure employment, interpersonal relationships, school, work, and sports, which intensified in the teen-age and adult years. 
Amblyopia and uncorrected refractive error may interfere with development, educational performance, and sporting ability, and an interference of educational performance may result in a long-term disabling effect on adults (Snowdon \& Stewart-Brown, 1997). Additionally, amblyopia can limit vocational opportunities, as well as potential lifetime earnings (Bane \& Beauchamp, 2001). For example, adults with amblyopia may encounter problems in racquet sports, driving, or jobs requiring fine motor coordination or near-work (Kemper et al., 2004; Snowdon \& Stewart-Brown, 1997). Additionally, adults with imperfect vision may be refused entry to the armed services or pilot training programs (Snowdon \& Stewart-Brown, 1997). Finally, individuals with amblyopia are at a greater risk of blindness as a result of injury or disease in the non-amblyopic eye (Tommila \& Tarkkanen, 1981).

\section{Costs associated with undetected early childhood vision disorders}

In 1995, the economic impact of visual disorders and visual disabilities was $\$ 38.4$ billion (Healthy People 2010, n.d.). That number translated to $\$ 22.3$ billion in direct costs and $\$ 16.1$ billion in indirect costs annually. Additionally, the National Children's Eye Care Foundation “estimated that amblyopia annually may cost our country as much as $\$ 41$ billion” (Bane \& Beauchamp, 2001, p. 117), a figure which factors in the number of children with amblyopia born annually, a $2 \%$ incidence of vision loss as a result of amblyopia, the cost of treatment, lost wages, and lost taxes.

Some vision screening experts have maintained that preschool vision screening will detect vision disorders at a time when treatment can reduce the need for, as well as the costs associated with, future and/or ongoing care. Various experts have reported costs associated with vision screening (e.g., see Donahue, Arnold, \& Ruben, 2003; Joish, Malone, \& Miller, 2003; König \& Barry, 2002; König, Barry, Leidl, \& Zrenner, 2002). For example, Donahue et al. reported that results of studies conducted in the United States and abroad have suggested that vision screening efforts achieved success in detecting amblyopia and that treatment of amblyopia was cost-effective. The National Eye Care Foundation estimated that vision screening would cost approximately $\$ 1.3$ billion annually, based on a fee of $\$ 35$ per screening, a $10 \%$ rate of false positives, and a $\$ 6,000$ average treatment cost per child (Bane \& Beauchamp, 2001).

\section{Preschool vision screening defined}

Screening, in general, is an established public health strategy for detecting individuals who have, or are at risk of having, significant health problems, especially when these health 
problems manifest in non-visible subtle signs and symptoms (Schmidt, 1998). Foster and Gilbert (1997) maintained that the term "screening" should describe programs that use a simple, noninvasive and inexpensive test to identify individuals who would benefit from specific interventions. Wilson and Jungner (1968), who were commissioned by the World Health Organization, stated that guidelines for early disease detection should include at least 10 principles:

1. The condition sought should be an important health problem.

2. There should be an accepted treatment for patients with recognized disease.

3. Facilities for diagnosis and treatment should be available.

4. There should be a recognizable latent or early symptomatic stage.

5. There should be a suitable test or examination.

6. The test should be acceptable to the population.

7. The natural history of the condition, including development from latent to declared disease, should be adequately understood.

8. There should be an agreed policy on whom to treat as patients.

9. The cost of case-finding (including diagnosis and treatment of patients diagnosed) should be economically balanced in relation to possible expenditure of medical care as a whole.

10. Case-finding should be a continuing process and not a "once and for all" project. (pp. 26-27)

Screening for vision problems specifically, which is basic to health supervision (Wasserman et al., 1992), is non-diagnostic and conducted primarily to divide a screened population into two groups: (a) children who have, or are at risk of having, vision disorders and should receive a comprehensive eye examination to benefit from early intervention or monitoring for later treatment, and (b) children that do not have vision disorders (Green \& Richmond, 1962; Marsh-Tootle, 1998; Schmidt, 1990, 1998). Conversely, children who have symptoms of vision problems should receive professional eye examinations (Marsh-Tootle, 1998; Simon \& Calhoun, 1998).

Vision screening designed to detect eye problems in school-aged children has been cited in the literature as far back as 1899 (Appelboom, 1985). Physicians, especially pediatricians, have been encouraged to screen vision for amblyopia since at least 1954 (Gundersen, 1954). In 
fact, in 1954, Gundersen advocated for training for physicians on visual acuity screening and information for medical students about amblyopia.

Emphasis on vision screening for preschoolers began in the 1960s when results from animal research suggested that cortical plasticity (capacity for being altered) was limited to a period early in life (Hartmann et al., 2000). Preschool vision screening has been widely endorsed (Agency for Healthcare Research and Quality, 2004; Hartmann et al., 2000), occurs in varied ways throughout the United States and in other countries, and has been called a cost-effective method (Ciner et al., 1998) for identifying children who need comprehensive eye examinations to diagnose and treat vision disorders (Ehrlich, Reinecke, \& Simons, 1983; Simons, 1996).

While various experts have espoused early detection and treatment to help achieve optimal vision outcomes in children with impaired vision (see next section), screening has been cited as more cost-effective than providing comprehensive eye examinations. For example, Bane and Beauchamp (2001) stated that to provide a comprehensive eye exam for every preschoolaged child in the United States "is not currently practical" (p. 116). Consequently, "vision screening remains the most viable method for detecting children who have amblyopia or amblyogenic conditions, for which early intervention is essential to successful outcomes" (Bane \& Beauchamp, 2001, pg. 116).

\section{Importance of preschool vision screening}

Among six screening tests typically conducted at school entry, vision, hearing, and developmental screening are more applicable to school readiness (Clemens, Doolittle, \& Hoyle, 2002). Results of studies conducted in the United States and abroad have suggested that vision screening efforts achieved success in detecting amblyopia (Donahue et al., 2003). Consequently, the American Academy of Pediatrics, the American Academy of Ophthalmology, and the federal government are placing greater emphasis on preschool vision screening (Donahue et al., 2003; Giangiacomo \& Morey, 2005).

Within the five senses, vision and hearing affects development, learning, communicating, working, health, and quality of life (Healthy People 2010, n.d.). Additionally, vision plays a key role in early development with visual information transmitted to the brain from each eye exceeding information transmitted from the remaining parts of the body, including the other four senses (Gesell, Ilg, \& Bullis, 1967; Seiderman \& Marcus, 1989). Seiderman and Marcus (1989) 
stated that the sense of sight is the more important of the 5 senses and that $80 \%$ of information transmitted to the brain comes through the eyes.

Many young children are at a higher risk of experiencing vision disorders, which can lead to vision impairment, as a result of hereditary, prenatal, or perinatal factors (Healthy People 2010, n.d.). Additional risk factors include low birth weigh, inadequate prenatal care, or lack of routine eye care (Preslan \& Novak, 1998). Impaired vision, in children, has been associated with developmental delays and subsequent requirements for special education, vocational, and social services, services that are often needed as children move into adulthood (Healthy People 2010, n.d.).

Children from low income, minority, uninsured, single-parent families, as well as those from families with parents who did not attend college, appear to be at greater risk of experiencing vision disorders (Castanes, 2003; Centers for Disease Control and Prevention, 2005; Fujiura \& Yamaki, 2000; Hudak \& Magoon, 1997; Kemper, Bruckman, \& Freed, 2003; Newacheck, Hughes, Hung, Wong, \& Stoddard, 2000; Newacheck et al., 1994). The prevalence of decreased vision and the need for medical treatment appears to be greater, though not significantly greater, among persons in the lowest income bracket (Ganley \& Roberts, 1983). Children with disabilities in low-income, minority families oftentimes experience a disproportionate level of blindness and visual impairment (Castanes, 2003). Additionally, nearpoor and poor children, as well as uninsured children, were approximately 3 times more likely to have an unmet health need, including vision care, than non-poor and privately insured children (Newacheck et al., 2000). Finally, children from poor families are significantly less likely to receive preventive medical care services (Newacheck et al., 1994).

To acquire a sense of the number of potential children who are at greater risk for vision disorders, in 2003 nearly half of children under age 5 of all races in the United States (43\%) lived in households with incomes $<200 \%$ of the federal poverty rate (United States Census Bureau [USCB], Age and Sex of all People, 2004). More than half of children of all races under age 6 and living in households with income $<200 \%$ below the federal poverty rate resided in single-parent households. In 2003, 28\% of children under age 6 lived in 2-parent households, $56.7 \%$ lived in male-headed, single parent households, and 76\% lived in female-headed, single parent homes (USCB, Families with Related Children Under 6, 2004). 
Although eye care professionals have reported a link between visual problems and poor academic performance, not all eye care professionals agree. Screening the vision of preschoolers to help ensure that vision problems do not interfere with future academic performance is included in this section because, although eye care professionals disagree about this area, some research suggests a linkage between vision problems and learning difficulties. Goss and Rainey (2002) stated that "it is surprising that anyone would doubt that vision could be related to reading performance and academic achievement” (p. 35). Borsting and Rouse (1994) reported that research exists to link vision problems with learning difficulties in school. Hoffman (1980) found that a population of children with learning disabilities seen at the Southern California College of Optometry demonstrated a larger incidence of vision problems than children without learning disabilities. Krumholtz (2000) found that early detection and treatment of visual problems increased the potential for more effective learning in a group of 25 children. Kulp and Schmidt (2002) found that good near vision, particularly good stereoacuity, was significantly correlated to academic performance in reading, mathematics, writing, and spelling. Conversely, while Day (1997a) suggested that children with untreated myopia may have difficulty seeing writing on a chalk board and Jensen (1997) reported that untreated hyperopia may contribute to learning difficulties in school, Day further added that refractive errors are "rarely responsible for poor school performance" (p. 1047). Koller and Goldberg (2000) stated that significant refractive errors may interfere with learning, however, "[m]any children with reduced vision go on to become excellent learners" (p. 104).

Parents and other individuals will, generally, recognize when a child has severe vision loss, but detecting less incapacitating vision loss is more difficult (Brown, 1975). Tongue (1987) explained why parents and other individuals may not notice that they children have vision problems:

Some parents refuse to believe that their preschool child has a visual problem significant enough to warrant glasses, because he or she sees airplanes in the sky, picks up tiny objects from the carpet, rides a tricycle, etc. Even a severely visually impaired child can see small objects if the contrast is good, such as an airplane against a blue sky, a raisin or penny on a light colored carpet. The child does not need to see any detail to be curious about the object and move closer to it, pick it up, and inspect it. (p. 1427) 
Consequently, many parents/caregivers may be unaware of their children's vision problems until they begin school (CDC, 2005). Typically, young children cannot express how they see, such as whether or not they are experiencing blurred vision; are unaware of how they should see; do not experience pain from vision problems; and are unaware that a vision problem exists, especially if their vision has always been poor or has gradually become poor (Brown, 1975; Schmidt, 1997). Jan et al. (1977) stated that diagnosis and treatment of ocular defects early in a child's life is of utmost importance, that distance visual acuity testing cannot occur effectively until a child is age 3 or $3 \frac{1}{2}$, and, consequently, because these ocular defects are oftentimes undiscovered by parents, mass visual screening of preschool children has been organized in many countries.

Visual acuity testing can begin at age 3 or $3 \frac{1}{2}$ because children are verbal, more docile, can name or match symbols on pediatric visual acuity charts, and will tolerate covering one eye to measure visual acuity in the other eye (Gundersen, 1954; Jan et al., 1977; McManaway (n.d.). Vision screening programs for children beginning at age 3 "after an initial screening at birth, has the potential to be highly effective at identifying children at risk for vision problems and therefore in need of a comprehensive vision examination" (Ciner et al., 1998, p. 571). Lifelong visual impairment can be reduced through timely screening (Brooks, 1996; Ottar-Pfeifer, 2005), early detection, and follow-up treatment (Calonge, 2004; Healthy Vision 2010, n.d.; Williams et al., 2002).

Early identification of children with vision abnormalities is critical because early management of treatable vision disorders influences the visual outcome (Cordonnier $\&$ de Maertelaer, 2005; Foster \& Gilbert, 1997; Ottar-Pfeifer, 2005; Williams et al., 2002) and the earlier treatment begins, the better the prognosis (Bacal \& Hertle, 1998; Day, 1997b). Ocular pathology, such as the targeted common vision disorders in young children - amblyopia, strabismus, and abnormal refractive errors - can be identified early, before irreversible damage occurs, with routine vision screening (Bacal et al., 1999; Hård, Sjödell, Borres, Zetterberg, \& Sjöstrand, 2002; Kvarnström, Jakobsson, \& Lennerstrand, 2001; Rubin \& Nelson, 1993; Simon \& Kaw, 2001a; Snowdon \& Stewart-Brown, 1997). For example, in Sweden, where 99\% of 4year-old children participated in vision screening, the incidence rate of amblyopia, with subsequent diagnosis and treatment, reduced from $2 \%$ to $0.2 \%$ (Kvarnström et al., 2001). 


\section{State and federal Mandates or Guidelines to Screen Vision of Preschoolers}

Although a uniform preschool-vision screening policy is nonexistent in the United States (Bane \& Beauchamp, 2001), the necessity of increasing vision screening efforts is garnering attention from the state and national levels (Giangiacomo \& Morey, 2005). Various national and state entities have or are recommending or mandating preschool vision screening. Even though vision screening is currently of state and federal interest, how individuals are trained to screen vision is not.

Healthy People 2010. Healthy People 2010, the nation's blueprint for healthier individuals by the year 2010, contains a vision objective for increasing to $52 \%$ the proportion of preschool children aged 3 to 5 that receive a vision screening (Healthy People 2010, n.d.). West Virginia Healthy People 2010 includes an identical objective (West Virginia Department of Health and Human Resources [WVDHHR], 2001).

United States Preventive Services Task Force. The United States Preventive Services Task Force (USPSTF), an independent panel of experts convened by the Agency for Healthcare Research and Quality within the United States Department of Health \& Human Services, recommended vision screening to detect amblyopia, strabismus, and visual acuity defects in children younger than age 5. Further, the USPSTF found fair evidence that treatment for amblyopia and strabismus could improve visual acuity and reduce long-term amblyopia (Calonge, 2004).

National organizations. In addition to the USPSTF (Calonge, 2004), at least six additional national organizations recommend preschool vision screening as a recommended standard of practice: (a) the American Academy of Ophthalmology, (b) American Association for Pediatric Ophthalmology and Strabismus, (c) the American Academy of Pediatrics, (d) the American Association of Certified Orthoptists (American Academy of Pediatrics, 2003), (e) the American Academy of Family Physicians (Broderick, 1998), and (f) the American Medical Association (Summary of Actions, 2005). A joint policy statement of the American Academy of Pediatrics, the American Association of Certified Orthoptists, the American Association for Pediatric Ophthalmology and Strabismus, and the American Academy of Ophthalmology states that visual acuity testing should begin "at the earliest possible age that is practical (usually at approximately 3 years of age)" (American Academy of Pediatrics, 2003, pg. 902). The National Association of School Nurses (2001) describes in an Issue Brief the importance of preschool 
vision screening, as well as the role of school health nurses in vision screening; however, this organization does not take a formal position on preschool vision screening (W. Miller, NASN Executive Director, personal communication, January 30, 2006).

Head Start and Medicaid. The majority of preschoolers do not receive vision screening until they enter kindergarten or elementary school, except those enrolled in Head Start (Bane \& Beauchamp, 2001). Passage of Public Law 99-457, the federal law requiring a statement regarding health status, including vision, when determining eligibility for early intervention services, led to mandatory vision screening for children entering Head Start (Ciner et al, 1998). Head Start operates under a federal mandate to screen vision, or collect vision screening results from children's primary care physicians, within 45 days of a child's enrollment (Head Start Program Performance and Other Regulations, 2001).

The Early and Periodic Screening, Diagnostic, and Treatment (EPSDT) is Medicaid's comprehensive and preventive child health program for individuals from birth to age 21 . The EPSDT component of the federal Medicaid program does not contain an explicit requirement to screen vision. Nevertheless, an assumption exists that vision screening is part of a child's general health screening (C. Ruff, personal communication, July 30, 2004). State agencies administering EPSDT are required to create distinct periodicity schedules for screening, dental, vision, and hearing services (USDHHS, Medicaid Early \& Periodic Screening \& Diagnostic Treatment Benefit, 2005.).

States. The number of states recommending or mandating preschool vision screening has increased since Ciner et al. (1999) published their article describing the status of preschool vision screening policy per state across the United States. At that time, preschool vision screening was required in 15 states and the District of Columbia, voluntary in 20, and nonexistent in 15 . The Vision Council of America (2005) recently reported that 30 states and the District of Columbus require vision screening, 1 state (Kentucky) enacted legislation mandating eye examinations, and 19 states lack preventive vision care legislation.

To describe the activity in the vision screening community since the Ciner et al. (1999) publication, and to compare the state policies between the Ciner et al. study and the Vision Council of America (2005) study, 16 states required vision screening in both studies, 16 states shifted from voluntary screening to legislated mandatory vision screening, and 19 states continue to possess either voluntary requirements $(n=7)$, a voluntary requirement under certain 
conditions $(n=1)$ or no policy $(n=9)$. Although Georgia and Vermont now require vision screening, this requirement begins in first grade.

Since the July 2005 publication of the Vision Council of America's report, Rhode Island (Levitt, 2005) and Wisconsin (Remey, 2004) enacted vision screening legislation and North Carolina shifted from mandating vision screening to mandating annual eye exams (Current Operations and Capital Improvements Appropriations Act of 2005, 2005).

Three programs in West Virginia mandate, or provide guidelines for, vision screening, which oftentimes includes screening the vision of preschoolers. The three programs are (a) the West Virginia Department of Education(WVDOE) (Compulsory preenrollment hearing, vision and speech and language testing; developmental screening for children under compulsory school age) (b) the West Virginia Department of Health and Human Resources' (WVDHHR) Child Care Resource and Referral program (J. Curry, personal communication, January 11, 2006), and (c) WV-PreK, a legislated preschool program for 4-year-old children jointly administered by the WVDOE and WVDHHR (P. Edwards, personal communication, January 20, 2006). West Virginia's compulsory preenrollment vision testing legislation encompasses mandatory vision screening for preschoolers (R. King, personal communication, January 20, 2006).

State vision screening policies suggest that additional individuals must receive training in preschool vision screening. Moreover, as additional states move to mandatory vision screening, additional lay screeners will require training in vision screening methodology.

\section{Study Rationale Tenet 4:}

Lay Screeners in Community Settings, When Insufficiently Trained, Will Oftentimes Modify Screening Protocols, Which May Significantly Reduce the Detection of Amblyopia

Primary vision impairment prevention strategies include educating health care professionals, as well as the general population, about various vision disorders and the benefits of detecting and treating these disorders early (Healthy People, 28. Vision and Hearing, n.d.). Another strategy is to screen children for vision impairments. Yet, screening is problematic when individuals are insufficiently trained.

Individuals in community settings, as a result of insufficient training, will typically modify screening protocols, which may significantly reduce the detection of amblyopia (MarshTootle, 1998). Various study results have suggested that screening varies with a screener's experience and training (Marsh-Tootle, 1998) and testing results are "highly dependent on the skills and experience of the examiner" (Donahue et al., 2003, p. 314). To lessen this concern, 
various experts in the preschool vision screening community have advocated for training or certification and recertification vision screening training programs in an effort to increase valid vision screening results, as well as increase the comfort levels of individuals who screen vision (e.g., see Hartmann et al., 2006; Menon et al., 2005)

\section{Study Rationale Tenet 5:}

Various Preschool Vision Screening Experts Have Suggested That Vision Screening Training Programs Will Help Ensure Accurate and Reliable Implementation of Vision Screening Tests Used by Lay Individuals in Community Settings

Lay screeners can be trained to conduct vision screening tests with preschool-aged children (Schmidt et al., 1999). Moreover, lay screeners with at least a high school degree can screen vision as effectively as pediatric nurses or nurses with three or more years of experience in a pediatric setting (The Vision In Preschoolers Study Group, 2005).

The necessity for preschool vision screening training programs was recently highlighted in two national studies (Hartmann et al., 2006; The Vision in Preschoolers Study Group, 2004, 2005) and one state study (Hered \& Rothstein, 2003). Hartmann et al. cited a need for broadened and strengthened training programs for professionals and lay screeners and recommended that certification and recertification programs should be further developed to improve accurate and reliable screening implementation. The format of the screening test and individuals administering tests were among factors The Vision in Preschoolers Study Group (2005) associated with successful visual acuity screening in the second phase of its national study. Further, The Vision in Preschoolers Study Group suggested that a training and certification process enhanced the implementation of vision screening tests (2004). Hered and Rothstein (2003) suggested that direct, practical training may increase the number of 3-year-old children screened and increase the comfort level of staff implementing screening tests.

Additional individuals in the field of preschool vision screening have suggested that:

1. Oftentimes individuals in community settings, as a result of insufficient training, will modify screening protocols, which may significantly reduce the detection of amblyopia (Marsh-Tootle, 1998).

2. Thorough and careful training is required for screening personnel to consistently use vision screening tests and methods to maintain a screening program's integrity (Shoemaker, 1998). 
3. Regardless of the test modality used to detect vision disorders in young children, test performance is dependant on adequate training in test administration (Simons, 1996).

4. Because diverse individuals screen vision, "there is a clear need for some means of assuring that a screener has the necessary expertise to use a given test effectively" (Simons, 1996, p. 22).

5. A training and certification process would help ensure that lay individuals adequately administer screening tests (Simons, 1996).

6. Low referral rates to eye care professionals from primary care practices may be associated with a lack of understanding about vision screening, which could be alleviated through certification and recertification vision screening training programs (Hartmann et al., 2006).

7. Direct, practical training in vision screening may improve clinical support staff comfort when screening the vision of preschoolers (Hered \& Rothstein, 2003).

8. Individuals screening children must be trained and certified in the proper use of screening tests (Fulton, 1992).

9. Without special training in vision screening, "mistakes and errors in visual evaluation cannot be avoided completely” (Käsmann-Kellner \& Ruprecht, 2000, p. 205).

10. Appropriate training of vision screening personnel would help bring about early detection and rehabilitation of amblyopia (Menon et al., 2005).

11. Non-ophthalmic personnel can reliably screen vision after receiving proper training (Lennerstrand et al., 1995).

Although the Hartmann et al. (2006) study did not explicitly review a linkage between training programs and screening results of children who would participate in vision screening (testable), it is interesting to note that individuals trained in VIC's Preschool Vision Screening Training Model achieved the highest testability rate among the four programs involved in this study. Data analysis involved dividing the four programs into community-based and primary care settings. Combining the testability rate of 1,258 three-year-old children in both settings, the numbers of children screened and the percentages of testable children were: 210 children screened, 70\% testable; 226 children screened, 85\% testable; 401 children screened, 70\% testable; and 421 screened in West Virginia with 93\% testable. Combining the testability rate of 1,613 four-year-old children in both settings, the numbers of children screened and the 
percentages of testable children were: 221 children screened, 94\% testable; 303 children screened, 88\% testable; 478 children screened; 93\% testable; and 611 screened in West Virginia with $98 \%$ testable.

\section{Study Rationale Tenet 6:}

No Empirically Studied Training Model Currently Appears to Exist for Training Lay Individuals to Screen the Vision of Preschoolers

Literature discovered during this review pertained to preschool vision screening practices in the United States (Ciner et al., 1999; Ehrlich et al., 1983), the results of studying specific vision screening tests nationally and internationally (e.g., see Becker, Hübsch, Gräf, \& Kaufmann, 2002; Hered, Murphy, \& Clancy, 1997; Kvarnström \& Jakobsson, 2005; Lim et al, 2000; Savage et al., 2005; Shallo-Hoffman, Coulter, Oliver, Hardigan, \& Blavo, 2004; Sturner, Green, Funk, Jones, \& Chandler, 1981; The Vision in Preschoolers Study Group, 2003, 2004, 2005), and the effects or results of various vision screening programs nationally and internationally (e.g., see Bardisi \& Bin Sadiq, 2002; De Becker et al., 1992; Hård et al., 2002; Hered \& Rothstein, 2003; Kvarnström et al., 2001; Newman \& East, 2000; Lennerstrand et al., 1995; Preslan \& Novak, 1996, 1998; Robinson, Bobier, Martin, \& Bryant, 1999; Sjöstrand \& Abrahamsson, 1997; Speeg-Schatz et a., 2004; Tananuvat et al., 2004; Thorburn \& Roland, 2000; Williams et al., 2001, 2003; Yawn et al., 1996).

No studies surfaced that specifically studied how to effectively train individuals to screen the vision of preschoolers. For example, when the preschool vision screening literature indicated that individuals were trained to screen vision, the literature neither explicitly described methodology used to train these individuals nor individuals' perceptions of whether the training prepared them for screening vision (e.g., see Crowley et al., 2005; Hered \& Rothstein, 2003; Robinson et al., 1999; Sturner et al., 1981).

The only documents discovered in this literature review, which somewhat resembled this study, were two posters describing an evaluation, from the participant perspective, of the training on protocols developed for teaching lay screeners to screen vision of Head Start preschoolers (Cyert et al., 1998; Schmidt et al., 1998) and a study looking at the frequency of preschool vision screening following an office-based training session for primary care staff (Hered \& Rothstein, 2003). However, the posters did not describe in detail the results of the evaluation and the one of the authors for both posters stated that results remain unpublished (B. Moore, personal communication, December 8, 2005). 


\section{Study Rationale Tenet 7:}

\section{A Linkage Appears to Be Nonexistent Between Preschool Vision Screening Literature Calling for Training and Educational and Professional Development Literature Describing How to Teach and What Workshops Should Entail}

The literature review for this study failed to locate articles that combined teaching methodology specifically with preschool vision screening training. During this literature review however, various assumptions emerged regarding principles of practice for teaching adults in general, which, subsequently, the researcher compiled, summarized, and referred to as Eight Guiding Principles for Effective Preschool Vision Screening Training. The Eight Guiding Principles, as identified and delineated by the researcher, are:

1. The workshop's content should include theory, demonstration, practice, and feedback.

2. The workshop's content should include clear, attainable objectives that relate specifically to the learning that should occur during the workshop.

3. The workshop's content should teach four primary vision screening components: (a) "why they are screening," or the importance of preschool vision screening; (b) "what they are screening for," or vision disorders screening tests are designed to detect; (c) "what they are screening with," or how to administer the screening tests; and (d) "what do they do with the children who do not pass screening," or the importance of encouraging parents and caregivers to arrange, and attend, comprehensive eye exams when their children fail vision screening.

4. The workshop's content should be sufficiently comprehensive to train on anticipated and unanticipated events that will or could occur during vision screening, such as providing tips for screening children with expressive communication delays.

5. The workshop's delivery system should include a variety of methods to meet the learning styles of diverse learners.

6. The workshop instructor should (a) be enthusiastic; (b) be organized and prepared, (c) possess personality characteristics and interpersonal skills that will engender an image of caring, trust, and encouragement; (d) possess the ability to attain, sustain, and maintain interest; (e) be knowledgeable about how to teach; (f) understand assumptions regarding adult learners; (g) understand assumptions regarding adult learning methodologies; (g) be knowledgeable about the content to teach; (i) focus on learning objectives; (j) provide advance organizers; (k) provide participants with a review of pertinent training material; (1) use training time efficiently and 
effectively; (m) provide feedback; (n) read and learn from responses to workshop evaluation questionnaires; and (o) use humor effectively.

7. The workshop should include job aids to help learners transfer knowledge and skills from the workshop to practice.

8. Workshops should include a meaningful and systematic evaluation process.

\section{Literature Supporting the Eight Guiding Principles for Effective Preschool Vision Screening Training}

This section describes the literature supporting the researcher's Eight Guiding Principles for Effective Preschool Vision Screening Training. For some principles the components and supporting literature will overlap.

Most individuals who screen the vision of preschoolers are adults, who bring to the table learning characteristics that instructors should address to achieve successful instructional events. Many instructors may possess expertise in the task of screening vision, but lack knowledge in the instructional process of how to teach others, especially adults. A classic mistake in adult education occurs when instructors believe that knowing a subject is enough to teach the subject effectively (Wlodkowski, 1999). For example, McLeod, Steinert, Meagher, and McLeod (2003) maintained that clinical teachers rarely receive formal or informal instruction in how to teach and tend to assume that expertise as a practitioner will automatically translate into effectiveness as a teacher. The authors described this belief as the "see one, do one, teach one" principle and maintained that this principle is prevalent in most academic milieu. Good teaching involves knowing how to create learning events that are meaningful and foster the promotion of personal and professional growth (Galbraith, 2004). However, Galbraith stated that creating meaningful learning events is:

... not an easy task since most teachers of adults in the multitude of adult education programs are expert in the content they teach, but usually have little preparation in the instructional process of helping adults learn. Becoming an effective teacher of adults means acquiring essential knowledge of the instructional process. (p. 4)

Therefore, the overarching goal of the Eight Guiding Principles for Effective Preschool Vision Screening Training is to meld suggestions and guidelines from various experts in the education, adult education, and professional development and training arenas to provide diverse instructors 
with essential knowledge for effectively helping adults learn to screen the vision of children ages 3,4 , and 5 .

\section{Guiding Principle 1:}

The Workshop's Content Should Include Theory, Demonstration, Practice, and Feedback

Effective training activities include theory, demonstration, practice, feedback, and coaching to application (Joyce and Showers, 1980). Joyce and Showers define "coaching to application" as "hands-on, in-classroom assistance with the transfer of skills and strategies to the classroom" (p. 380). During a synthesis of 30 years of research and experience, Showers, Joyce, and Bennett (1987), suggested that a combination of theory, demonstration, practice, and feedback appeared critical to helping learners transfer knowledge and skills from training to practice.

\section{Theory}

Theory in the in-service environment has been defined as "the rationale, theoretical base, and verbal description of an approach to teaching or a skill or instructional technique" (Joyce \& Showers, 1980, p. 382). Translating this definition to the vision screening workshop, theory could be described as providing research-based information to learners regarding the importance of preschool vision screening and the approach, or vision screening tests and methodologies, used specifically to screen vision of preschoolers.

\section{Demonstration and Practice}

For learning to occur, learners should be active in the learning task (Ellis, Worthington, \& Larkin, 1994; Garet, Porter, Desimone, Birman \& Yoon, 2001; Guild, 1996; Illeris, 2004; Sarasin 1999). For example, Garet et al. found that active learning was associated with enhanced knowledge and skills. Guild reported that learner involvement helps focus attention, clarify content, make ideas relevant to individual situations, assist retention, and create a sense of investment in the presentation. Consequently, adult instructors should use as much activity as possible in their programs (Bryson, 1936). The more passive teaching method of lecture is one technique for achieving a behavioral outcome of increased knowledge and awareness (Knowles, 1980; Malone, Straka, \& Logan, 2000). Lecture has been considered an effective instructional technique if the lecturer possesses content knowledge and presentational skills (Farrah, 2004). Lecture, alone, however, is ineffective for teaching specific motor skills and is oftentimes incomplete without supplemental demonstration to help adult learners understand how something 
works, as well as the procedures involved in making that something work, which ultimately helps achieve a behavioral outcome of understanding and assists in applying and generalizing newly learned information (Gilley, 2004; Guild, 1996; Knowles, 1980).

Gilley (2004) defined demonstration as a method of instruction to illustrate a procedure, technique, or operation. Joyce and Showers (1980) defined demonstration as modeling the skill either through a live demonstration or some type of media, adding that research suggests demonstration is "very likely to be an important component" (p. 382) of any training program that involves learning a skill and transferring, or generalizing, that skill to another environment. Mager (1996) maintained that modeling has the potential to convey more in-depth information regarding how a task should be performed. Dean (1994) defined demonstration as "a process in which learners observe, practice, and then perform a skill” (p. 107). Dean added that demonstration is an appropriate way to evaluate psychomotor skills.

Curriculum planners of continuing medical education (CME) programs are currently questioning methods of instruction and training, as well as how to connect content and teaching (Armstrong \& Parsa-Parsi, 2005). Armstrong and Parsa-Parsi commented that most CME programs continue to be lecture-based, although lecture-based programs, statistically, tend to be ineffective. Dean (2004) maintained that lecture is more effective for information acquisition than for developing psychomotor skills and that learners learn and retain more when they are actively engaged in the teaching and learning transaction. Gilley (2004), providing 10 advantages of including demonstration in a learning event, stating that demonstrations:

1. Are helpful when adult learners need to learn a step-by-step procedure for using a skill.

2. Arouse interest or motivation and direct the adult learner's attention to the skill to be learned.

3. Provide a visual image of the skill to be learned, which helps encode information.

4. Help make the best use of time in a learning event when time is limited, adding that physically demonstrating a skill may accomplish more than hours of lecture regarding how to perform a skill.

5. Assist in reducing the gap between theory and practice.

6. Enable learners to employ more than one of the senses, which enhances learning. 
7. Provide variety to the learning event, which permits adult learners to focus on something different, relax, and enjoy the learning event.

8. Permit adult learners to view the exact manner in which a skill is to be performed.

9. Provide a break from complex material that may be difficult to comprehend.

10. Prepare adult learners for practicing the skill to be learned.

It is interesting to note that some assumptions regarding adult learners adhere to the philosophies of John Dewey, whom Robyler (2003) suggested that "no one voice in education has had more pervasive and continuing influence on educational practice" (p. 63). For example, Dewey maintained that children learn best through hands-on experiences (Robyler, 2003). This thought appears to translate to adult learners as well. Rogers (1969) stated that "much significant learning is acquired through doing" (p. 162) and "learning is facilitated when the student participates responsibly in the learning process" (p. 162). Additionally, Knox (1977) suggested that "[m]ost learning requires more than a single trial or exposure" (p. 437).

Mackie (1981) and Spitzer (1996) maintained that instructors should provide learners with opportunities to practice, which helps learners "reach a level of automatic implementation on the job" (Garavaglia, 1993, p. 66). Bryson (1936) stated, “ . . . doing the thing to be learned, under the watchful eye and the helpful criticism of the instructor, is most satisfactory" (p. 107) for occupational training, or training on skills to be used in the workplace. Dick et al. (2001) suggested that practice helps learners transform an intellectual skill about how to do something into a motor skill. Gilley (2004) suggested that demonstration should be followed by practice sessions to provide learners the opportunity to perform the demonstrated skill and receive feedback on that performance.

Joyce and Showers (1980) defined practice as "trying out a new skill or strategy" (p. 382), adding that practicing a skill assists learners in mastering new skills. Gagne (1985) defined practice as a learner's repeating a learned procedure with intent to improve performance. Taylor (1996) suggested that practice permits participants to clear "their working-memory registers by transforming new information into long-term memory" (p. 173). Mitchell (1993) stated that individuals learn through practice. Gagne also maintained that practice helps learners retain new information. Listing provision of "learning guidance" and "eliciting performance" as his fifth and sixth of nine instructional events (p. 246), Gagne explained that learning guidance, for a 
motor skill, consists of practicing the motor skill. He equated eliciting performance with asking a learner to demonstrate the learned motor skill.

Employing a vision screening test is a psychomotor or motor skills task. Merely demonstrating how to use the tests may be insufficient for helping all adults learn. Although learners possibly will accomplish a substantial amount of motor skill learning by mentally practicing and rehearsing the skills after watching an instructor-led demonstration, learners cannot receive feedback provided by the kinesthetic sense of how it "feels" to perform the motor skill or to access the outcome of implementing the motor skill, such as whether they can accurately repeat the steps of the motor skill (Gagne, 1985). Gagne further asserted that motor skill development improves with practice and that an essential condition for learning a motor skill is allowing for repeated practice of the motor performance. Practice also permits the instructor to observe participants implement a skill, thus the instructor can assess whether participants understand the material to be learned (Clark \& Taylor, 1996).

Sarasin (1999) maintained that adult learners "learn better if they are involved actively in the learning process" (p. 23); consequently, instructions should include activities such as role play and simulation. Training should involve role play and authentic simulation that will approximate as closely as possible the conditions under which learned skills and knowledge will be used in the real world (Garavaglia, 1993; Smith, 1982; Winton, 1990; Wlodkowski, 2004). Gilley (2004) defined simulation as a teaching technique which permits adult learners to obtain skills involved in situations as close to real world as possible. Galbraith and Zelenak (1991) suggested that simulation provides learners with more experience than lectures and increases motivation to learn by permitting learners to physically practice what they learned in situations that approximate reality.

\section{Feedback}

Not only should instructors provide learners the opportunity to practice a new skill, but instructors should also provide immediate feedback to learners about their performance (Dick, Carey, \& Carey, 2001; Mackie, 1981; Wlodkowski, 2004). Feedback has been defined as "knowledge of results" or knowing whether what was practiced was performed correctly or incorrectly (Dick et al., 2001, pg. 193). 
Immediate feedback helps "shape and reinforce new learning" (Knox, 1977, p. 450). Additionally, feedback enhances motivation because learners can evaluate their progress, understand their level of competence, and immediately correct errors (Wlodkowski, 2004).

Providing feedback is Gagne's (1985) seventh of nine instructional events. Gagne stated that feedback "provides the learner with the confirmation (or verification) that learning has accomplished its purpose" (p. 75). Gagne suggested that after a learner demonstrates a motor skill, for example, the learner should receive information "about the correctness and the degree of correctness of the performance" (p. 254).

Practicing a learned motor skill, with feedback, has been described as a powerful component of the learning process by providing adult learners with activities directly related to learning objectives and active learner participation in the learning event (Dick et al., 2001). Moreover, Dick et al. suggested that knowledge regarding correctly performing a skill is oftentimes the best reinforcement for performing the skill.

\section{Guiding Principle 2:}

The Workshop's Content Should Include Clear, Attainable Objectives That Relate Specifically to the Learning That Should Occur During The Workshop

Adult learners want to know what instructors expect of them as learners, their role in the teaching and learning transaction, where they are going in terms of an end goal, and how they are going to get there (Galbraith, 1994). Sarasin (1999) maintained that adult learners "are more likely to participate with enthusiasm and confidence if they understand why they are doing an activity and what is expected of them" (p. 22). One strategy for satisfying this adult learner characteristic is to provide clear, attainable learning objectives at the beginning of a teaching and learning transaction. A learning objective has been defined as a statement that communicates to participants what they are expected to learn as a result of attending an education or training session (Dean, 2004, Dick et al. 2001, and Gagne, Wager, Golas, \& Keller, 2005).

Malone et al. (2000) suggested that learning objectives should provide learners "a map of where the training is intended to take them" (p. 56). Wlodkowski (1999) maintained that learning objectives achieve a unifying force; they provide the mutual bond for learning. Malone et al. added that the training environment should include a "direct relationship between the training outcomes targeted and the specific objectives identified" (p. 56).

Learning objectives, the second of Gagne's (1985) nine instructional events, inform learners of what to expect during the learning activity and prepare learners to receive 
information. Dean (1994) defined learning activity as "a set of structured experiences designed to help learners achieve one or more learning objectives" which is "usually considered to be the heart and soul of helping adults learn" (p. 83). Providing clear and understandable learning objectives "up front" is third on the 24-item list of Caffarella's (2002) Helpful Hints for Instructors. Galbraith (2004) suggested that instructors should provide learners with oral and written information that provide a rationale for and an explanation of learning objectives. Caffarella (2002) also maintained that the starting point for assessing the results of a learning activity begins with the learning objectives. Finally, learning objectives (a) should be stated in terms of what learners will be able to know, do, or feel at the end of a training session; (b) should imply instructional intent; (c) but should not specify how a behavior will be learned (Caffarella, 2002; Dick et al., 2001).

\section{Guiding Principle 3:}

The Workshop's Content Should Teach Learners Four Primary Vision Screening Components: (A) “Why They Are Screening," or The Importance of Preschool Vision Screening; (B) "What They Are Screening For," or Vision Disorders Screening Tests Are Designed to Detect; (C) "What They Are Screening With," or How to Administer the Screening Tests; and (D) "What Do They Do With the Children Who Do Not Pass Screening," or the Importance of Encouraging Parents and Caregivers to Arrange, and Attend, Comprehensive Eye Exams When Their Children Fail Vision Screening

The third guiding principle implies that an instructor should provide broader information beyond teaching the motor skills of implementing preschool vision screening tests. While this guiding principle is primarily grounded in training experience through the VIC program, literature is available to support this principle. For example, Bacal et al. (1999) maintained that not only should screeners be knowledgeable about vision screening tests and comfortable performing these tests, but screeners should also understand the importance of screening the vision of preschoolers. McLeod et al. (2003) theorized that knowing why, in addition to knowing how, fosters deeper learning.

One could argue that it would be difficult to teach the importance of vision screening without explaining the common vision disorders screening is designed to detect. Additionally, one could argue that it would be nonsensical to teach someone to screen vision without teaching how to use a screening test. Marsh-Tootle (1998) maintained that oftentimes individuals in community settings, as a result of insufficient training, will modify screening protocols, which may significantly reduce the detection of amblyopia. Marsh-Tootle further stated that various 
study results suggested that screening varies with a screener's experience and training. Schmidt et al. (1999) stated that it is "essential" that trainees practice screening tests during training.

For preschool vision screening to be effective, children who do not pass screening should receive a follow-up, comprehensive eye examination with an eye care professional to determine whether a vision problem occurs and to development a treatment plan to help correct the vision problem (Fulton, 1992; Yawn \& Kurland, 1998). While the notion of scheduling and attending a follow-up eye examination following a failed screening appears to be a logical next step, this does not always occur. For example, Yawn et al. (1996) found a median lag time of 0.8 years for children seeing an ophthalmologist (mean 1.8 years and range 8 days to 9 years) and a median lag time of 1.8 years for children seeing an optometrist (mean 2.4 years and range 3 days to 3.7 years, which translates to time without treatment. Preslan and Novak (1998) found that only $30 \%$ of 68 children complied with follow-up care after failing a vision screening. Barriers to followup care in the Preslan and Novak study included lack of parental understanding regarding the importance of vision care. Mark and Mark (1999) and Yawn and Kurland (1998) reported five parental barriers to securing follow-up care: (a) lack of time, (b) lack of financial resources, (c) difficulty scheduling appointments, (d) forgetting about the appointment, and (e) awaiting insurance.

Because a screening program is ineffective without follow-up eye care to treat detected vision problems, one could argue that screeners who are knowledgeable about barriers to followup eye care would have information to help prevent those barriers. Prevent Blindness America's certification training program for screening adults emphasizes the importance of follow-up eye care (Shoemaker, 1997). Moreover, research is provided in this section that described barriers to follow-up care after children failed vision screening. Thus, one could argue that a preschool vision screening training workshop should include information about how to talk with parents/caregivers regarding the importance of follow-up care.

Based on the researcher's personal experience, research results, and information about a training program for screening vision of adults, it appears that screeners who receive instruction about the importance of vision screening, the vision disorders screening is designed to detect, how to administer screening tests correctly, how to talk with parents about the importance of receiving follow-up eye care, and the barriers that can prevent follow-up eye care, would be 
better equipped to effectively screen vision initially and help ensure children who fail vision screening receive follow-up care.

\section{Guiding Principle 4:}

The Workshop's Content Should Be Sufficiently Comprehensive to Train on Anticipated and Unanticipated Events That Will or Could Occur During Vision Screening, Such as Providing Tips for Screening Children With Expressive Communication Delay

Instructors should ensure that the learning environment represents real world situations

(Gilley, 2004). Lay individuals who learn the motor skill of using a vision screening test and who practice using the screening test in a structured preschool vision screening workshop environment with peer learners are likely to anticipate that, when they employ the newly learned skill with children, the children will participate. However, screening young children can be difficult because some children may be unwilling to cooperate (Bacal et al, 1999; Kemper, 2004; Simons, 1996); consequently, not all children will be eager to participate in preschool vision screening activities. Although simulation of preschool vision screening in a workshop is typically as close to real world as possible, it is unlikely that adult learners assuming the role of child in the role play will adequately portray all situations that may occur in real world screening.

Nolan (1994) suggested that learning transfer involves giving learners the ability to move from generalized learning promoted in a learning environment to situation specific types of competence required in real world applications. One strategy for generalizing learning is to build "into the design of learning experiences provision for the learners to plan — and even rehearsehow they are going to apply their learnings [sic] to their day-to-day lives" (Knowles, 1980, p. 50). Dean (1994) suggested that an instructor, in assisting learners to retain and transfer knowledge learned in training, can help "learners anticipate obstacles to transferring new material" (p. 90). To translate Nolan's and Dean's suggestions to the preschool vision screening workshop environment, merely training individuals to use vision screening tests will not sufficiently prepare them to screen children in the "real world" because not all children will comport to the ideal practice scenario of the workshop. Therefore, it seems natural that individuals attending a preschool vision screening workshop should receive knowledge about anticipated, and even unanticipated, situations that may occur during screening, such as what to do when children are reluctant to participate in screening. Additionally, an experienced instructor 
can share tips with learners regarding how to encourage reluctant children to participate in vision screening.

This sharing of tips could be called providing learners with "procedural knowledge" or “information about contingencies or what to do if certain events occur" (Ford, 1994, p. 22). Providing procedural knowledge about unanticipated events that could occur during vision screening goes beyond the motor skill learning task of simply knowing how to use a test to screen vision.

\section{Guiding Principle 5: \\ The Workshop's Delivery System Should Include a Variety of Methods to Meet the Learning Styles of Diverse Learners}

Implicit in the teaching/learning transaction is the knowledge that learners are diverse in how they learn and the length of time required to learn (Davis, 1993). Piskurich (2003) suggested that "good" trainers attend to how adults learn in order to deliver training that adults can relate to and to increase the probability that learners will learn. Adult learners bring to the teaching/learning environment an array of learning styles; thus, instructors of adult learners should use a variety of methods to attend to the learning styles of diverse learners (Bryson, 1936; Dick et al., 2001; Farrah, 2004; Galbraith, 1991,1994; Hequet, 1996; Mackie, 1981; Merriam \& Caffarella, 1999; Spitzer, 1996; Wlodkowski, 1999, 2004). Houle (1996) described method as "an established and systematic way of work used to achieve an educational objective" (p. 201). Examples include lecture, discussion, coaching, role play, and simulated games. Individuals, in general, appear to attend more to things that change as opposed to things that remain static; consequently, educators should change instructional methods, instructional materials, and interpersonal learning patterns in the teaching/learning transaction, such as including individual and small-group learning activities (Wlodkowski, 2004).

Beatty, Benefield, and Linhart (1991) maintained that instructors of adult learners must be sensitive to the learning styles that accompany adult learners to the learning environment. Smith (1982) defined learning styles as "the individual's characteristic ways of processing information, feeling, and behaving in learning situations" (p. 24). Galbraith (2004) stated that learners possess a preferred style for approaching learning and described learning styles as "the ways that individuals prefer to engage and process information in learning activities" (1991, p. 19). The concept of learning style also includes environmental factors, such as the amount of light learners prefer when learning, sound level, chair preferences, time of day, and an informal 
and supportive learning environment versus an environment that is more formal and impersonal (Smith, 1982).

Effective instructors of adult learners use their understanding of differences in learning styles to tailor adult learning experiences (Knowles, Holton, \& Swanson, 1998). Dick et al. (2001) suggested that program designers should determine participants' learning styles and preferences for learning. Mackie (1981) believed that instructors should consider differences in individual learning styles and capacities. Caffarella (2002) maintained, however, that instructors continually are challenged by the differences that learners bring to learning activities and how to address those differences in instructional techniques. Caffarella provided three key rules for instructors to consider:

1. The multiplicity of ways people learn and respond to learning situation is a given.

2. Instructors have the responsibility for designing instruction so these differences are acknowledged and used to enhance the what, when, where, and how of learning situations.

3. Instructors and learners together work to form learning communities that encompass an awareness and feeling of connection among adults and respect for all involved in the instructional process. (p. 181)

The need to heed learning styles of adult learners crosses the boundaries of various types of learning environments. For example, Armstrong and Parsa-Parsi (2005) suggested that continuing medical education (CME) designers should consider individuals' learning styles when planning education programs for adults in health or medical oriented learning situations. Various models exist in the literature that describe learning styles and learning orientations (e.g., see Kolb, 1984; Sarasin, 1999) and no single, unanimously accepted learning style model appears to exist (James \& Maher, 2004).

Sarasin (1999) defined learning style as a "certain pattern of behavior in approaching a learning experience, taking in new information, developing new skills, and retaining that new information and those new skills" (p. 33). Sarasin stated that to understand learning styles is to understand "how students approach a learning experience, how they learn from that experience, how they evaluate the experience, and how they apply new information and skills to situations in life" (p. 33).

Sarasin's (1999) learning style model includes auditory, visual, and tactile/kinesthetic learning styles. For example, auditory learners require oral information to learn and prefer 
information to be presented as individual facts in order to first understand the facts before attempting to understand a whole concept. Visual learners use their senses throughout the learning process and require mental images or visual aids, such as drawings, charts, diagrams, or outlines, to aid them in making sense of new information. Additionally, visual learners prefer to learn about a whole concept before trying to understand individual parts of a concept. While Sarasin links visual representation of new information to visual learners, Deming (1991) maintained that visual representation will enhance learning of all participants, even participants who would not describe themselves as visual learners. Finally, tactile/kinesthetic learners learn by doing and need to be active and dynamic participants in the learning process to learn something new. Tactile/kinesthetic learners prefer to do something to understand the individual parts of a concept and master a concept.

\section{Guiding Principle 6:}

The Workshop Instructor Should (A) Be Enthusiastic; (B) Be Organized and Prepared; (C) Possess Personality Characteristics and Interpersonal Skills That Will Engender an Image of Caring, Trust, and Encouragement; (D) Possess the Ability to Attain, Sustain, and Maintain Interest; (E) Be Knowledgeable about How to Teach; (F) Understand Assumptions Regarding Adult Learners; (G) Understand Assumptions Regarding Adult Learning Methodologies; (H) Be Knowledgeable about the Content to Teach; (I) Focus on Learning Objectives; (J) Provide Advance Organizers; (K) Provide Participants With a Review of

Pertinent Training Material; (L) Use Training Time Efficiently and Effectively; (M) Provide Feedback; (N) Read and Learn From Responses to Workshop Evaluation Questionnaires; (O) Use Humor Effectively; and (P) Attend to the Physical and Psychological Needs of Learners

Caffarella (2002) maintained that instructors play a key role in achieving successful training events because instructors are responsible for helping participants learn. This section provides literature to support at least 16 characteristics that an instructor should possess to help achieve successful training events.

1. Be Enthusiastic

Knowles (1980) proposed that instructors "must be enthusiastic about their subject, and about teaching it to others" (p. 157). Wlodkowski (1998) defined enthusiastic instructors as "people who care about and value their subject matter" (p. 43). Caffarella (2002) suggested that instructors exhibit enthusiasm when they are "passionate about their subject and committed to teaching it to others" (p. 300).

Head Start personnel in Wolfe's (1991) study listed enthusiasm as the fourth most important instructor trait, behind instructors who are well prepared, knowledgeable about the 
subject, and provide opportunities for hands-on experiences and interaction among participants. An enthusiastic and energetic instructor helps motivate learners (Caffarella, 2002; Wlodkowski, 1998). Finally, Davis (1993) suggested that enthusiasm motivates learners and, conversely, learners will lose interest in the subject matter if the instructor appears bored.

\section{Be Organized and Prepared}

Being organized and prepared when presenting a workshop has been identified as two effective instructor characteristics. For example, Caffarella (2002) listed organized and prepared instructors in her list of Nine Criteria to Consider When Obtaining Instructors (p. 300). Students may lack confidence in unprepared instructors (Eble, 1977).

Being prepared and organized can be interpreted as being familiar with the instructional materials in order to converse with workshop participants as opposed to relying on note cards to relay information (Wlodkowski, 1999). Head Start participants in Wolfe's (1991) study listed "well prepared" as their most important instructor trait. In fact, being prepared was listed higher than being knowledgeable about the subject, providing opportunities for hands on practice and interaction among learners, and showing enthusiasm.

3. Possess Personality Characteristics and Interpersonal Skills That Will Engender an Image of Caring, Trust, and Encouragement

Knowles (1980) suggested that an instructor's behavior is the "single most potent force in establishing a social climate" (p. 226) for learning to occur. Galbraith (1991) maintained that in the teaching/learning environment, instructors of adults must "possess personality characteristics and interpersonal skills that will engender an image of caring, trust, and encouragement" (p. 7). Additionally, instructors must demonstrate a sense of caring, support, respect, credibility, and authenticity (Galbraith, 1991, 1992). Authenticity involves permitting learners to view the instructor as a real person who is unafraid of revealing frailties and failures (Galbraith, 1992, Rogers, 1969).

Knowles (1980) further maintained that instructors "must have such other traits of personality as friendliness, humor, humility, and interest in people, that make for effectiveness in leading adults" (p. 157). Rogers (1969) further suggested that effective instructors care for the learner, "prizing his feelings, his opinions, his person" (p. 109). 
Draves (1997) stated that for the best possible teaching experience, an instructor should possess at least four characteristics:

1. Listening skills.

2. The ability to help insecure learners, adding that enhancing security promotes learning for adult learners.

3. Behaviors that will build a supportive environment, such as:
a. Smiling.
b. Responding to a raised hand.
c. A pat on the shoulder.
d. An expression of enthusiasm
e. Listening with patience
f. Warm attentiveness to others.
g. Helping a student with difficulty.

4. Humor, adding that humor promotes learning.

Apps (1981) provided various instructor qualities that both young and adult learners prefer, which suggested that instructors should:

1. Possess an interest in learners and believe in their capacity to learn.

2. Know how to create a positive atmosphere for learning.

3. Be alert to learners' spoken and unspoken reactions.

4. Possess a good personality.

5. Exhibit an interest in the subject matter.

6. Possess the ability to make the subject interesting

7. Demonstrate objectivity in presenting the subject matter and in dealing with learners. Additionally, Apps provided a list of six nonpreferred instructor characteristics:

1. Poor communication skills.

2. Poor personalities.

3. Lack of enthusiasm.

4. Lack of organization.

5. Lack of objectivity.

6. Little interest in students. 


\section{Possess the Ability to Attain, Maintain, and Sustain Interest}

Achieving successful instruction has been associated with the motivation level of learners. Wlodkowski (2004) defined motivation as "the natural human capacity to direct energy in the pursuit of a goal” (p. 142). Motivated learners retain material better (Forman, 2003); "without motivation, the likelihood of learning is minimal" (Kidd, 1973, p. 249). Conversely, when participants are unmotivated to learn, as can be evidenced when participants are hostile or negative, learning transfer is minimal (McNamara, 1982). Christophel (1990) asserted that motivation appears to enhance students' desire to learn, but suggested that the "underlying implication of student motivation appears to lie in the process of 'how' students are taught, rather than 'what' they are taught" (p. 323). Motivation to learn tends to occur when adults perceive learning material as important and that their efforts will make a difference (Wlodkowski, 2004).

To systematically produce instruction designed to motivate the learner and to help instructors understand the motivation to learn, Keller (1987a, 1987b) developed the ARCS Model based on a review of psychological literature on motivation. The ARCS Model is comprised of four instructional attributes: (a) Attention, (b) Relevance, (c) Confidence, and (d) Satisfaction. Keller maintained that instructors must attain a learner's attention and subsequently sustain that attention throughout the instructional event to motivate learners.

Also emphasizing learner attention, Gage (1985) listed attention as the first of his nine instructional events for helping ensure that learning occurs. In that instructional event, Gagne suggested that to prepare learners to receive new information, an instructor must first gain the learner's attention. Pike (2003) asserted that success is "50 percent assured if your audience's interest is working for you from the beginning" (p. 23). Instructors can gain attention by describing for learners the benefits of the workshop, oftentimes referred to as the WIIFM (what's in it for me?) (Forman, 2003, Pike, 2003). Pike stated that "Every person to whom we will ever make a presentation is tuned to radio station WII-FM-What's In It For Me?” (p. 43) In addition to the WIIFM, Pike maintained that participants tend to ask themselves two questions: "What will it help me do my job faster, better, easier?" and "What benefits am I going to gain?" (p. 23)

Keller (1987b) contended that instructors can create conditions to stimulate the learner's desire to be interested and involved. For example, Keller suggested that a learner will be attentive at the beginning of an instructional event. Burns (1985) found that learner attention is at its lowest after 15 to 20 minutes. Therefore, to sustain attention, the instructor should alter the 
pace of instruction and include participative activities (Keller, 1987b). Gorham and Christophel (1990) maintained that using humor in the learning environment is another technique for motivating students.

One method for attaining, maintaining, and sustaining participant interest is to motivate participants upfront (Wlodkowski, 1998). Dick et al. (2001) suggested four ways to attain initial attention: (a) using emotional or personal information, (b) asking questions, (c) creating mental challenges, and (d) using human-interest examples.

As a second technique, Caffarella (2002) asserted that instructors can capture participants' interest by ensuring they are personally involved with the learning material. She maintained that to ensure personal involvement in large group learning environments, instructors can share human-interest stories at the beginning of the learning activity.

A third technique for attaining, sustaining, and maintaining interest is to include a variety of teaching methods to address participants' diverse learning modalities or styles. O'Meara (1996) suggested that instructors should be comfortable with various teaching techniques in order to maintain and renew interest and participation throughout the learning event. O'Meara offered seven teaching techniques that could be incorporated in training events: (a) demonstration, (b) simulation, (c) case study, (d) discussion, (e) individual tasks, and (f) group projects. Bryson (1936) suggested that frequent changes of activity will ward off weariness and boredom. Pike (2003) stated that using variety will assist in creating and maintaining interest. Several models exist in the literature to describe learning styles and learning orientations (e.g., see Kolb, 1984; Sarasin, 1999). Sarasin's model was described in Guiding Principle 5.

A fourth technique for attaining, sustaining, and maintaining participant interest involves using visual aids, such as Microsoft PowerPoint, as a supplement to lecture. Knowles (1992) suggested that participant engagement in learning increases with the use of visual aids. Szarek (1996) stated that visuals "provide interest, sharpen attention and increase retention" (p. 13). In studying possible learning and attitudinal benefits of 107 college students who participated in lecture only, lecture with still pictures, and lecture with animated graphics experimental conditions, Mentch (2002) found that learner scores were significantly higher for students in the lecture with animated graphics group than students in both the still picture group and the lecture only group. Caffarella (2002) cautioned instructors to avoid overusing visual aids, adding that such teaching techniques may distract the learner or cause the learner to attend more to the "bells 
and whistles" and less to the learning material. Parkinson and Hollamby (2003) and Farface (1996) added that an inappropriate use of visual aids may interfere with learning, such as devoting more than 15 minutes to a slide show - a point when learners tend to lose interest_without dividing the slide show into smaller modules.

\section{Be Knowledgeable About How to Teach}

Instructors must know the content they will teach and how to help learners understand the content (American Federation of Teachers, 2002). Bryson (1936) maintained that an adult educator "should know the psychology of the learning process and the principles of some accepted system of pedagogy" (p. 71). Many adult educators are well grounded in the subject they teach, but lack preparation in the instructional process of helping adults learn (Galbraith, 2004). Individuals who graduate from programs that prepare college teachers often are not trained in how to teach (Apps, 1981). Moreover, clinical teachers rarely receive formal or informal instruction in how to teach and tend to assume that their expertise as a practitioner will automatically translate into their effectiveness as a teacher (McLeod et al., 2003). McLeod et al. described this assumption as the "see one, do one, teach one" principle and maintained that this principle is prevalent in most academic milieu. Consequently, these adult educators are likely to lack experience, knowledge, and skills related to the "how" of teaching. Moreover, educators, who are also technical experts in the learning content, are typically familiar with the topic and forget that novice learners lack this familiarity. For example, technical expert educators, instead of breaking content into small manageable units, may overload learners with information (Clark \& Taylor, 1996).

From a study designed to identify important concepts and pedagogic principles that could enhance clinical practitioners' teaching abilities, McLeod et al. (2003) identified 30 pedagogical concepts that 13 education experts rated as potentially important for enhancing clinical instructors' teaching success. McLeod et al. positioned the 30 pedagogical concepts into four broad categories: (a) Curriculum, (b) How adults learn, (c) Helping adults learn, and (d) Assessment. Twenty-seven of the 30 pedagogical concepts are delineated in Table 1 . Twenty of the 30 pedagogical concepts translate well to the Eight Guiding Principles for Effective Preschool Vision Screening Training. Others cannot easily be incorporated within the current design of the Vision Initiative for Children's preschool vision screening workshop. 
Table 1

27 Pedagogical Concepts, Positioned Into 4 Broad Categories, That Clinical Instructors Should Know to Enhance Teaching Ability

\begin{tabular}{|c|c|}
\hline 4 broad categories & Pedagogical concepts \\
\hline 1. Curriculum & $\begin{array}{l}\text { Goals and objectives } \\
\text { Curriculum structure and design }{ }^{\mathrm{a}}\end{array}$ \\
\hline 2. How Adults Learn & $\begin{array}{l}\text { Motivation for learning }^{\mathrm{a}} \\
\text { Transfer of learning }^{\mathrm{a}} \\
\text { Self-regulation of learning } \\
\text { Adult learning theory }^{\mathrm{b}} \\
\text { Case-based learning }^{\mathrm{b}} \\
\text { Self-directed, teacher-directed instruction } \\
\text { Idiosyncratic problem solving }^{\mathrm{a}}\end{array}$ \\
\hline 3. Helping Adults Learn & $\begin{array}{l}\text { Pedagogical implications of learner differences } \\
\text { Knowledge, skills, and attitudes }^{\mathrm{a}} \\
\text { Coaching }^{\mathrm{b}} \\
\text { Peer and near-peer tutoring }^{\mathrm{a}} \\
\text { Role modeling } \\
\text { Supervision of learners } \\
\text { Lesson structure and planning }^{\mathrm{b}} \\
\text { Relevance for learning }^{\mathrm{a}} \\
\text { Learning environment }^{\mathrm{a}} \\
\text { Communication skills and concepts }^{\mathrm{b}} \\
\text { Problem solving for learning }\end{array}$ \\
\hline 4. Assessment & $\begin{array}{l}\text { Summative versus formative assessment } \mathrm{t}^{\mathrm{a}} \\
\text { Key concepts for assessment } \mathrm{t}^{\mathrm{b}} \\
\text { Criterion versus norm-referenced assessment }{ }^{\mathrm{a}} \\
\text { Unintended consequences of assessment } \mathrm{t}^{\mathrm{b}} \\
\text { Reasons for assessing learners }{ }^{\mathrm{a}} \\
\text { Assessment to drive learning }{ }^{\mathrm{a}} \\
\text { Performance-based assessment }{ }^{\mathrm{a}}\end{array}$ \\
\hline
\end{tabular}

Note. Created from text in McLeod et al., 2003.

${ }^{a}$ Concepts that translate well to the Eight Guiding Principles for Effective Preschool Vision Screening Training

${ }^{\mathrm{b}}$ Concepts that cannot easily be incorporated specifically within the design of the Vision Initiative for Children's Preschool Vision Screening Training.

Pratt (2002) cautioned against employing a "one-size-fits-all" approach to teaching adults and, by studying hundreds of teachers of adults during 10 years of research in 5 different 
countries, found that no single view of teaching dominated what he called "good teaching." Taylor, Marienau, and Fiddler (2000) defined teaching as "an imprecise, mysterious art" (p. 316), suggesting that no single teaching model works in all teaching/learning interactions. Thus, O’Meara (1996) and Sarasin (1999) suggested that instructors should be comfortable with various teaching techniques in order to maintain and renew interest and motivation, maintain a varied and exciting learning environment, and encourage active participation throughout the learning event.

Additionally, one of Caffarella's (2002) nine criteria to consider when obtaining instructors to teach adult learners pertains to knowing how to teach. This criterion states: "Instructors are competent in a number of instructional techniques and processes, match those techniques to their subject matter and the learners, and are able to use a variety of methods" (p. $300)$.

Instructors should not rely on one specific learning theory (i.e., humanism, behaviorism, and constructivism) when working with adult learners because no single pedagogy equally matches all disciplines and topics (American Federation of Teachers, 2002; Cross, 1981). Instead, Robyler (2003) suggested that instructors should follow approaches that focus on the characteristics of the subject matter and individual learning needs.

Finally, Dean (1994) stated that instructors should possess content expertise, as well as process expertise. Dean differentiated content and process expertise by defining content expertise as the knowledge and skill in content to be learned and defining process expertise as having knowledge and skill regarding how to help adults learn the content.

\section{Understand Assumptions Regarding Adult Learners}

Regardless of the context for learning, various adult education experts suggested that understanding adults, in general, and understanding how adults learn, in particular, is critical to effective teaching. For example, instructors should understand the diversity and variability of adult learners, including the multifaceted physiological, psychological, sociological and developmental aspects of adult learners (Galbraith, 1991). Instructors working with adult learners should understand who adult learners are and how they learn (Merriam \& Brockett, 1997).

Instructors should apply adult learning theory to the delivery of content (American Federation of Teachers, 2002; Killion \& Harrison (1997). Understanding relevant characteristics 
about adult learners is oftentimes viewed as one of the most important activities that adult educators should undertake (Dean, 2004). Dean further suggested that understanding relevant characteristics about adult learners assists adult educators in developing instructional materials that will match the specific needs of adult learners.

Although various adult education experts suggested that understanding how adults learn is critical to effective teaching, and various individuals, since the 1920s, have contemplated how adults learn, this literature review revealed numerous assumptions about adult learners but no single, definitive model because no single model exists to explain the adult learner (Merriam, 2001). Long (2004) theorized that to speak of adult learners as if a generic adult can represent all adults is erroneous. Rather, educators should strive for a balance between recognizing individual idiosyncratic adult learner characteristics and normative characteristics that permit viewing adult learners as a group.

While Knowles (1973) initially made a distinction between assumptions about teaching children (pedagogy) and assumptions about teaching adults (andragogy), defining pedagogy as the art and science of teaching children and andragogy as the art and science of teaching adults. To illustrate the difference between pedagogy and andragogy, Knowles (1973) theorized that children are conditioned to a subject-centered orientation to learning whereas adults are more oriented to problem-centered learning. For example, children are "ready to learn whatever society (especially the school) says they ought to learn" (Knowles, 1980, p. 44), whereas adults "become ready to learning something when they experience a need to learn it in order to cope more satisfyingly with real-life tasks or problems" (p. 44). He explained:

I am not talking about a clear-cut differentiation between children and adults as learners. Rather I am differentiating between the assumptions about learners that have traditionally been made by those who practice pedagogy in contrast to the assumptions made in andragogy. I believe that the assumptions of andragogy apply to children and youth as they mature, and that they, too, will come to be taught more and more andragogically. (p. 43)

Knowles (1980) later revised his thoughts:

I am at the point now of seeing that andragogy is simply another model of assumptions about learners to be used alongside the pedagogical model of assumptions, thereby providing two alternative models for testing out the 
assumptions as to their 'fit' within particular situations. Furthermore, the models are probably most useful when seen not as dichotomous but rather as two ends of a spectrum, with a realistic assumption in a given situation falling in between the two ends. (p. 43)

Appearing to echo Knowles's revised thoughts regarding a distinction between pedagogy and andragogy, Mackie (1981) suggested that most principles regarding adult learners can be defined more as quality teaching versus bad teaching and less as a distinction between teaching for adults and teaching for children.

The adult learning literature is replete with characteristics attributed to adult learners (e.g., see Apps, 1981; Brookfield, 1986; Caffarella, 2002; Cross, 1981; James, 1983; c \& Cook, 2003; Galbraith, 1994; Knowles 1973, 1980, 1989; Knox, 1977; Lindeman, 1961; Long, 2002; Merriam \& Brockett, 1997; Thorndike, 1935; Wlodkowski, 1999; Zemke \& Zemke, 1996). Many characteristics are similar; others are dissimilar. To illustrate one similarity, Lindeman (1961), who has been called the pioneering adult learning theorist (Knowles et al., 1998, p. 39), suggested in 1926 that adults are motivated to learn by needs and interests and that learning is life-centered. Long (2002) continued this thinking 76 years later, stating that adults are autonomous beings with goals, desires, and expectations and the adult's orientation to learning is related to application, including real-life problem solving.

In knowing how to teach diverse adults, the instructor has available as guidelines various assumptions related to teaching adults and assumptions regarding adult learning characteristics. For example, Knowles (1973) and Zemke and Zemke (1996) suggested that adults enter an educational activity primarily because they experience some inadequacy in coping with current life problems. Additionally, Knowles proposed that an immediacy of time application is attached to adult learning in that adults typically want to apply tomorrow what they learn today while children's learning typically prepares them for the next level of education. It is interesting to note that experts in the adult learning community suggested that adults tend to be pragmatists and task- or problem-oriented in their learning in that they want learning to be meaningful and easily applicable in their lives (Caffarella, 2002; Cross, 1981; Draves, 1997; Gilley, 2004; Illeris, 2004; James, 1983; Knowles, 1973, 1980, 1989; Knox, 1977; Lindeman, 1961; Long, 2004; Rogers, 1969; Sarasin, 1999; Wlodkowski, 1999). This assumption appears to follow John Dewey’s 
notion that instruction, for children, should focus on relevant and meaningful activities (Robyler, 2003).

Attempts to acquire through a literature review a universally defined set of assumptions regarding adult learning characteristics exceeded the scope of this dissertation. For example, Houle (1996) indicated that an earlier work he published in 1992, The Literature of Adult Education, included 1,241 references. A Google search on January 5, 2006, using the individual search terms within the phrase of "defined set of assumptions regarding adult learner characteristics" returned 1,250,000 results.

For this dissertation, most of the assumptions and adult learning characteristics in this literature review built on or expanded assumptions first presented by Eduard Lindeman in 1926 and Malcolm Knowles in 1973. Results of an extensive literature review about adult learners suggest that while Knowles's introduction of adult learning as a theory has been questioned (Cross, 1981), Knowles's assumptions about adult learners have stood the test of time. For example, Merriam and Brockett (1977) maintained that Knowles' assumptions made a significant impact on how educators understand and work with adults.

Rachal (2002) maintained that no operational definition of andragogy exists. Similarly, no universally operational definition concerning assumptions about learning characteristics or an agree-upon, singular list of basic principles of adult learners emerged in this literature review. However, the literature was replete with various principles of good practice regarding training and educating adults. Because attempting to create a universal list clearly exceeds the scope of this dissertation, Table 2 reflects the researcher's attempt to distill various characteristics into a list the researcher refers to as 17 Assumptions Regarding Adult Learners, as well as relevant supporting literature and citations, that appear appropriate to guide instructors as they develop and deliver face-to-face preschool vision screening workshops. Table 2 is based on this literature review and the researcher's personal experience of training nearly 1,000 individuals to screen the vision of preschoolers during the past 5 years. 
Table 2

17 Assumptions Regarding Adult Learners as They Relate to Preschool Vision Screening Training Workshops

\begin{tabular}{|c|c|}
\hline Assumptions & Supporting literature \\
\hline $\begin{array}{l}\text { 1. Maintain the ability to } \\
\text { learn }\end{array}$ & $\begin{array}{l}\text { Although adults experience a gradual decline in physical/sensory } \\
\text { capabilities, adults maintain the capacity to learn (Cross, 1981; } \\
\text { James 1983; Kidd, 1973; Knowles, 1980). }\end{array}$ \\
\hline $\begin{array}{l}\text { 2. Task-oriented with needs } \\
\text { and interests to satisfy }\end{array}$ & $\begin{array}{l}\text { Adult learners tend to be life-, task-, or problem-centered and are } \\
\text { motivated to engage in learning when the subject matter is } \\
\text { meaningful to them and as they experience needs and interests in } \\
\text { their real-life situations that learning will satisfy, although } \\
\text { sometimes resistant adult learners need to know why they need } \\
\text { to learn something before they are willing to learn that } \\
\text { something (Bryson, 1936; Caffarella, 2002; Cross, 1981; James, } \\
\text { 1983; Knowles, 1980, 1989; Knox, 1977; Lindeman, 1961; } \\
\text { Zemke \& Zemke, 1996). }\end{array}$ \\
\hline $\begin{array}{l}\text { 3. Want to know instructor's } \\
\text { expectations for them, where } \\
\text { they are going, and how they } \\
\text { will get there }\end{array}$ & $\begin{array}{l}\text { Adult learners want to know what the instructor expects of them } \\
\text { as learners, what is expected of them in the teaching and learning } \\
\text { transaction, where they are going in terms of an end goal, and } \\
\text { how they are going to get there (Galbraith, 1994). }\end{array}$ \\
\hline 4. Voluntarily learn & $\begin{array}{l}\text { Adults are autonomous beings with goals, desires, and } \\
\text { expectations, which may or may not be identical to the goals and } \\
\text { objectives of the learning event, and are less likely to willingly } \\
\text { engage in learning unless the learning is meaningful to them. } \\
\text { Participation in the learning process is voluntary, unlike } \\
\text { compulsory attendance for children; circumstances prompting } \\
\text { the learning may be external, but the decision to learn is the } \\
\text { learner's. Learners may withdraw participation if they believe } \\
\text { the activity does not meet their needs, is incomprehensible, or is } \\
\text { conducted at a level beyond their abilities (Brookfield, 1986; } \\
\text { Caffarella, 2002; Cross, 1981; Draves, 1997; Illeris, 2004; } \\
\text { Knowles, 1980; Lindeman, 1961; Long, 2002; Wlodkowski, } \\
\text { 1999; Zemke \& Zemke, 1996). }\end{array}$ \\
\hline
\end{tabular}


Assumptions

5. Pragmatic and want to apply tomorrow what they learn today

6. Need to feel competent when applying learning

7. Intrinsically motivated

8. Have diverse adult roles that impact what, how, and where they learn

9. Can be distracted by diverse adult roles
Supporting literature

Adult learners view themselves as "producers or doers" (Knowles, 1980 , p. 45), are, therefore, pragmatic in their learning, problemoriented, and want to apply tomorrow what they learn today by doing, producing, or deciding something that is of real value to them (Caffarella, 2002; Cross, 1981; Draves, 1997; Gilley, 2004; Illeris, 2004; Keller, 1987a; Kidd, 1973; Knowles, 1973, 1980; Knox, 1977; Long, 2004; Rogers, 1969; Sarasin, 1999; Taylor et al., 2000; Wlodkowski, 1999, 2004).

Adult learners tend to take errors personally, feel inadequate about performing and receiving judgment in the learning environment, and possess a strong need to feel competent when they apply new learned knowledge and skills; consequently, they want to be successful learners because success directly or indirectly indicates competence. If they do not expect or experience success in the learning event, their motivation to learn will decline (Cross, 1981; Dick et al., 2001; Sarasin, 1999; Taylor et al.,2000; Wlodkowski, 1999; Zemke \& Zemke, 1996).

While adult learners are responsive to some extrinsic motivators for learning, such as better jobs, promotions, and salary increases, the more potent motivators are intrinsic motivators, such as the desire for increased self-esteem, quality of life, responsibility, and job satisfaction, and they feel better when they have successfully learned something they wanted to learn and something they value (Knowles, 1980; 1989, Wlodkowski, 1999).

What, how, and where adults learn is affected by the competing and multiple demands on their time as a result of the diverse roles they play as adults, including worker, parent, partner, friend, and spouse, as well as their personal contexts as learners, such as gender, race, ethnicity, social class, disabilities and abilities, and cultural background (Caffarella, 2002; Davis, 1993; Draves, 1997; James, 1983; Smith, 1982; Wlodkowski, 2004).

Adult learners can be distracted by the diverse roles they play as adults, such as time pressures, difficult work situations, and domestic concerns (Merriam \& Brockett, 1997). 
Assumptions

10. Want prior knowledge and experience acknowledged
11. Quick to judge learning material and instructor

12. Prefer active involvement in learning

13. Prefer single-concept, single-theory workshops

14. Have individual differences in how they learn
Supporting literature

Adult learners enter an educational activity with a greater volume and a different quality of knowledge and experience than youths and will learn best when instructors acknowledge this experience and new information builds on their past knowledge and experience (Caffarella, 2002, Galbraith, 2004; James, 1983; Knowles, 1989; Knox, 1977; Smith, 1982).

Adult learner attitudes influence their motivation to learn from the moment instruction begins and adult learners will immediately judge the instructor, the subject, the learning situation, and their personal expectancy for success (Wlodkowski, 1999). Moreover, adult learners are likely to withdraw from learning when activities do not meet their needs or appear incomprehensible (Brookfield, 1986).

Adult learners have preferred and different ways of processing information and they prefer active involvement in the learning process as opposed to being passive recipients of knowledge (Caffarella, 2002; Garet et al., 2001; James, 1983; Knox, 1977; Smith, 1982).

Adult learners tend to prefer single-concept, single-theory workshops that focus on "how-to" content, application, and relevant material (Friend \& Cook, 2003; Gilley, 2004; Zemke \& Zemke, 1996).

Adults have preferences for and different ways of processing information (American Federation of Teachers, 2002; Caffarella, 2002; Galbraith, 1992). Adult learners' individual differences increase with age; therefore, instructors must provide for differences in style, time, place, and pace of learning (James, 1983; Knox, 1977; Lindeman, 1961; Smith, 1982). 
Assumptions

15. Want to feel safe, comfortable, and valued in the learning environment
16. Possess physiological variables that typically are not present in younger students

17. Enjoy laughing
Supporting literature

Many adult learners participate in learning with mixed feelings, self-consciousness, and fear about their personal learning abilities and are more receptive to the learning process when they are physically and psychologically comfortable: (a) where a non-threatening learning environment affords physical comfort, such as good illumination, absence of distractions, and appropriate temperatures; mutual trust and respect, mutual helpfulness, freedom of expression, and acceptance of differences; (b) where learners are encouraged to trust themselves, make mistakes, and try again; and (c) where learners have a comfortable degree of personal space (Brookfield, 1986; Caffarella, 2002; Cross, 1981; Gilley, 2004; Hiemstra \& Sisco, 1990; James, 1983; Kidd, 1973; Knowles, 1980; Long, 2002; Merriam \& Brockett, 1997; Sarasin, 1999; Smith, 1982; Thorndike, 1935; Zemke \& Zemke, 1996). Sarasin (1999) stated that adult learners tend to be less motivated to learn in structured environments, such as those that line desks in rows. Finally, many adult learners tend to prefer instructors who refrain from displaying their authority or superiority (Thorndike, 1935).

Adult learners, typically, possess physiological variables that are not common to younger learners, such as diminished auditory and visual acuity, reduced energy levels, and increasing frequency of health problems (Long, 2004).

Adult learners enjoy laughing and will be more interested in learning that provides this possibility (Wlodkowski, 1999).

\section{Understand Assumptions Regarding Adult Learning Methodologies}

Galbraith (1991) stated that to help facilitate learning, instructors must understand adult learning methodologies. Methods has been defined as "tools to use within the instructional process to enhance the teaching and learning encounter" (Galbraith, 2004). Such methods include discussion and simulation (Galbraith \& Zelenak, 1991).

Knowles (1980) maintained that the role of instructor of adults is not to teach, in the sense of "make a person learn" (p. 48); rather the role is to help adults learn. Dean (1994) stated that adult educators must possess process expertise, or knowledge and skills regarding how to help adults learn. Additionally, Knowles stated that, to help adults learn, instructors must "be creative in their thinking about teaching methods" (p. 157). For example, Cross (1981) suggested 
that short-term memory impairment occurs in older adult learners. She offered four tips for instructors to help overcome short-term memory impairment:

1. New information should be meaningful and should include aids to help the learner organize and relate the new information to previously stored information.

2. New information should be presented at a pace which will permit mastery.

3. New information should be presented one idea at a time to minimize competing intellectual demands.

4. Information should be summarized frequently to facilitate retention and recall.

Adult methodologies can include adapting one's teaching to physiological physical characteristics of adult learners. For example, Cross (1981) suggested that adjusting teaching for physical aging includes greater lighting in the learning environment, less auditory confusion, and slower pace when presenting new information. To accommodate adult learners wearing bifocals, educators should avoid using projected media requiring learners to shift fields of vision from 18 inches to 20 feet and back to 18 inches (Long, 2004). Additionally, educators should ensure voice and media levels accommodate adults with loss of vision and planned activities do not tax energy levels (Long, 2004).

Another way to ensure instructors do not tax energy levels is to avoid providing an excessive amount of new information. Davis (1993) maintained that learners can assimilate new information only in small amounts. Sarasin (1999) suggested that adult learners prefer information in "chunks" in order to assimilate new information. Summarizing material is one approach to helping adult learners synthesize what they have learned (Sarasin, 1999; Zemke \& Zemke, 1996). Synthesizing "promotes memory recall and long-term retention of information by encouraging students to process and assimilate what they learned within the context of what they know" (Sarasin, 1999, p. 26).

\section{Be Knowledgeable About the Content to Teach}

A copious amount of literature is available that describes the importance of the adult educator's possession of content expertise in the teaching/learning environment (e.g., see American Federation of Teachers, 2002; Apps, 1981; Brookfield, 1991; Caffarella, 2002; Dean, 2004; Galbraith, 1991, 2004; Gilley, 2004; Knowles, 1980; Long, 2002; Pike, 2003; Wlodkowski, 1999). Galbraith (1991) maintained that implicit in the teaching/learning environment is an instructor's proficiency in content. Knowles (1980) stated that instructors 
should have knowledge about content and should be "successful practitioners of their subject or skill” (p. 157). Dean (2004) suggested that possessing content expertise is typically associated with the characteristics of successful adult educators. To ensure learners attach meaning and value to the subject they are to learn, Galbraith (2004) maintained that adult instructors must be technically proficient in the content area they teach. Brookfield (1991) suggested that instructors should be perceived as "having content mastery, expert knowledge, and depth of insight in the area in which they teach — of having 'something to offer' learners" (p. 51). Apps (1981) stated that instructors should know their subject matter. Moreover, learners prefer to receive instruction from one whom they perceive has greater factual knowledge, skills mastery, and reasoning facility than they possess (Brookfield, 1991).

Pike (2003) suggested that individuals cannot teach what they do now know and that the most effective instructors "generally are those who have experienced what they are teaching" (p. 275). Wlodkowski (1999) asserted that instructors should thoroughly know the subject they teach and that this knowledge will enhance their confidence in teaching and answering questions, as well as their flexibility, creativity, spontaneity, and improvisation. Long (2002) maintained that in order to set the proper context for teaching, instructors should be knowledgeable about the topic for which they are responsible for teaching. Additionally, Caffarella (2002) suggested that, where applicable, instructors should also be successful practitioners of the knowledge and/or skills they teach, which enhances the instructor's credibility. She stated that learners more readily accept information from instructors they believe to be credible. Pike wrote that participants want to learn from instructors who possess both "head" and "heart" knowledge, with the latter referring to experience with the subject matter. Finally, Gilley (2004) maintained that, particularly when demonstrating a skill to be learned, the preparation and skill level of the adult educator cannot be overemphasized. Gilley stated that an adult educator who is not properly prepared and knowledgeable about the skill might confuse, overwhelm, or discourage learners, leading learners to believe they cannot master a skill if the adult educator cannot master the skill. Consequently, learners may lose respect for what they consider to be an inept instructor.

\section{Focus on Learning Objectives}

Intensive courses should include a focus on learning objectives (Daniel, 2000). Dick et al. (2001) suggested that focusing on learning objectives helps ensure that instructors complete three tasks: (a) specifying the knowledge and skills they plan to teach, (b) developing a strategy for 
teaching the knowledge and skills, and (c) establishing evaluation criteria. Additionally, focusing on learning objectives helps prevent "instructional gaps or duplication" (Dick et al, 1991, p. 123).

Workshops typically are bound by time constraints, implying that focusing on learning objectives will help ensure material is covered within the scheduled start/stop time. Wlodkowski (1999) stated that "time is precious to adults" (p. 160). Adult learners are likely to consider an investment of their time in training as important as the cost of the training or the amount of effort training may require (Kidd, 1973). Additionally, at least one participant in every training will check whether the instructor discussed all objectives (Pike, 2003).

Although literature regarding the need to focus on learning objectives did not explicitly surface in this review, the literature implied that focusing on learning objectives would assist instructors in staying on task. Hence, it appears logical that a focus on learning objectives would help ensure that material is covered and adult learners would leave the workshop environment on time and feeling that they had not wasted their time.

\section{Provide Advance Organizers}

Ausubel and Robinson (1969) defined an advance organizer as "introductory material that is presented in advance of and at a higher level of generality, inclusiveness, and abstraction than the learning task itself; designed to promote subsumptive learning by providing ideational scaffolding or anchorage for the learning task and/or by increasing the discriminability between the new ideas to be learned and related ideas in cognitive structure" (pp. 606-607). Ausubel (1968) maintained that advance organizers should be "introduced in advance of learning" (p. 149) to provide a framework for helping learners organize information (Ausubel \& Robinson, 1969). Ellis et al. (1994) maintained that learning increases when instructors present material in a style that assists learners in organizing, storing, and retrieving knowledge.

To employ advance organizers, Caffarella (2002) suggested (a) beginning a training session with an acknowledgement and review of what participants already know and (b) providing participants a framework for helping organize new learning material and understanding how the new knowledge can be transferred into their own settings. Wlodkowski (1999) theorized that concrete advance organizers and visual tools, such as graphics, examples, questions, activities, and diagrams, will support learning new material by (a) directing attention to important elements of new material, (b) highlighting relationships between previously learned 
and new material to be presented, and (c) reminding learners of relevant information or experiences embedded within their cognitive structure. Deming (2001) suggested providing learners with visual handouts to provide a mental outline that will help learners organize new information.

\section{Provide Participants With a Review of Pertinent Training Material}

Knox (1977) maintained that providing new information rapidly and with brief exposure, as may occur in a workshop, can limit the amount of new knowledge adult learners will store and recall; thus reviewing the content is one strategy for helping adult learners remember the new knowledge and skills. Cross (1981) theorized that an instructor's summarization of material assists adult learners in retaining and recalling information.

\section{Use Training Time Efficiently and Effectively}

Guiding Principle Number 8 overlaps with this section. Additionally, literature to explicitly support this component did not surface during the review. For example, Caffarella (2002) listed "being aware of time" in her list of 24 hints for instructors, although she did not expand on the importance of this component. Similarly, Davis (1993) listed "keeping track of time" as one of her 14 tips for capturing learners' interest. Like Caffarella, she did not overtly describe the importance of this component.

As discussed in Number 8, workshops typically are time bound. Dick et al. (2001) suggested that an error involved with content presentation occurs when instructors present too much information "especially when much of it is unrelated to the objective" (p. 193). Witt (1996) suggested that instructors should refrain from rushing the presentation pace, adding that participants will "learn quicker and remember it longer if they have a few seconds after each idea to process it fully" (p. 112). Hence, it appears logical that if an instructor uses training time inefficiently and ineffectively, content presentation, or the "totality of what is to be learned" (Dick et al., 2001, p. 193) will be unsuccessful.

Another concern involved with the inefficient and ineffective use of training time is to start the workshop later than the scheduled starting time or to continue the workshop beyond the scheduled ending time. For example, beginning later than the scheduled starting time rewards participants who arrive late and penalizes participants who arrive on time (Mackenzie, 1990; Pike, 2003). Eble (1977) suggested that ending a session before the scheduled stop time was preferred to extending the session beyond the scheduled ending time. Pike maintained that 
participants tend to be displeased when a training program continues beyond the scheduled stopping time. Mackenzie postulated that continuing the event beyond the scheduled end time can result in resentment from participants who scheduled other activities following the meeting.

Viewing this section from the perspective of the adult learner, Wlodkowski (1999) stated that "time is precious to adults" (p. 160). Hence, as discussed in Number 8, if instructors use training time inefficiently and ineffectively, adult learners are more likely to leave the concluded workshop feeling resentful, which can have a negative impact on learning.

\section{Provide Feedback}

Davis (1993) stated that "[f]requent, immediate, and specific feedback helps students learn" (p. 182). Instructors should provide learners the opportunity to practice what they should be able to do after completing a workshop, and instructors should provide immediate feedback to learners about their performance (Dick et al., 2001). Providing feedback is Gagne's seventh of nine instructional events. Gagne stated that after a learner demonstrates a motor skill, for example, the learner should receive information "about the correctness and the degree of correctness of the performance" (p. 254).

Feedback has been defined as "knowledge of results" or knowing whether what was practiced was performed correctly or incorrectly (Dick et al., 2001, pg. 193). Practicing a learned motor skill, with feedback, has been described as a powerful component of the learning process because this component provides adult learners with activities directly related to learning objectives and active learner participation in the learning event (Dick et al., 2001). Moreover, Dick et al. suggested that, for adult learners, knowledge regarding correctly performing a skill is oftentimes the best reinforcement for performing the skill.

\section{Read and Learn From Responses to Workshop Evaluation Questionnaires}

The "acid test" of any instructional event is how well learners respond to the instructional event (Dean, 1994, p. 116). Dean added that requesting learner feedback about the instructional event is one form of evaluation. Beatty et al. (1991) defined evaluation as "the mutual, interactive, and systematic process of identifying, gathering, and analyzing information in order to make decisions which would enhance learning for all persons involved" (p. 164). Beatty et al. defined "all persons" as both learners and facilitators of learning. Dean (1994) stated that evaluation can assist instructors in knowing what participants learned, what is most useful to 
learners, and what changes are needed in future learning activities. When instructors do not use evaluations to improve training, evaluations are meaningless (Mizell, 2003).

A "good" instructor is "constantly finding ways to improve their instructional skills" (Hiemstra \& Sisco, 1990, p. 124). They further maintained that "[e]ffective instruction results from evaluating both how well learners are performing and how well you are doing as an instructor" (p. 124). Therefore, it appears that, as a result of reading evaluation questionnaires, instructors can improve how they help adult learners learn.

\section{Use Humor Effectively}

The use of humor has been noted as an effective tool for stimulating learner attention and enjoyment in the teaching/learning transaction, providing feedback to the educator, and as a memory recall aid (Farrah, 2004). Humor has also been described as an instructor immediacy behavior for building rapport with learners (Eble, 1977; Thweatt \& McCroskey, 1996). Thweatt and McCroskey described immediacy as "communication behaviors that reduce perceived distance between people" (p. 198), such as engaging in eye contact, encouraging learners to talk, and providing and asking for feedback (Gorham \& Christophel, 1990).

Gorham and Christophel (1990) described studies indicating that a teacher's use of immediacy behaviors, including humor, were significantly associated with student learning outcomes. Regarding the teacher immediacy behavior of humor specifically, Gorham and Christophel found that more immediate teachers use more humor and engender more learning. Draves (1997) maintained that humor allows adult learners to relax and "helps promote learning" (p. 18). Adamson, O'Kane, and Shevlin (2005) found that correlations based on ratings of teaching effectiveness from 453 undergraduate students demonstrated that instructor humor was significantly related to teaching effectiveness. Frymier and Wanzer (1998) found that a high humor orientation in the classroom - where humor is used frequently and effectively — was associated with increased student learning. Frymier and Wanzer cautioned, however, that a teacher with low humor orientation may lack personality characteristics to effectively employ humorous behaviors and, consequently, learners may perceive the use of humor as inappropriate.

The necessity of possessing a sense of humor in adult learner methodology was evident even 70 years ago (Bryson, 1936). Caffarella (2002) suggested that the use of humor is one strategy to "spark the interest of even the most reluctant participants" (p. 195). Wlodkowski (1999), listing the use of humor as 1 of 60 strategies for motivating learners, suggesting that 
people enjoy laughing, will be interested in anyone or anything that provides a laughing opportunity, and that adult learners are more willing to participate in learning activities when those activities invite or evoke interest. Bringing a sense of humor into the learning environment can remove barriers to communication and encourage bonding and connection between (a) learner and instructor, (b) learner and other learners in the same environment, and (c) learner and subject matter (Berk, 1998; Cohen, 1996).

Neelam, Molstad, and Donahue (1999) suggested that "[h]umor is a valuable teaching tool for establishing a classroom climate conducive to learning" (p. 400). The effective use of humor appears to produce at least 12 benefits for the teaching/learning environment:

1. Engendering trainees' receptivity toward the learning activity.

2. Enhancing commitment to the learning.

3. Fostering participants' involvement in the learning process.

4. Increasing learning.

5. Reducing stress and tension by helping participants relax.

6. Helping gain learners' attention.

7. Facilitating positive perceptions of instructors.

8. Giving participants a sense of belonging to the group of learners.

9. Creating an environment conducive to learning.

10. Making learning fun.

11. Showing that the instructor is human.

12. Improving morale, enjoyment, comprehension, interest, and rapport (Cohen, 1996; Deming, 2001; Frymier \& Wanzer, 1998; Hassed, 2001; MacDonald, 2004; Neelam et al., 1999; Neuliep, 1991; Schwarz, 1989; Ulloth, 2002; White, 2001; Ziegler, 1999).

Hassed (2001) and MacDonald (2004) suggested that laughter and humor achieve at least six psychological and physiological benefits:

1. Decreased stress response as a result of a reduction in stress hormone.

2. Improved immune function.

3. Increased pain tolerance.

4. Improved mood.

5. Enhanced creativity.

6. Reduced blood pressure. 
An instructor need not be a stand-up comedian to employ the teacher immediacy behavior of humor (Cohen, 1996; Draves, 1997; Kaupins, 1991; Robinson, 1985). Rather, using humor effectively in a workshop environment includes these 10 examples:

1. Personal and general anecdotes or stories that may or not be related to the subject or topic.

2. Funny stories that may or may not be related to the subject or topic.

3. Jokes.

4. Riddles.

5. Puns.

6. Cartoons.

7. Funny comments.

8. Physical or vocal comedy, which includes facial expressions or body movements.

9. Brief humorous, self-deprecating comments directed at the instructor.

10. Brief humorous comments directed at the topic, subject, or class procedures (Bryant, Comisky, \& Zillmann, 1979; Frymier \& Wanzer, 1998; Gorham \& Christophel, 1990; Neuliep, 1991; Torok, McMorris, \& Lin, 2004).

Using humor effectively excludes tendentious humor, which can embarrass, intimidate, or retaliate against learners. Kaupins (1991) cautioned instructors to avoid ethnic, sexist, racist, and derogatory humor, as well as negative humor that belittles or offends students. Pike (2003) suggested that humor should neither be off-color nor involve offensive language.

Most of the research in this literature review pertains to teachers in educational settings. Results of one study exploring humor from the perspective of business professors and corporate trainers, however, imply that the use of humor in the classroom also applies to the training environment. Kaupins (1991) surveyed 183 business professors and 243 corporate trainers and found that both groups were similar in their perspectives on and uses of humor. Both groups ranked short stories and exaggeration as the top two types of humor used in university and corporate settings. Both groups agreed that helping trainees or students relax was the most important reason for using humor.

\section{Attend to the Physical and Psychological Needs of Learners}

Merriam and Brockett (1997) maintained that the learning environment has a role in successful learning. An inadequate physical environment will interfere with learning; thus, the 
instructor must consider the physical setting, as well as the physical needs of the participants (Caffarella, 2002; Galbraith, 1992). For example, the learning environment should take into consideration physical and psychological components. The physical environment refers to training space, including room size, temperature, lighting, acoustics, seating type and arrangements, and how technology is arranged and used (Merriam \& Brockett, 1997).

Merriam and Brockett theorized that a physically uncomfortable learning space will interfere with learning. For example, when the training environment consists of poor lighting, uncomfortable seating, and uncomfortable room temperature, learners find it difficult to concentrate (Beatty et al., 1991). Knowles (1980) stated:

In regard to adult education, people have the need to see, the need to hear, the need to be comfortable, and the need for rest, at the minimum. If writing is too small, if voices are too soft, if chairs are too hard, and if the time between breaks is too long, people tend to become so preoccupied with the symptoms of their unsatisfied physical needs that they cannot concentrate on learning. (p. 84)

Galbraith (1991) maintained that, while the physical environment is an important component of a conducive learning environment, instructors may be unable to control the physical environment, but they can control the psychosocial or psychological environment.

The psychological environment refers to a climate in which learners and the instructor can engage in genuine exchange (Merriam \& Brockett, 1997). This includes the instructor's helping learners feel welcome and at ease in the opening minutes of a learning activity, attending to the fears and doubts that adults may experience about the learning activity, and recognizing that learners come to the learning activity with a range of life experiences that could serve as learning resources, as well as other experiences that could detract from learning, such as time pressures, difficult work situations, and domestic concerns (Merriam \& Brockett, 1997). An environment that elicits participant confidence in their ability to learn fosters motivation to learn (Rosenbaum \& Baker, 1996). Such an environment includes a climate of mutual trust and respect, supportiveness, openness to challenge and criticism, risk taking, pleasure, and friendliness (Galbraith, 1991, 1992). Hiemstra and Sisco (1990) maintained that an atmosphere where participants "feel good" about themselves, those around them, and the instructor "can help establish a spirit of mutual inquiry" (p. 34). 


\section{Guiding Principle 7: \\ Job Aids Should Be Provided to Help Learners Transfer Knowledge and Skills From the Workshop to Practice}

Instruction is effective when learners perform on the job the newly acquired knowledge and skills learned in a workshop (Dick et al., 2001). Knowledge has been defined as the application of learned verbal information (Gagne et al., 2005). Performing on the job the newly acquired knowledge and skills is part of the concept of transferring knowledge and skills from the workshop to practice (Garavaglia, 1993).

Transfer of learning has been defined as the "so what" or "now what" phase of the learning process (Caffarella, 2002; Wolfe \& Snyder, 1997) Ford (1994) maintained that the "common sense" definition of transfer is that learners will subsequently use the newly acquired knowledge and skills achieved through training in appropriate settings. Dean (1994) defined transfer as "being able to apply information learned in one context, such as a classroom, to another context, such as on the job" (p. 89). Ford (1984) stated that training transfer is "concerned with the extent to which the knowledge, skills, and attitudes acquired from an educational program are subsequently used" (p. 30). Ford (1994) defined transfer of knowledge and skills to practice as the "direct application of the learning outcomes . . . to the exact situations or settings depicted in the educational activity" (p. 23).

Dick et al. (2001) asserted that transfer of learning from training to the place of practice is emerging as a critical concern of educators and trainers. Until fairly recently, instructors placed less emphasis on transfer of knowledge from a workshop to the workplace and tended to employ a "train-and-hope" approach to professional development (Dick et al., 2001; Wolfe \& Snyder, 1997). In this approach, instructors plan training events, train participants, and hope participants will automatically transfer knowledge and skills to the workplace. A common thought is that adult learners will automatically use, or transfer, newly trained skills and knowledge to the appropriate settings; however; regardless of how well an instructor plans and executes a training event and regardless of the learners' intent to employ newly learned knowledge and skills, transfer does not always occur (Ford, 1994).

One barrier to transferring knowledge and skills from practice to the workplace involves memory. Caffarella (2002) maintained that, typically, adults will forget new skills, especially when the new skills are not used on a daily basis. Ford (1994) stated that when skills are not immediately activated or not executed for considerable time periods, this disuse can lead to "skill 
deterioration, which means that a skill is no longer functional when needed" (p. 30). Thorndike (1932) stated that the longer the interval between learning and use of the learning, the greater the forgetting. Bryson (1936) stated:

Knowledge and skill are not things that can be tied up in neat packages, labeled, and put away on shelves and then found again by some card-index system in the mind when they happen to be needed. Even people gifted with good memories find it necessary to make constant use of knowledge if it is to be kept fresh and valid. (p. 56)

One method for helping learners transfer learning from the workshop to the workplace is to provide learners with job aids. Dick et al. (2001) defined job aids as "any device that is used by the performers to reduce their reliance on their memory to perform a task" (p. 195). Caffarella (2002) defined job aids as "[m]echanisms for providing information, such as written checklists and charts, work samples, websites, and audio or videotapes, that give short and clear directions on how to do specific tasks or functions" (p. 217). Rossett and Gautier-Downs (1991) defined a job aid "as a repository for information, processes, or perspectives that is external to the individual and that supports work and activity by directing, guiding, and enlightening performance" (p. 4).

Rossett and Gautier-Downes (1991) stated that job aids "provide steps, illustrations, and examples that keep performance on track" (p. 5). Rossett and Gautier-Downes further stated: "To be considered a job aid, the object in question - whether it be a poster, manual, tape, or computer program - must store and make accessible the information, processes, or perspectives on which effective human work and activity are based" (p. 4). Finally, Rossett and Gautier-Downes stated that job aids "exert their influence as references when the need to know arises" (p. 6) and "help employees to transfer their skills from the classroom to the work site" (p. 20).

Although individuals tend to develop new behaviors when they train together with others in a social organization (Winton, 1990), the computer is one mechanism for accessing job aids after a workshop "when the need to know arises" (Rossett \& Gautier-Downes, 1991). For example, job aids, such as checklists, flowcharts, or even workshop slides, can be uploaded to the Internet for asynchronous learning. Killion (2000) defined asynchronous as learning that is available 24 hours a day. Asynchronous online learning materials permit workshop participants to infinitely access information to refresh knowledge and skills from a workshop for "just-in- 
time learning" (Killion, 2000). Killion suggested that asynchronous online materials permit individuals to learn at their own pace, experience fewer distractions, focus on specific needs, and receive assistance when needed.

Gilley (2004) suggested that providing learners with information sheets outlining the steps to follow when executing a motor skill will help ensure that learners understand and follow those steps, as well as help learners check their progress in implementing the steps correctly. Joinson (1996) maintained that because a step-by-step checklist is portable-meaning trainees can leave a training event with the checklist in hand - this type of job aid can help trainees use what they learned in the training session, or transfer their learning from training to practice. Rossett and Gautier-Downes (1991) suggested that flowcharts can assist individuals, who infrequently perform a procedure, to feel confident when performing the procedure. Dean (1994) stated that flowcharts assist learners in identifying tasks that are to be performed in sequence. In Wolfe's (1991) study, Head Start personnel listed handouts/resources/materials that could be referenced later as the top important factor for transferring learning to the workplace.

In addition to job aids, such as a checklist, another method for supporting workshop participants who do not immediately execute newly learned knowledge and skills is to provide "refresher" training (Ford, 1994; Wolfe \& Snyder, 1997). Ford suggested that refresher training can reinforce previously learned knowledge and skills, especially when learners do not immediately implement that knowledge and skills.

Another method for supporting workshop participants who do not immediately execute newly learned knowledge and skills is to provide participants with workshop follow-up strategies. Follow-up strategies help ensure transfer of learning from the workshop to the work setting (Caffarella, 2002; Winton, 1990; Wolfe \& Snyder, 1997). Examples of follow-up strategies include: job aids, such as planning sheets, forms, flowcharts, checklists, and "how-to" or "reminder" posters; clean copies of handouts and materials used in training; peer-to-peer or administrator-to-peer support; back-home plans; mentors; coaching; and follow-up letters and telephone calls (Catlett \& Winton, 1997; Wolfe \& Snyder, 1997). 


\section{Guiding Principle 8: \\ Workshops Should Include a Meaningful and Systematic Evaluation Process}

The training program is a major influence on participants' achievement and, consequently, is typically the focus of program evaluation (Knox, 2002). Knox maintained that, oftentimes, detailed information collected directly from participants can be helpful in evaluating a program. Evaluation emphasizes the necessity of gathering data from participant reactions in order to identify weaknesses and strengths (Dick et al., 2001; Knox, 2002) and to render judgments about the value, merit, and worth of the entity being evaluated (Guba \& Lincoln, 1981; Worthen et al., 1997). Collecting and analyzing gathered data can lead to more effective teaching materials (Dick et al, 2001) or better workshop delivery (Mizell, 2003).

Program evaluation has been defined as a process implemented to determine whether the program's design and delivery were effective and whether proposed outcomes were met, as well as a systematic investigation of a program's merit or worth (Caffarella, 2002; Guba \& Lincoln, 1981; Guskey, 2000; Kirkpatrick, 1998). Guskey defined systematic as a "thoughtful, intentional, and purposeful process ... done for clear reasons and with explicit intent” (p. 42). Guskey defined investigation as the "collection and analysis of appropriate and pertinent information" that is "based on the acquisition of specific, relevant, and valid evidence examined through appropriate methods and techniques," as opposed to opinion or conjecture (p. 42). Guba and Lincoln (1981) defined merit as "an intrinsic property of an entity being evaluated" (p. 45), which can be estimated (a) by determining the degree to which the entity conforms to expectations on which a group of experts agree and (b) by comparing the entity to other similar entities. Guba and Lincoln defined worth as "an extrinsic property" (p. 45) that "is determined by comparing the entity's impact or outcomes to some set of external requirements" (pp. 45-46). Such requirements come from a group of stakeholders affected by the entity, such as Head Start personnel for this study, as opposed to a group of experts. Finally, Guskey and Kirkpatrick (1998) maintained that evaluation helps identify what worked, what did not work, and what can be improved.

Dean (2004) stated that evaluation can occur during four time periods: (a) before a teaching and learning transaction begins, (b) during the transaction, (c) immediately after the transaction, and (d) some time after learning occurred. Although collecting participant reactions to a workshop — what Guskey (2002) described as the "happiness quotient" and Kirkpatrick 
(1998) described as "happiness sheets"-appears to be the more common method for evaluating professional development in the educational environment (Guskey, 1998), Guskey maintained participant reaction is only the first of five levels of measuring professional development evaluation. Guskey's (2000) five levels for measuring professional development in education builds on Kirkpatrick's (1998) four levels typically used in the human resource development arena in business and industry. Guskey's five levels are:

1. Participants' reactions: Participants' reactions to the professional development experience.

2. Participants' learning: Measuring the knowledge, skills, and attitudes that participants gained.

3. Organization support and change: Measuring the organizational characteristics and attributes required for successfully implementing what was learned at the workshop.

4. Participants' use of new knowledge and skills: Measuring whether participant learning made a different in their professional practice.

5. Student learning outcomes: Measuring whether the professional development program or activity benefited students.

Kirkpatrick's four levels are:

1. Reaction: Participants' reactions to the training program.

2. Learning: The extent to which learners changed attitudes, improved knowledge, and/or increased skill.

3. Behavior: The extent to which learners changed their behavior.

4. Results: The final results that occurred as a result of attending the program, such as increased production, improved quality, decreased costs, and higher profits.

Although no single best model exists for evaluating a program (Dick et al., 2001; Worthen et al., 1997), this study employed the first two levels of both Guskey's and Kirkpatrick's models, with a modification of the second level. Modifications included measuring knowledge only and determining whether participants maintained knowledge learning over time.

One inexpensive, less time-consuming method for assessing participants' reactions is through pencil-and-paper evaluation forms at the end of a professional development or training activity (Guskey, 2000; Kirkpatrick, 1998). A second method is a "delayed evaluation" in which learners are requested to complete evaluation documents several days following a professional 
development activity (Guskey, 2000). Dean (2004) stated that evaluating a teaching and learning transaction some time after learning occurred is conducted to determine whether learning was retained or to identify the impact of the learning or training program on an organization. An advantage of the delayed evaluation is that learners have time to reflect on and provide richer responses; a major disadvantage of this method, however, is that rarely do all participants complete and return the evaluation document (Guskey, 2000). 


\section{CHAPTER 3}

\section{Methodology}

The overall purpose of this investigation was to explore, from the perspective of Head Start personnel, whether the Vision Initiative for Children (VIC) prepares Head Start personnel to screen the vision of preschoolers and whether Head Start participants encounter screening experiences that were not discussed during VIC's workshop. The researcher's goal is that the VIC preschool vision screening training program prepares participants to screen vision regardless of their education level. That is, the training program is geared toward individuals with and without higher education degrees. Thus, a related purpose for this investigation was to explore whether a significant difference in responses occurred as a result of participants' educational level (no degree, working on a degree, or college degree).

This study relied on 6 research questions and 12 subquestions. This section describes the methodology used for answering these questions:

1. What do participants report about VIC's workshop?

a. Across all participants, what do participants report about the instructional content and delivery system of VIC's preschool vision screening workshop?

(1) Is there a significant difference in means on participants' scores in instructional content and delivery system due to education?

b. Across all participants, what do participants report about the workshop instructor's teaching skills?

(1) Is there a significant difference in means on participants' scores in instructor skills due to education?

c. Across all participants, what do participants report about the logistical arrangements of VIC's preschool vision screening workshop?

(1) Is there a significant difference in means on participants' scores in logistical arrangements due to education?

2. What do participants report about VIC's workshop after they screen vision?

a. Across all participants, do participants report that the overall workshop was effective in preparing them to screen vision?

b. Across all participants, what additional support do participants report they need from VIC to screen the vision of preschoolers? 
3. Do participants learn new preschool vision screening knowledge at VIC's workshop?

a. Is there a significant difference in means on participants' scores between the pretest and posttest?

b. Is there a significant difference in means on participants' scores between the pretest and posttest due to education?

4. Do participants maintain knowledge learned at VIC's workshop?

a. Is there a significant difference in means on participants' scores between the workshop posttest and the 3-month posttest?

b. Is there a significant difference in means on participants' scores between the workshop posttest and the 3-most posttest due to education?

5. What job aids do participants report using to transfer learned knowledge from the workshop to practice?

6. What occurred during preschool vision screening that was not discussed in VIC's workshop?

\section{Methods}

This section describes the study's design, participants, setting, independent and dependent variables, and instrumentation to answer the research questions.

\section{Design}

This formative program evaluation study was designed to assess VIC's preschool vision screening workshop from the perspective of a sample of Head Start individuals to render a judgment about the value of the workshop (Worthen, et al. 1997) in preparing these Head Start individuals to screen vision. This evaluation is considered formative because it was conducted to refine, improve, or change a program while it is in progress (Caffarella, 2002; Guba \& Lincoln, 1985). Therefore, if warranted, findings of this study will be used to refine, improve, and or change the VIC preschool vision screening training model.

Although this study is primarily program evaluation, it is considered evaluation research according to Patton's (2002) definition. Patton defined program evaluation as "the systematic collection of information about the activities, characteristics, and outcomes of programs to make judgments about the program, improve program effectiveness, and/or inform decisions about future programming" (p. 10). Patton suggested that a researcher is engaged in evaluation research when an "examination of effectiveness is conducted systematically and empirically through careful data collection and thoughtful analysis" (p. 10). 
While " $[\mathrm{t}]$ here is no one acceptable systematic process for conducting a program evaluation" (Caffarella, 2002; pg. 230), this program evaluation study followed an evaluation process that Knowles (1980) espoused:

1. Form the questions to be answered.

2. Collect data that will answer the questions.

3. Analyze the collected data.

4. Interpret the analyzed data from the perspective of how the data answer the questions.

5. Modify the program under evaluation in light of the findings.

This formative program evaluation study design incorporated a within- and betweensubjects, causal-comparative, quasi-experimental approach. The within-subjects approach refers to exploring whether the level of knowledge changed within the same subjects as a result of attending VIC's preschool vision screening workshop. This looks at multiple measures to explore differences in knowledge before and after the workshop. The between-subjects approach refers to exploring changes that occurred across participants when they were categorized by education. Initially, participants were to be categorized across three independent variables: (a) education, (b) job title, and (c) previous preschool vision screening experience. However, after data were collected, the researcher realized that the definition of job titles differed significantly across programs and, thus, comparing responses according to job title would be challenging. For example, the job title of teacher in one program referred to the lead teacher with a master's degree while the job title of teacher in another program referred to a teacher's aid with no college degree. Additionally, the researcher learned that the demographic question designed to ascertain whether participants possessed previous preschool vision screening experience was unclear and nonspecific. This item asked participants to indicate the number of children screened in the past. Because the question did not explicitly ask whether participants had screened vision prior to attending VIC's workshop, the researcher could only define past experience as whether or not participants completed this item. Thus, if a participant did not complete this item, the researcher was unable to discern whether the participant failed to complete the item or whether the participant had no previous preschool vision screening experience.

The study design was causal-comparative because the purpose of this research was to determine how the independent variable of education affected the dependent variable of scores on the instruments and the research did not allow for an experimental design (McMillan \& 
Schumacher, 1997). Finally, the study design included a quasi-experimental approach because participants were not randomly selected or assigned. Instead, this study used intact groups of participants that were scheduled for training prior to implementation of this study (Wiersma, 1995).

In this study, the researcher served a dual role, that of researcher and that of VIC program director/trainer. The researcher was hired to help design and create the VIC program, as well as its training component, and has served as its program director/trainer since 2001. The researcher as program director/trainer has conducted all 87 vision screening training workshops since the first workshop in September 2001.

\section{Participants}

Knowles (1980) stated that "[ $\mathrm{t}] \mathrm{he}$ opinions and feelings of the participants in a program, while they are completely subjective, are a primary source of information on which to base an evaluation" (p. 210). The number of participants required to sufficiently evaluate a program appears to be 30. For example, Dick et al (2001) reported 30 to be an adequate number for conducting a field trial with an appropriate sample from the target population. Additionally, Salkind (2000) stated that many statisticians believe a sample size of 30 is large enough to represent a population. Therefore, the researcher attempted to garner at least 30 participants for this study.

Fifty-nine participants from the 6 workshops conducted for this study met the eligibility criteria: (a) employed by Head Start and (b) attending VIC's workshop for the first time. Additionally, participants were eligible to participate in this study if they were employed by a school system but worked at a Head Start agency through a collaborative arrangement.

Of the 59 potential participants, 47 (80\%) completed West Virginia University Institutional Review Board (IRB)-approved Consent and Information forms, 10 (6\%) opted to not participate from the beginning, and 2 completed the workshop posttest, but did not complete the pretest. The 10 participants who opted out were from one Head Start agency that had unionized shortly before the workshop. Thus, only the 47 participants who completed WVU IRB-approved Consent and Information Forms were included in the study.

Of the 47 study participants, 26 (55\%) completed all instruments (West Virginia University Institutional Review Board-approved (IRB) Consent and Information Form, Pretest, Posttest, Workshop Evaluation, Postworkshop Evaluation, and 3-Month Posttest). Although 26 
participants did not meet the recommended number of 30, attempts were made to collect all documents from all 47 participants. However, unless the researcher received permission to contact a participant four or more times, contact attempts stopped after the third try. Table 3 illustrates the instruments completed by the 47 participants.

\section{Table 3}

Study Instruments Completed by the 47 Participants

\begin{tabular}{lc}
\hline \multicolumn{1}{c}{ Instrument } & No. participants \\
\hline IRB consent and information document & 47 \\
Attendance/demographics record & 47 \\
Pretest & 47 \\
Posttest & 46 \\
Workshop evaluation & 47 \\
Postworkshop evaluation & 27 \\
3-Month posttest & 26 \\
\hline
\end{tabular}

Reasons the 47 participants did not complete all study instruments included:

- 15 participants opted to not complete the study because they were not designated screeners in their agency.

- 2 participants left agency employment.

- 1 participant reported she was uncomfortable completing instrumentation because her involvement in screening was minimal.

- 1 participant completed the postworkshop evaluation but not the 3-month posttest.

- 2 participants did not complete postworkshop instruments without supplying a reason.

Although all participants who signed WVU IRB-approved Consent and Information Forms implied they would screen vision for the study, of the 15 participants who later opted to not complete the study, $13(81 \%)$ were employed as teachers at one Head Start facility where teachers typically do not screen vision, 1 was a Family Service Worker who reported that Board of Education school health nurses screened vision, and 1 was a site manager who chose to not participate in screening.

Of the 47 study participants, $45(96 \%)$ were female and $2(4 \%)$ were male. Ages ranged from 23 to 61, with a median and a mean age of 42 . Table 4 depicts additional participant demographic characteristics: Internet access and usage, length of time employed in current job 
and in their field, whether their current job requires them to screen vision, and whether their higher education studies included training in vision screening. $\mathrm{s}$

Table 4

Demographic Characteristics of 47 Participants

\begin{tabular}{lcc}
\hline \multicolumn{1}{c}{ Demographic characteristics } & No. participants & $\%$ \\
\hline Internet access: Yes & 33 & 70 \\
Internet usage: Daily & 10 & 21 \\
Internet usage: $2-3$ times a week & 8 & 17 \\
Internet usage: 1 time a week & 6 & 13 \\
Internet usage: $2-3$ times a month & 6 & 13 \\
Internet usage: 1 time a month & 0 & 0 \\
Internet usage: $<1$ time a month & 6 & 13 \\
Required to screen vision in current job & 0 & 70 \\
Education included vision screening training & \multirow{2}{*}{ Average } & Span \\
\cline { 2 - 3 } & 9 yrs & 1 day to 31 yrs \\
Average employment time: In current job & 10 yrs & 1 day to 28 yrs \\
Average employment time: In field &
\end{tabular}

Note. The number of participants with Internet access and numbers for usage categories do not match because some participants marked "no" for Internet access and also marked a category for Internet usage.

Nearly one-third (30\%) of the 47 participants did not have a college degree and more than half (55\%) had a college degree. Table 5 depicts the educational levels of the 47 participants. 
Table 5

Educational Levels of the 47 Participants

\begin{tabular}{lcc}
\hline \multicolumn{1}{c}{ Educational level } & No. participants & $\%$ \\
\hline No college degree & 14 & 30 \\
Working toward a degree & 7 & 15 \\
College degree & 26 & 55 \\
\hline
\end{tabular}

Table 6 describes the type of degrees that 26 of the participants possessed, as well as percentages of participants per category.

Table 6

Type of Degree for 26 Participants With Completed College Degrees

\begin{tabular}{lcc}
\hline \multicolumn{1}{c}{ Type of degree } & No. participants & $\%$ \\
\hline 2 year: Associates & 11 & 42 \\
Board of Regents & 1 & 4 \\
4 yr: Area unknown & 5 & 19 \\
4 yr: Education & 2 & 8 \\
4 yr: Public administration & 1 & 4 \\
2 yr: Licensed Practical Nurse & 1 & 4 \\
4 yr: Nursing & 1 & 4 \\
4 yr: Nursing + Masters & 1 & 4 \\
Masters in early childhood education & 1 & 4 \\
Masters in education & 1 & 4 \\
College degree, years unknown & 1 & 4 \\
\hline
\end{tabular}

The 47 study participants represented 8 (33\%) of the state's 24 Head Start grantees and 2 county Boards of Education that worked with Head Start in a collaborative arrangement. Table 7 depicts the represented agencies, as well as the number and percentage of participants in each agency. 
Table 7

Head Start Agencies Represented in Study

\begin{tabular}{lcc}
\hline \multicolumn{1}{c}{ Agency } & $\#$ & $\%$ \\
\hline $\begin{array}{l}\text { Appalachian Council Head Start, which covers 3 of the state's 55 counties: } \\
\text { Putnam, Clay, and Boone }\end{array}$ & 27 & 57 \\
$\begin{array}{l}\text { Putman County Board of Education, working with Appalachian Council Head } \\
\text { Start in a collaborative arrangement }\end{array}$ & 1 & 2 \\
$\begin{array}{l}\text { Council of Southern Mountains Head Start, which covers McDowell County } \\
\text { Family Development Inc. Head Start, which covers 10 counties: Wood, Wirt, }\end{array}$ & 3 & 6 \\
Jackson, Roane, Gilmer, Calhoun, Doddridge, Tyler, Pleasants, and Ritchie & 2 & 4 \\
Gilmer County Board of Education, working with Family Development Inc., Head & 1 & 2 \\
Start in a collaborative arrangement & 1 & 2 \\
Head Start provided by the Kanawha County school system & 2 & 4 \\
Head Start provided by the Monongalia County school system & 3 & 6 \\
Nicholas County Community Action Partnership Head Start & 5 & 11 \\
Raleigh County Community Action Association, Inc., Head Start & 2 & 4 \\
Upshur Human Resources, Inc., Head Start & \\
\hline
\end{tabular}

As depicted in Table 7, the 8 Head Start grantees provide services in $19(35 \%)$ of the state's 55 counties. The 19 counties represent resource rich and resource poor pockets of the state as depicted by the West Virginia KIDS COUNT Fund, which provides an annual sequential ranking of counties based on a county's scores on 11 of 12 core measures of the condition of children (West Virginia KIDS COUNT Fund, 2005). The 11 core measures are:

1. Percent low birth-weight babies.

2. Infant mortality rate.

3. Child death rate.

4. Percent of eligible children served by Head Start.

5. Percent of children approved for free and reduced-price meals.

6. Teen birth rate.

7. Percent of births to unmarried teens.

8. Percent of high school dropouts.

9. Juvenile delinquency case rate.

10. Teen violent death rate.

11. Percent of births to mothers with less than a $12^{\text {th }}$ grade education. 
A county ranked as 1 scored the highest on the core measures, while a county ranked as 55 scored the lowest. Counties represented in this study include the second highest (Monongalia) and lowest (McDowell) ranked counties. Table 8 depicts the ranking of each county represented in the study on 11 of the 12 core measures of the condition of children.

Table 8

Study Counties’ Ranking on 11 of 12 Core Measures of the Condition of Children

\begin{tabular}{|c|c|}
\hline County & Ranking \\
\hline Monongalia & 2 \\
\hline Putnam & 3 \\
\hline Pleasants & 4 \\
\hline Jackson & 11 \\
\hline Gilmer & 20 \\
\hline Clay & 21 \\
\hline Nicholas & 22 \\
\hline Wirt & 26 \\
\hline Ritchie & 28 \\
\hline Tyler & 29 \\
\hline Raleigh & 33 \\
\hline Doddridge & 34 \\
\hline Calhoun & 37 \\
\hline Upshur & 38 \\
\hline Wood & 39 \\
\hline Roane & 41 \\
\hline Kanawha & 45 \\
\hline Boone & 49 \\
\hline McDowell & 55 \\
\hline
\end{tabular}

Finally, participants represented a purposeful, typical case sample because all were scheduled for training prior to implementing the study. The initial workshop schedule called for seven workshops for nine Head Start grantees. One workshop for Mingo County Head Start on September 2, 2004, was cancelled. Thus, six workshops were conducted for eight Head Start programs. Two workshops were held for one Head Start program and three workshops combined at least two Head Start programs. Table 9 illustrates the study workshop schedule. 
Table 9

Study Workshop Schedule

\begin{tabular}{ll}
\hline \multicolumn{1}{c}{ Agencies trained } & \multicolumn{1}{c}{ Date } \\
\hline Family Development Inc., Head Start & August 24, 2004-a.m. \\
$\begin{array}{l}\text { Family Development Inc., Head Start } \\
\text { Raleigh County Community Action Association, Inc., Head Start } \\
\text { and Nicholas County Community Action Partnership Head Start } \\
\text { Appalachian Council Life Bridge Head Start and Kanawha }\end{array}$ & August 24, 2004-p.m. \\
$\begin{array}{l}\text { County School Head } \\
\text { Council of Southern Mountains Head }\end{array}$ & September 1, 2004 \\
$\begin{array}{l}\text { Monongalia County Schools Head Start and Upshur Human } \\
\text { Resources, Inc., Head Start }\end{array}$ & September 3, 2004 \\
\hline
\end{tabular}

\section{Setting}

Four workshops were conducted in community-based Head Start offices. One workshop was conducted as a training session at a conference. One workshop was conducted at the West Virginia University Eye Institute.

\section{Variables}

The primary independent variable in this program evaluation study was VIC's preschool vision screening workshop to teach preschool vision screening knowledge and provide job aids to transfer knowledge to the workplace. Three job aids include (a) a handout packet, (b) a Vision Screening At-A-Glance Flowchart, and (c) a password-protected Screener Support web site. Each participant received identical training and job aids. One additional independent variable included education with three levels: (a) no college degree, (b) working on college degree, and (c) college degree.

The dependant variables in this program evaluation study were participants' (a) scores on the pretest, posttest, and 3-month posttest and (b) responses to items within the Workshop Evaluation and the Postworkshop Evaluation.

\section{Instrumentation}

In addition to a WVU IRB -approved Consent and Information Form, 6 instruments were used to collect data for answering the 6 research questions and 12 subquestions. None of the instruments were commercially designed; all were created for this study. Each instrument is described in the following section: 


\section{Instrument 1: Attendance/demographics record.}

An Attendance/Demographics Record served as a sign-in sheet and a method for collecting demographics on each participant (see Appendix E for Attendance/Demographics Record). The design of this instrument was based only on data required to describe the sample or to categorize and analyze participant responses to the five additional instruments.

The Attendance/Demographics Record was a 1-page document consisting of 21 items, such as: (a) participant name for organizing and analyzing data; (b) participant age; (c) whether participants had Internet access; (d) how often participants used the Internet; (e) length of time in current employment; (f) length of time in current field; (g) whether job responsibilities required preschool vision screening; (h) college degree and type of degree; (i) whether college coursework prepared participants for preschool vision screening; (j) preschool tests used prior to the workshop, how training on those tests occurred, and the length of training sessions; $(\mathrm{k})$ average number of children ages 3, 4, and 5 screened prior to the workshop, and (1) number of children ages 3, 4, and 5 participants anticipated screening between the workshop date and February 1, 2005, the point at which data collection was scheduled to stop.

\section{Instrument 2: Pretest.}

A pretest administered at the beginning of the workshop can serve as a needs assessment to determine knowledge and skills learners do not bring to the learning environment (Dean, 1994; Dick et al., 2001). Participants were presented with a pretest immediately before instruction began (see Appendix F for Pretest/Posttest/3-Month Posttest). The pretest was a 3page document consisting of 15 multiple choice items, 2 matching items, and 3 true/false items that were discussed during the workshop lecture/Power Point slide presentation.

To estimate the content-related validity of this instrument, Head Start providers from two programs were asked to complete the document for item clarity during a small-scale pilot training at the WVU Eye Institute on August 20, 2004. These participants were asked to note unclear items. No changes were suggested. To estimate construct validity, the researcher reviewed pilot participant responses to determine whether the instrument collected sufficient information to establish whether participants learned new vision screening knowledge. The document remained unchanged. 


\section{Instrument 3: Posttest.}

The posttest employed immediately at the conclusion of the workshop measures whether learning occurred (Malone et al, 2000), as well as the amount of material learned (Dean, 1994; Dick et al., 2001)). Dean further stated that knowing whether participants learned material and whether they learned what the instructor desired are two functions of a posttest. Assessing performance, or verifying that learning occurred, is the eighth of Gagne's (1985) nine instructional events. Gagne suggested that one way to assess performance is to test learners to establish that the "newly learned capability has reasonability stability" and to provide "additional practice that serves to consolidate what has been learned" (p. 255).

The posttest was identical to the pretest with one additional item, which asked participants to rate on a 3-point Likert-type scale their confidence level when answering the questions on the posttest (see Appendix F for Pretest/Posttest/3-Month Posttest). Because the posttest was identical to the pretest, with the one additional question, content and construct validity was estimated when the instrument was used as a pretest.

\section{Instrument 4: VIC Preschool Vision Screening workshop evaluation.}

Knox (2002) maintained that detailed information collected directly from participants is useful for evaluating a program. Malone et al. (2000) stated that "satisfaction measures reflect how well the participant liked the experience and can be measured with rating scales in a selfreport or interview format" (p. 59).

The Workshop Evaluation measured participants' reactions to the workshop (see Appendix G for Workshop Evaluation). This instrument, which fulfills what Guskey (2000) identified as the "happiness quotient," integrated items contained within evaluation examples from four instructional design and professional development models: (a) Caffarella's (2002) evaluation for adult learners; (b) Dick et al. (2001) instructional design model; (c) Knox's (2002) evaluation model for continuing education; and (d) Guskey's (2000) evaluation model for educational programs. For example, Caffarella suggested assessing participant reactions to session content and process, presenter skills, logistical arrangements, and overall workshop.

The Workshop Evaluation was a 4-page document consisting of 49 items clustered into 4 specific sections and 1 general section: (a) Instructional Content and Delivery System, (b) Instructor Skills, (c) Logistical Arrangements, and (d) Overall Workshop (Caffarella, 2002). To determine participant reactions to what was taught in the workshop (content) and how the 
content was presented (delivery system), the Instructional Content and Delivery System subscale contained 17 items in forced-choice format with responses based on a 3-point Likert-type scale anchored by "yes, definitely" and "no": (a) 1 = No; (b) 2 = Somewhat, (c) 3 = Yes, definitely. For example, participants were asked whether (a) the learning objectives were clear and realistic (Item 1), (b) the content was too difficult to learn (Item 15), (c) they understood what they were supposed to learn (Item 12), (d) whether the way content was delivered met their preferred learning style (Item 14), (e) whether modeling and demonstration enhanced learning (Item 7), and (f) whether practicing the screening tests enhanced learning (Items 8 and 9). The Likert-type scale was reversed for Items 15 and 17

To determine participant reactions to the skills of the instructor in presenting the workshop content, the Instructor Skills subscale included 15 forced-choice items with an identical 3-point Likert-type scale anchored by "yes, definitely" and "no": (a) 1 = No; (b) $2=$ Somewhat, (c) $3=$ Yes, definitely. For example, participants were asked whether (a) the instructor was enthusiastic when delivering the content (Item 1), (b), the instructor attempted to make them feel comfortable during the workshop (Item 4), (c) the instructor adequately helped them learn new material (Item 5), (d) the instructor moved through the workshop too quickly or too slowly (Item 8), and (e) the instructor answered questions or addressed concerns (Item 11). The Likert-type scale was reversed for Item 15.

To determine participant reactions to the physical environment of the workshop, the Logistical Arrangements subscale included five forced-choice items with an identical 3-point Likert-type scale anchored by "yes, definitely" and "no": (a) 1 = No; (b) 2 = Somewhat, (c) $3=$ Yes, definitely. For example, participants were asked whether (a) the room was the right temperature (Item 3), (b) the chairs were comfortable, and (c) refreshments were fresh and tasty (Item 1).

To determine participant reactions to the workshop as a whole, the Overall Workshop subscale included six forced-choice items with an identical 3-point Likert-type scale anchored by “yes, definitely" and "no": (a) 1 = No; (b) 2 = Somewhat, (c) 3 = Yes, definitely. For example, participants were asked whether (a) the workshop was a waste of their time (Item 3), (b) the workshop was high quality overall (Item 4), and they had fun (Item 6). The Overall Workshop subscale also included five open-ended items, such as (a) what did participants like best and (b) 
what did participants like least about the workshop. The Likert-type scale was reversed for Item 3.

To estimate the content-related validity of this instrument, Head Start providers from two programs were asked to complete the document for item clarity during a pilot training at the WVU Eye Institute on August 20, 2004. No suggested changes were offered.

\section{Instrument 5: Vision Initiative for Children's postworkshop evaluation.}

Although adult learning begins with participation in a training session, learning does not entirely occur until participants apply what they learned (Mizell, 2003). Thus, although evaluation can occur before learning occurs, during learning, immediately following learning, and some time after learning is completed, "[d]elayed evaluation may provide the most telling information about what has been learned, what is most useful to the learners, and changes needed in the learning activities for the future" (Dean, 1994, p. 101). While it is appropriate to distribute posttraining surveys within 3 months to 1 year following initial training (Garavaglia, 1993; Mitchell, 1993), 6 months is the more common time frame (Garavaglia, 1993).

This Postworkshop Evaluation, a modified version of the follow-up survey used in VIC's previous program evaluation pilot study, was a 3-page document consisting of 15 open-ended and forced-choice items. Five of the 15 items were open-ended; 10 were forced-choice items that required yes/no responses or responses within a 3-point Likert-type scale anchored by "extremely helpful" and "not helpful" on one scale: (a) 1 = Not Helpful, (b) 2 = Sort of Helpful, and (c) 3 = Extremely Helpful a second 3-point Likert-type scale anchored by "yes, definitely" and "no": (a) 1 = No, (b) 2 = Somewhat, (c) 3 = Yes, definitely. Examples of open-ended items included requesting information about experiences that occurred during screening that were not discussed at the workshop and requesting information regarding additional follow-up support that participants required to screen the vision of preschoolers. Three of the 15 items included subitems.

Initially, this instrument was to be completed online. However, because 14 of 47 participants $(30 \%)$ reported they did not have Internet access, participants were asked to complete the Vision Initiative for Children's Postworkshop Evaluation online or as a mailed document after they screened the vision of preschoolers. This instrument was designed to gauge participants' reactions to the workshop after implementing the knowledge learned during the 
workshop. Participants were requested to complete this document immediately after screening vision in order to collect responses as close to the screening event as possible.

To estimate content validity of the Postworkshop Evaluation, the researcher proposed to request two child care providers and four Head Start providers from two different Head Start programs to complete the document for item clarity. Time constraints did not permit this activity to occur. To estimate construct validity, the researcher proposed to review participant forcedchoice responses and open-ended comments to determine whether the instrument captured sufficient information to address relevant research questions. Time constraints did not permit this activity to occur.

\section{Instrument: 3-month posttest.}

Although evaluation can occur before learning occurs, during learning, immediately following learning, and some time after learning is completed, delayed evaluation can measure learners' retention of material over time (Dean, 1994). To measure retention of knowledge learned at the workshop and to determine which job aids participants used to retain knowledge, participants were asked to complete an online or mail posttest 3 months after the initial workshop (see Appendix F for Pretest/Posttest/3-Month Posttest). The 3-month posttest was identical to the pretest with one additional question, which asked participants to describe which job aid they reviewed prior to completing the posttest. Content and construct validity were estimated when the instrument was first used as a pretest.

\section{Procedures}

Because evaluation is often a multifaceted endeavor, more than one approach can be employed in combination during the evaluation process (Caffarella, 2002; Knowles, 1980). Additionally, evaluation should include a variety of sources of information gathered through different methods (Guskey, 2000) This study, therefore, relied on six data sources at multiple points in time for answering the 6 research questions and 11 subquestions. The data sources were described in the previous Instrumentation section.

All procedures and instruments received WVU Institutional Review Board (WVU-IRB) approval before the study was implemented (see Appendix A for WVU Institutional Review Board-approved Consent and Information Form). This program evaluation study began with a pilot of instrument implementation with Head Start providers from two programs on August 20, 
2004, at the WVU Eye Institute. One change occurred. The researcher requested participants in the study to complete the posttest prior to the PowerPoint workshop review slides.

This section is arranged according to procedures at the workshop site at the beginning of each workshop and at the end of each workshop, as well as the procedures for storing and analyzing data collected during and after each workshop.

\section{Procedures at the Workshop Site at the Beginning of the Workshop}

At the workshop setting and before the workshop began, the researcher discussed the study with participants. Participants received the West Virginia University Institutional Review Board-approved Content and Information document, and were given the opportunity to review the document. Participants were asked to sign the document if they wanted to participate in the study. Participants received and were asked to complete the Attendance/Demographics Record. Finally, participants received and were asked to complete the Pretest. The workshop's lecture/PowerPoint presentation began after documents were completed.

One change occurred after the second workshop. Beginning with the third workshop, the researcher distributed a file folder to each participant and asked participants to list their name on the file folders, to place all documentation in the file folders, and to return the file folders at the end of the workshop.

\section{Procedures at the Worksite at the End of the Workshop}

The researcher initially planned to ask participants to complete the Posttest at the end of the workshop. However, following the pilot workshops and after considering that participants were likely to answer the majority of posttest questions correctly if the posttest were administered after the review section of the workshop, the researcher changed the point at which participants in the study would complete the posttest. Participants completed the posttest prior to participating in the PowerPoint review slides. After completing the posttest, participants completed the Workshop Evaluation.

Knowles (1980) maintained that asking participants to list their names on evaluation instruments may not produce the most reliable results; however, listing names on documents permits cross-checking and determining whether participants completed all documents. Therefore, participants in this study were asked to list their names on documents for crosschecking to determine which participants completed which documents. Completed instruments 
were collected and filed in individual participant folders, which were maintained within a separate expandable folder created for each workshop.

\section{Procedures After the Workshop}

Data from the Attendance/Demographics Record, Pretest, Posttest, and the Workshop Evaluation, which were completed and collected at each workshop, were entered into a Microsoft Excel spreadsheet and coded prior to copying data to SPSS ${ }^{2}$ 11.0.0 for Windows Student Version for analysis. For example, "no college degree" was coded "1", "working toward a degree" was coded "2", and "with college degree" was coded "3". A separate Microsoft Excel table was created to track which participants completed or did not complete which instruments.

As a result of time constraints and other issues, data collection activities were not completed as proposed. Initially, names, e-mail addresses, and workshop dates were to be entered into a Microsoft Access database to generate dates for distributing reminder notices to participants to complete remaining instruments. Because of time constraints involved with general day-to-day activities of operating the program and other activities, such as grant writing to continue the program, this procedure did not occur as planned.

The researcher initially proposed to remind participants up to three times via e-mail or regular mail to go online to complete the Postworkshop Evaluation and to create and run queries for distributing e-mail or regular mail reminders for completing the online 3-month posttest. The researcher anticipated that reminders could be distributed primarily via e-mail. However, 14 of the 47 participants (30\%) did not have access to the Internet and only 10 of the 33 participants $(30 \%)$ with access to the Internet used the Internet daily. Reminders were to be distributed 1 week prior to posttest completion date. Participants were to receive up to 3 reminders to complete the online or mailed 3-month posttest. Because of time constraints involved with dayto-day activities of operating the program and other activities, such as grant writing to continue the program, this procedure did not occur as planned. Instead, the researcher contacted participants via telephone or e-mail near the end of the study to request participants to complete and return both the Postworkshop Evaluation and 3-month Posttest instruments. Tracking data for this activity were collected in a Microsoft Excel spreadsheet.

The Tracking Data spreadsheet included fields for participant name, whether the researcher received screening results, the postworkshop evaluation, and the 3-month follow-up test; contact attempts; and results of each contact attempt. Forty-seven participants were 
contacted at least 1 time, 28 were contacted 2 times, 17 were contacted 3 times, 5 were contacted 4 times, and 1 was contacted 5 times. Eighteen of the 47 participants contacted the first time either explicitly stated they did not want to complete remaining instruments (3 of 18), would not complete follow-up instruments because someone else in their agency was screening vision (5 of 18), were no longer employed at the agency (2 of 18), were uncomfortable completing follow-up instruments because they provided only minimal assistance during screening events (1 of 18), or did not respond to the first contact and were teachers in an agency where someone other than teachers conducted vision screening ( 7 of 18). Participants were contacted a fourth or fifth time only when the researcher left a telephone message on the $3^{\text {rd }}$ contact ( 3 of 47 participants) or talked with the participant and a follow-up was required.

The researcher initially proposed to remind participants to complete the Postworkshop Evaluation after vision screening results were received at the VIC office. Because of issues involved with monitoring vision screening results from study participants, as well as screening results from other programs across the state, this activity did not occur as planned. Consequently, postworkshop instruments were not completed as planned. For example, participants were to complete the Postworkshop Evaluation immediately after screening vision for the first time. The time between the first screening activity and the date when Postworkshop Evaluations were completed ranged from 11 days to 5 months and 6 days, with a median time of 3 months and 14 days. It is unknown whether the length of time between screening vision and completing the postworkshop evaluation affected responses. Similarly, participants were to complete the 3month posttest 3 months after their initial workshop. However, time lapsed between workshop and completion of the 3-month posttest ranged from 2 months and 22 days to 5 months and 27 days with a median time of nearly 5 months (4 months, 27 days).

Participants had the option of completing online postworkshop instruments via VIC's password-protected Screener Support web site or paper instruments via mail with self-addressed, postage-paid envelopes. Although the researcher initially anticipated that the majority of participants would complete postworkshop instruments online, only 4 of 27 (15\%) participants completed documents online while 18 (67\%) returned instruments via mail and 5 (19\%) returned instruments via facsimile. The following section describes how data from the 6 instruments were analyzed to answer the 6 research questions and 12 subquestions. 


\section{Data Analysis}

Knox (2002) stated that data analysis is conducted to "produce conclusions and recommendations based on both data analysis and interpretation, which usually includes value judgment.” (p. 219). This section describes how data from the 6 instruments were collected and analyzed to answer the 6 research questions and 12 subquestions. For the framework of this section, data collection and analysis are described according to each research question and subquestion.

Data analysis began by conducting Cronbach's Alpha on the Workshop Evaluation to determine the instrument's internal consistency. An analysis of the data included descriptive and inferential statistics. Descriptive statistics included measures of central tendency, counts, percentages, and frequencies. Inferential statistics included between groups analysis of variance (ANOVA), repeated measures ANOVAs, and repeated measures $t$ tests. Responses to openended items were categorized and described by categories, frequencies, and percentages. Except for repeated measures ANOVAs, data were analyzed with into $\operatorname{SPSS}^{\circledR} 11.0$ for Windows Student Version. Repeated measures ANOVAs were analyzed with SPSS ${ }^{\circledR}$ 14.0. The accepted risk level, or significance level, was set at $\alpha=.05$. Negative scores in four items in the immediate workshop evaluation were reversed. Refer to Appendix I for a visual representation of the research questions and subquestions, instruments from which data were collected, and how data were analyzed.

\section{How Data Were Collected and Analyzed to Answer Research Question 1:} Across all Participants, What do Participants Report About VIC's Workshop?

Data were collected from the Workshop Evaluation. This question was answered through responses to subquestions.

\section{How Data Were Collected and Analyzed to Answer Research Question 1. a.:} Across all Participants, What do Participants Report About the Instructional Content and Delivery System of VIC's Preschool Vision Screening Workshop?

Data were collected from the Instructional Content and Delivery System subscale of the Workshop Evaluation. Scores were totaled for each individual participant and compared against a possible score. Frequencies and percentages were reported. Negative Items 15 and 17 were reversed. 
How Data Were Collected and Analyzed to Answer Research Question 1. a. (1): Is There a Significant Difference in Means on Participants' Scores in Instructional Content and Delivery System due to Education?

Data regarding education were collected from Item 17 of each Attendance/Demographics Record administered at the beginning of the workshop. Scores from the Instructional Content and Delivery System subscale of the Workshop Evaluation administered at the end of each workshop were totaled for each individual participant and compared against a possible score. Responses to negative Items 15 and 17 were reversed. A between groups ANOVA using a significance level of $\alpha=.05$ was conducted. Scores served as the dependant variable. Education served as the independent variable, with three levels: (a) no college degree, (b) currently working toward a degree, and (c) college degree.

\section{How Data Were Collected and Analyzed to Answer Research Question 1. b.: Across all Participants, What do Participants Report About the Workshop Instructor's Teaching Skills?}

Data were collected from the Instructor Skills subscale of each Workshop Evaluation administered at the conclusion of each workshop. Scores were totaled for each participant and compared with a possible score. Frequencies and percentages were reported. Responses to negative Item 15 were reversed.

How Data Were Collected and Analyzed to Answer Research Question 1. b. (1): Is There a Significant Difference in Means on Participants' Scores in Instructor Skills due to Education?

Data regarding education were collected from Item 17 of each Attendance/Demographics Record administered at the beginning of each workshop and responses within the Instructor Skills subscale for each Workshop Evaluation administered at the end of each workshop. Scores were totaled for each individual participant and compared with a possible score. Frequencies and percentages were reported. Responses to negative Item 15 were reversed. A between groups ANOVA using a significance level of $\alpha=.05$ was conducted. Scores on this instrument served as the dependant variable. Education served as the independent variable, with three groups: (a) no college degree, (b) currently working toward a degree, and (c) college degree. 
How Data Were Collected and Analyzed to Answer Research Question 1. c.: Across all Participants, What do Participants Report

About the Logistical Arrangements of VIC's Preschool Vision Screening Workshop?

Data were collected from the Logistical Arrangements subscale of each Workshop Evaluation administered at the conclusion of each workshop. Scores were totaled individual participants and compared with a possible score. Frequencies and percentages were reported.

How Data Were Collected and Analyzed to Answer Research Question 1. c. (1): Is There a Significant Difference in Means on Participants' Scores in Logistical Arrangements due to Education?

Data were collected from Item 17 of the Attendance/Demographics Record administered at the beginning of each workshop and responses to the Logistical Arrangements subscale within the Workshop Evaluation administered at the end of each workshop. A between groups ANOVA using a significance level of $\alpha=.05$ was conducted. Scores on this instrument served as the dependant variable. Education served as the independent variable, with three groups: (a) no college degree, (b) currently working toward a degree, and (c) college degree.

How Data Were Collected and Analyzed to Answer Research Question 2: What do Participants Report About VIC's Workshop After They Screen Vision?

Data were collected from the Postworkshop Evaluation to answer subquestions, which were used to answer this question.

How Data Were Collected and Analyzed to Answer Research Question 2. a.: Across all Participants, do Participants Report That the Overall Workshop Was Effective in Preparing Them to Screen Vision?

Data were collected from Item 12 of the Postworkshop Evaluation administered after participants screened vision. Responses from all participants were totaled for each individual participant and compared with a possible score. Frequencies and percentages were reported.

How Data Were Collected and Analyzed to Answer Research Question 2. b.: Across all Participants, What Additional Support do Participants Report They Need From VIC to Screen the Vision of Preschoolers?

Data were collected from open-ended responses to Item 15 of the Postworkshop Evaluation administered after participants screened vision. Responses were categorized and described by categories, frequencies, and percentages. 
How Data Were Collected and Analyzed to Answer Research Question 3:

Do Participants Learn New Preschool Vision Screening Knowledge at VIC's Workshop?

Data were collected from scores on the workshop pretest and posttest administered at the beginning of the workshop and again at the end of the workshop. Scores from the pretest and the posttest were compared and reported as the number and percentages of participants that scored lower, the same as, or higher on the posttest when compared to the pretest.

How Data Were Collected and Analyzed to Answer Research Question 3. a.: Is There a Significant Difference in Means on Participants' Scores Between the Pretest and Posttest?

Data were collected from scores on the pretest and posttest administered before each workshop began and at the conclusion of each workshop. A repeated measures $t$ test using a significance level of $\alpha=.05$ were conducted with two levels of scores: pretest and posttest. The repeated measure was scores.

How Data Were Collected and Analyzed to Answer Research Question 3. b.: Is There a Significant Difference in Means on Participants' Scores Between the Pretest and Posttest due to Education?

Data were collected from responses to Item 17 on the Attendance/Demographics Record completed at the beginning of the workshop and scores from the pretest administered at the beginning of each workshop and the posttest administered at the end of each workshop. A repeated measures ANOVA using a significance level of $\alpha=.05$ was conducted using pretest and posttest scores as the dependant variables and education as the independent variable with three levels: (a) no college degree, (b) working toward a degree, and (c) college degree. The repeated measure was scores on the pretest and the posttest.

\section{How Data Were Collected and Analyzed to Answer Research Question 4: Do Participants Maintain Knowledge Learned at VIC's Workshop?}

Data were collected from scores on the posttest administered at the end of each workshop and the 3-month posttest, which was completed online or as a mailed document 3 months after each workshop. Mailed documents included postage-paid envelopes to help ensure participants returned completed documents. Scores from the workshop posttest and the 3-month posttest were compared and reported as the number and percentage of participants that scored lower, the same as, or higher on the 3-month posttest than they scored on the workshop posttest. 
How Data Were Collected and Analyzed to Answer Research Question 4. a.: Is There a Significant Difference in Participants' Scores Between the Workshop Posttest and the 3-month Posttest?

Data were collected from scores on the posttest administered at the conclusion of each workshop and the 3-month posttest. A repeated measures $t$ test using a significance level of $\alpha=$ .05 were conducted with two levels of scores: pretest and posttest. The repeated measure was scores.

How Data Were Collected and Analyzed to Answer Research Question 4. b.: Is There a Significant Difference in Means on Participants' Scores Between the Workshop Posttest and the 3-month Posttest due to Education?

Data were collected from responses to Item 17 of the Attendance/Demographics Record administered at the beginning of each workshop and scores on the posttest administered at the end of each workshop and the 3-month posttest. A repeated measures ANOVA using a significance level of $\alpha=.05$ was conducted using two time periods: pretest and posttest and three education levels: (a) no college degree, (b) currently working toward a degree, and (c) college degree. The repeated measure was scores. When significant $F$ test results occurred, post hoc tests were conducted.

\section{How Data Were Collected and Analyzed to Answer Research Question 5: What Job Aids do Participants Report Using to Transfer Learned Knowledge From the Workshop to Practice?}

Data were collected from Items 3, 3a, 3b, and 3c of the Postworkshop Evaluation administered after participants screened vision. Responses were categorized and described according to categories, frequencies, and percentages for all participants.

How Data Were Collected and Analyzed to Answer Research Question 6: What Occurred During

Preschool Vision Screening That Was Not Discussed in VIC's Workshop?

Data were collected from responses to Item 2.a. of the Postworkshop Evaluation completed after participants screened vision. Responses to this open-ended item were categorized and described according to categories, frequencies, and percentages. 


\section{CHAPTER 4}

\section{Results}

Because lay vision screeners rarely receive formal training in how to screen vision and because older children were seen in a pediatric eye clinic with vision disorders that should have been detected earlier through vision screening, a pediatric ophthalmologist, Geoffrey Bradford, MD, and the researcher created the Vision Initiative for Children (VIC) in 2000 as a statewide outreach program of the West Virginia University Eye Institute. VIC trains, equips, and provides ongoing support to lay individuals who are mandated, or have a desire, to screen the vision of children ages 3,4 , and 5 .

Through VIC's model, lay individuals participate in interactive, face-to-face workshops and receive age-appropriate screening tests and ongoing support. VIC has trained more than 1,000 individuals; its database holds nearly 15,000 vision screening events. Trained individuals include Head Start employees, school health nurses, primary care practice nurses, pediatricians, and child care providers. VIC currently partners with lay screeners in West Virginia, but plans to expand its program to Head Start programs in other states. The purpose of this study was to explore, from the perspective of Head Start personnel, whether the Vision Initiative for Children prepares Head Start personnel to screen the vision of preschoolers and whether Head Start participants encounter screening experiences that were not discussed during VIC's workshop.

This chapter describes the analysis of data to answer the 6 research questions and 12 subquestions in this program evaluation study. To enhance readability, subquestions are collapsed within research questions and research questions are reported according to headings instead of specific research questions.

\section{Data Analysis}

Knox (2002) stated that data analysis is conducted "to produce conclusions and recommendations based on both data analysis and interpretation, which usually includes value judgment." (p. 219). Statistics used to analyze data included: (a) Cronbach's alpha, (b) frequency distribution, (c) between groups ANOVA, (d) repeated measures $t$ tests, and (e) repeated measures ANOVA. Content analysis was used as a technique to analyze open-ended, written responses in the instruments (Johnson \& LaMontagne, 1993; Patton, 2002). In this procedure, participant names and corresponding participant number were keyed into a Microsoft Excel spreadsheet. All responses to open-ended items were keyed in, verbatim. A category field was 
added adjacent to the response field. Responses were read and reread until categories emerged. Units of analysis were not identified because responses tended to be short in length. Responses were coded and placed in tentative categories. Finally, categories were refined.

Data regarding demographics, missing items, as well as data for all instruments, were first entered into Microsoft Excel spreadsheets. Data for instruments were placed into SPSS ${ }^{\circledR}$ 11.0 for Windows Student Version for analyses. All data were analyzed through procedures in SPSS $^{\circledR} 11.0$ for Windows Student Version except for two repeated measures ANOVA tests, which were conducted on SPSS ${ }^{\circledR} 14.0$ for Windows.

To assess data entry reliability, an accuracy technique was implemented (Rous, Lobianco, Moffett, \& Lund, 2005). In that technique, 15\% $(n=7)$ of the 47 participants were randomly selected through the random selection function of $\operatorname{SPSS}^{\circledR} 11.0$ for Windows Student Version. Each item on each instrument completed by the randomly selected seven participants was reviewed for data entry accuracy. A combined set of workshop and postworkshop instruments contained 149 items. A set of instruments completed only at the workshop contained 114 items. Three of the seven randomly selected participants completed only the workshop instruments and four completed all documents. From 938 entered items, 1.4\% $(n=13)$ were coded inaccurately, resulting in a data entry accuracy rate of $98.6 \%$. All inaccurate codes were corrected in the Microsoft Excel spreadsheets, as well as the SPSS ${ }^{\circledR}$ data set.

The next data analysis procedure involved computing internal consistency measures for each of the four content areas in the Workshop Evaluation. Nunnally and Bernstein (1994) stated that internal consistency "describes estimates of reliability based on the average correlation among items within a test." (p. 251). Cronbach's alpha was conducted to determine if instrument items measured "the same thing" (Vogt, 1999, p. 64).

Cronbach's alpha was computed on each of the four subscales-Instructional Content and Delivery System, Instructor Skills, Logistical Arrangements, and Overall Workshopalthough the latter subscale, Overall Workshop, was not included in this data analysis. Cronbach's alpha was not reported for the full scale because alpha "assumes unidimensionality which contradicts the notion of separate subscales" (R. F. DeVellis, personal communication, September 14, 2005). Cronbach's alpha was .64 for the Instructional Content and Delivery System subscale, .57 for the Instructor Skills subscale, .88 for the Logistical Arrangements subscale, and .05 for the Overall Workshop subscale. Analysis of data from the Overall 
Workshop subscale were not required to answer the six research questions or 12 subquestions. While Nunnally and Bernstein (1994) described an alpha of .70 as "modest" (p. 265) and Vogt (1999) stated that coefficients less than .70 are "usually considered unreliable" (p. 245), other investigators accept lower alpha levels. For example, DeVellis (2003) suggested that an alpha below .60 is unacceptable, while an alpha falling between .60 and .65 is acceptable, but undesirable, an alpha falling between .70 and .80 is respectable, and an alpha falling between .80 and .90 is very good.

Nunnally and Bernstein (1994) explained that a low alpha commonly means "the test is either too short or the items have very little in common.” (p. 252). However, Nunnally and Bernstein further maintained that a "satisfactory level of reliability depends on how a measure is being used" (p. 264).

To help interpret reasons for low alpha, DeVellis (R. F. DeVellis, personal communication, September 14 and 15, 2005) suggested that scales with low alpha are likely to contain items with more individual variation and that separate items within a subscale probably correlate less with the common theme of all items in a subscale combined as a group. DeVellis further suggested that subscale items were either less skillfully constructed or the common theme was more elusive, either to the person writing the items or the individuals responding to the items. The problem with low alpha, according to DeVellis, is that a measure has less of its total variance attributable to the variable of interest and is less likely to show a relationship with other variables in subsequent analyses.

DeVellis (2003) suggested that deleting items from scales could increase alpha. Deleting various items from the Instructional Content and Delivery System subscale did not increase the reliability coefficient higher than .69. For example, deleting Item 17 (Should we delete the dancing chicken from the PowerPoint presentation?) would have increased alpha only to.69, which still remains in DeVellis' undesirable range.

\section{Participant Reports About VIC's Workshop}

This section describes participant reports regarding three Workshop Evaluation subscales: (a) Instructional Content and Delivery System, (b) Instructor Skills, and (c) Logistical Arrangements. For purposes of analysis, tallied responses equal scores and may be referred to both as responses and scores. This section also describes participant reports regarding what they liked best and least about the workshop, overall comments, and suggestions for improvement. 


\section{Instructional Content and Delivery System}

Responses from 47 participants to 17 items in the Instructional Content and Delivery System subscale of the VIC Preschool Vision Screening Workshop Evaluation distributed at the end of each workshop were analyzed to determine participant reactions to what was taught in the workshop (content) and how the content was presented (delivery system). For example, participants were asked whether (a) the learning objectives were clear and realistic (Item 1), (b) whether the way in which content was delivered met their preferred learning style (Item 14), and (c) whether practicing the screening tests enhanced learning (Items 8 and 9).

A frequency distribution was created to organize the data in a logical order to determine how often certain scores occurred (Howell, 2002; Salkind, 2000) and to review total scores for each item in the Instructional Content and Delivery System subscale of the Workshop Evaluation to determine needed modifications for future workshops (Caffarella, 2002; Dick et al., 2001; Guba \& Lincoln, 1981; Guskey, 2000; Kirkpatrick, 1998; Mizell, 2003; Worthen et al., 1997). To review subscale items, refer to Items 1 through 17 in Part 1 of the Workshop Evaluation in Appendix G.

Forty-seven participants completed 973 of 987 (99\%) total items in the subscale. Responses were totaled and compared with a possible score of 63. Tallied scores fluctuated from a low of 50 to the possible 63 , with a mean of 60 . Figure 1 provides the frequency distribution of tallied responses as scores. 


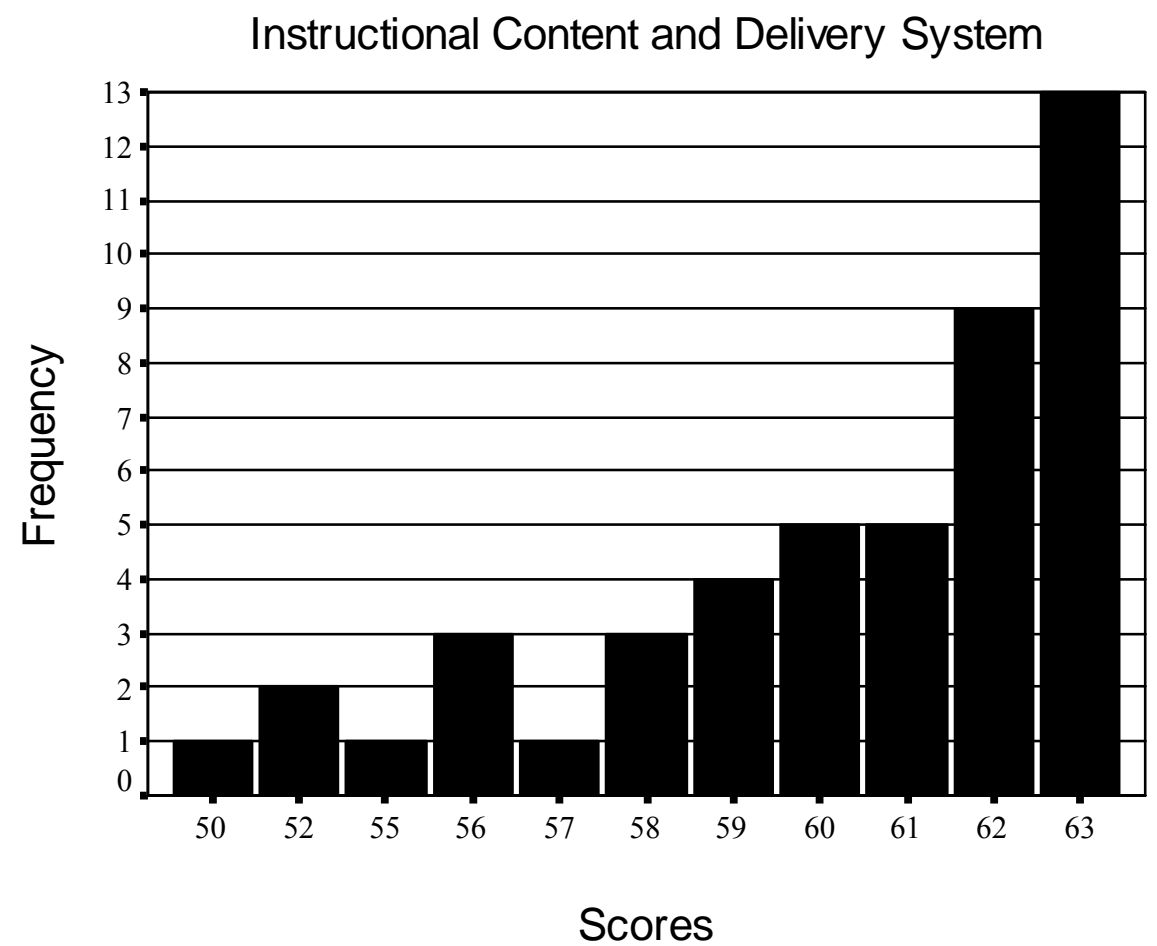

Figure 1. Frequency of 47 participants' tallied responses as scores for 17 items in the Instructional Content and Delivery subscale of the Workshop Evaluation administered at the end of each workshop. Tallied responses fluctuated from a low of 50 to the possible score of 63 .

An analysis of higher tallied responses indicated that $100 \%$ of participants reportedly believed practicing the tests was a necessary part of the workshop while $98 \%$ reported that the instructor's modeling and demonstration of tests was also a necessary part of the workshop. Additionally, $96 \%$ of participants reported that instructor feedback during practice enhanced their learning and 92\% reported that the animated Microsoft PowerPoint presentation also enhanced their learning. Table 10 provides further clarification of each Instructional Content and Delivery System subscale item, as well as the tallied percentages for, and number of participants responding to, each item. 
Table 10

Frequency of Responses From 47 Participants to Instructional Content and Delivery System Subscale of the Workshop Evaluation

\begin{tabular}{|c|c|c|c|c|}
\hline Item & $\% \mathrm{No}$ & \% Somewhat & $\%$ Yes & $n$ \\
\hline 1. Were the training objectives clear and realistic? & 0 & 0 & 100 & 47 \\
\hline 2. Did you learn what you expected to learn? & 2.1 & 10.6 & $87.2 *$ & 47 \\
\hline $\begin{array}{l}\text { 3. Was there an adequate amount of time allotted to each } \\
\text { topic? }\end{array}$ & 0 & 6.4 & 93.6 & 47 \\
\hline $\begin{array}{l}\text { 4. Did the information about vision disorders help you } \\
\text { learn what the screening tests are designed to detect? }\end{array}$ & 0 & 10.9 & 89.1 & 46 \\
\hline $\begin{array}{l}\text { 5. Did the animated PowerPoint presentation help you } \\
\text { learn about preschool vision screening? }\end{array}$ & 0 & 8.5 & 91.5 & 47 \\
\hline $\begin{array}{l}\text { 6. a. Was the PowerPoint presentation adequate in } \\
\text { vocabulary? }\end{array}$ & 0 & 4.3 & 95.7 & 47 \\
\hline $\begin{array}{l}\text { 6. b. Was the PowerPoint presentation adequate in the } \\
\text { amount of slides per topic? }\end{array}$ & 0 & 2.1 & 97.9 & 47 \\
\hline $\begin{array}{l}\text { 6. c. Was the PowerPoint presentation adequate in clarity } \\
\text { of descriptions? }\end{array}$ & 0 & 4.3 & 95.7 & 47 \\
\hline $\begin{array}{l}\text { 6. d. Was the PowerPoint presentation adequate in clarity } \\
\text { of examples? }\end{array}$ & 0 & 6.4 & 93.6 & 47 \\
\hline $\begin{array}{l}\text { 6. e. Was the PowerPoint presentation adequate in content } \\
\text { sequence (simple to more complex)? }\end{array}$ & 0 & 14.0 & 86.0 & 43 \\
\hline $\begin{array}{l}\text { 7. Did the instructor's modeling and demonstration of } \\
\text { tests help you learn how to use the tests? }\end{array}$ & 0 & 2.1 & 97.9 & 47 \\
\hline $\begin{array}{l}\text { 8. Did practicing the tests help you learn how to use the } \\
\text { screening tests? }\end{array}$ & 0 & 0 & 100 & 46 \\
\hline $\begin{array}{l}\text { 9. When you practiced with a partner, did the instructor's } \\
\text { feedback help you learn? }\end{array}$ & 0 & 4.3 & 95.7 & 46 \\
\hline $\begin{array}{l}\text { 10. Will the information about encouraging parents to } \\
\text { schedule a follow-up eye exam help you talk with parents } \\
\text { of children who do not pass vision screening? }\end{array}$ & 0 & 14.9 & 85.1 & 47 \\
\hline
\end{tabular}




\begin{tabular}{|c|c|c|c|c|}
\hline Item & $\% \mathrm{No}$ & $\%$ Somewhat & $\%$ Yes & $n$ \\
\hline $\begin{array}{l}\text { 11. Did the theory information about the importance of } \\
\text { screening the vision of preschoolers help you understand } \\
\text { why you should conduct preschool vision screening? }\end{array}$ & 0 & 2.1 & 97.9 & 47 \\
\hline $\begin{array}{l}\text { 12. Do you understand what you were supposed to learn } \\
\text { today? }\end{array}$ & 0 & 8.5 & 91.5 & 47 \\
\hline $\begin{array}{l}\text { 13. Now that you have practiced using the tests, do you } \\
\text { feel ready to screen vision? }\end{array}$ & 0 & 24.4 & 75.6 & 45 \\
\hline $\begin{array}{l}\text { 14. Think about how you learn new material. Did the } \\
\text { workshop meet your learning style? }\end{array}$ & 0 & 10.9 & 89.1 & 46 \\
\hline 15. Was the content too difficult to learn? & 82.6 & 6.5 & 10.9 & 46 \\
\hline $\begin{array}{l}\text { 16. If you thought the instructor was humorous and you } \\
\text { laughed during the workshop, did the humor and laughter } \\
\text { help you learn? }\end{array}$ & 0 & 14.9 & 85.1 & 47 \\
\hline $\begin{array}{l}\text { 17. Should we delete the dancing chicken from the } \\
\text { PowerPoint presentation? }\end{array}$ & 88.6 & 2.3 & 9.1 & 44 \\
\hline
\end{tabular}

Note: Because of rounding, totals may not always equal 100.

To determine whether a significant difference occurred in participant tallied response on the Instructional Content and Delivery System subscale due to the independent variable of education, participant scores were subjected to a one-way analysis of variance with three levels of education: (a) no degree, (b) working toward a degree, and (c) college degree. The significance level was set at $\alpha=.05$. Scores were first analyzed for homogeneity of variance using the Levene's test. The results of the Levene test indicated that the variance in scores among the three levels of education for the Instructional Content and Delivery System was equal $(p=.047)$. Scores for this subscale were then subjected to a one-way analysis of variance. Using $\alpha=.05$, the results of this analysis did not yield a main effect for education for the Instructional Content and Delivery System subscale, $F(2,44)=.863, p>.05$, indicating that the null hypothesis of no statistical significance cannot be rejected and that the scores in the Instructional Content and Delivery System were similar regardless of participant education level. 


\section{Instructor Skills}

Responses from 47 participants to 15 items in the Instructor Skills subscale of the Workshop Evaluation distributed at the end of each workshop were analyzed to determine participant reactions to the skills of the instructor in teaching the workshop content. For example, participants were asked whether (a) the instructor was enthusiastic when delivering the content (Item 1), (b), the instructor attempted to make them feel comfortable during the workshop (Item 4), and (c) the instructor adequately helped them learn new material (Item 5).

A frequency distribution was created to organize the data in a logical order to determine how often certain scores occurred (Howell, 2002; Salkind, 2000) and to review total scores for each item in the Instructor Skills subscale of the Workshop Evaluation to determine needed modifications for future workshops (Caffarella, 2002; Dick et al., 2001; Guba \& Lincoln, 1981; Guskey, 2000; Kirkpatrick, 1998; Mizell, 2003; Worthen et al., 1997). To review all items for this subscale, refer to Items 1 through 15 in Part 2 of the Workshop Evaluation in Appendix G.

Forty-seven participants completed 697 of 705 (99\%) items in this subscale. Responses were totaled and compared with a possible score of 45 . Tallied scores fluctuated from a low of 24 to the possible 45 , with a mean of 43 . Figure 2 provides the frequency distribution of tallied responses as scores.

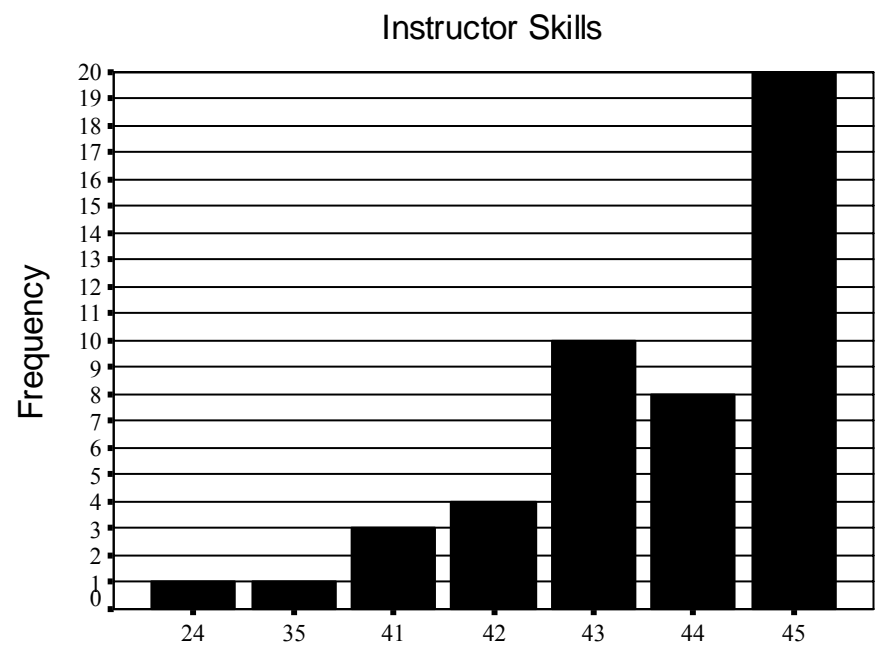

Scores

Figure 2. Frequency of 47 participants' tallied responses as scores for 15 items in the Instructor Skills subscale of the Workshop Evaluation administered at the end of each workshop. Tallied responses fluctuated from a low of 24 to the possible score of 45 . 
An analysis of higher tallied responses indicated that $100 \%$ of participants reported the instructor possessed expert knowledge of the content, made an effort to help them feel comfortable, answered their questions and addressed their concerns, and focused the training on learning objectives. This item-by-item analysis also indicated that $98 \%$ of participants reported that the instructor provided them with adequate help in learning new material, provided sufficient feedback during practice, used training time effectively, and was, overall, a good teacher. Table 11 further clarification of each Instructional Skills subscale item, as well as the tallied percentages for, and number of participants responding to, each item.

\section{Table 11}

Frequency of Responses From 47 Participants to Instructor Skills Subscale of the Workshop Evaluation

\begin{tabular}{|c|c|c|c|c|}
\hline Item & $\%$ No & \% Somewhat & $\%$ Yes & $n$ \\
\hline 1. Was the instructor enthusiastic? & 0 & 4.3 & 95.7 & 47 \\
\hline 2. Did the instructor use high-quality teaching materials? & 0 & 4.3 & 95.7 & 47 \\
\hline $\begin{array}{l}\text { 3. Did the instructor have expert knowledge of the } \\
\text { content? }\end{array}$ & 0 & 0 & 100 & 47 \\
\hline $\begin{array}{l}\text { 4. Did the instructor make an effort to help you feel } \\
\text { comfortable? }\end{array}$ & 0 & 0 & 100 & 47 \\
\hline $\begin{array}{l}\text { 5. Did the instructor provide you with adequate help in } \\
\text { learning the new material? }\end{array}$ & 0 & 2.1 & 97.9 & 47 \\
\hline 6. Did the instructor hold your interest? & 0 & 4.3 & 95.7 & 47 \\
\hline 7. Did the instructor use humor appropriately? & 0 & 4.3 & 95.7 & 46 \\
\hline $\begin{array}{l}\text { 8. Was the instructor's pace appropriate (i.e., not too } \\
\text { slow, not too fast)? }\end{array}$ & 2.2 & 15.2 & 82.6 & 46 \\
\hline $\begin{array}{l}\text { 9. Did the instructor focus the training on the workshop } \\
\text { objectives? }\end{array}$ & 0 & 0 & 100 & 46 \\
\hline $\begin{array}{l}\text { 10. Was knowing what topics had been covered and what } \\
\text { topics were to be covered a necessary part of the } \\
\text { workshop? }\end{array}$ & 2.2 & 28.3 & $69.6^{*}$ & 46 \\
\hline
\end{tabular}




\begin{tabular}{|c|c|c|c|c|}
\hline Item & $\% \mathrm{No}$ & $\%$ Somewhat & $\%$ Yes & $n$ \\
\hline $\begin{array}{l}\text { 11. Did the instructor answer your questions and address } \\
\text { your concerns? }\end{array}$ & 0 & 0 & 100 & 47 \\
\hline 12. Did the instructor use the training time effectively? & 0 & 2.2 & 97.8 & 46 \\
\hline $\begin{array}{l}\text { 13. Did the instructor provide sufficient feedback on your } \\
\text { practice exercises? }\end{array}$ & 0 & 2.2 & 97.8 & 46 \\
\hline 14. Is the instructor a good teacher? & 0 & 2.2 & 97.8 & 46 \\
\hline $\begin{array}{l}15 . \text { Did the instructor provide too much repetition or } \\
\text { review? }\end{array}$ & 73.9 & 2.2 & 23.9 & 46 \\
\hline
\end{tabular}

Note: Because of rounding, percentages may not always equal 100.

To determine whether a significant difference occurred in participant responses on the Instructor Skills subscale due to the independent variable of education, participant scores for the three subscales were subjected to a one-way analysis of variance with three levels of education: (a) no degree, (b) working toward a degree, and (c) college degree. The significance level was set at $\alpha=.05$. To test the effects of education on scores for Instructor Skills, scores were first analyzed for homogeneity of variance using the Levene's test. The results of the Levene test indicated that the variance in scores among the three levels of education for Instructor Skills was equal ( $p=.207)$. Scores for this subscale were then subjected to a one-way analysis of variance. Using $\alpha=.05$, the results of this analysis did not yield a main effect for education for the Instructor Skills subscale, $F(2,44)=.518, p>.05$, indicating that the null hypothesis of no statistical significance cannot be rejected and that the scores were similar regardless of participant education level.

\section{Logistical Arrangements}

Responses from 45 participants to 5 items in the Logistical Arrangements subscale of the Workshop Evaluation distributed at the end of each workshop were analyzed to determine participant reactions to the physical environment of the workshop. For example, participants were asked whether (a) the room was the right temperature (Item 3), (b) the chairs were comfortable, and (c) refreshments were fresh and tasty (Item 1).

A frequency distribution was created to organize the data in a logical order to determine how often certain scores occurred (Howell, 2002; Salkind, 2000) and to review total responses 
for each item in the Logistical Arrangements subscale of the Workshop Evaluation to determine needed modifications for future workshops (Caffarella, 2002; Dick et al., 2001; Guba \& Lincoln, 1981; Guskey, 2000; Kirkpatrick, 1998; Mizell, 2003; Worthen et al., 1997). To review all items for this subscale, refer to Items 1 through 5 in Part 3 of the Workshop Evaluation in Appendix G.

Forty-five participants completed 91 of 163 total items in the subscale. Completed items were fewer for this subscale because each workshop did not include refreshments. Responses were totaled and compared with a high of 15 . Tallied responses fluctuated from a low of 3 to the possible 15, with a mean of 8.69. Figure 3 provides the frequency distribution of tallied responses as scores.

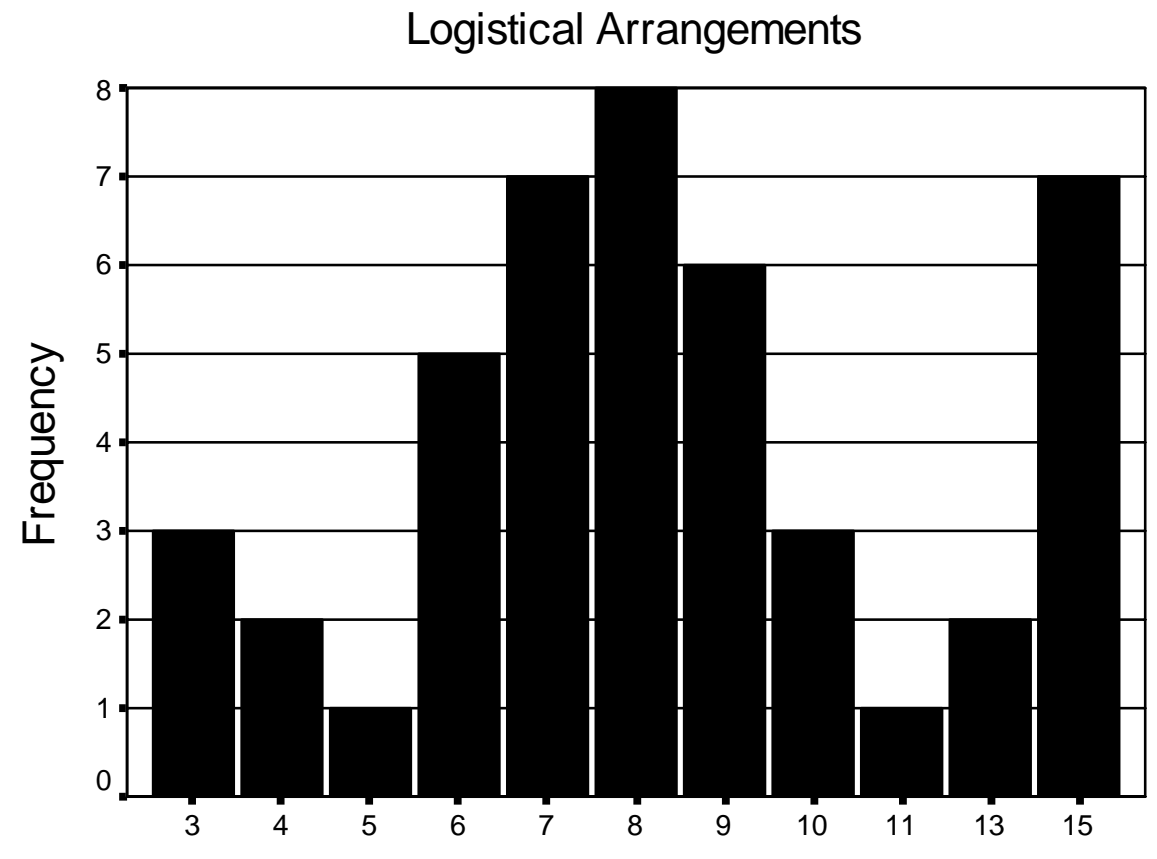

\section{Scores}

Figure 3. Frequency of 45 participants' tallied responses as scores for 5 items in the Logistical Arrangements subscale of the Workshop Evaluation administered at the end of each workshop. Tallied responses fluctuated from a low of 3 to the possible score of 15 .

An analysis of tallied responses indicated that $80 \%$ of participants believed the workshop schedule was planned well and 58\% believed refreshments were fresh and tasty. Less than half of participants reported beverages were appropriately hot or cold and served on time, the room was the appropriate temperature, or that chairs were comfortable. Table 12 provides further 
clarification of each Logistical Arrangements subscale item, as well as tallied percentages for, and number of participants responding to, each item.

Table 12

Frequency of Responses From 45 Participants to Logistical Arrangements Subscale of the Workshop Evaluation

Item $\quad \%$ No $\quad \%$ Somewhat $\%$ Yes $\quad n$

1. Were the refreshments fresh and tasty?

36.8

57.9

19

2. Were the beverages appropriately hot or cold and

36.8

15.8

$47.4 \quad 19$ ready on time?

3. Was the room the right temperature?

37.5

40.0

4. Were the chairs comfortable?

7.3

43.9

$48.8 \quad 41$

5. Was the workshop schedule planned well (i.e., breaks in a timely manner)?

To determine whether a significant difference occurred in participant responses on the Logistical Arrangements subscale of the Workshop Evaluation due to the independent variable of education, participant scores for were subjected to a one-way analysis of variance with three levels of education: (a) no degree, (b) working toward a degree, and (c) college degree. The significance level was set at $\alpha=.05$. To test the effects of education on scores for the Logistical Arrangements subscale, scores were first analyzed for homogeneity of variance using the Levene's test. The results of the Levene test indicated that the variance in scores among the three levels of education for the this was equal $(p=.460)$. Scores for this subscale were then subjected to a one-way analysis of variance. Using $\alpha=.05$, the results of this analysis did not yield a main effect for education for the Logistical Arrangements subscale, $F(2,42)=.067, p>.05$, indicating that the null hypothesis of no statistical significance cannot be rejected and that the scores in the Logistical Arrangements subscale of the Workshop Evaluation were similar regardless of participant education level. 


\section{Participant Perceptions About the Workshop, Suggestions for Improvement, and Overall Comments}

This section provides open-ended comments in the workshop evaluation, which asked participants to describe what they liked best and least about the workshop, as well as suggestions to improve the workshop. This section of the workshop evaluation also offered participants the opportunity to provide additional comments about the workshop in general.

\section{Workshop Components Participants Liked Best}

Thirty-five (74\%) of 47 participates reported parts of the workshop they liked best; responses were reduced to 4 categories: (a) All components, (b) Confidence in ability to screen, (c) Instructional Content and Delivery System, and (d) Instructor Skills. Some participants responses fit more than one category. Two participants reported they enjoyed all workshop components. Three participants reported the workshop enhanced their confidence in their ability to screen (i.e., "feel like now I can screen 3 to 5 years appropriately").

The Instructional Content and Delivery System category included six subcategories. Seven participants liked the information presented in the workshop (i.e., "information about childhood vision problems"), two liked the eyeball game, and two liked the length of the training (i.e., "short and sweet!"). Two enjoyed receiving the Vision Screening At-A-Glance Flowchart and the vision screening kit, 2 enjoyed the Microsoft PowerPoint presentation, but 12 liked the hands-on practice best (i.e., "practicing w/partner made me feel more comfortable").

The Instructional Skills category also included six subcategories. Three participants mentioned the instructor's enthusiasm., one reported that the instructor was pleasant and friendly and, one enjoyed that the instructor used a variety of teaching skills. Three enjoyed the instructor generally (i.e., "the instructor"), one reported the instructor made learning fun, and one enjoyed the instructor's humor (i.e., "This workshop was one of the best I had ever attended. Not too long. Very informative. Useful and instructor kept our interest - Humor kept it from being boring").

\section{Workshop Components Participants Liked Least}

Twenty-eight (60\%) of 47 participants reported parts of the workshop they liked least; open-ended responses were reduced to 5 categories: (a) All components, (b) Instructional Content and Delivery System, (c) Logistical Arrangements, (d) Paperwork, and (e) Scheduling. Two participants reported they enjoyed all of the workshop components and 12 reported there 
was nothing about the workshop they liked least; 1 disliked learning definitions, 1 disliked the tests, and another thought the length of the workshop evaluation was too long. Comments related to logistical arrangements included: two did not enjoy the refreshments or wanted refreshments, especially cookies; three believed the training room's temperature was too cold; one wanted the training location closer to home; and 1 disliked sitting. Four participants offered comments related to scheduling: two disliked how breaks were scheduled (i.e., "break too close to end"); one, who participated in an afternoon workshop) disliked the time of day the workshop was scheduled (i.e., "evening - time of day"), and one believed teacher's aids should have participated in the workshop.

\section{Suggestions for Workshop Improvement}

Twenty-five (53\%) of 47 participants completed the open-ended item regarding suggestions for improvement; open-ended responses were reduced to 3 categories: (a) No suggestions for improvement, (b) Dancing chicken, and (c) Miscellaneous but specific. Twentyone participants reported they had no suggestions for improvement. One of the 21 also stated she enjoyed the music break (dancing chicken). One suggested the workshop should include more dancing chicken slides, another suggested the vision screening kit should include the Lea Symbols ${ }^{\mathrm{TM}}$ puzzle, one suggested that the evaluation be shortened in length, and one suggested that VIC inform primary care physicians about the need to screen vision (i.e., " "Preaching to the choir' Make doctors aware of need to screen").

\section{Overall Comments}

Twenty-eight (60\%) of 47 participants provided overall comments; open-ended responses were reduced to 6 categories: (a) No comments to add, (b) Instructional Skills, (c) Good workshop, (d) Thanks for the workshop, (e) Refreshed or learned new material, and (f) Suggestions. Six participants wrote NA, none, or nothing. Comments related to Instructor Skills included: (a) "The instructor was great," (b) "Very well planned, organized, taught well," and (c) “Impressed, did a really good job conveying information through multiple resources." Eight participants commented that the workshop was good (i.e., "I really enjoyed the workshop. It was fun, informative and we will be using this" and "All Head Starts/Day cares would benefit from this workshop.”). Two participants thanked the instructor for the workshop. One participant commented the workshop provided refresher training and one commented "I learned a lot that will help me when I do screenings." Two participants offered suggestions in the comments 
section: "Be able to report screenings on line", offer a Train-the-Trainer model, and "Add eyecover sticker to the boxes." The latter suggestion referred to adding a different type of occluder to the vision screening kit. Table 13 provides categorized open-ended responses, as well as the tallied percentages or, and number of participants responding to, each item in each category.

Table 13

Open-Ended Comments Regarding What Participants Liked Best and Least About VIC's Workshop, Suggestions for Improvement, and General Comments

\begin{tabular}{lcc}
\hline \multicolumn{1}{c}{ Liked Best } & & \\
\hline \multicolumn{1}{c}{ Category } & Frequency & $\%^{*}$ \\
\hline All components & 2 & 4.8 \\
Confidence in ability to screen & 3 & 7.1 \\
Instructional Content and Delivery System & & \\
Informative - Example: "Good information." & 7 & 16.7 \\
Eyeball game - Example: "Eyeballs." & 2 & 4.8 \\
$\begin{array}{l}\text { Hands-on practice - Example: "Practicing w/partner made } \\
\text { me feel more comfortable." }\end{array}$ & 12 & 28.6 \\
Kit and flowchart & 2 & 4.8 \\
Length of training - Example "Short and sweet!" & 2 & 4.8 \\
"PowerPoint presentation." and "Presentation." & 2 & 4.8 \\
Instructional Skills & & \\
$\begin{array}{l}\text { Enthusiasm - Example: "The enthusiasm of the instructor." } \\
\text { "Used variety of learning/teaching skills" }\end{array}$ & 3 & 7.1 \\
$\begin{array}{l}\text { Instructor in general - Examples: "Presented in a very } \\
\text { manner." and "Pleasant and friendly." }\end{array}$ & 1 & 2.4 \\
\begin{tabular}{l} 
"Made learning fun." \\
\hline
\end{tabular} & 4 & 9.5 \\
\hline
\end{tabular}


Liked Best

\section{Category}

Humor - Example: "This workshop was one of the best I had ever Frequency $\%$ attended. Not too long. Very informative. Useful and instructor kept our interest - Humor kept it from being boring"

\begin{tabular}{|c|c|c|}
\hline \multicolumn{3}{|l|}{ Liked Least } \\
\hline Category & Frequency & $\%$ \\
\hline "I enjoy all of the workshop." (1) or wrote "NA", "None", or "Nothing" & 14 & 50.0 \\
\hline $\begin{array}{l}\text { Instructional Content and Delivery System - Definitions } \\
\text { Example: "Not learning the definitions right away." }\end{array}$ & 1 & 3.6 \\
\hline Logistical Arrangements & 7 & 25.0 \\
\hline \multicolumn{3}{|l|}{ "Drive home." } \\
\hline \multicolumn{3}{|l|}{ "No refreshments." and "Food - need cookies." } \\
\hline \multicolumn{3}{|l|}{ "Sitting." } \\
\hline \multicolumn{3}{|l|}{ "The room was too cold.", "Cold room.", and "Too cold in chapel." } \\
\hline Paperwork - "The evaluation was too long." and "Test!!" & 2 & 7.1 \\
\hline Scheduling & 4 & 14.3 \\
\hline \multicolumn{3}{|l|}{ "Break." and "Break - was too close to end." } \\
\hline \multicolumn{3}{|l|}{ "Evening - time of day." (participant's workshop was in afternoon) } \\
\hline "Not having teacher aids to be in training to." & & \\
\hline
\end{tabular}


Suggestions for Improvement

\begin{tabular}{lcc}
\hline Category & Frequency & $\%^{*}$ \\
\hline Wrote "NA", "None", or "Nothing" & 20 & 80.0 \\
"More dancing chicken." or "None. I liked the music break." & 2 & 8.0 \\
Miscellaneous but specific & 3 & 12.0 \\
"To get the (Lea Symbols ${ }^{\mathrm{TM}}$ ) puzzle to add to (vision screening) kit." & & \\
"Shorter evaluation." & & \\
" "Preaching to the choir' Make doctors aware of need to screen." &
\end{tabular}
General Comments

\begin{tabular}{lcc}
\hline \multicolumn{1}{c}{ Category } & Frequency & $\% *$ \\
\hline No comments to add - Wrote "NA", "None", or "Nothing" & 6 & 21.4 \\
Instructional Skills & 8 & 28.6
\end{tabular}

"The instructor was great"

"Continue the good work. Good job"

"You're great! Good luck with your doctorate."

"Very well planned, organized, taught well."

"Great trainer with a professional attitude. Thanks."

"Impressed, did a really good job conveying information through multiple resources."

"None - except good job!"

"Motivating presenter."

Thanks for the workshop

Refreshed or learned new material

2

7.1

"Since I don't screen all the time this helped me to refresh."

"I learned a lot that will help me when I do screenings." 


\begin{tabular}{lcc}
\hline \multicolumn{1}{c}{ Category } & Frequency & $\%$ \\
\hline Good workshop & 8 & 28.6 \\
"Very good workshop." and "Very good training." & & \\
"I will use this information to help with vision screening. & \\
Good workshop." & \\
"I really enjoyed the workshop. It was fun, informative and we will & \\
be using this." & \\
"All Head Starts/Day cares would benefit from this workshop." & 2 \\
Suggestions & & \\
"Be able to report screenings on line. Train the trainer." & \\
"Add eyecover sticker to the boxes."
\end{tabular}
Note. Because of rounding, percentages may not equal 100.

\section{Participant Reports About VIC's Workshop After Screening Vision}

This section describes participant reports about the effectiveness of VIC's workshop after they screened vision. Furthermore, this section describes additional support needed from VIC to continue screening vision.

\section{Effectiveness of Workshop in Preparing Participants to Screen Vision}

To determine the effectiveness of VIC's workshop in preparing participants to screen vision, responses from 27 participants who responded to Item 12 of the Postworkshop Evaluation were analyzed according to frequencies and percentages. Item 12 asked: Was the overall workshop effective in preparing you to screen vision? "Effective" was determined according to each participant's interpretation. Responses were collected in a 3-point Likert-type scale anchored by "yes, definitely" and "no": (a) $1=$ No; (b) 2 = Somewhat, (c) $3=$ Yes, definitely.

Data analysis indicated that the workshop was effective in preparing the majority of participants to screen the vision of preschoolers. Of the 27 participants responding to this item, $25(93 \%)$ reported that the workshop was effective in preparing them to screen vision and $2(7 \%)$ reported that the workshop was "somewhat" effective. The high percentage and mean score suggests that participant responses were similar regardless of education level. 


\section{Additional Support Participants Report They Need From VIC to Continue Screening Vision}

To determine additional support participants required after their workshops to screen the vision of preschoolers, open-ended responses were collected from Item 15 of the Postworkshop Evaluation, which asked: "What support do you need from VIC to screen the vision of preschoolers that you are not receiving?" Twenty-seven(57\%) of 47 participants completed the Postworkshop Evaluation; 22 (81\%) of 27 participants responded to this item.

Employing content analysis as the data analysis technique to analyze open-ended responses(Johnson \& LaMontagne, 1993; Patton, 2002), open-ended responses from 22 participants were categorized and described by categories, frequencies, and percentages. Data were reduced to six categories: (a) More screening forms, (b) N/A, (c) Need to use available support, (d) None, (e) Parent information, and (f) Refresher course for new information. Fourteen of 22 participants (64\%) reported that no additional support was required. The second highest category — "Refresher course for new information"-was reported by four participants. Of the four, three reported that they did not have Internet access, which would permit them to visit VIC's password-protected Screener Support web site, which provides refresher material, and program updates. Table 14 illustrates the frequency and percentage of responses fitting within the 6 categories.

Table 14

Frequency and Percentage Distribution of Support Needed Categories According to Responses From 22 Participants

\begin{tabular}{lcc}
\hline \multicolumn{1}{c}{ Category } & Frequency & Percent \\
\hline None & 14 & 29.8 \\
N/A & 1 & 2.1 \\
Refresher course for new information & 4 & 8.5 \\
More screening forms & 1 & 2.1 \\
Need to use available support (web site) & 1 & 2.1 \\
Parent information & 1 & 2.1
\end{tabular}

\section{Did Participants Learn New Preschool Vision Screening Knowledge at VIC's Workshop?}

This section describes whether participants learned new preschool vision screening knowledge and whether scores differed from the pretest to the posttest. This section also describes whether education had an effect on score differences between the pretest and posttest.

To determine whether participants learned new preschool vision screening knowledge at VIC's workshop, pretest and posttest mean scores for 46 participants were compared for 
differences. Identical tests were administered at the beginning of each workshop and, again, at the conclusion of each workshop. Scores between the two tests were reported by the number and percentage of participants who scored lower on the posttest than the pretest, the same on both tests, and higher on the posttest than on the pretest.

Differences in mean scores for 46 participants indicated that participants learned new preschool vision screening knowledge. Of the 46 participants, 44 (98\%) scored higher on the posttest than the pretest, while $1(2 \%)$ scored the same on both tests, and $1(2 \%)$ scored lower on the posttest than the pretest. The mean score was 2.93. Table 15 illustrates the mean scores difference between the workshop pretest and posttest according to frequency and percentages.

\section{Table 15}

Frequency and Percentage Distribution of Scores Between the Workshop Pretest and Posttest for 46 Participants

\begin{tabular}{lcr}
\hline \multicolumn{1}{c}{ How scored } & Frequency & Percent \\
\hline Higher on the posttest; lower on the pretest & 44 & 97.9 \\
Same on both tests & 1 & 2.1 \\
Lower on the posttest; higher on the pretest & 1 & 2.1
\end{tabular}

To determine whether mean differences on participants' scores between the pretest and posttest were significant, a repeated measures $t$ test was conducted with a significance level of $p$ $<.05$. The repeated measure was scores on the pretest and the posttest. Forty-six (98\%) of 47 participants completed both tests. On average, participants' scores significantly increased from the pretest $(M=16.04, S E=.62)$ to the posttest $(M=22.63, S E=.44, t(45)=-10.94, p<.001)$.

To determine whether a significant difference in scores occurred due to education, a repeated measures ANOVA test was conducted, with the significance level set at $\alpha=.05$. Independent variables included pretest, posttest, and 3 levels of education. The repeated measure was scores. The interaction term for the independent levels of pretest/ posttest and the betweensubjects independent level of education was not significant, with $F=.712(d f 1=2, d f 2=42), p$ $>.05)$. This allowed analysis of the within-subjects factors of pretest and posttest to be conducted. The estimated marginal means were 16.038 at pretest and 22.415 at posttest. The analysis of the within-subjects factors of pretest and posttest was significant with $F=83.146$ ( $d f 1$ $=1, d f 2=42, p<.001)$, indicating that the difference in mean scores between the pretest and the posttest was significant. The test for the between-subjects independent variable of education was 
not significant with $F=.923(d f 1=2, d f 2=42, \mathrm{p}>.05)$, indicating that the null hypothesis of no statistical significance cannot be rejected and that the score differences between the pretest and posttest were significant regardless of participant education level.

\section{Did Participants Maintain Knowledge Learned at VIC's Workshop?}

This section describes whether participants maintained new preschool vision screening knowledge and whether scores differed from the workshop posttest to the 3-month posttest. This section also describes whether education had an effect on score differences between the posttest to the 3-month posttest.

To determine whether participants maintained knowledge learned at VIC's workshop, workshop posttest and 3-month posttest mean scores for 26 participants were compared for differences. Identical tests were administered at the beginning of each workshop, at the conclusion of each workshop, and, again, 3 months after each workshop. Scores between the two tests were reported by the number and percentage of participants who scored lower on the posttest than the pretest, the same on both tests, and higher on the posttest than on the pretest.

Differences in mean scores for 26 participants indicated that participants maintained vision screening knowledge at the workshop. However, it is unknown whether participants truly maintained knowledge from the posttest to the 3-month posttest because some participants reviewed job aids to complete the 3-month posttest. An additional question on the 3-month posttest asked participants to disclose which job aid they reviewed to complete the posttest. Of the 26 participants completing the 3-month posttest, 18 (69\%) reviewed job aids and $8(31 \%)$ did not review job aids. One participant did not complete this item. However, participants who reviewed job aids scored both lower and higher on the 3-month posttest than they scored on the posttest administered at the conclusion of each workshop. Of the 26 participants completing the 3-month posttest, $16(62 \%)$ scored higher on the 3-month posttest, 12 (75\%) of the 16 reviewed job aids and $4(25 \%)$ did not. Two of the 26 participants $(8 \%)$ scored the same on both tests; 1 $(50 \%)$ reviewed job aids, $1(50 \%)$ did not. Eight (31\%) of the 26 participants scored lower on the 3-month posttest; 4 (50\%) reviewed job aids, 3 (38\%) did not, and 1 (13\%) left the item blank. Information regarding participants who did and did not review job aids to complete the 3-month posttest is visually presented in Table 16. 
Table 16

Frequency Distribution of Reviewing Job Aids to Complete 3-Month Posttest

\begin{tabular}{|c|c|c|c|c|c|c|}
\hline How scored & $\begin{array}{c}\# \\
\text { participants } \\
\text { of } 26\end{array}$ & $\begin{array}{c}\text { Frequency: } \\
\text { Reviewed } \\
\text { job aids }\end{array}$ & $\%$ & $\begin{array}{l}\text { Frequency: } \\
\text { Did not } \\
\text { review job } \\
\text { aids }\end{array}$ & $\%$ & $\begin{array}{c}\text { Blank } \\
\text { item }\end{array}$ \\
\hline $\begin{array}{l}\text { Higher on } 3 \text {-month posttest; } \\
\text { lower on workshop posttest }\end{array}$ & 16 & 12 & .75 & 4 & 0.25 & 0 \\
\hline Same on both tests & 2 & 1 & .50 & 1 & 0.50 & 0 \\
\hline $\begin{array}{l}\text { Lower on 3-month posttest; } \\
\text { higher on workshop posttest }\end{array}$ & 8 & 4 & .50 & 3 & 37.5 & 1 \\
\hline
\end{tabular}

Of the 26 participants completing the 3-month posttest, $16(62 \%)$ scored higher on the 3 month posttest than they scored on the workshop posttest; $2(8 \%)$ scored the same on both tests, and $8(31 \%)$ scored lower on the posttest than the pretest. The mean score was 2.31 .

The frequency distribution of differences in workshop posttest and 3-month posttest suggests that participants maintained vision screening knowledge at VIC's workshop. Table 17 illustrates the mean scores differences between the workshop posttest and the 3-month posttest according to frequency and percentages.

Table 17

Frequency and Percentage Distribution of Scores Between the Workshop Posttest and 3-Month Posttest for 26 Participant

\begin{tabular}{lcc}
\hline \multicolumn{1}{c}{ How scored } & Frequency & Percent \\
\hline $\begin{array}{l}\text { Higher on the 3-month posttest; lower on the workshop } \\
\text { posttest }\end{array}$ & 16 & 61.5 \\
Same on both tests & 2 & 7.7 \\
$\begin{array}{l}\text { Lower on the 3-month posttest; higher on the workshop } \\
\text { posttest }\end{array}$ & 8 & 30.8 \\
\hline
\end{tabular}

To determine whether differences on participants' scores between the posttest and the 3month posttest were significant, a repeated measures $t$ test was conducted with a significant level of $\alpha=.05$. The repeated measure was scores on the pretest and the posttest. Twenty-six (55\%) of 47 participants completed both tests. On average, participants' scores significantly increased 
from the workshop posttest $(M=22.88, S E=.63)$ to the 3 -month posttest $(M=24.81, S E=.52$, $t(25)=-2.34, p<.05)$.

To determine whether a significant difference in scores occurred due to education, a repeated measures ANOVA test was conducted, with the significance level set at $\alpha=.05$. Independent variables included workshop posttest and 3-month posttest, and 3 levels of education. The repeated measure was scores. The interaction term for the independent levels of workshop posttest/3-month posttest and the between-subjects independent level of education was not significant, with $F=.204(d f 1=2, d f 2=22), p>.05)$. This allowed analysis of the withinsubjects factors of workshop posttest and 3-month posttest to be conducted. Although participants with no college degree scored lower on the 3-month posttest than participants working toward a degree or with a degree, scores were not significantly lower. Similarly, while participants with a degree scored higher than participants working or a degree or with no degree, scores were not significantly higher. The estimated marginal means for education level were 23.286 for "no college degree," 23.333 for "working on college degree," and 24.200 for "with college degree." The analysis of the within-subjects factors of workshop posttest and 3-month posttest was not significant with $F=2.731(d f 1=1, d f 2=22, p>.05)$, indicating that the difference in scores when participants were placed in three educational levels was not significantly different. The test for the between-subjects independent variable of education was not significant with $F=.517(d f 1=2, d f 2=22, p>.05)$, indicating that the null hypothesis of no statistical significance cannot be rejected and that the difference in scores between the workshop posttest and 3-month posttest was significant regardless of participant education level.

\section{Job Aids Participants Reported Using to Transfer Knowledge From the Workshop to Practice}

To determine the job aids participants used to transfer learned knowledge from the workshop to the workplace, responses to Items 3, 3.a., 3.b., and 3.c. from the Postworkshop Evaluation were counted and described in frequencies and percentages for 27 (57\%) of 47 participants who completed this instrument. Job aids include a handout packet with material from the workshop; a 1-page Vision Screening At-A-Glance Flowchart, which describes the steps to follow when screening vision; and a password-protected Screener Support web site, which includes slides from the workshop, as well as other material screeners can access to refresh screening knowledge and skills. To review the items to answer this Research Question, refer to Appendix H for Postworkshop Evaluation. 
Item 3 of the Postworkshop Evaluation asked participants to rate on a 3-point Likert-type scale_-anchored by "Not helpful" and "Extremely helpful": (a) $1=$ Not helpful, (b) 2 = Sort of helpful, and (c), 3 = Extremely helpful—how well the three job aids helped them refresh knowledge and skills learned at the workshop. Item 3.a., an open-ended item, asked participants to describe which job aid was most helpful? Item 3. b. asked participants to describe material reviewed in the job aid they selected in Item 3. a. Finally, Item 3. c. asked participants to report when they reviewed job aids. Choices were (a) within the week after the workshop, (b) during the week before screening, (c) between a week after the workshop and the week of screening, and (d) other.

Of the 27 participants who completed the Postworkshop Evaluation, 25 (93\%) responded to the Handout Packet component of Item 3, regarding the helpfulness of the Handout Packet, Web Site, and Vision Screening At-A-Glance Flowchart for refreshing knowledge and skills learned at the workshop;13 (48\%) responded to the Web Site component; and $22(81 \%)$ responded to the Flowchart component. For Item 3.a., regarding which job aid was most helpful, $26(96 \%)$ of 27 participants responded. For Item 3. b., regarding which job aids were used, 22 $(81 \%)$ of 27 participants responded. For the section of Item 3. b., regarding material reviewed in job aids, only 5 (19\%) of 27 participants responded. In retrospect, it is possible this item confused participants. For Item 3.c., regarding when job aids were reviewed, 26 (96\%) of 27 participants responded. Frequencies and percentages are reported according to the number of participants that responded to individual items out of the 27 that completed this instrument.

Regarding the helpfulness of job aids, the majority of participants reported finding both the Handout Packet and the Vision Screening At-A-Glance Flowchart more helpful than the web site for refreshing knowledge and skills learned at the workshop. Most reported that the Flowchart was more helpful of the three job aids. In fact, the web site was not mentioned. Of 26 participants responding to this item, 3 (12\%) listed the Flipchart (perhaps confusing the screening test name of Flipchart with the job aid name of Flowchart), 15 (58\%) listed the Vision Screening At-A-Glance Flowchart, 6 (23\%) listed the Handout Packet, and 2 (23\%) listed both the Flowchart and Handout Packet as job aids they considered more helpful. The majority of participants reviewed job aids during the week before they screened children. Table 18 provides the frequencies and percentages of responses to Items 3, 3.a., 3.b., and 3.c. 
When Participants Reviewed Job Aids

\begin{tabular}{|c|c|c|c|}
\hline When reviewed & Frequency & $\%$ & Total responses of 27 \\
\hline Within the week after the workshop & 4 & 15.4 & 26 \\
\hline During the week before screening & 16 & 61.5 & 26 \\
\hline $\begin{array}{l}\text { Between a week after the workshop and the week } \\
\text { of screening }\end{array}$ & 1 & 3.8 & 26 \\
\hline $\begin{array}{l}\text { Within the week after the workshop and during the } \\
\text { week before screening }\end{array}$ & 1 & 3.8 & 26 \\
\hline $\begin{array}{l}\text { Within the week after the workshop and between a } \\
\text { week after the workshop and the week of screening }\end{array}$ & 3 & 11.5 & 26 \\
\hline $\begin{array}{l}\text { Within the week after the workshop, during the } \\
\text { week before screening, and between a week after } \\
\text { the workshop and the week of screening }\end{array}$ & 1 & 3.8 & 26 \\
\hline
\end{tabular}

\section{Events Occurring During Vision Screening That Were Not Discussed in VIC's Workshop}

To determine experiences participants encountered during screening that were not discussed in VIC's workshop, responses to Item 2.a. of the Postworkshop Evaluation were analyzed using content analysis as the data analysis technique (Johnson \& LaMontagne, 1993; Patton, 2002). See Appendix H, Postworkshop Evaluation, to review this item.

Written responses were reduced to 6 categories, with 4 including more than one component: (a) Follow-up to failed screening, (b) N/A, (c) Nothing, (d) Screening: Achieving child and parent cooperation, (e) Screening: Achieving child cooperation, and (f) Screening environment: Distraction. "NA" and "Nothing" were separated because "N/A" could be interpreted as "nothing occurred" or "this item is non-applicable to me." Table 19 provides further clarification of analysis for this item, including frequencies and percentages for the six categories and specific examples. 
Table 19

Frequency/Percent of Categorical Responses From 27 Participants Regarding Experiences That Occurred During Screening Which Were not Discussed in the Workshop

Categories $\quad$ Frequency Percentage

Follow-up to failed screening: Pediatricians stating vision is "good" $\quad 1 \quad 3.7$

$\begin{array}{lll}\text { N/A } & 2 & 7.4\end{array}$

Nothing $\quad 10 \quad 37.0$

Screening: Achieving child and parent cooperation $\quad 1 \quad 3.7$

$\begin{array}{lll}\text { Screening: Achieving child cooperation } & 8 & 29.6\end{array}$

$\begin{array}{lll}\text { Screening environment: Distractions } & 5 & 18.5\end{array}$

Comments Within "Nothing” Category

Can't think of anything

Everything went as planned. The child was a little hesitant with the eye patch, but we talked about that in training.

Nothing

Subject well covered

Comments Within "Screening: Achieving Child and Parent Cooperation"

How to deal with certain children's behaviors and parental refusal

Comments Within "Screening: Achieving Cooperation"

Alternative ways to screen young 3 year olds

Children that will not cooperate

Children who are too young/mature to understand

Some 3 yr olds had difficulty. Ways to make them more comfortable. They needed rescreened not referred.

Sometimes for children that don't understand, it (tests) can be quite time consuming. How many attempts should be made or how much time spent with child before determining to rescreen or refer.

The only thing I can think of is there was alot of peeking. It was hard to keep them from peeking and using both eyes.

Comments Within "Screening environment: Distractions

Children who are unscreenable due to distractions, fear, etc.

Distraction was a problem.

Other children present answering for child you were screening. Since we have a lot of parent participation, they have a lot of questions about vision.

Having to many children in same room.

The noise \& distractions were more of a problem we had not anticipated. 


\section{CHAPTER 5}

\section{Summary of the Statement of the Problem}

The purpose of this program evaluation study was to explore, from the perspective of Head Start personnel, whether the Vision Initiative for Children (VIC) prepares Head Start personnel to screen the vision of preschoolers and whether Head Start participants encounter screening experiences that were not discussed during VIC's workshop. Though the sample size was small and it is unknown whether a larger sample size would have yielded the same effects as found in this study, this study yielded perceptions that were primarily positive. And, the positive perceptions permit insights into what workshop content should contain and how that content should be delivered, as well as experiences encountered during practice that were not discussed during the workshop.

This program evaluation study captured perceptions of 47 Head Start participants through an evaluation administered at the end of each workshop and 27 of the 47 participants through a postworkshop evaluation completed after participants screened vision. The workshop evaluation determined participant perceptions of the workshop's instructional content and delivery system, the instructor's skills in teaching and delivering the content, and the logistical arrangements of the workshop. The postworkshop evaluation determined participant perceptions of the workshop after they screened vision. The overarching questions for the postworkshop evaluation were: "Now that you have screened vision, tell me how the workshop worked, or did not work, for you?" and "Do you believe the workshop adequately prepare you to screen vision?"

The majority of Head Start participants who completed the workshop evaluation gave high scores to the workshop and, thus, reported positive perceptions of the workshop's instructional content and delivery system, instructor skills, and logistical arrangements. The majority of Head Start participants who also completed the postworkshop evaluation gave high scores to the workshop, thus suggesting that they perceived the Vision Initiative for Children's preschool vision screening model positively after screening vision. Moreover, perceptions were similar regardless of participant education level.

\section{Summary of the Research Methodology}

Fifty-nine participants from 6 workshops conducted for this study met the eligibility criteria: (a) employed by Head Start and (b) attending VIC's workshop for the first time. 
Additionally, participants were eligible to participate in this study if they were employed by a school system but worked at a Head Start agency through a collaborative arrangement.

Of the 59 eligible participants, 47 (80\%) completed West Virginia University Institutional Review Board (IRB)-approved Consent and Information forms, and all workshop instruments, except for 1 who did not complete the posttest. Twenty-seven of the 47 (57\%) completed postworkshop instruments, except for 1 who did not complete the 3-month posttest. To determine whether the workshop met the needs of individuals from diverse educational backgrounds, education attainment was categorized into 3 levels for statistical analysis: (a) no college degree, (b) working toward a degree, and (c) college degree.

This study included 5 instruments to answer 6 research questions and 12 subquestions related to the problem statement. In addition to a document that collected demographic information, instruments included (a) a pretest, (b) a posttest, (c) an evaluation completed at the workshop, (d) a postworkshop evaluation completed after participants screened vision, and (e) a 3-month posttest (see Appendixes F for Pretest/posttest/3-month posttest, G for the Workshop Evaluation, and $\mathrm{H}$ for the Postworkshop Evaluation). The pretest was designed to determine vision screening knowledge participants brought to the workshop. The posttest was designed to determine whether participants learned new vision screening knowledge. The workshop evaluation was designed to determine participant perceptions of the workshop across the areas of (a) instructional content and the delivery of that content, (b) the instructor's skills, (c) the logistical arrangements of the workshop, and (d) the overall workshop. The postworkshop evaluation was designed to determine participant perceptions of the workshop after they implemented vision screening. The 3-month posttest was designed to determine whether participants maintained knowledge learned at the workshop. Participants could complete postworkshop instruments online or as mailed documents. Of the 27 participants completing postworkshop documents, 4 (15\%) competed these documents online and 23 (85\%) completed the mail documents or completed documents transmitted via e-mail and returned via facsimile machine.

\section{Conclusion of Research Findings}

Twenty-five of 27 participants (93\%) reported that the workshop was effective. Thus, research results pertaining specifically to the purpose of this program evaluation study suggest that VIC prepared this sample of Head Start personnel to screen vision. This high percentage also 
suggests that participants believed the workshop was effective regardless of education level.

Results also indicated that participants either encountered no vision screening experiences (44\%) that were not discussed in the workshop or they encountered screening experiences pertaining to soliciting child and/or parent cooperation for screening or distracting screening environments (52\%). One participant reported that the workshop failed to describe that children may fail a vision screening while the child's pediatrician reported the child had "good" vision. Only one participant encountered challenges with parent cooperation for the screening, which is high atypical of the researcher's experience. Child cooperation challenges included one participant who reported problems with children trying to peek around occluders and three who reported challenges with screening young 3-year-olds. One participant wanted to know the number of attempts to make before concluding that the child is untestable.

Major findings were (a) watching the instructor model and demonstrate the vision screening tests (for $98 \%$ of participants) and (b) practicing the tests (for $100 \%$ of participants) were necessary parts of the workshop. Receiving feedback during practice (for $96 \%$ of participants) and the animated Microsoft PowerPoint presentation (for $92 \%$ of participants) enhanced participants' learning. Additionally, participants reportedly preferred the Vision Screening At-A-Glance Flowchart as a job aid for transferring knowledge from the workshop to the workplace, followed by the Handout Packet and the password-protected Screener Support Web Site.

\section{Relationship of Findings Regarding the Purpose of the Study to Previous Research}

To relate findings regarding the purpose of this study to previous research is difficult because the literature review did not yield studies of preschool vision screening training programs. However, the literature review yielded numerous scholarly writings espousing the importance of preschool vision screening and problems that arise when vision screeners are improperly trained, or not trained at all. This section describes the pertinent research and expert comments regarding the need for preschool vision screening training programs and properly trained screeners.

As many as 1 in 10 or 20 (5\% to 10\%) preschool-aged children experience undetected vision disorders that can lead to permanent vision impairment if these disorders remain undetected and treated (Calonge, 2004). Common early childhood vision problems include amblyopia (lazy eye), strabismus (misaligned eyes), and abnormal refractive errors (near- and 
farsightedness and astigmatism). Vision screening with proper tests can detect these vision disorders at a time when achieving good vision outcomes is more likely to occur, preferably before children reach age 4 (McManaway, n.d.; Giangiacomo \& Morey, 2005; Jakobsson et al., 2002; Simon and Kaw, 2001a).

Although preschool children generally can function, and learn, using one healthy eye when vision in the other eye is severely reduced (Dubowy, 2005; Koller \& Goldberg, 2000), some researchers have linked vision problems with young children who are at risk for academic, behavioral, and social development problems, such as those who have low self-esteem as a result of experiencing ridicule for their misaligned eyes or for wearing patches (Johnson et al., 1996; Käsmann-Kellner \& Ruprecht, 2000; Koller \& Goldberg, 2000; Romano, 1990). Moreover, children with undetected and untreated vision problems grow into young and older adults with visual impairment, or permanent vision loss when older adult eye disease, such as macular degeneration, affects the healthy eye. When compared with the general population, individuals with amblyopia are at a higher risk of becoming blind (Kemper et al., 2004; Tommila \& Tarkkanen, 1981). Chua and Mitchell (2004) found that individuals with amblyopia were three times more likely to experience vision loss in their better seeing eye when compared to individuals without amblyopia. Finally, Rahi et al. (2002) found that individuals with amblyopia possessed a lifetime risk of $1.2 \%$ to $3 \%$ for serious vision loss in the better eye.

Many non-ophthalmic lay individuals on the front-line of vision screening, such as Head Start personnel, operate under mandates to screen vision, but approach this mandate without formal training, proper tests, or knowledge regarding the vision disorders they should detect. With insufficient training, these individuals will oftentimes modify screening protocols, which may significantly reduce the detection of amblyopia (Marsh-Tootle, 1998). Regardless of the test modality used to detect vision disorders in young children, test performance is dependant on adequate training in test administration; accordingly, a training and certification process would help ensure that lay individuals adequately administer screening tests (Simons, 1996).

When these individuals do receive formal training, it is probable that they are trained by instructors who lack knowledge regarding how to help adults learn. Many instructors may possess expertise in the task of screening vision, but lack knowledge in the instructional process of how to teach others, especially adults. A classic mistake in adult education occurs when instructors believe that knowing a subject is enough to teach the subject, effectively 
(Wlodkowski, 1999). For example, McLeod et al. (2003) maintained that clinical teachers rarely receive formal or informal instruction in how to teach, yet tend to assume that expertise as a practitioner will automatically translate into effectiveness as a teacher. Many adult educators are well grounded in the subject they teach, but lack preparation in the instructional process of helping adults learn (Galbraith, 2004). Moreover, individuals who graduate from programs that prepare college teachers often are not trained in how to teach (Apps, 1981).

Various experts in the preschool vision screening field have advocated for training to prepare lay individuals to screen vision:

1. Because diverse individuals screen vision, "there is a clear need for some means of assuring that a screener has the necessary expertise to use a given test effectively" (Simons, 1996, p. 22).

2. A training and certification process would help ensure that lay individuals adequately administer screening tests (Simons, 1996).

3. Direct, practical training in vision screening may improve clinical support staff comfort when screening the vision of preschoolers (Hered \& Rothstein, 2003) [while Hered \& Rothstein were referring to primary care medical staff, it is probable that direct, practical training would also improve the comfort of Head Start personnel in screening vision].

4. Individuals screening children must be trained and certified in the proper use of screening tests (Fulton, 1992).

5. Without special training in vision screening, "mistakes and errors in visual evaluation cannot be avoided completely” (Käsmann-Kellner \& Ruprecht, 2000, p. 205).

6. Appropriate training of vision screening personnel would help bring about early detection and rehabilitation of amblyopia (Menon et al., 2005).

VIC's Preschool Vision Screening Training Model incorporates assumptions regarding adult learners, teaching suggestions found in the literature, age-appropriate vision screening tests, ongoing support, and an initial certification/recertification process. Though the sample size for this program evaluation study was small, results clearly suggest that VIC's preschool vision screening training program, with minimal revisions, could serve as a training and certification process for teaching lay individuals to screen vision. At the least, individuals who are designing preschool vision screening programs or teaching others to screen the vision of preschoolers could use VIC's model as a guideline. 


\section{Limitations}

This section describes six limitations. The first limitation pertains to the workshop evaluation, which included items that may have confused participants. For example, Item 1 on the last page of the workshop evaluation asked participants to check boxes of the job aids they would review to refresh knowledge and skills. Available items were: Handout packet, Vision Screening At-A-Glance Flowchart, Website, Both, and Neither. The "Both" should have read: All three. Item 14 of the pretest/posttest asked participants to describe their response if a child failed one eye on one test, but passed with the other eye and also passed the second test. The correct answer was: "c. Encourage the parent/guardian to schedule and attend a comprehensive eye exam." Because some agencies automatically rescreen children before referring a child for an eye exam, (the b. response), the researcher accepted both "b." and "c." as correct responses. Item 16 of the Instructional Content and Delivery System of the workshop evaluation regarding humor should have stated: "Did the instructor's use of humor hold your attention?" The goal of this item was not that humor and laughter helped participants learn, but, rather, the goal was to determine whether humor held their attention, which enhances learning (Wlodkowski, 1999). Finally, Item 3 of the postworkshop evaluation must have confused participants. Few participants completed 3.b., which asked them to describe material reviewed in each of the three job aids. Consequently, editing and field testing must occur before implementing this instrument in the future.

A second design limitation also pertains to the workshop evaluation. Scores in the Logistical Arrangements subscale, overall, were lower than scores for other subscales, which is not atypical to the researcher's experience in conducting 87 workshops. To provide more meaningful information for this study, however, the Logistical Arrangements subscale should have included items asking whether, and how, logistical arrangements affects participants.

A third limitation involves the password-protected Screener Support Web Site job aid. Although $70 \%$ of the 47 participants had Internet access, the password-protected web site was not online at the beginning of the study. Consequently, some participants screened vision before the web site was available to participants during the week of October 18, 2004. Though only one participant reported challenges to logging onto the web site, it is unknown whether web site usage would have differed if the web site were live at the beginning of the study. Whether additional participants encountered problems logging on is also unknown. 
A fourth limitation involves the researcher's dual role of instructor and researcher, while may, or may not, have influenced results. Knowles (1980), however, maintained that instructors "next to the participants themselves, are in the best position to judge the results achieved" p. 204. The researcher diligently attempted to remain objective to ensure the dual role did not contaminate the study. Additionally, the researcher minimized contact with participants, which is one method for controlling contamination (Gorard, 2001).

The fifth limitation pertains to the small sample size and unequal education groups. For example, knowing whether this study included enough participants to achieve sufficient statistical power for stating that scores were similar regardless of education level is unknown. Further, it is unknown whether results would have differed had the study included 100 or 500 participants with equal numbers in each education group or if all 47 participants had completed all instruments. Ensuring that all participants complete a full study is nearly impossible, which is supported by Gorard (2001), who stated:

In an ideal world you, as a researcher, would select a high quality sample, and all of those people selected to participate in the study would agree to do so. In reality this will not happen. Cases will be lost to non-response in at least two ways. Some cases will provide no data at all. People selected by you will refuse to participate in your experiment, or will not return your questionnaire. Part-cases will also be lost where only incomplete data is [sic] collected" p. 26.

It is possible that a larger proportion of the 47 participants who started the study would have completed the study if notices had been consistently e-mailed or mailed to remind participants to complete the postworkshop evaluation and 3-month posttest.

Finally, the seventh limitation pertains to the opportunistic sample, or those Head Start participants who were scheduled for training prior to implementing this study. For example, one workshop included 27 participants, but 13 of the 27 (48\%) were not required to screen vision as part of their job title, which the researcher did not learn until the workshop began. Participants agreed to screen children for the study, but 10 of the $13(77 \%)$ did not. For a similar future study, the researcher should include a study eligibility criterion that participants are required to screen vision as part of the job title they hold. 


\section{Recommendations}

Guskey (2000) and Kirkpatrick (1998) maintained that evaluation helps identify what worked, what did not work, and what can be improved. Accordingly, because this study was a program evaluation study, this section describes workshop components that worked well and components that can be improved, as well as ways to make these improvements.

Recommendations are based on results of this program evaluation study. Additionally, each component includes supportive literature culled from the literature review in Chapter 2, unless the review lacked relevant literature.

\section{Workshop Components That Worked Instructional Content and Delivery System}

Participant reports suggested that the following five components of the Instructional Content and Delivery System worked well and do not require improvement (all but one component includes related literature):

1. Clear and realistic training objectives and amount of time allotted to each topic. This component supports the $3^{\text {rd }}$ of the researcher's 17 Assumptions Regarding Adult Learners as They Relate to Preschool Vision Screening Training Workshops described in Chapter 2, which states that adult learners want to know instructor's expectations for them, where they are going, and how they will get there. Further, findings confirm contentions that adult learners want to know what the instructor expects of them as learners, what is expected of them in the teaching and learning transaction, where they are going in terms of an end goal, and how they are going to get there (Galbraith, 1994).

2. Animated PowerPoint presentation to support lecture. Knowles (1992) suggested that participant engagement in learning increases with the use of visual aids. Szarek (1996) stated that visuals "provide interest, sharpen attention and increase retention" (p. 13). Ninety-two percent of participants reported that VIC's animated PowerPoint presentation helped them learn about preschool vision screening, which confirms Mentch's (2002) findings. Mentch studied possible learning and attitudinal benefits of 107 college students who participated in lecture only, lecture with still pictures, and lecture with animated graphics experimental conditions. Mentch found that learner scores were significantly higher for students in the lecture with animated graphics group than students in both the still picture group and the lecture only group. 
3. Instructor's modeling and demonstration of tests. Lecture, alone, is ineffective for teaching specific motor skills and is oftentimes incomplete without supplemental demonstration to help adult learners understand how something works, as well as the procedures involved in making that something work, which ultimately helps achieve a behavioral outcome of understanding, and assists in applying and generalizing newly learned information (Gilley, 2004; Guild, 1996; Knowles, 1980).

4. Practicing the tests and receiving instructor feedback. Mackie (1981) and Spitzer (1996) maintained that instructors should provide learners with opportunities to practice, which helps learners "reach a level of automatic implementation on the job" (Garavaglia, 1993, p. 66). Not only should instructors provide learners the opportunity to practice a new skill, but instructors should also provide immediate feedback to learners about their performance (Dick et al., 2001; Mackie, 1981; Wlodkowski, 2004).

5. Providing theory about the importance of screening vision of preschoolers. Theory in the inservice environment has been defined as "the rationale, theoretical base, and verbal description of an approach to teaching or a skill or instructional technique" (Joyce \& Showers, 1980, p. 382). Translating this definition to the vision screening workshop, theory could be described as providing to learners research-based or scholarly information regarding the importance of preschool vision screening and the approach, or vision screening tests and methodologies, used specifically to screen vision of preschoolers.

The more effective workshop components of the Instructional Content and Delivery System, which received the higher participant scores, were (a) watching the instructor model the screening tests and demonstrate the tests with a participant, (b) practicing using the tests with a peer participant, (c) receiving instructor feedback during practice, and (d) viewing the animated PowerPoint presentation.

\section{Instructor Skills}

Participant reports suggest that the following 11 Instructor Skills were present and do not require improvement (each skill includes related literature):

1. Exhibiting enthusiasm. An enthusiastic and energetic instructor helps motivate learners (Caffarella, 2002; Davis, 1993; Wlodkowski, 1998). Davis also maintained that learners lose interest in the subject matter if the instructor appears bored. Additionally, three participants 
mentioned the instructor's enthusiasm when responding to the workshop evaluation openended item regarding what they liked best about the workshop.

2. Holding participants' interest. Gagne (1985), listing attention as the first of his nine instructional events for helping ensure that learning occurs, suggested that to prepare learners to receive new information, an instructor must first gain the learner's attention. Additionally, Pike (2003) asserted that success is “50 percent assured if your audience's interest is working for you from the beginning" (p. 23). One participant responding to the workshop open-ended item regarding what they liked best about the workshop indicated that the instructor "kept our interest" and another wrote "motivating presenter."

3. Using high-quality teaching materials. Chapter 2 lacked literature supporting this skill.

4. Focusing training on workshop objectives. Adult learners want to know what instructors expect of them as learners, their role in the teaching and learning transaction, where they are going in terms of an end goal, and how they are going to get there (Galbraith, 1994). Sarasin (1999) maintained that adult learners "are more likely to participate with enthusiasm and confidence if they understand why they are doing an activity and what is expected of them" (p. 22).

5. Using training time effectively. Although no literature surfaced to explicitly support this skill, Wlodkowski (1999) stated that "time is precious to adults" (p. 160) and Kidd (1973) suggested that adult learners are likely to consider the investment of their time in training as important as the cost of the training or the amount of effort training may require. If training time is used ineffectively, workshops are likely to continue beyond the scheduled stop time, which Mackenzie (1990) maintained can result in resentment from participants who scheduled other activities following the meeting. One participant responding to an openended item regarding general comments wrote that the workshop was "very well planned, organized, and taught well."

6. Possessing expert content knowledge. Galbraith (1991) maintained that implicit in the teaching/learning environment is an instructor's proficiency in content. Knowles (1980) stated that instructors should have knowledge about content and should be "successful practitioners of their subject or skill” (p. 157). Dean (2004) suggested that possessing content expertise is commonly associated with the characteristics of successful adult educators. To ensure learners attach meaning and value to the subject they are to learn, Galbraith (2004) 
maintained that adult instructors must be technically proficient in the content area they teach. Moreover, Brookfield (1991) contended that learners prefer to receive instruction from one whom they perceive has greater factual knowledge, skills mastery, and reasoning facility than they possess.

7. Helping participants feel comfortable. Merriam and Brockett (1997) maintained that the learning environment has a role in successful learning. For example, the learning environment should take into consideration physical and psychological components. An inadequate physical environment will interfere with learning; thus, the instructor must consider the physical setting, as well as the physical needs of the participants (Caffarella, 2002; Galbraith, 1992). The physical environment refers to training space, including room size, temperature, lighting, acoustics, seating type and arrangements, and how technology is arranged and used (Merriam \& Brockett, 1997). The psychological environment refers to a climate in which learners and the instructor can engage in genuine exchange (Merriam \& Brockett, 1997). This includes the instructor's helping learners feel welcome and at ease in the opening minutes of a learning activity, attending to the fears and doubts that adults may experience about the learning activity, and recognizing that learners come to the learning activity with a range of life experiences that could serve as learning resources, as well as other experiences that could detract from learning, such as time pressures, difficult work situations, and domestic concerns (Merriam \& Brockett, 1997). Such an environment includes a climate of mutual trust and respect, supportiveness, openness to challenge and criticism, risk taking, pleasure, and friendliness (Galbraith, 1991, 1992). It is interesting to note that one participant responding to an open-ended item in the workshop evaluation regarding what they liked best about the workshop specifically mentioned that the instructor was "pleasant and friendly." Conversely, in reporting what they liked least about the workshop, two participants commented about refreshments and three commented the room temperature was too cold.

8. Providing adequate help in learning new material. Taylor et al. (2000) defined teaching as “an imprecise, mysterious art" (p. 316), suggesting that no single teaching model works in all teaching/learning interactions. Thus, O’Meara (1996) and Sarasin (1999) suggested that instructors should be comfortable with various teaching techniques in order to maintain and renew interest and motivation, maintain a varied and exciting learning environment, and 
encourage active participation throughout the learning event. One participant responding to the open-ended item in the workshop evaluation regarding what they liked best about the workshop wrote: "Used variety of teaching/learning styles." In the open-ended general comments section, one wrote: "Impressed, did a really good job conveying information through multiple resources."

9. Answering questions and addressing concerns. Instructors must know the content they will teach and how to help learners understand the content (American Federation of Teachers, 2002). Answering questions and addressing concerns are ways to help learners understand the content.

10. Providing feedback during practice. Immediate feedback helps "shape and reinforce new learning" (Knox, 1977, p. 450) and enhances motivation because learners can evaluate their progress, understand their level of competence, and immediately correct errors (Wlodkowski, 2004). Listing the provision of feedback as his seventh of nine instructional events, Gagne (1985) stated that feedback "provides the learner with the confirmation (or verification) that learning has accomplished its purpose" (p. 75).

11. Being a good teacher. One of Caffarella's (2002) nine criteria to consider when obtaining instructors to teach adult learners pertains to knowing how to teach. This criterion states: "Instructors are competent in a number of instructional techniques and processes, match those techniques to their subject matter and the learners, and are able to use a variety of methods" (p. 300). Additionally, Dean (1994) stated that instructors should possess content expertise, as well as process expertise. Dean differentiated content and process expertise by defining content expertise as the knowledge and skill in content to be learned and defining process expertise as having knowledge and skill regarding how to help adults learn the content. One participant responding to the open-ended item in the workshop evaluation regarding what they liked best about the workshop wrote: "Used variety of teaching/learning styles." In the open-ended general comments section, one wrote: "Impressed, did a really good job conveying information through multiple resources." Participants also wrote that the instructor "made learning fun", "The instructor was great", the workshop was "very well planned, organized, and taught well", and another stated that the workshop was "fun, informative." 
Leading the list of instructor skills, which received $100 \%$ of responses, were (a) possessing expert knowledge of the content, (b) making an effort to help participants feel comfortable, (c) focusing training on objectives, and (d) answering participant questions and addressing their concerns.

\section{Logistical Arrangements}

While the majority of participants responded favorably to logistical arrangements, results indicated that all logistical components require improvement, which will be discussed in the next section. Reviewing logistical arrangements from a perspective of 5 years of preschool vision screening training experience, it was not surprising that participants rated this component of the workshop lower than other components. It is important to note, however, that instructors commonly lack control of refreshments, temperature, and seating. Instructors, however, can ensure that the training schedule is planned well and includes timely breaks.

\section{Workshop Components That Can Be Improved Instructional Content and Delivery System}

While participant tallied scores were primarily high in the Instructional Content and Delivery System subscale of the workshop evaluation, scores were below $90 \%$ for $8(47 \%)$ of the 17 items, suggesting room for improvement. The researcher arbitrarily selected $<90 \%$ as the point where improvements should occur. Nine improvements include:

1. Ensuring participants learn what they expected to learn. The instructor could ask participants at the beginning of the workshop to describe explicitly what they expect to learn during the workshop. Previous experience of the researcher, however, suggests that many participants will state they expect to learn to screen vision without expanding on exactly what they expect to learn.

2. Explicitly helping participants make the connection between vision disorder information and the vision disorders screening tests are designed to detect. Perhaps the wording of this item was confusing. Without interviewing participants, the researcher is unclear how to specifically improve this area.

3. Helping participants feel comfortable when encouraging parents to arrange follow-up eye exams when their children fail vision screening. Although the animated PowerPoint presentation and Handout Packet included information to share with parents about the importance of a follow-up eye exam when their children failed vision, 15\% of participants 
reported the information was "somewhat" helpful for encouraging parents to arrange a follow-up eye exam. As an improvement, the information sheet should be revised and the workshop schedule should include role play to practice talking with parents, which supports Sarasin's (1999) contention that role play and simulation enhances learning. Additionally, if funding permitted, a parent could join VIC as a team trainer. The parent, from an experiential perspective, could relay ways to encourage other parents to arrange a follow-up eye exam.

4. Helping participants feel prepared to screen vision at the end of the workshop. Although $98 \%$ of participants reported that watching the instructor model and demonstrate tests and $100 \%$ reported that practicing the tests were necessary parts of the workshop, and $96 \%$ reported that instructor feedback during practice enhanced their learning, 24\% reported they were "somewhat" ready to screen vision.

That $100 \%$ of participants reported practicing the tests were necessary parts of the workshop - and that hands-on practice was mentioned most often by participants reporting what they liked best about the workshop - confirms contentions that for learning to occur, learners should be active in the learning task (Ellis et al., 1994; Garet et al., 2001; Guild, 1996; Illeris, 2004; Sarasin 1999). However, although practicing helps learners transform an intellectual skill about how to do something into a motor skill (Dick et al, 2001) and practicing assists learners in mastering new skills (Joyce and Showers, 1980), that 24\% felt only "somewhat" ready to screen is of concern.

Regardless of how well the practice component is structured, the primary method for ensuring participants are ready to screen vision is for participants to screen children and not other adult participants. It is the researcher's experience, however, that structuring practice to include children is difficult. For example, including children would require one or more individuals to care for the children until the practice component began or workshops would need to occur only at facilities where children were readily available, such as child care centers or Head Start centers. This, however, would disrupt children in their normal, daily routine. In workshops subsequent to this study, the researcher has experimented with requesting screener pairs to practice tests in front of the full group, with members of the full group serving as coaches. While this activity provides repetition and reinforcement of what to do correctly and what to avoid during test administration, participants are not always 
comfortable practicing in front of the full group. The researcher has not yet, formally, evaluated this addition to the workshop.

Additionally, during the workshop participants are informed that they will likely need to screen vision of preschoolers five or six times before feeling completely comfortable using the tests, based on researcher experience. Perhaps adding this information to a slide will help participants feel prepared to screen vision at the end of the workshop.

5. Ensuring that the workshop's delivery system meets diverse learning styles. This improvement confirms the $14^{\text {th }}$ of the researcher's 17 Assumptions Regarding Adult Learners as They Relate to Preschool Vision Screening described in Chapter 2, which states that adult learners have individual differences in how they learn. Further, findings confirm contentions that adults have preferences for and different ways of processing information (American Federation of Teachers, 2002; Caffarella, 2002; Galbraith, 1992). Because the workshop includes lecture for auditory learners; animated PowerPoint slides, demonstration, and modeling for visual learners; and opportunities to practice tests for tactile/kinesthetic learners, and because two participants reported in open-ended comments that the instructor used multiple resources and methods to satisfy diverse learning styles, the researcher is unclear how to specifically improve this area without interviewing the five participants who reported the workshop "somewhat" met their learning styles.

6. Ensuring that the content is not too difficult to learn. While findings suggested that participants learned a significant amount of knowledge during the workshop and the handout packet included an information sheet on vision terms, some participants verbally indicated during the workshops that learning the names of vision disorders was overwhelming, which supports Gagne (1985), who contended that learning labels close together in time works against rapid learning. One participant specifically offered "not learning the definitions right away" as a component of the workshop she liked least. However, it is interesting to note that this participant did not report that the content was too difficult to learn, that she did not learn what she expected to learn, or that she did not learn what the workshop intended her to learn. Although the instructor verbally emphasized that knowing the names of vision terms was not critical to screening vision, it is possible that some learners equated difficulty remembering terms with their learning to screen vision. Without interviewing the eight participants for 
whom the content was explicitly not too difficult to learn, the researcher is unclear how to improve this area.

7. Ensuring that instructor humor and participant laughter maintains interest. Item 16 of this component of the workshop evaluation asked participants whether humor and laughter helped them learn. This item should have asked, instead, whether instructor humor and participant laughter maintained interest, which enhances learning (Wlodkowski, 1999). Without interviewing the seven participants who stated humor and laughter "somewhat" helped them learn, the researcher is uncertain how to improve this area.

8. Determining whether to keep the dancing chicken. The PowerPoint slides includes an animated slide with timed music and pictures of former American Idol William Hung, and a dancing chicken, which serves as a mini-break between topics, which was derived from contentions that the use of humor improves morale, enjoyment, comprehension, interest, and rapport (Cohen, 1996; Deming, 2001; Frymier \& Wanzer, 1998; Hassed, 2001; MacDonald, 2004; Neelam et al., 1999; Neuliep, 1991; Schwarz, 1989; Ulloth, 2002; White, 2001; Ziegler, 1999) while also motivating learners (Caffarella, 2002; Wlodkowski, 1999). The researcher's experience suggests that the majority of 1,000 participants enjoyed this segment. Additionally, in open-ended responses, one participant commented that she liked the music break and one suggested that the presentation include more slides of the dancing chicken. Because this item reversed the scoring scale, it is possible that participants circled the incorrect yes/no response. Without interviewing the five participants who appeared to be less favorable of the dancing chicken, the researcher is unclear how to specifically improve this area.

\section{Instructor Skills}

While participant scores were high overall, scores were below $90 \%$ for 3 of the 15 items in the Instructor Skills subscale of the workshop evaluation, suggesting that these areas could be improved. Because participants did not explain reasons for their responses, it is difficult to provide specific improvements to the workshop. Three improvements include:

1. Ensuring the workshop pace is neither too fast or too slow. This improvement confirms Keller's (1987b) contention that to sustain attention, and, thus, enhance learning, the instructor should alter the pace of instruction, as well as Witt (1996), who suggested that instructors should refrain from rushing the presentation pace, adding that participants will 
"learn quicker and remember it longer if they have a few seconds after each idea to process it fully" (p. 112). The animated PowerPoint presentation included slides that asked participants about the researcher/instructor's pace. Participants verbally acknowledged that the pace was appropriate, yet evaluation responses indicated the pace was not always appropriate. Perhaps the instructor could ask participants to close their eyes and indicate, by raising their hands, whether the pace was too fast or too slow. Without interviewing the eight participants who reported the instructor's pace was inappropriate, the researcher is unclear how to specifically improve this area. Additionally, it may be possible that the instructor's pace may never satisfy $100 \%$ of participants.

2. Knowing which topics were covered and which remained on the "to-do list." The PowerPoint presentation included slides which checked open boxes adjacent to topics that had been covered and remained to be covered. During the study workshops, because these slides bored the researcher or overwhelmed the researcher regarding remaining slides to cover, it clearly became apparent to the researcher that the slides were unnecessary and tended to possess the potential of overwhelming participants. Except for one slide at the beginning of the workshop to describe the steps the workshop would cover to reach the learning objectives and a summary slide at the end, other slides were removed from workshop presentations subsequent to this study.

3. Refraining from providing too much repetition or review. This component supports contentions of Knox (197) who maintained that reviewing the content is one strategy for helping adult learners remember new knowledge and skills, and Cross (1981), who theorized that an instructor's summarization of material assists adult learners in retaining and recalling information. It is possible that participants marked this item in response to the "to-do list" slides described in the previous paragraph. Or, it is possible that the review slides at the end of the PowerPoint presentation contained too many items. Without interviewing the 12 participants who were dissatisfied with repetition or review, the researcher is unclear how to specifically improve this area. 


\section{Logistical Arrangements}

Scores were below 90\% for each of the 5 items in the Logistical Arrangements subscale, suggesting that all areas require improvement. As stated earlier, oftentimes the instructor lacks control of logistical arrangements. Findings support the researcher's $15^{\text {th }}$ of 17 Assumptions Regarding Adult Learners as They Relate to Preschool Vision Screening Training Workshops described in Chapter 2, which states that adult learners want to feel safe, comfortable, and valued in the learning environment. Further, findings confirm contentions that many adult learners participate in learning with mixed feelings, self-consciousness, and fear about their personal learning abilities and are more receptive to the learning process when they are physically and psychologically comfortable: (a) where a non-threatening learning environment affords physical comfort, such as good illumination, absence of distractions, and appropriate temperatures; mutual trust and respect, mutual helpfulness, freedom of expression, and acceptance of differences; (b) where learners are encouraged to trust themselves, make mistakes, and try again; and (c) where learners have a comfortable degree of personal space (Brookfield, 1986; Caffarella, 2002; Cross, 1981; Gilley, 2004; Hiemstra \& Sisco, 1990; James, 1983; Kidd, 1973; Knowles, 1980; Long, 2002; Merriam \& Brockett, 1997; Sarasin, 1999; Smith, 1982; Thorndike, 1935; Zemke \& Zemke, 1996). Therefore, when the instructor can control logistical arrangements, the instructor should ensure that:

1. Refreshments are fresh and tasty.

2. Beverages are appropriately hot or cold and ready on time.

3. The room temperature meets the needs of the majority of participants.

4. Chairs are comfortable.

5. The workshop schedule is planned well and includes timely breaks.

\section{Screening Vision Following the Training Workshop}

Because 9 (33\%) of 27 participants indicated they encountered challenges obtaining child cooperation during vision screening activities, "Tips for Screening Reluctant Children" should be placed on the back of the Vision Screening At-A-Glance Flowchart. Additionally, because 5 (19\%) of 27 participants reported experiencing distracting screening environments, an improvement would involve placing "Tips for Creating A Screening-Friendly Environment" on the back of the Vision Screening At-A-Glance Flowchart. Both improvements are examples of job aids that "provide steps, illustrations, and examples that keep performance on track" (Rossett 
\& Gautier-Downes, 1991, p. 5). Moreover, the two improvements follow Gilley's (2004) contention that providing learners with information sheets outlining the steps to follow will help ensure that learners understand and follow those steps.

\section{Implications for Practice and Future Research}

Given limitations of this study, particularly the small sample size, results of this program evaluation study provide insights into components of a preschool vision screening workshop model that work well for participants. Results also provide insights into workshop components that require improvement.

\section{Implications for Practice}

Because the sample size of this program evaluation was small, instructors and curriculum designers are cautioned against generalizing findings to the larger population of Head Start personnel. However, study findings suggest that VIC's Preschool Vision Screening Training Model effectively prepared this sample of Head Start participants to screen the vision of preschoolers, regardless of education level. Therefore, especially if findings were similar with a larger sample size, VIC's model could serve as a certification program to train lay screeners. Additionally, findings suggest that preschool vision screening instructors or curriculum designers should ensure, at the least, that their workshops include: (a) modeling and demonstrating screening tests for participants, (b) providing participants the opportunity to practice administering screening tests, and (c) providing feedback during practice. Finally, these individuals should consider providing job aids to help participants transfer knowledge from the workshop to the workplace.

\section{Implications for Future Research}

Findings of this program evaluation study have implications for seven additional studies for future research. For example, VIC's 1,000 trained screeners would be invited to complete questionnaires designed to determine agreement or disagreement with the researcher's Eight Guiding Principles for Effective Preschool Vision Screening Training. Similarly, a second study could involve surveying VIC's 1,000 trained screeners to determine agreement or disagreement with the researcher's 17 Assumptions Regarding Adult Learners as They Relate to Preschool Vision Screening Training Workshops.

Because the sample size for this study was small, future research should involve revising instruments and the workshop, based on findings from this study, and conducting this study 
again with a broader group of screeners, including Head Start, school health nurses, and other individuals who request training. The design for this third study should include postworkshop observations to determine whether participants implement screening tests appropriately, as well as interviews when low scores occur and to enrich postworkshop evaluations after participants conduct their first screening activity. Additionally this third study would determine whether participants believe VIC's workshop incorporates findings of the previous two studies involving guidelines for vision screening workshops and assumptions regarding adult learners. To ensure noncontamination of results, however, VIC should contract a researcher and use multiple observers.

A fourth study involving VIC's trained screeners would be to survey those with valid email addresses to determine their reactions to VIC's password-protected Screener Support Web Site, why they do or do not access the site, and what would encourage them to use the site as a refresher job aid. Screeners commonly access the web site only to complete initial certification or recertification requirements.

A fifth study building off of this program evaluation study would involve conducting focus groups with parents to determine the most appropriate approach for encouraging parent/caregivers to arrange and attend a follow-up, comprehensive eye exam when their children fail vision screening. VIC has more than 14,000 screening events in its database. Parents of children who failed vision screening and attended eye exam appointments would be asked to participate in the study. A sixth study, a qualitative study also using parents currently in VIC's database, would involve telephone and/or face-to-face interviews to explore why a subset of parents immediately schedule and attend an eye exam; why others wait until they receive phone calls from VIC personnel to assist them in making appointments; why others schedule appointments, but do not attend the appointments; and why others do not schedule appointments. Findings could be compared with those of Mark and Mark (1999) and Yawn and Kurland (1998).

Finally, participants reported hands-on practice most often as workshop components they liked best. In fact, one participant specifically stated," "Practicing w/partner made me feel more comfortable."Additionally, 98\% of participants reported that watching the instructor model and demonstrate tests, 100 percent reported that practiticing the tests, and $96 \%$ reported that receiving feedback during practice helped them learn to screen vision. Providing instructorobserved practice sessions via a CD-ROM-based training format, where participants learn 
completely by interacting with the CD-ROM, appears to be impossible. Thus, a seventh study should compare participant reactions to face-to-face training with CD-ROM training. Such a study should also measure vision screening training knowledge obtained and vision screening tests conducted appropriately for each training model.

\section{Summary}

In conclusion, for this group of Head Start participants, VIC's Preschool Vision Screening Training Model prepared them for screening vision of children ages, 3, 4, and 5. During screening activities, participants encountered no experiences that were not discussed during the workshop while some experienced distracting screening environments or challenges involving child and or parent cooperation with screening. To assist future screeners, VIC will include Tips for Creating A Screening-Friendly Environment and Tips for Screening Reluctant Children on the back of the Vision Screening At-A-Glance Flowchart. Participants preferred the Flowchart and Handout Packet as job aids over the Screener Support Web Site and preferred the Flowchart over the Handout Packet. Additionally, participants reported watching the instructor model and demonstrate screening tests, practicing administering the tests, and receiving instructor feedback during practice as the top methods for learning to screen vision, which clearly has implications for CD-ROM-based training models. Finally, though the sample size was small, results provide insights into the content preschool vision screening training programs should provide and how that content should be delivered to assist lay screeners in their overarching goal of preventing children with untreated early childhood vision disorders from growing into adults who may lose vision in their healthy eye from older adult eye disease, such as macular degeneration. 


\section{References}

Adamson, G., O’Kane, D., \& Shevlin, M. (2005). Students' ratings of teaching effectiveness: A laughing matter? [Abstract]. Psychological Reports, 96(1), 225-226. Retrieved November 4, 2005, from the PubMed database.

Altintas, O., Etus, V., Etus, H., Ceylan, S., \& Caglar, Y. (2005). Risk of strabismus and amblyopia in children with hydrocephalus [Abstract]. Graefe's Archive for Clinical and Experimental Ophthalmology, 243(12), 1213-1217. Retrieved January 16, 2006, from the PubMed database.

American Academy of Pediatrics. (n.d.). Vision screening practices of pediatricians. Periodic Survey \# 22 [Electronic version]. Retrieved January 14, 2006, from http://www.aap.org/research/periodicsurvey/ps22ex2.htm

American Academy of Pediatrics. (2003). Eye examination in infants, children, and young adults by pediatricians [Electronic version]. Retrieved July 28, 2004, from http://aappolicy.aappublications.org/cgi/reprint/pediatrics;111/4/902.pdf

American Academy of Pediatrics. (2005). Preschool Vision Screening Initiatives. Retrieved February 18, 2006, from http://www.medicalhomeinfo.org/screening/vision.html American Federation of Teachers. (2002). Principles for professional development: AFT's guideliens for creating professional development programs that make a difference [Electronic version]. Retrieved February 27, 2004, from http://www.aft.org/pubsreports/downloads/teachers/PRINCIPLES.pdf

Appelboom, T. M. (1985). A history of vision screening [Abstract]. Journal of School Health, 55(4), 138-141. Retrived October 24, 2005, from the PubMed database.

Apps, J. W. (1981). The adult learner on campus: A guide for instructors and administrators. Chicago: Follett Publishing Company.

Armstrong, E., \& Parsa-Parsi, R. (2005). How can physicians' learning styles drive educational planning? Academic Medicine, 80(7), 680-684.

Ausubel, D. P. (1968). Educational psychology: A cognitive view. New York: Holt, Rinehart and Winston, Inc.

Ausubel, D. P., \& Robinson, F. G. (1969). School learning: An introduction to educational psychology. New York: Holt, Rinehart and Winston, Inc. 
Bacal, D. A., \& Hertle, R. W. (1998). Don't be lazy about looking for amblyopia [Electronic version]. Contemporary Pediatrics, 15(6), 99-100, 103-104, 107.

Bacal, D. A., \& Wilson, M C. (2000). Strabismus: Getting it straight [Electronic version]. Contemporary Pediatrics, 17(2), 49-60. Retrieved May 2, 2003, from http://www.contemporarypediatrics.com/contpeds/article/articleDetail.jsp?id=139717

Bacal, D. A., Rousta, S. T. \& Hertle, R. W. (1999). Why early vision screening matters. Contemporary Pediatrics Archive, (16)2, 155-163

Bane, M. C., \& Beauchamp, G. R. (2001). Update on vision screening. Review of Ophthalmology, 8(3), 116-118.

Bardisi, W. M., \& Bin Sadiq, B. M. (2002). Vision screening of preschool children in Jeddah, Saudi Arabia. Saudi Medical Journal, 23(4), 445-449.

Beatty, P. T., Benefield, L. L., \& Linhart, L. J. (1991) Evaluating the teaching and learning process. In M. W. Galbraith (Ed.), Facilitating adult learning: A transactional process (pp. 163-192). Malabar, FL: Krieger Publishing Company.

Becker, R., Hübsch, S., Gräf, M. H., \& Kaufmann, H. (2002). Examination of young children with Lea Symbols. British Journal of Ophthalmology. Retrieved March 17, 2005, from www.bjophthalmol.com

Berk, R. A. (1998). Professors are from Mars, students are from Snickers: How to write and deliver humor in the classroom and in professional presentations [Electronic version]. Madison, WI: Mendota Press. Retrieved January 15, 2006, from http://books.google.com

Birman, B. F., Desimone, L., Porter, A. C., \& Garet, M. S. (2000). Designing professional development that works [Electronic version]. Educational Leadership, 57(8), 28-33. Retrieved January 15, 2006, from the Academic Search Elite database.

Bitpipe, Inc. (n.d.). Workshops. Retrieved January 15, 2006, from http://www.bitpipe.com/tlist/ Workshops.html

Borsting, E., \& Rouse, M W. (1994). Detecting learning-related visual problems in the primary care setting [Abstract]. Journal of the American Optometric Association, 65(9), 642-650. Retrieved November 13, 2005, from the PubMed database. 
Bradford, G. E., Nottingham Chaplin, P. K., \& Odom, J. V. (2003, May). Preschool vision screening practices by primary care physicians in West Virginia. Poster session presented at the annual meeting of The Association for Research in Vision and Ophthalmology, Fort Lauderdale, FL.

Bradford, G., Nottingham Chaplin, P. K., Odom, J. V. \& Schwartz, T. (2003, March). A new, modified Lea Symbols chart simplifies preschool visual acuity screening. Poster session presented at the annual meeting of the American Association of Pediatric Ophthalmology and Strabismus, Kona, HI.

Bradford, G. E., Wadia, J. T., \& Nottingham Chaplin, P. K. (2004, April). Preschool vision screening: A survey of university-based primary care physicians. Poster session presented at the annual meeting of The Association for Research in Vision and Ophthalmology, Fort Lauderdale, FL.

Broderick, P. (1998). Pediatric vision screening for the family physician. American Family Physician, 58(3), 691-700, 703-704. Retrieved March 4, 2006, from http://www.aafp.org/ afp/980901ap/broderic.html

Brookfield, S. (1991). Grounding teaching in learning. In M. W. Galbraith (Ed.), Facilitating adult learning: A transactional process (pp. 33-56). Malabar, FL: Krieger Publishing Company.

Brookfield, S. D. (1986). Understanding and facilitating adult learning. San Francisco: JosseyBass Inc., Publishers.

Brooks, S. E. (1996). Amblyopia. Ophthalmology Clinics of North America, 9(2), 171-184.

Brown, M. S. (1975). Vision screening of preschool children: How to check on visual acuity and heterophoria as part of a routine physical examination. Clinical Pediatrics, 14(10), 968973.

Bryant, J., Comisky, P., \& Zillmann, D. (1979). Teachers' humor in the college classroom. Communication Education, 28, 110-118. Retrieved February 27, 2005, from the Communication \& Mass Media Complete database.

Bryson, L. (1936). Adult education. New York: American Book Company.

Burns, R. A. (1985, May). Information impact and factors affecting recall. Paper presented at the Annual National Conference on Teaching Excellence and Conference of Administrators, Austin, TX. 
Caffarella, R. S. (2002). Planning programs for adult learners: A practical guide for educators, trainers, and staff developers ( $2^{\text {nd }}$ ed.). San Francisco: Jossey-Bass.

Calhoun, J. H. (n.d.). Strabismus and amblyopia [Electronic version]. Retrieved March 4, 2006, from http://www.aapos.org/associations/5371/files/Strabamb.pdf

Calonge, N. (2004). Screening for visual impairment in children younger than age 5 years: Recommendation statement [Electronic version]. Annals of Family Medicine, 2(3), 263266. Retrieved October 24, 2005, from http://www.annfammed.org/cgi/reprint/2/3/263

Campbell, L. R., \& Charney, E. (1991). Factors associated with delay in diagnosis of childhood amblyopia. Pediatrics, 87(2), 178-185.

Castanes, M. S. (2003). Major review: The underutilization of vision screening (for amblyopia, optical anomalies and strabismus) among preschool age children. Binocular Vision \& Strabismus Quarterly, 18(4), 217-232.

Catlett, C., \& Winton, P. J. (1997). Putting it all together [Electronic version]. In P. J. Winton, J. A. McCollum, \& C. Catlett (Eds.), Reforming personnel preparation in early intervention: issues, models \& practical strategies (pp. 527-544). Baltimore: Paul H. Brookes Publishing Co. Retrieved February 8, 2004, from http://www.fpg.unc.edu/ $\sim$ scpp/pdfs/Reforming/21-527_544.pdf

Centers for Disease Control and Prevention. (2005, May). Visual impairment and use of eye-care services and protective eyeware among children - United States, 2002 [Electronic version]. Morbidity and Mortality Weekly Report, 54(17), 425-429. Washington, DC: U.S. Government Printing Office. Retrieved September 30, 2005, from http://www.cdc .gov/mmwr/PDF/wk/mm5417.pdf

Centers for Medicare \& Medicaid Services. (2005). Medicaid Early \& Periodic Screening \& Diagnostic Treatment Benefit, State Agency Requirements (U.S. Department of Health and Human Services). Retrieved March 4, 2006, from http:/www.cms.hhs.gov/ MedicaidEarlyPeriodicScrn/03_StateAgencyResponsibilities.asp\#TopOfPage

Chang, Y. S., Shih, M. H., Tseng, S. H., Cheng, H. C., \& Teng, C. L. (2005). Ophthalmologic abnormalities in high school students with mental retardation in Taiwan [Abstract]. Journal of the Formosan Medical Association, 104(8), 578-584. Retrieved January 16, 2006, from the PubMed database. 
Christophel, D. M. (1990). The relationships among teacher immediacy behaviors, student, motivation, and learning. Communication Education, 39(4), 323-340. Retrieved February 16, 2006, from the Communication \& Mass Media Complete database.

Chua, B., \& Mitchell, P. (2004). Consequences of amblyopia on education, occupation, and long term vision loss [Electronic version]. British Journal of Ophthalmology, 88, 1119-1121. Retrieved April 7, 2005, from www.bjophthalmol.com

Ciner, E. B., Dobson, V., Schmidt, P. P., Allen, D., Cyert, L., Maguire, M., et al. (1999). A survey of vision screening policy of preschool children in the United States. Survey of Ophthalmology, 43(5), 445-57.

Ciner, E. B., Schmidt, P. P., Orel-Bixler, D., Dobson, V., Maguire, M., Cyert, L., et al. (1998). Vision screening of preschool children: Evaluating the past, looking toward the future. Optometry and Vision Science, 75(8), 571-584.

Clark, R. C., \& Taylor, D. (1996). The causes and cures of learner overload. In D. Zielinski (Ed.), Adult learning in your classroom ( $3^{\text {rd }}$ ed., pp. 173-175). Minneapolis, MN: Lakewood Books.

Clemens, C., Doolittle, R. P., \& Hoyle, M. (2002). Kindergarten health assessment reports: What do schools really learn from them [Abstract]? Clinical Pediatrics, 41(2), 93-98. Retrieved January 14, 2006, from the LexisNexis ${ }^{\mathrm{TM}}$ Academic database.

Cohen, J. B. (1996). Laughing in the classroom: How humor enhances education. English Leadership Quarterly, 18, 2-4.

Compulsory preenrollment hearing, vision and speech and language testing; developmental screening for children under compulsory school age, W. Va. Code. Ann. § 18-5-17. (2003). Retrieved April 11, 2004, from the LexisNexis ${ }^{\mathrm{TM}}$ Academic \& Library Solutions database.

Cordonnier, M, \& de Maertelaer, V. (2005). Screening for amblyogenic factors in preschool children with the Retinomax hand-held refractor: Do positive children have amblyopia and is treatment efficacious [Abstract]? Strabismus, 13(1), 27-32. Retrieved November 13, 2005, from the PubMed database.

Corkill, A. J., Bruning, R. H., \& Glover, J. A. (1988, November/December). Advance organizers: Concrete versus abstract. Journal of Educational Research, 82(2), 76-81. Retrieved March 1, 2005, from the Academic Search Elite database. 
Cross, K. P. (1981). Adults as learners: Increasing participation and facilitating learning. San Francisco: Jossey-Bass Inc., Publishers.

Crowley, A. A., Bains, R. M., \& Pellico, L. H. (2005). A model preschool vision and hearing screening program. The American Journal of Nursing, 105(6), 52-55.

Current Operations and Capital Improvements Appropriations Act of 2005, § 10.22(c)(b)(2). (2005). Retrieved October 1, 2005, from http://www.ncleg.net/Sessions/2005/Bills/ Senate/HTML/S622v9.html

Cyert, L., Ciner, E., Dobson, V., Maguire, M., Moore, B., \& Orel-Bixler, D. (1998, December). Vision in preschoolers study: Lay screener training and certification. Poster session presented at the annual meeting of the American Academy of Optometry, San Francisco.

Daniel, E. L. (2000). A review of time-shortened courses across disciplines. College Student Journal, 34(2), 298-308. Retrieved November 9, 2005, from the Academic Search Elite database.

Davis, B. G. (1993). Tools for teaching. San Francisco: Jossey-Bass Inc., Publishers.

Day, S. (1997a). Blurred and weak vision. In D. Taylor (Ed.), Paediatric Ophthalmology (pp. 1046-1050). Malden, MA: Blackwell Science.

Day, S. (1997b). Normal and abnormal visual development. In D. Taylor (Ed.), Paediatric Ophthalmology (pp. 13-18). Malden, MA: Blackwell Science.

Dean, G. J. (1994). Designing instruction for adult learners. Malabar, FL: Krieger Publishing Company.

Dean, G. J. (2004). Designing instruction. In M. W. Galbraith (Ed.), Adult learning methods: A guide for effective instruction ( $4^{\text {th }}$ ed., pp. 93-118). Malabar, FL: Krieger Publishing Company.

De Becker, I., MacPherson, H. J., LaRoche, G. R., Braunstein,, J., Cottle, R., McIntyre, L. L., et al. (1992). Negative predictive value of a population-based preschool vision screening program [Abstract]. Ophthalmology, 99(6), 998-1003. Retrieved March 31, 2004, from the PubMed database.

Deming, B. (2001). Ten steps to being positively engaging. Training \& Development, 55(1), 1819. Retrieved February 27, 2005, from the Academic Search Elite database.

DeRespinis, P. A. (2001). Eyeglasses: Why and when do children need them? Pediatric Annals, 30(8), 455-461. 
DeVellis, R. F. (2003). Scale development: Theory and applications ( $2^{\text {nd }}$ ed.). Thousand Oaks, CA: Sage Publications, Inc.

Dick, W., Carey, L., \& Carey, J. O. (2001). The systematic design of instruction ( $5^{\text {th }}$ ed.). New York: Addison-Wesley Educational Publishers, Inc.

Dobson, V. (1998, September 10-11). Target population. In E. Hartmann (Ed.), Vision Screening in the Preschool Child (pp. 46-55). Bethesda, MD.

Donahue, S. P., Arnold, R. W., \& Ruben, J. B. (2003). Preschool vision screening: What should be we detecting and how should we report it? Uniform guidelines for reporting results of preschool vision screening studies. Journal of AAPOS, 7(5), 314-315.

Draves, W. A. (1997). How to teach adults ( $2^{\text {nd }}$ ed.). Manhattan, KS: The Learning Resources Network.

Dubowy, S. M. (2005). Vision screening of young children: Taking a second look [Electronic version]. Journal of AAPOS, 18(8), 41-49. Retrieved January 14, 2006, from http://www .jaapa.com/issues/j20050801/pdfs/vision0805.pdf

Eble, K. E. (1977). The craft of teaching. San Francisco: Jossey-Bass Publishers.

Ehrlich, M. I., Reinecke, R. D., \& Simons, K. (1983). Preschool vision screening for amblyopia and strabismus. Programs, methods, guidelines, 1983. Survey of Ophthalmology, 28(3), 145-163.

Ellis, E. S., Worthington, L. A., \& Larkin, M. J. (1994). Executive summary of research synthesis on effective teaching principles and the design of quality tools for educators (Technical Report No. 6). Eugene, OR: National Center to Improve the Tools of Educators. (ERIC Document Reproduction Service No. ED386854)

Epelbaum, M., Milleret, C., Buisseret, P., \& Dufier, J. L. (1993). The sensitive period for strabismic amblyopia in humans [Abstract]. Ophthalmology, 100(3), 323-328. Retrieved January 21, 2006, from the PubMed database.

Farface, J. (1996). 10 steps to better slide shows. In D. Zielinski (Ed.), Delivering training: Mastery in the classroom ( $3^{\text {rd }}$ ed., pp. 131-132). Minneapolis, MN: Lakewood Books.

Farrah, S. J. (2004). Lecture. In M. W. Galbraith (Ed.), Adult learning methods: A guide for effective instruction ( $4^{\text {th }}$ ed.) (pp. 227-252). Malabar, FL: Krieger Publishing Company.

Ford, J. K. (1994). Defining transfer of learning: The meaning is in the answers. Adult Learning, $5(4), 22-23,30$. 
Forman, D. C. (2003). Eleven common-sense learning principles. $T+D, 57(9)$, 39-46. Retrieved March 4, 2003, from the Academic Search Elite database.

Foster, A., \& Gilbert, C. (1997). Epidemiology of visual impairment in children. In D. Taylor (Ed.), Paediatric Ophthalmology (pp. 3-12). Malden, MA: Blackwell Science.

Friend, M., \& Cook, L. (2003). Interactions: Collaboration skills for school professionals (4 ${ }^{\text {th }}$ ed.). Boston: Allyn and Bacon.

Frymier, A. B., \& Wanzer, M. B. (1998, November). “Make 'em laugh and they will learn”: A closer look at the relationship between perceptions of instructors' humor orientation and student learning. Paper presented at the Annual Meeting of the National Communication Association, New York. (ERIC Document Reproduction Service No. ED427377)

Fujiura, G. T., \& Yamaki, K. (2000). Trends in demography of childhood poverty and disability. Exceptional Children, 66(2), 187-199.

Fulton, A. (1992). Screening preschool children to detect visual and ocular disorders. Archives of Ophthalmology, 110(11), 1553-1554.

Gagne, R. (1985). The conditions of learning and theory of instruction (4 ${ }^{\text {th }}$ ed.). New York: Holt, Rinehart \& Winston.

Gagne, R. M., Wager, W. W., Golas, K. C., \& Keller, J. M. (2005). Principles of instructional design $\left(5^{\text {th }}\right.$ ed.). Belmont, CA: Wadsworth/Thomson Learning.

Galbraith, M. W. (1991). The adult learning transactional process. In M. W. Galbraith (Ed.), Facilitating adult learning: A transactional process (pp. 1-32). Malabar, FL: Krieger Publishing Company.

Galbraith, M. W. (1992). Nine principles of good facilitation. Adult Learning, 3(6), 10-11, 20.

Galbraith, M. W. (1994). Connecting instructional principles to self-esteem. Adult Learning, $5(3), 24-25,31$.

Galbraith, M. W. (2004). The teacher of adults. In M. W. Galbraith (Ed.), Adult learning methods: A guide for effective instruction (4 ${ }^{\text {th }}$ ed.) (pp. 3-22). Malabar, FL: Krieger Publishing Company.

Galbraith, M. W., \& Zelenak, B. S. (1991). Adult learning methods and techniques. In M. W. Galbraith (Ed.), Facilitating adult learning: A transactional process (pp. 101-134). Malabar, FL: Krieger Publishing Company. 
Ganley, J. P., \& Roberts, J. (1983). Eye conditions and related need for medical care among persons 1-74 years of age: United States, 1971-72 (DHHS Publication No. (PHS) 831678). Hyattsville, MD: U.S. Department of Health and Human Services.

Garavaglia, P. L. (1993). How to ensure transfer of training. Training \& Development, 47(10), 63-68. Retrieved January 16, 2006, from the Academic Search Elite database.

Garet, M. S., Porter, A. C., Desimone, L., Birman, B. F., \& Yoon, K. S. (2001). What makes professional development effective? Results from a national sample of teachers [Electronic version]. American Educational Research Journal, 38(4), 915-945. Retrieved January 15, 2006, from http://aztla.asu.edu/profdev1.pdf

Gesell, A., Ilg, F. L., \& Bullis, G. E. (1967). VISION: It's development in infant and child (2 ${ }^{\text {nd }}$ ed.). New York: Hafner Publishing Company, Inc.

Giangiacomo, J., \& Morey, S. S. (2005). Improving preschool vision screening programs. Missouri Medicine, 102(1), 55-58.

Gilley, J. W. (2004). Demonstration and simulation. In M. W. Galbraith (Ed.), Adult learning methods: A guide for effective instruction ( $4^{\text {th }}$ ed.) (pp. 361-381). Malabar, FL: Krieger Publishing Company.

Gorard, S., (2001). Quantitative methods in educational research: The role of numbers made easy. New York: Continuum.

Gorham, J., \& Christophel, D. M. (1990). The relationship of teachers' use of humor in the classroom to immediacy and student learning. Communication Education, (39)1, 46-62. Retrieved May 27, 2005, from the Communication \& Mass Media Complete database.

Goss, D. A., \& Rainey, B. B. (2002). Articles of interest: More evidence that vision and learning are related [Electronic version]. Indiana University Journal of Optometry, 5(2), 35-37. Retrieved November 13, 2005, from http://www.opt.indiana.edu/IndJOpt/ijofall02.pdf

Green, M., \& Richmond, J. B. (1962). Pediatric diagnosis: Interpretation of signs and symptoms in different age periods ( $2^{\text {nd }}$ Ed.). Philadelphia: W. B. Saunders Company.

Guba, E. G., \& Lincoln, Y. S. (1985). Effective evaluation. San Francisco: Jossey-Bass Publishers.

Guild, P. B. (1996). How to involve learners in your lectures. In D. Zielinski (Ed.), Delivering training: Mastery in the classroom ( $3^{\text {rd }}$ ed., pp. 131-132). Minneapolis, MN: Lakewood Books. 
Gundersen, T. (1954). Glaucoma and amblyopia ex anopsia: Two preventable forms of blindness. Journal of the American Medical Association, 156(10), 933-935.

Guskey, T. R. (1998). The age of our accountability. Journal of Staff Development, 19(4).

Retrieved March 4, 2006, from http://www.nsdc.org/library/publications/jsd/ guskey194.cfm

Guskey, T. R. (2000). Evaluating professional development. Thousand Oaks, CA: Corwin Press, Inc.

Guskey, T. R. (2002). Does it make a difference? Educational Leadership, 59(6), 45-51.

Retrieved January 31, 2004, from Academic Search Elite database.

Guskey, T. R. (2003) What makes professional development effective [Electronic version]? Phi Delta Kappan, 84(10), 748-750. Retrieved February 9, 2004, from the Academic Search Elite database.

Hård, A., Sjödell, L., Borres, M. P., Zetterberg, I., \& Sjöstrand, J. (2002). Preschool vision screening in a Swedish city region: Results after alteration of criteria for referral to eye clinics. Acta Ophthalmologica Scandinavica, 80(6), 608-611.

Hartmann, E. E. (1998, September 10-11). Brief overview of amblyopia. In E. Hartmann (Ed.), Vision Screening in the Preschool Child (pp. 16-19). Bethesda, MD.

Hartmann, E. E., Bradford, G. E., Chaplin, P. K., Johnson, T., Kemper, A. R., Kim, S., et al. (2006). Project universal preschool vision screening: A demonstration project [Abstract]. Journal of Pediatrics, 117(2), e226-237.

Hartmann, E. E., Dobson, V., Hainline, L., Marsh-Tootle, W., Quinn, G. E., Ruttum, M. S., et al. (2000). Preschool vision screening: Summary of a task force report. Pediatrics, 106(5), 1105-1116. Retrieved March 4, 2005, from http://www.pediatrics.org/cgi/content/full/ $106 / 5 / 1105$

Hassed, C. (2001). How humour keeps you well [Abstract]. Australian Family Physician, 30(1), 25-28.

Head Start Bureau. (n.d.). Head Start program performance standards and other regulations, Subpart B - early childhood development and health services, $\$ 1304.20(C)(2)(b)$ (U.S. Department of Health and Human Services. Administration for Children \& Families, Administration on Children, Youth and Families). Retrieved March 13, 2006, from http://www.acf.hhs.gov/programs/hsb/pdf/1304_20.pdf 
Head Start Bureau. (2005). Head Start program fact sheet (U.S. Department of Health and Human Services, Administration for Children \& Families, Administration on Children, Youth and Families). Retrieved March 4, 2005, from http://www.acf.hhs.gov/programs/ $\mathrm{hsb} / \mathrm{research} / 2005 . \mathrm{htm}$

Healthy People 2010 (n.d.). 28. Vision and hearing. Retrieved October 23, 2005, from http:// www.healthypeople.gov/Document/HTML/Volume2/28Vision.htm\#_Toc489325914

Healthy Vision 2010 (n.d.). Examinations and prevention, Objective 28-2. Retrieved October 23, 2005, from http://www.healthyvision2010.org/exams/preschool.asp

Hequet, M. (1996). The new trainer. In D. Zielinski (Ed.), Delivering training: Mastery in the classroom ( $3^{\text {rd }}$ ed., pp. 107-111). Minneapolis, MN: Lakewood Books.

Hered, R. W., \& Rothstein, M. (2003). Preschool vision screening frequency after an officebased training session for primary care staff. Pediatrics, 112(1), e17-e21. Retrieved March 4, 2006, from http://pediatrics.aappublications.org/cgi/content/full/112/1/e17

Hered, R. W., Murphy, S., \& Clancy, M. (1997). Comparison of the HOTV and Lea Symbols charts for preschool vision screening [Abstract]. Journal of Pediatric Ophthalmology and Strabismus, 34(1), 24-28.

Hiemstra, R., \& Sisco, B. (1990). Individualizing instruction: Making learning personal, empowering, and successful. San Francisco: Jossey-Bass Publishers.

Hoffman, L. G. (1980). Incidence of vision difficulties in children with learning disabilities [Abstract]. Journal of the American Optometric Association, 51(5), 447-451. Retrieved November 13, 2005, from the PubMed database.

Horton, J. C. (2001). Critical periods in the development of the visual system. In D. B. Bailey Jr., J. T. Bruer, F. J. Symons, \& J. W. Lichtman (Eds.), Critical thinking about critical periods (pp. 45-65). Baltimore: Paul H. Brookes Publishing Co.

Houle, C. O. (1996). The design of education ( $2^{\text {nd }}$ ed.). San Francisco: Jossey-Bass Publishers. Howell, D. C. (2002). Statistical methods for psychology ( $5^{\text {th }}$ ed.). Pacific Grove, CA: Duxbury. Hrisos, S., Clarke, M. P., \& Wright, C. M. (2004). The emotional impact of amblyopia treatment in preschool children: Randomized controlled trial [Abstract]. Ophthalmology, 111(8), 1550-1556. 
Hudak, D. T., \& Magoon, E. H. (1997). Poverty predicts amblyopia treatment failure [Abstract]. Journal of the American Association for Pediatric Ophthalmology and Strabismus, 1(4), 214-5. Abstract retrieved May 29, 2005, from the PubMed database.

Illeris, K. (2004). Adult education and adult learning. Malabar, FL: Krieger Publishing Company.

Jakobsson, P., Kvarnström, G., Abrahamsson, M., Bjernbrink-Hörnblad, E., \& Sunnqvist, B. (2002). The frequency of amblyopia among visually impaired persons [Electronic version]. Acta Ophthalmologica Scandinavica, 80(1), 44-46. Retrieved March 17, 2005, from the Biomedical Reference Collection: Comprehensive Edition database.

James, W. B. (1983). An analysis of perceptions of the practices of adult educators from five different settings. Proceedings of the Adult Education Research Conference: No. 24. Montreal: Concordia University/University of Montreal.

James, W. B., \& Maher, P. A. (2004). Understanding and using learning styles. In M. W. Galbraith (Ed.), Adult learning methods: A guide for effective instruction $\left(4^{\text {th }} \mathrm{ed}\right.$.) (pp. 119-140). Malabar, FL: Krieger Publishing Company.

Jan, J. E., Freeman, R. D., \& Scott, E. (1977). Visual impairment in children and adolescents. New York: Grune \& Sratton.

Jensen, H. (1997). Refraction and refractive errors. In D. Taylor (Ed.), Paediatric Ophthalmology (pp. 57-74). Malden, MA: Blackwell Science.

Johnson, L. J., \& LaMontagne, M. J. (1993). Using content analysis to examine the verbal or written communication of stakeholders within early intervention. Journal of Early Intervention, 17(1), 73-79.

Johnson, R., Nottingham, D., Stratton, R., \& Zaba, J. (1996). The vision screening of academically and behaviorally at-risk pupils. Journal of Behavioral Optometry, 7(2), 3942.

Joinson, D. (1996). Using checklists as an aid to transfer of training. The new trainer. In D. Zielinski (Ed.), Delivering training: Mastery in the classroom ( $3^{\text {rd }}$ ed., pp. 171-172). Minneapolis, MN: Lakewood Books.

Joish, V. N., Malone, D. C., \& Miller, J. M. (2003). A cost-benefit analysis of vision screening methods for preschoolers and school-age children [Abstract]. Journal of AAPOS, 7(4), 283-290. Retrieved January 14, 2006, from the PubMed database. 
Joyce, B., \& Showers, B. (1980). Improving inservice [sic] training: The messages of research. Educational Leadership, 37(5), 379-385.

Käsmann-Kellner, B., \& Ruprecht, K. W. (2000). Vision screening survey of all children starting primary school in 1998 in the Federal State of Saarland, Germany. Strabismus, 8(3), 201207. Retrieved February 26, 2005, from the Biomedical Reference Collection: Comprehensive Edition database.

Kaupins, G. E. (1991). Humour in university and corporate training: A comparison of trainer perceptions. The Journal of Management Development, 10(1), 33-41.

Keller, J. M. (1987a). Strategies for stimulating the motivation to learn. Performance \& Instruction, 26(8), 1-7.

Keller, J. M. (1987b). The systematic process of motivational design. Performance \& Instruction, 26(9), 1-7.

Kemper, A, Harris, R., Lieu, T. A., Homer, C. J., \& Whitener, B. L. (2004). Screening for visual impairment in children younger than age 5 years: A systematic evidence review for the U. S. Preventive Services Task Force. Agency for Healthcare Research and Quality, Rockville, MD. Retrieved October 22, 2005, from http:/www.ahrq.gov/downloads/pub/ prevent/pdfser/visualser.pdf

Kemper, A. R. (2004). Valuing vision. Pediatrics, 113(2), 404-405. Retrieved March 4, 2006, from http://pediatrics.aappublications.org/cgi/content/full/113/2/404

Kemper, A. R., Bruckman, D., \& Freed, G. L. (2003). Receipt of specialty eye care by children [Abstract]. Ambulatory Pediatrics, 3(5), 270-274. Abstract retrieved May 29, 2005, from the PubMed database.

Kerr, N. C., \& Arnold, R. W. (2004). Vision screening for children: Current trends, technology, and legislative issues. Current Opinion in Ophthalmology, 15(5), 454-459.

Kidd, J. R. (1973). How adults learn (Rev. ed.). Chicago: Follett Publishing Company.

Killion, J. (2000). Log on to learn [Electronic version]. Journal of Staff Development, 21(3), no page numbers listed. Retrieved March 7, 2004, from http://www.nsdc.org/library/ publications/jsd/killion213.cfm

Killion, J., \& Harrison, D. (1997). The multiple role of staff developers [Electronic version]. Journal of Staff Development, 18(3), no pages listed. Retrieved February 21, 2004, from http://www.nsdc.org/library/publications/jsd/killion183.cfm 
Kirkpatrick, D. L. (1998). Evaluating training programs: The four levels ( $2^{\text {nd }}$ ed.). San Francisco: Berrett-Koehler Publishers, Inc.

Kiviranta, T., Eronen, U., Jokinen, K., Jääskeläinen-Heikkinen, E., Kekäläinen, Lehtomäki, P., et al. (2006). Improvements in vision assessment of children with motor impairment for rehabilitation and special education I. Poster session presented at the annual meeting of The International Cerebral Palsy Symposium, Oulu, Finland.

Knowles, M. S. (1973). The adult learner: A neglected species. Houston, TX: Gulf Publishing Company.

Knowles, M. S. (1980). The modern practice of adult education: From pedagogy to andragogy (Rev. ed.). Chicago: Follett Publishing Company.

Knowles, M. S. (1989). The making of an adult educator: An autobiographical journey. San Francisco: Jossey-Bass Inc., Publishers.

Knowles, M. S. (1992). Applying principles of adult learning in conference presentations. Adult Learning, 4(1), 11-14. Retrieved November 7, 2005, from the Academic Search Elite database.

Knowles, M. S., Holton, E. F., III, \& Swanson, R. A. (1998). The adult learner: The definitive classic in adult education and human resource development. Houston, TX: Gulf Publishing Company.

Knox, A. B. (1977). Adult development and learning. San Francisco: Jossey-Bass Inc., Publishers.

Knox, A. B. (2002). Evaluation for continuing education: A comprehensive guide to success. San Francisco: Jossey Bass.

Kolb, D. A. (1984). Experiential learning: Experience as the source of learning and development. Englewood Cliffs, NJ: Prentice-Hall.

Koller, H. P. (2002). An ophthalmologist's approach to visual processing/learning differences. Journal of Pediatric Ophthalmology \& Strabismus, 39(3), 133-141.

Koller, H. P., \& Goldberg, K. B. (2000). Your role in detecting learning differences. Review of Ophthalmology, 7(3), 104-106. Retrieved November 13, 2005, from the Academic Search Elite database. 
König, H. H., \& Barry, J. C. (2002). Economic evaluation of different methods of screening for amblyopia in kindergarten [Electronic version]. Pediatrics, 109(4), p. e59. Retrieved January 15, 2006, from http://pediatrics.aappublications.org/cgi/content/full/109/4/e59

König, H. H., Barry, J. C., Leidl, R., \& Zrenner, E. (2002). Economic evaluation of orthoptic screening: Results of a field study of 21 German kindergartens. Investigative Ophthalmology \& Visual Science, 43(10), 3209-3215.

Krueger, D. E., \& Ederer, F. (Eds.). (1984). Report on the National Eye Institute's visual acuity impairment survey pilot study. Bethesda, MD: Office of Biometry and Epidemiology, National Eye Institute, National Institutes of Health, Public Health Service, Department of Health and Human Services.

Krumholtz, I. (2000). Results from a pediatric vision screening and its ability to predict academic performance. Optometry, 71(7), 426-430.

Kulp, M. T., \& Schmidt, P. P. (2002). A pilot study. Depth perception and near stereoacuity: Is it related to academic performance in young children? [Abstract]. Binocular Vision \& Strabismus Quarterly, 17(2), 129-134. Retrieved November 13, 2005, from the PubMed database.

Kvarnström, G., \& Jakobsson, P. (2005). Is vision screening in 3-year-old children feasible? Comparison between the Lea Symbol chart and the HVOT (LM) chart. Acta Ophthalmologica Scandinavica, 83(1), 76-80.

Kvarnström, G., Jakobsson, P., \& Lennerstrand, G. (2001). Visual screening of Swedish children: An ophthalmological evaluation. Acta Ophthalmologica Scandinavica, 79(3), 240-244.

Lennerstrand, G., Jakobsson, P., \& Kvarnström, G. (1995). Screening for ocular dysfunction in children: Approaching a common program [Abstract]. Acta Ophthalmologica Scandinavica. Supplement. (214). 26-38. Retrieved January 21, 2006, from the PubMed database.

Levitt, M. (2005, July). Rhode Island and Arkansas pass mandatory pre-k screening bills [Electronic version]. American Academy of Ophthalmology Washington Report, 10(10). Retrieved September 30, 2005, from http:/www.aao.org/aao/news/washington/ article3_20050729.cfm 
Lim, H. C., Quah, B. L., Balakrishnan, V., Lim, H. C., Tay, V., \& Emmanuel, S. C. (2000). Vision screening of 4-year-old children in Singapore. Singapore Medical Journal, 41(6), 271-278.

Lindeman, E. C. (1961). The meaning of adult education. Montreal, Canada: Harvest House Limited.

Long, H. B. (2002). Teaching for learning. Malabar, FL: Krieger Publishing Company.

Long, H. B. (2004). Understanding adult learners. In M. W. Galbraith (Ed.), Adult learning methods: A guide for effective instruction ( $4^{\text {th }}$ ed.) (pp. 23-38). Malabar, FL: Krieger Publishing Company.

MacDonald, C. M. (2004). A chuckle a day keeps the doctor away: Therapeutic humor and laughter [Abstract]. Journal of Psychosocial Nursing and Mental Health Services, 42(3), 18-25. Retrieved June 2, 2005, from the PubMed database.

MacEwen, C. J., Baines, P. S., \& Desai, P. (1999). Eye injuries in children: The current picture [Electronic version]. British Journal of Ophthalmology, 83(8), 933-936.

Mackenzie, A. (1990). The time trap. New York: AMACOM.

Mackie, K. (1981). The application of learning theory to adult teaching. Nottingham, England: Department of Adult Education, University of Nottingham.

Mager, R. F. (1996). No self-efficacy, no performance. In D. Zielinski (Ed.), Delivering training: Mastery in the classroom ( $3^{\text {rd }}$ ed., pp. 91-94). Minneapolis, MN: Lakewood Books.

Malone, D. M., Straka, E., \& Logan, K. R. (2000). Professional development in early intervention: Creating effective inservice [sic] training opportunities. Infants and Young Children, 12(4), 53-62.

Marcinak, J. F. \& Werntz Yount, S. C. (1995). Evaluation of vision screening practices of Illinois pediatricians. Clinical Pediatrics, 34, 353-357. Retrieved March 29, 2004, from the LexisNexis ${ }^{\text {TM }}$ Academic \& Library Solutions database.

Mark, H., \& Mark, T. (1999). Parental reasons for non-response following a referral in school vision screening. Journal of School Health, 69(1), 35-38. Retrieved March 12, 2005 , from the Academic Search Elite database.

Marsh-Tootle, W. (1998, September 10-11). Traditional vision screening methods and outcomes. In E. Hartmann (Ed.), Vision Screening in the Preschool Child (pp. 97-129). Bethesda, MD. 
McLeod, P. J., Steinert, Y., Meagher, T., \& McLeod, A. (2003). The ABCs of pedagogy for clinical teachers. Medical Education, 37(7), 638-644. Retrieved August 26, 2004, from the Academic Search Elite database.

McManaway, J. W. (n.d.). Vision screening of infants and children [Electronic version]. Retrieved January 6, 2006, from http://www.aapos.org/associations/5371/files/ visscreen.pdf

McMillan, J. H., \& Schumacher, S. (1997). Research in education: A conceptual introduction ( $4^{\text {th }}$ ed.). New York: Addison-Wesley Educational Publishers, Inc.

McNamara, J. R. (1982). Why they don't do what we train them to do. In P. G. Jones (Ed.), Adult learning in your classroom: The best of TRAINING magazine's strategies and techniques for managers and trainers (pp. 99-101). Minneapolis, MN: Lakewood Publications, Inc.

Menon, V., Chaudhuri, Z., Saxena, R., Gill, K., \& Sachdev, M. M. (2005). Profile of amblyopia in a hospital referral practice [Abstract]. Indian Journal of Ophthalmology, 53(4), 227234. Retrieved January 16, 2006, from the PubMed database.

Mentch, M. W. (2002). The effects of static and animated graphics in electronic presentations on learning and attitudes. Unpublished doctoral dissertation. Kent State University.

Merriam, S. B. (2001). Andragogy and self-directed learning: Pillars of adult learning theory. In S. B. Merriam (Ed.), The new update on adult learning theory (pp. 3-12). San Francisco: Jossey-Bass.

Merriam, S. B., \& Brockett, R. G. (1997). The profession and practice of adult education: An introduction. San Francisco: Jossey-Bass Inc., Publishers.

Merriam, S. B., \& Caffarella, R. S. (1999). Learning in adulthood: A comprehensive guide. (2 ${ }^{\text {nd }}$ ed.). San Francisco: Jossey-Bass.

Michaelides, M., \& Moore, A. T. (2004). The genetics of strabismus [Abstract]. Journal of Medical Genetics, 41(9), 641-646. Retrieved January 16, 2006, from the PubMed database.

Mills, M. D. (1999). The eye in childhood [Electronic version]. American Family Physician, 60(3), 907-916, 918. Retrieved June 5, 2001, from http:/www.aafp.org/afp/990901ap/ 907.html

Mish, F. C. (Ed.). (2003). Merriam-Webster's Collegiate ${ }^{\circledR}$ Dictionary (11 ${ }^{\text {th }}$ ed.). Springfield: MA. 
Mitchell, G. (1993). The trainer's handbook: The AMA guide to effective training ( $2^{\text {nd }}$ ed). New York: AMACOM.

Mizell, H. (2003). Facilitator: 10, Refreshments: 8, Evaluation: 0. Journal of Staff Development, 24(4), 10-13.

National Association of School Nurses. (2001). Issue brief: School health nursing services role in health care. Screening for vision impairment. Retrieved February 10, 2006, from http://www.nasn.org/Portals/0/briefs/2001briefvision.pdf

National Eye Institute. (2005). Amblyopia. Retrieved January 7, 2006, from http://www.nei.nih .gov/health/amblyopia/index.asp

National Vital Statistics Reports. (2005, September). Births, marriages, divorces, and deaths: Provision data for March 2005 (U.S. Department of Health and Human Services. Centers for Disease Control and Prevention. National Center for Health Statistics). Retrieved September 28, 2005, from http://www.cdc.gov/nchs/data/nvsr/nvsr54/nvsr54_05.pdf

Neelam, K., Molstad, S., \& Donahue, R. (1999). Using humor in the college classroom to enhance effectiveness in 'dread courses'. College Student Journal, 33(3), 400-406. Retrieved December 2, 2003, from the Academic Search Elite database.

Neuliep, J. W. (1991, October). An examination of the content of high school teachers' humor in the classroom and the development of an inductively derived taxonomy of classroom humor. Communication Education, 40(4), 343-355. Retrieved May 27, 2005, from the Communication \& Mass Media Complete database.

Newacheck, P., Jameson, W. J., \& Halfon, N. (1994). Health status and income: The impact of poverty on child health. Journal of School Health, 64(6), 229-233.

Newacheck, P. W., Hughes, D. C., Hung, Y., Wong, S., \& Stoddard, J. J. (2000). The unmet health needs of America's children [Electronic version]. Pediatrics, 105(4), 989-997.

Newman, D. K., \& East, M. M. (2000). Prevalence of amblyopia among defaulters of preschool vision screening. Ophthalmic Epidemiology, 7(1), 67-71.

Nolan, R. E. (1994). From the classroom to the real world. Adult Learning, 5(4), 26.

Nottingham Chaplin, P. K., (2003, December). A report on the evaluation of the Vision Initiative for Children's preschool vision screening workshop. Unpublished manuscript. West Virginia University. 
Nunnally, J. C., \& Bernstein, I. H. (1994). Psychometric theory ( $3^{\text {rd }}$ ed.). New York: McGrawHill, Inc.

O’Connor, A. R., Stephenson, T. J., Johnson, A., Tobin, M. J., Ratib, S., Moseley, M., et al. (2004). Visual function in low birthweight children [Abstract]. British Journal of Ophthalmology, 88(9), 1149-1153. Retrieved January 16, 2006, from the PubMed database.

Olitsky, S. E., Nelson, B. A., \& Brooks, S. (2002). The sensitive period of visual development in humans. Journal of Pediatric Ophthalmology \& Strabismus, 39(2), 69-72.

O’Meara, F. (1996). The Pedagogue's Decalogue. In D. Zielinski (Ed.), Delivering training: Mastery in the classroom ( ${ }^{\text {rd }}$ ed., pp. 135-137). Minneapolis, MN: Lakewood Books.

Orel-Bixler, D. (1999). Clinical vision assessments for infants. In D. Chen (Ed.), Essential elements in early intervention: Visual impairment and multiple disabilities (pp. 107-156). New York: AFB Press.

Ottar-Pfeifer, W. (2005). When should children have their eyes checked [Abstract]? Insight, 30(2), 17-20. Retrieved November 13, 2005, from the PubMed database.

Packwood, E. A., Cruz, O. A., Rychwalski, P. J., \& Keech, R. V. (1999). The psychosocial effects of amblyopia study. Journal of AAPOS, 3(1), 15-17.

Parkinson, J., \& Hollamby, P. (2003). "PowerPoint": Just another slide show or a useful learning aid? School Science Review, 84(309). 61-68.

Patton, M. Q. (2002). Qualitative research \& evaluation methods ( $3^{\text {rd }}$ ed.). Thousand Oaks, CA: Sage Publications, Inc.

Pike, R. W. (2003). Creative training techniques handbook: Tips, tactics, and how-to's for delivering effective training ( $3^{\text {rd }}$ ed.). Amherst, MA: HRD Press Inc.

Piskurich, G. M. (2003). Trainer basics. Alexandria, VA: ASTD Press.

Pratt, D. D. (1992). Good teaching: One size fits all? In J. M. Ross-Gordon (Ed.), Contemporary Viewpoints on Teaching Adults Effectively: New Directions for Adult and Continuing Education (No. 93, pp. 3-16). San Francisco: Jossey-Bass.

Preslan, M. W., \& Novak, A. (1996). Baltimore vision screening project. Ophthalmology, 103(1), 105-109.

Preslan, M. W., \& Novak, A. (1998). Baltimore vision screening project. Phase 2. Ophthalmology, 105(1), 150-153. 
Rachal, J. R. (2002). Andragogy's detectives: A critique of the present and a proposal for the future. Adult Education Quarterly, 52(3), 210-227. Retrieved May 8, 2004, from the Academic Search Elite database.

Rahi, J. S., Logan, S., Timms, C., Russell-Eggitt, I., \& Taylor, D. (2002). Risk, causes, and outcomes of visual impairment after loss of vision in the non-amblyopic eye: A population-based study. The Lancet, 360(9333), 597-602. Retrieved May 2, 2003, from the Academic Search Elite database.

Remey, S. (2004, July). Academy helps win children's vision victories [Electronic version]. American Academy of Ophthalmology Washington Report, 9(11). Retrieved March 4, 2006, from http://www.aao.org/aao/news/washington/article3_20050729.cfm

Roberts, J. (1978). Refraction status and motility defects of persons 4-74 years: United States, 1971-1972 (DHEW Publication No. [PHS] 78-1654). Hyattsville, MD: U. S. Department of Health, Education, and Welfare, Public Health Service, National Center for Health Statistics.

Robinson, A. D. (1985). How to have a safe trip to the cutting edge. Training and Development Journal, 39(5), 45-48. Retrieved November 2, 2005, from the Academic Search Elite database.

Robinson, B., Bobier, W. R., Martin, E., \& Bryant, L. (1999). Measurement of the validity of a preschool vision screening program. American Journal of Public Health, 89(2), 193-198. Retrieved March 27, 2005, from the Academic Search Elite database.

Robyler, M. D. (2003). Integrating educational technology into teaching ( ${ }^{\text {rd }}$ ed.). Upper Saddle River, NJ: Prentice Hall.

Rogers, C. R. (1969). Freedom to learn. Columbus, OH: Charles E. Merrill Publishing Company.

Rogers, G. L., Chazan, S., Fellows, R., \& Tsou, B H. (1982). Strabismus surgery and its effect upon infant development in congenital esotropia. Ophthalmology, 89(5), 479-483.

Romano, P. E. (1990). Vision/eye screening: Test twice and refer once. Pediatric Annals, 19(6), 359-367.

Rose, S. E. (1998). Amblyopia: The silent thief. Journal of School Health, 68(2), 76-79. Retrieved March 13, 2005, from the Academic Search Elite database. 
Rosenbaum, B. L., \& Baker, B. (1996). 5 training behaviors that increase motivation to learn. The new trainer. In D. Zielinski (Ed.), Delivering training: Mastery in the classroom $\left(3^{\text {rd }}\right.$ ed., pp. 85-86). Minneapolis, MN: Lakewood Books.

Rossett, A., \& Gautier-Downes, J. (1991). A handbook of job aids. San Diego, CA: Pfeiffer \& Company.

Rous, B., Lobianco, T., Moffett. C. L., \& Lund, I. (2005). Building preschool accountability systems: Guidelines resulting from a national study. Journal of Early Intervention, 28(1), $50-64$.

Rubin, S. E. (2001). Management of strabismus in the first year of life. Pediatric Annals, 30(8), 474-480.

Rubin, S. E., \& Nelson, L. A. (1993). Amblyopia. Diagnosis and management [Abstract]. Pediatric Clinics of North America, 40(4), 727-735.

Salkind, N. J. (2000). Statistics for people who (think they) hate statistics. Thousand Oaks, CA: Sage Publications, Inc.

Sarasin, L. C. (1999). Learning style perspectives: Impact in the classroom. Madison, WI: Atwood Publishing.

Satterfield, D., Keltner, J. L., \& Morrison, T. L. (1993). Psychosocial aspects of strabismus study [Abstract]. Archives of Ophthalmology, 111(8), 1100-1105.

Savage, H. I., Lee, H. H., Zaetta, D., Olszowy, R., Hamburger, E., Weissman, M., et al. (2005). Pediatric amblyopia risk investigation study (PARIS) [Abstract]. American Journal of Ophthalmology, 140(6), 1007-1013. Retrieved January 16, 2006, from the PubMed database.

Schmidt, P. P. (1990). Vision screening. In A. A. Rosenbloom \& M. Morgan (Eds.), Principles and practice of pediatric optometry (pp. 467-485). Philadelphia: Lippincott, Williams \& Wilkins.

Schmidt, P. P. (1997). Screening for the vision problems of young children. In B. Moore (Ed.), Eye care for infants and young children (pp. 175-189). Boston: Butterworth-Heinemann.

Schmidt, P. P. (1998, September 10-11). Current vision screening programs for the preschool child. In E. Hartmann (Ed.), Vision Screening in the Preschool Child (pp. 129-164). Bethesda, MD. 
Schmidt, P. P., Cyert, L., Ciner, E., Dobson, V., Maguire, M., \& Moore, B. (1999). Screening the vision of Head Start preschoolers. Poster session presented at the annual meeting of the American Academy of Optometry, Seattle, WA.

Schwarz, G. (1989). The importance of being silly. Educational Leadership, 151(52067), 82-83. Retrieved February 25, 2005, from the Academic Search Elite database.

Seiderman, A. S., \& Marcus, S. E. (1989). 20/20 is not enough: The new world of vision. New York: Alfred A. Knopf, Inc.

Shallo-Hoffman, J., Coulter, R., Oliver, P., Hardigan, P., \& Blavo, C. (2004). A study of preschool vision screening tests' testability, validity and duration: Do group differences matter [Electronic version]? Strabismus, 12(2), 65-73. Retrieved February 26, 2005, from the Biomedical Reference Collection: Comprehensive Edition database.

Shoemaker, J. A. (1997). Adult vision screening by nonphysicians. Journal of Ophthalmic Nursing \& Technology, 16(5), 244-250.

Shoemaker, J. A. (1998, September 10-11). Practical aspects of children's vision screening programs. In E. Hartmann (Ed.), Vision Screening in the Preschool Child (pp. 175-182). Bethesda, MD.

Showers, B., Joyce, B., \& Bennett, B. (1987). Synthesis of research on staff development: A framework for future study and a state-of-the-art analysis. Educational Leadership, 45(3), 77-87. Retrieved March 10, 2004, from the Academic Search Elite database.

Simon, J. W., \& Calhoun, J. H. (1998). A child's eyes: A guide to pediatric primary care. Gainesville, FL: Triad Publishing Company.

Simon, J. W. \& Kaw, P. (2001a). Commonly missed diagnoses in the childhood eye examination. American Family Physician. Retrieved July 27, 2004, from http://www.aafp.org/afp/20010815/623.html

Simon, J. W., \& Kaw. P. (2001b). Vision screening performed by the pediatrician. Pediatric Annals, 30(8), 446-452.

Simons, K. (1996). Preschool vision screening: Rationale, methodology and outcome. Survey of Ophthalmology, 41(1), 3-30.

Simons, K. (2005). Amblyopia characterization, treatment, and prophylaxis. Survey of Ophthalmology, 50(2), 123-166. 
Sjöstrand, J., \& Abrahamsson, M. (1997). Prevention of amblyopia and the concept of cure [Abstract]. European Journal of Ophthalmology, 7(2), 121-129. Retrieved March 31, 2004, from the PubMed database.

Smith, R. M. (1982). Learning how to learn: Applied theory for adults. New York: Cambridge, The Adult Education Company.

Snowdon, S. K., \& Stewart-Brown, S. L. (1997). Preschool vision screening. Health Technology Assessment, 1(8), University of Oxford, Health Services Research Unit, Department of Public Health.

Speeg-Schatz, C., Lobstein, Y., Burget, M., Berra, O., Riehl, C., \& Hoffman, C. (2004). A review of preschool vision screening for strabismus and amblyopia in France: 23 years experience in the Alsace region [Abstract]. Binocular Vision \& Strabismus Quarterly, 19(3), 151-158. Retrieved January 16, 2006, from the PubMed database.

Spitzer, D. R. (1996). 20 ways to motivate trainees. In D. Zielinski (Ed.), Delivering training: Mastery in the classroom ( $3^{\text {rd }}$ ed., pp. 79-81). Minneapolis, MN: Lakewood Books.

Stifter, R., Burggasser, G., Hirmann, E., Thaler, A., \& Radner, W. 2005. Monocular and binocular reading performance in children with microstrabismic amblyopia [Abstract]. British Journal of Ophthalmology, 89(10), 1324-1329. Retrieved January 16, 2006, from the PubMed database.

Strabismus (Cross-Eyes). (1998). American Family Physician, 58(3), 703. Retrieved September 29, 2005, from http://www.aafp.org/afp/980901ap/980901a.html

Sturner, R. A., Green, J. A., Funk, S. G., Jones, C. K., \& Chandler, A. C. (1981, March/April). A developmental approach to preschool vision screening. Journal of Pediatric Ophthalmology and Strabismus, (18)2, 61-67.

Summary of actions: Medical student section resolutions. (2005). Annual meeting the American Medical Association House of Delegates, Chicago, IL, June 18, 2005. Retrieved September 30, 2005, from http://www.ama-assn.org/ama1/pub/upload/mm/15/ a05_final_actions.pdf

Szarek, E. (1996). 16 ways to save time in the classroom. In D. Zielinski (Ed.), Delivering training: Mastery in the classroom ( $3^{\text {rd }}$ ed., pp. 13-16). Minneapolis, MN: Lakewood Publications, Inc. 
Szumlas, G. A. (2002). Development of an office-based curriculum of common pediatric primary care skills for residents. Academic Medicine, 77(7), 749.

Tananuvat, N., Manassaikorn, A., Worapong, A., Kupat, J., Chuwuttayakorn, J., \& Wattananikorn, S. (2004). Vision screening in schoolchildren: Two year results. Journal of the Medical Association of Thailand, 87(6), 679-685.

Taylor, K., Marienau, C., \& Fiddler, M. (2000). Developing adult learners: Strategies for teachers and trainers. San Francisco: Jossey-Bass.

Teplin, S. W. (1995). Visual impairment in infants and young children. Infants and Young Children, 8(1), 18-51.

The Pediatric Eye Disease Investigator Group. (2002). The clinical profile of moderate amblyopia in children younger than 7 years. Archives of Ophthalmology, 120(3), 281287.

The Vision in Preschoolers Study Group. (2003). Threshold visual acuity testing of preschool children using the crowded HOTV and Lea Symbols acuity tests. Journal of AAPOS, 7(6), 396-399.

The Vision in Preschoolers Study Group. (2004). Comparison of preschool vision screening tests as administered by licensed eye care professionals in the vision in preschoolers study. Ophthalmology, 111(4), 637-650.

The Vision in Preschoolers Study Group. (2005). Preschool vision screening tests administered by nurse screeners compared with lay screeners in the vision in preschoolers study. Investigative Ophthalmology \& Visual Science, 46(8), 2639-2658.

Thompson, J. R., Woodruff, G., Hiscox, F. A., Strong, N., \& Minshull, C. (1991). The incidence and prevalence of amblyopia detected in childhood [Abstract]. Public Health, 105(6), $455-462$.

Thorburn, R., \& Roland, M. (2000). The effectiveness of preschool vision screening by health visitors. British Journal of Community Nursing, 5(1), 41-44.

Thorndike, E. L. (1935). Adult interests. New York: The MacMillan Company.

Thweatt, K. S., \& McCroskey, J. C. (1996). Teacher nonimmediacy and misbehavior: Unintentional negative communication. Communication Research Reports, 13(2), 198204. Retrieved November 1, 2005, from http:/www.jamescmccroskey.com/publications/ 166.pdf 
Tommila, V., \& Tarkkanen, A. (1981). Incidence of loss of vision in the healthy eye in amblyopia. British Journal of Ophthalmology, 65(8), 575-577.

Tongue, A. C. (1987). Refractive errors in children. Pediatric Clinics of North America, 34(6), 1425-1437.

Torok, S. E., McMorris, R. F., \& Lin, W. (2004). Is humor an appreciated teaching tool? Perceptions of professors' teaching styles and use of humor. College Teaching, 52(1), 1420. Retrieved February 25, 2005, from the Academic Search Elite Database.

Ulloth, J. K. (2002, November). The benefits of humor in nursing education [Abstract]. The Journal of Nursing Education, 41(11), 476-481. Retrieved December 2, 2003, from the PubMed database.

United States Census Bureau. (2004). Age and sex of all people, family members and unrelated individuals iterated by income-to-poverty ratio and race: 2003 below 200\% of povertyall races. Retrieved May 29, 2005, from http://pubdb3.census.gov/macro/032004/pov/ new01_200_01.htm

United States Census Bureau. (2004). Families with related children under 6 by number of working family members and family structure: 2003 below 200\% of poverty-all races. Retrieved May 29, 2005, from http://pubdb3.census.gov/macro/032004/pov/ new08_200_01.htm

United States Preventive Services Task Force. (2004, May). Screening for visual impairment in children younger than age 5 years (Agency for Healthcare Research and Quality). Retrieved February 25, 2005, from http:/www.ahrq.gov/clinic/3rduspstf/visionscr/ vischrs.pdf

United States Public Health Service (1994). Vision screening in children. American Family Physician, 50(3), 587-590. Retrieved February 25, 2005, from the Academic Search Elite database.

Verbrugge, L. M., \& Patrick, D. L. (1995). Seven chronic conditions: Their impact on US adults' activity levels and use of medical services. American Journal of Public Health, (85)2, 173-182. Retrieved February 27, 2005, from the Academic Search Elite database.

Vereecken, E. P., \& Brabant, P. (1984). Prognosis for vision in amblyopia after the loss of the good eye. Archives of Ophthalmology, 102(2), 220-224. 
Vision Council of America. (2005, July). Making the grade? An analysis of state and federal children's vision care policy. Alexandria, VA. Retrieved March 4, 2006, from http://www.2020advocacy.com/s_2020/

Vogt, W. P. (1999). Dictionary of statistics \& methodology: A nontechnical guide for the social sciences $\left(2^{\text {nd }}\right.$ ed.). Thousand Oaks, CA: SAGE Publications, Inc.

Wall, T. C., Marsh-Tootle, W., Evans, H. H., Fargason, C. A., Ashworth, C. S., \& Hardin, J. M. (2002). Compliance with vision-screening guidelines among a national sample of pediatricians. Ambulatory Pediatrics, 2(6), 449-455.

Wasserman, R. C., Croft, C. A., \& Brotherton, S. E. (1992). Preschool vision screening in pediatric practice: A study from the pediatric research in office settings (PROS) network Pediatrics, 89(5), 834-838. Retrieved March 20, 2004, from http://www.aap.org/ research/periodicsurvey/peds5_92.htm

Webber, A. L., \& Wood, J. (2005). Amblyopia: Prevalence, natural history, functional effects and treatment. Clinical and Experimental Optometry, 88(6), 365-375. Retrieved January 16, 2006, from http://www.optometrists.asn.au/gui/files/ceo886365.pdf

West Virginia Department of Health and Human Resources. (2004). Age Group Distribution by County, West Virginia Population, 2000, Both Genders, Table 3. Retrieved May 29, 2005, from http://www.wvdhhr.org/bph/oehp/vital02/vs_3A.htm

West Virginia Department of Health and Human Resources. (2001). West Virginia Healthy People 2010 [Electronic version]. Retrieved March 21, 2004, from http://www.wvdhhr.org/bph/hp2010/objective/28.htm

West Virginia KIDS COUNT Fund. (2005). 2005 West Virginia Kids Count Data Book [Electronic version]. Retrieved February 5, 2006, from http://www.wvkidscountfund.org/ pdfs/Data\%20Book/Kidscount_1-90_lo-res.pdf

White, G. W. (2001). Teachers' report of how they used humor when students perceived use of such humor. Education. Retrieved May 23, 2005, from the Academic Search Elite database.

Wiersma, W. (1995). Research methods in education: An introduction (6 ${ }^{\text {th }}$ ed.). Needham Heights, MA: Allyn and Bacon. 
Wiesel, T. N., \& Hubel, D. H. (1965). Comparison of the effects of unilateral and bilateral eye closure on cortical unit responses in kittens. Journal of Neurophysiology, 28(6), 10291040. Retrieved January 14, 2006, from http://jn.physiology.org/cgi/reprint/28/6 /1029.pdf?ijkey $=1198182165 \mathrm{~cd} 63 \mathrm{c} 05$ eefb964bf9fcc $1 \mathrm{cf6d} 11 \mathrm{eec}$

Williams, C., Harrad, R. A., Harvey, I., Sparrow, J. M., and the ALSPAC Study Team. (2001). Screening for amblyopia in preschool children: Results of a population-based, randomized controlled trial. Ophthalmic Epidemiology, 8(5), 279-295.

Williams, C., Northstone, K., Harrad, R. A., Sparrow, J. M., Harvey, I., ALSPAC Study Team (2002). Amblyopia treatment outcomes after screening before or at age 3 years: follow up from randomized trial [Electronic version]. British Medical Journal, 324(7353), 15491551. Retrieved July 4, 2002, from http://bmj.bmjjournals.com/cgi/reprint_abr/324/7353/ 1549.pdf

Williams, C., Northstone, K., Harrad, R. A., Sparrow, J. M., Harvey, I., and the ALSPAC Study Team. (2003). Amblyopia treatment outcomes after preschool screening v school entry screening: Observational data from a prospective cohort study [Electronic version]. British Journal of Ophthalmology, 87(8), 988-993. Retrieved March 4, 2006, from http://bjo.bmjjournals.com

Wilson, J. M. G., \& Jungner, G. (1968). Principles and practice of screening for disease. Geneva, Switzerland: Division of Editorial and Reference Services, World Health Organization.

Winton, P. J. (1990). A systemic approach for planning inservice [sic] training related to Public Law 99-457. Infants and Young Children, 3(1), 51-60.

Witt, G. A. (1996). Six media guidelines for memorable training. In D. Zielinski (Ed.), Delivering training: Mastery in the classroom ( $3^{\text {rd }}$ ed., pp. 111-112). Minneapolis, MN: Lakewood Publications, Inc.

Wlodkowski, R. J. (1999). Enhancing adult motivation to learn (Rev. ed.). San Francisco: Jossey-Bass Publishers.

Wlodkowski, R. J. (2004). Creating motivating learning environments. In M. W. Galbraith (Ed.), Adult learning methods: A guide for effective instruction ( $4^{\text {th }}$ ed.) (pp. 141-164). Malabar, FL: Krieger Publishing Company. 
Wolfe, B. L. (1991). Effective practices in inservice [sic] education: An exploratory study of the perceptions of Head Start participants. Unpublished doctoral dissertation. University of Wisconsin-Madison.

Wolfe, B. L., \& Snyder, P. (1997). Follow-up strategies: Ensuring that instruction makes a difference [Electronic version]. In P. J. Winton, J. A. McCollum, \& C. Catlett (Eds.), Reforming personnel preparation in early intervention: Issues, models \& practical strategies (pp. 173-190). Baltimore: Paul H. Brookes Publishing Co. Retrieved February 8, 2004, from http://www.fpg.unc.edu/ scpp/pdfs/Reforming/07-173_190.pdf

Worthen, B. R., Sanders, J. R., \& Fitzpatrick, J. L. (1997). Program evaluation: Alternative approaches and practical guidelines ( $2^{\text {nd }}$ ed.). White Plains, NY: Addison Wesley Longman, Inc.

Wu, C., \& Hunter, D. G. (2006). Amblyopia: Diagnostic and therapeutic options. American Journal of Ophthalmology, 141(1), 175-184.

Yawn, B. P., \& Kurland, M. (1998). Barriers to seeking care following school vision screening in Rochester, Minnesota. Journal of School Health, 68(8), 319-324. Retrieved March 12, 2005, from the Academic Search Elite database.

Yawn, B. P., Lydick, E. G., Epstein, R., \& Jacobsen, S. J. (1996). Is school vision screening effective? Journal of School Health, 66(5), 171-175.

Zemke, R., \& Zemke, S. (1996) Adult learning: what do we know for sure? In D. Zielinski (Ed.), Delivering training: Mastery in the classroom ( $3^{\text {rd }}$ ed., pp. 79-83). Minneapolis, MN: Lakewood Books.

Ziegler, J. B. (1999, December). Humor in medical teaching: The place of humor in medical teaching seems paradoxical. The Medical Journal of Australia, 171(11-12), 579-580. Retrieved December 2, 2003, from http://www.mja.com.au/public/issues/ 171_11_061299/ziegler/ziegler.html 


\section{Appendix A}

\section{West Virginia University Institutional Review Board-Approved Consent and Information Form}

\section{WestVirginiaUniversity}

Consent and Information Form

Vision Initiative for Children's Preschool Vision Screening Workshop: Field Perceptions of Meeting Eight Guiding Principles , of Effective PreschoolVision Screening Training

Introduction: rese arch stuch, which has been explained to me by P. Kay Notting h conducted by P. Kay Nottingham Chaplin, MA, dire ctor of the Vision Initiative for Children (VIC) to fulfill the requirements for a doctoral dissertation in Special Education in the Department of Educational Theory and Practice within the College of Human Resources and Education at West Virginia University, under the supervision of Dr. Elizabeth Dooley, and to evaluate the Vision Initiative for Children's Partners in Preschool Vision Screening Model under the supervision of Ge offrey E. Bradford, MD.

Purposes of the Study:

The purpose of this study is to explare whether VIC's preschool vision screening taining model can serve as a standardized training progr am for teaching and supporting heterogeneous individuals to screen the vision of children ages 3 and 4 . This study is designed to determine whether diverse participants believe VIC's workshop and job aids are comprehensive enough to prepare us for screening the vision of preschoolers. The test is whether VIC's workshop incorporates Eight Guiding Principles of Effective Preschool Vision Screening Training. If we believe VIC meets the guiding principles, then VIC's workshop and job aids are sufficiently comprehensive to continue the study regionally and then to serve as a standardized t aining model.

Description of Procedures:

This study involves an analysis of data from completed instruments to determine whether I learn knowledge and skills at VIC's workshop and retain that knowle dge and skills, to collect my immediate re actions to the workshop, and to collect my reactions to the workshop after I screen vision. For all documentation, I have been asked to complete, or participate in the completion of, seven instruments: (1) an Attendance/Demographics Record at VIC's works hop that serves as a sign-in sheet and information to help analyze other instruments, (2) a pretest at VIC's workshop to me asure the preschool vision screening knowledge and skills I bring to the workshop, (3) a Practice Observation Checklist and Results document when I practice vision screening tests with a parther during the workshop, (4) a posttest at VIC's workshop to measure knowledge and skills l le arned st VIC's workshop, (5) an Imme diate Works hop Evalustion at the end of the works hop, (6) an online or mailed Pastworkshop Evaluation atter screening preschoolers following the workshop, and (7) an online or mailed 3 . Month Posttest 3 months after the workshop. Workshops run around 2 hours for medcal practices and 3 \% hours to 4 hours for all other works hops. I will receive e-mail ar mail reminders to complete the Postworkshop Evaluation and the 3-Month Pasttest. The length of time to complete the post-workshop evaluation and 3 month posttest is individualized, but should re quire no longer than an aver age of 15 minutes. To make instruments as bias-free as possible, I have been instructed to respond to all instruments as hanestly as possible and not to think about how P. Kay Nottingham Chaplin might feel about negafive responses.

I have been told that I may see the documents before signing this consent and that I do not have to answer all the questions if I decide to participate. Approximately 200 to 300 subjects are expected to participate in this study.

\begin{tabular}{|l|l|l|l|}
\hline Submission date & Page lof 2 & Initials & Date \\
\hline
\end{tabular}

\begin{tabular}{|c|c|}
\hline 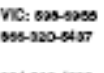 & 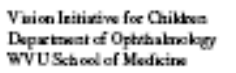 \\
\hline $\begin{array}{l}004-456-4000 \\
000-442-6027 \\
004-456-005:\end{array}$ & $\begin{array}{l}\text { Slodim Orve } \\
\text { PO Bex gig3 } \\
\text { Morganlown W W } 26506.9193\end{array}$ \\
\hline
\end{tabular}

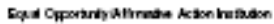


Vision Initatwe for Children's Preschool Vision Screening Workshop: Field Perceptions of Meeting Eight Guidng Ptinciples of Elfective Preschool Vision Screening Training

Risks and Discomforts:

There are no known or expected risks from participating in this study.

Alternatives:

I understand that I do not have to participate in this study and can still participate in the training workshop.

Benefits:

I understand that this study is not expected to be of direct benefit to me, but the knowledge gained may be of benefit to others.

\section{Contact Persons:}

For more information about this research, I can contact P. Kay Nottingham Chaplin, MA, at 304/598-6968, or her supervisor, Geoffrey $\mathrm{E}$. Bradford, $\mathrm{MD}$, at the same number. For information regarding my rights as a rese ar ch project, I may contact the Office of Rese arch Compliance at 304/293-7073.

Confidentiality:

I understand that any information about me obtained as a result of ny participation in this research will be kept as confidential as legaly possible. I understand that my research records and test results, just like hospital records, may be subpoensed by court order or may be inspected by the study sponsor or federal re gul atory authorities (including the FDA if applicable) without my additional consent. In any publications that result from this research, neither my name nor any information from which I might be identfied will be published without my consent.

Voluntary Participastion:

Participation in this study is voluntary. I understand that I am free to withdraw my consent to participate in this study at any time and that such refusal to participate will not affect my status as a VIC preschool vision screening partner. Refusal to participate or withdr awal will involve no penalty to me. I have been given the opportunity to ask questions about the research, and I have received answers concerning areas I did not understand. In the event new information becomes svalable that may affect my willingness to continue to participate in the study, this information will be given to me so I may make an informed decision about my perticipetion.

The original Consent and Information Form, the original seven instruments, the handout packet, and the Vision Screening At-A-Glance Flipchart, indicating WVU Institutional Review Board approval, are on file in the VIC office and I can see a stamped copy amytime I want.

Upon signing this form, I will receive an unsigned copy. I can request and receive a signed copy from the VIC office.

I willingly consent to participate in this research.

Signature of Participant

Signature of Co-Investigator
Date

Date
Time

Time 


\section{Appendix B}

Vision Initiative for Children's Vision Screening Kit

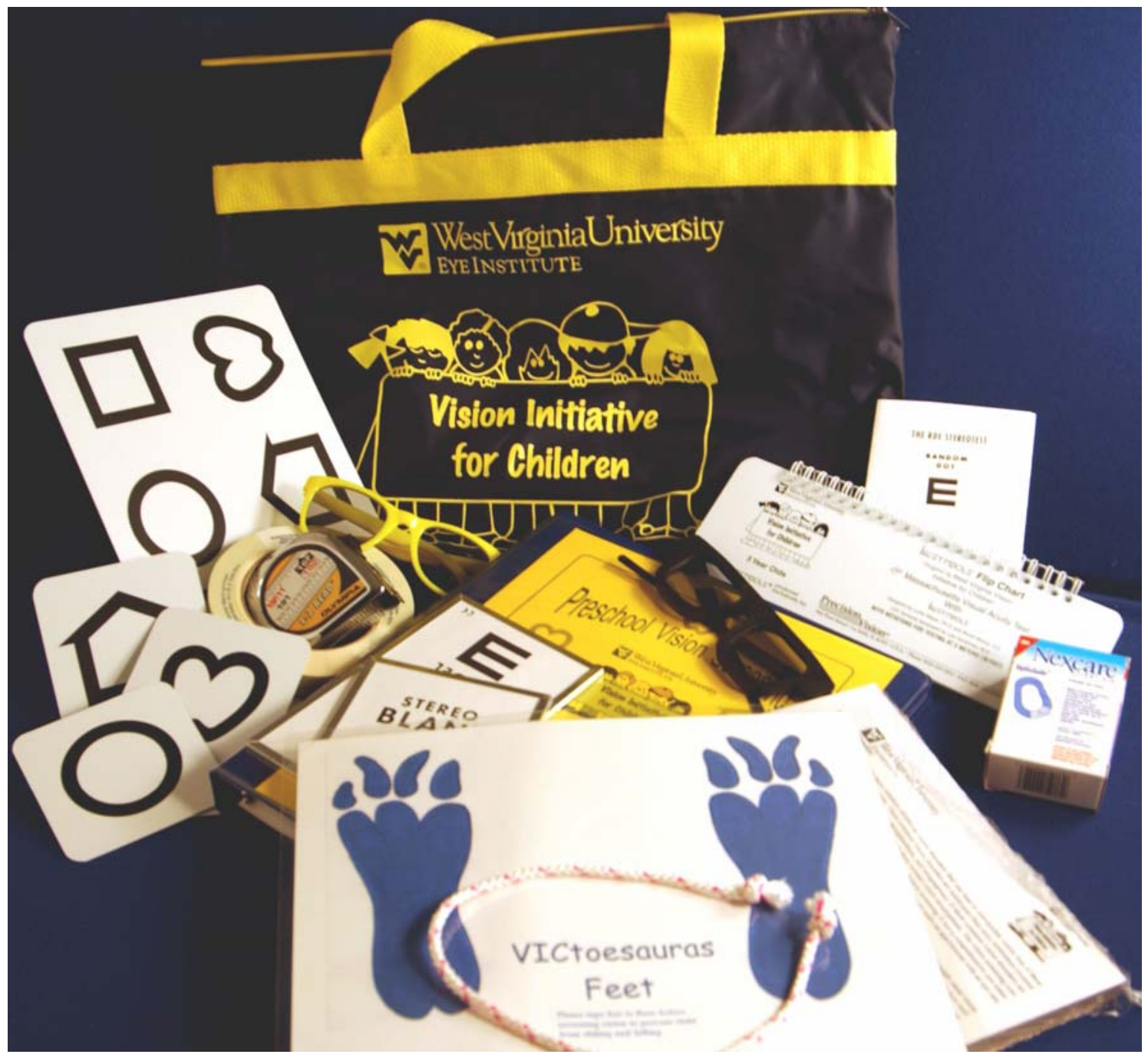




\section{Appendix C}

Lea Symbols ${ }^{\mathrm{TM}}$ Flipchart

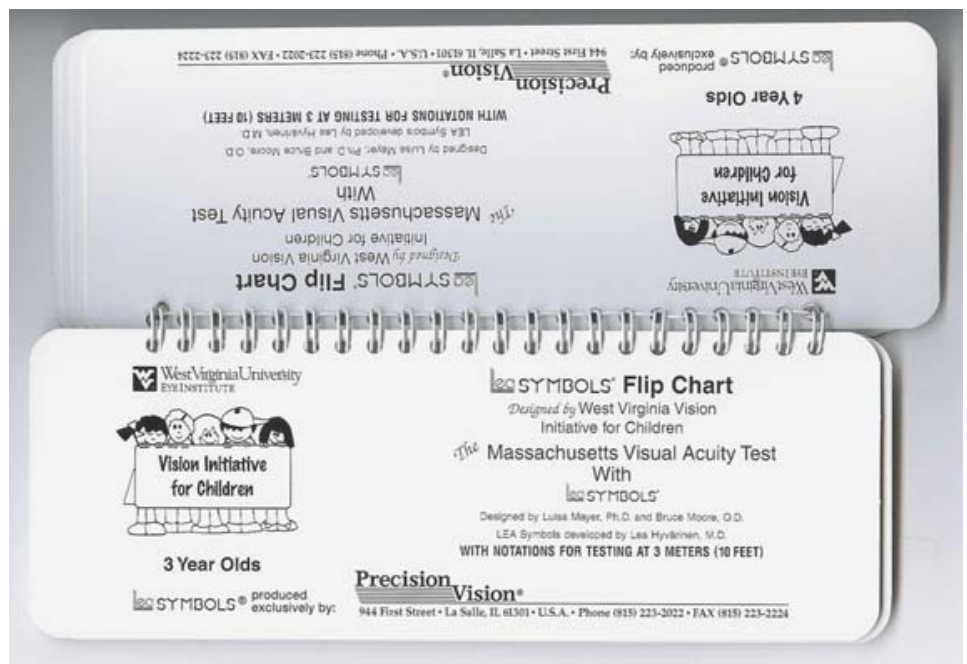

Front and Back Covers of Lea Symbols ${ }^{\mathrm{TM}}$ Flipchart

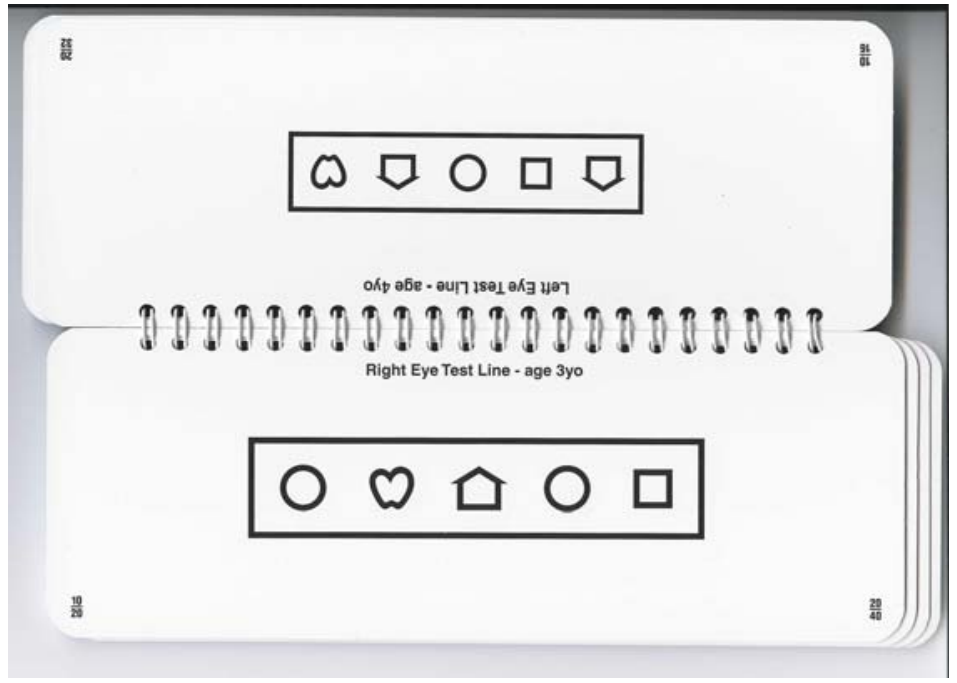

Inside pages of Lea Symbols ${ }^{\mathrm{TM}}$ Flipchart; larger test line is for 3-year-old children 


\section{Appendix D}

Random Dot E Stereoacuity Test

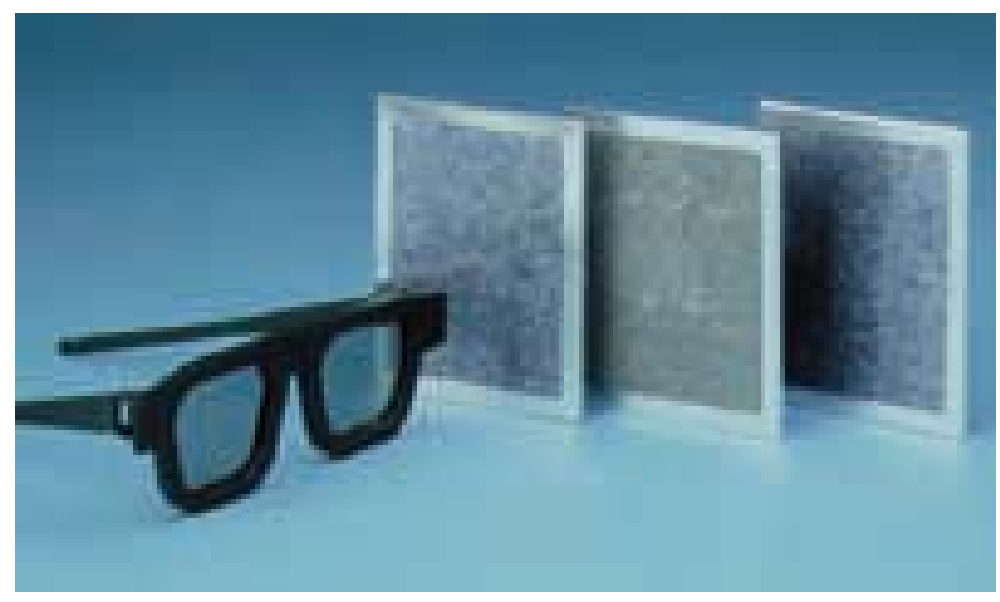

Random Dot E polarized glasses and three test cards 


\section{Appendix E}

Attendance/Demographics Record

\section{Attendance/Demographics Record}

Directions: Please print. Please complete all sections.

1. $\square$ First workshop $\square$ Refresher workshop

2. Date:

3. Training location:

4. Name:

5. E-mail:

6. Your age:

7. Do you have Internet access? $\square$ Yes $\square$ No

8. How often do you use the Internet?

$\square$ Daily $\square$ 2-3 times a week $\square$ At least 1 time a week $\square$ 2-3 times a month

$\square$ At least 1 time a month $\quad \square$ Less than 1 time a month $\quad \square$ Never

9. Employer:

10. Mailing address:

11. Telephone number:

12. Job Title:

13. Length of time in your current job:

14. Length of time in your field:

15. Does your job require you to screen the vision of children ages 3 and 4 ? $\quad \square$ Yes $\quad \square$ No

16. Are you employed by a Head Start agency? $\square$ Yes $\square$ No

17. College Degree:

18. Did your college coursework train you to screen vision of children ages 3 through 5 ?

$\square$ Yes $\square$ No 
19. What vision screening tests are you currently using to screen vision of children ages 3 through 5 ?

a. How were you trained to use these screening tests?

b. How long was the training session?

20. On average, how many children have you screened prior to today's workshop that were age: $3 ?$ $4 ?$ $5 ?$

21. On average, how many children do you anticipate screening between today and Feb. 1, 2005, that are age: 3 ? $4 ?$ $5 ?$ 


\section{Appendix F}

Pretest/Posttest/3-Month Posttest

\section{T E S T}

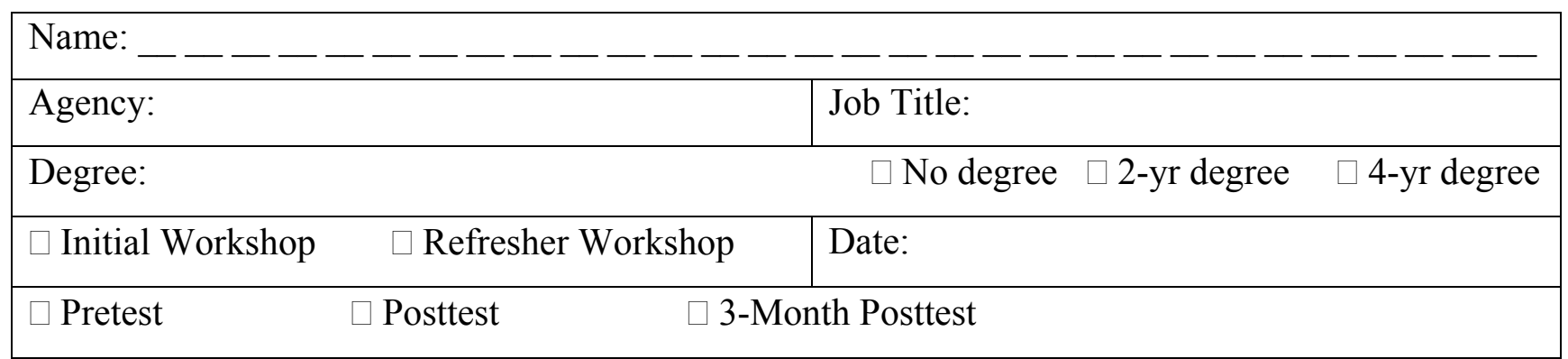

Directions: Circle the correct response.

1. Vision screening is a uniform, set of simple tests designed to:
a. Detect vision problems.
b. Diagnose vision problems.
c. Detect possible vision problems.
d. Diagnose possible vision problems.

2. What 3 vision disorders is vision screening designed to detect?
a. Abnormal refractive errors, ptosis, amblyopia
b. Abnormal refractive errors, strabismus, cataract
c. Abnormal refractive errors, ptosis, cataract
d. Abnormal refractive errors, strabismus, amblyopia

3. The prevalence of vision disorders in young children is:
a. 1 in 50
b. 1 in 500
c. 1 in 20
d. 1 in 200

4. Preschool vision screening is important because children have better chances for normal vision development when vision problems are detected and treated early, preferably before a child is age:
a. 5 .
b. 8 .
c. 10 .
d. 12 . 
5. Match the test to the appropriate testing distances:

\begin{tabular}{|l|l|}
\hline Lea Symbols $^{\mathrm{TM}}$ Flip Chart & a. Stand close to the child \\
\hline Lea Symbols $^{\mathrm{TM}}$ Testing Card & b. 16 inches \\
\hline Random Dot E & c. 10 feet \\
\hline
\end{tabular}

6. To pass the Lea Symbols ${ }^{\mathrm{TM}}$ test, children must identify the symbols:
a. 5 of 5 trials
b. 3 of 5 trials
c. 4 of 5 trials
d. 2 of 5 trials

7. Match the definitions:

\begin{tabular}{|c|c|}
\hline Ptosis & $\begin{array}{l}\text { a. Hyperopia, myopia, anisometropia, and } \\
\text { astigmatism }\end{array}$ \\
\hline Strabismus & b. Droopy eye lid \\
\hline Amblyopia & c. Crossed or misaligned eyes \\
\hline Abnormal refractive errors & $\begin{array}{l}\text { d. Poor vision development because the brain does } \\
\text { not receive normal sensory input from an eye with } \\
\text { a defect in it }\end{array}$ \\
\hline _ Visual acuity & $\begin{array}{l}\text { e. Visual blending of two images into one image for } \\
\text { depth perception }\end{array}$ \\
\hline _ Stereopsis & $\begin{array}{l}\text { f. Test of the eye's ability to distinguish object } \\
\text { details and shapes at a specified distance }\end{array}$ \\
\hline
\end{tabular}

8. Parents know their children best; thus, prior to screening, parents typically know if their children have vision problems that require treatment.
a. True
b. False

9. To pass the Random Dot E, children must identify the "E":
a. 5 of 5 trials
b. 3 of 5 trials
c. 4 of 5 trials
d. 2 of 5 trials

10. If a child resists having one eye covered, but not the other, what might be going on?
a. The child may have strabismus.
b. The child may have a cataract.
c. The child may have abnormal refractive errors.
d. The child may have amblyopia. 
11. If a child has prescription eye glasses, but forgot them at home, it is ok to screen the child:
a. True
b. False

12. If the child passes the vision screening, but the parent still has a concern, you should:
a. Ask another trained individual in your agency to conduct a $2^{\text {nd }}$ screening.
b. Encourage the parent to schedule and attend a full eye examination.
c. Tell the parent to not worry; the screening would have picked up her concern.
d. Try to diagnose the concern.

13. If you mistakenly screen a 4-year-old with the 3-year-old side of the Lea Symbols ${ }^{\mathrm{TM}}$ Flip Chart and the child passes, you should:
a. I won't be using the flip chart.
b. Move on to the Random Dot E, without rescreening.
c. Screen again using the 4-year-old side.
d. Screen another child and then return to the child I incorrectly screened and start over.

14. If a child does not pass one eye of the Lea Symbols ${ }^{\mathrm{TM}}$ Flip Chart and passes the other eye of the Lea Symbols ${ }^{\mathrm{TM}}$ Flip Chart and the Random Dot E, what should you do?
a. Nothing, the child has passed vision screening.
b. Rescreen according to our agency policy.
c. Encourage the parent/guardian to schedule and attend a comprehensive eye exam.
d. Ask another screener to rescreen the child for a $2^{\text {nd }}$ opinion.

15. When you use the large teaching card with the Lea Symbols ${ }^{\mathrm{TM}}$ Flip Chart, are the child's eyes covered or uncovered?
a. One eye is covered.
b. Both eyes are uncovered.

16. When you use the Lea Symbols ${ }^{\mathrm{TM}}$ Flip Chart, are the child's eyes covered or uncovered?
a. One eye is covered.
b. Both eyes are uncovered.

17. If you are doing the Random Dot $\mathrm{E}$ and a child is wearing prescription eye glasses, what do you do?
a. Remove the child's prescription eye glasses until I finish testing with the Random Dot E.
b. Place the polarized glasses under the child's prescription eye glasses.
c. Place the polarized glasses over the child's prescription eye glasses.
d. Screen first with both sets of glasses and rescreen using only the polarized glasses.

18. What do you do if a child is untestable - meaning the child will not participate in vision screening - and your screening policies do not require rescreening?
a. Bribe the child with candy.
b. Ask another screener in the community to screen the child.
c. Operate as if the child has no problems and screen again next year.
d. Make a referral and encourage the parent to take the child to an eye exam appointment. 
19. After I have screened a minimum of 50 children, I can provide medical advice about vision disorders to parents of children who failed the screening.

a. True

b. False

20. After today's workshop, how often should you screen?
a. 2 times a year, once in the fall and once in the spring
b. 1 time only
c. Annually

21. For posttest only - Did you feel confident when answering the questions on the posttest?

$\square$ Yes $\quad \square$ Somewhat $\quad \square$ No

22. For 3-month test only - Which job aids did you review to complete the posttest (check all that apply)?

$\square$ Hand-out packet $\quad \square$ Vision Screening At-A-Glance Flowchart $\quad \square$ Web site $\quad \square$ None 


\section{Appendix G}

Workshop Evaluation

\begin{tabular}{|c|c|c|}
\hline \multicolumn{3}{|c|}{ VIC Preschool Vision Screening Workshop Evaluation } \\
\hline \multicolumn{3}{|c|}{ Name: } \\
\hline Training Location: & \multicolumn{2}{|c|}{$\square$ Initial $\square$ Refresher } \\
\hline \multicolumn{3}{|c|}{$\begin{array}{l}\text { Please assist us in evaluating the quality of VIC's training workshop by completing this questionnaire. } \\
\text { For each question, circle the number that best represents your view: } \\
\qquad 1=\text { No } 2 \text { = Somewhat } 3=\text { Yes, definitely }\end{array}$} \\
\hline \multicolumn{3}{|l|}{ Part 1: Instructional Content and Delivery System } \\
\hline \multicolumn{2}{|l|}{$\begin{array}{l}\text { 1. Were the training objectives clear and realistic? } \\
\text { Comments/suggestions: }\end{array}$} & 123 \\
\hline \multicolumn{2}{|l|}{$\begin{array}{l}\text { 2. Did you learn what you expected to learn? } \\
\text { Comments/suggestions: }\end{array}$} & 123 \\
\hline \multicolumn{2}{|l|}{$\begin{array}{l}\text { 3. Was there an adequate amount of time allotted to each topic? } \\
\text { Comments/suggestions: }\end{array}$} & 123 \\
\hline \multicolumn{2}{|c|}{$\begin{array}{l}\text { 4. Was the information about vision disorders a necessary part of this workshop? } \\
\text { Comments/suggestions: }\end{array}$} & 123 \\
\hline \multicolumn{2}{|l|}{$\begin{array}{l}\text { 5. Did the animated PowerPoint presentation help you learn? } \\
\text { Comments/suggestions: }\end{array}$} & 123 \\
\hline \multicolumn{3}{|c|}{ 6. Was the PowerPoint presentation adequate in the following categories? } \\
\hline a. Vocabulary & & 123 \\
\hline b. Amount of slides per topic & & 123 \\
\hline c. Clarity of descriptions & & 123 \\
\hline d. Clarity of examples & & 123 \\
\hline \multicolumn{2}{|l|}{$\begin{array}{l}\text { e. Content sequence (simple to more complex) } \\
\text { Comments/suggestions: }\end{array}$} & 123 \\
\hline \multicolumn{2}{|c|}{$\begin{array}{l}\text { 7. Was the instructor's modeling and demonstration of tests a necessary part of this } \\
\text { workshop? } \\
\text { Comments/suggestions: }\end{array}$} & 123 \\
\hline \multicolumn{2}{|l|}{$\begin{array}{l}\text { 8. Was practicing the test a necessary part of this workshop? } \\
\text { Comments/suggestions: }\end{array}$} & 123 \\
\hline \multicolumn{2}{|c|}{$\begin{array}{l}\text { 9. When you practiced with a partner, did the instructor's feedback help you learn? } \\
\text { Comments/suggestions: }\end{array}$} & 123 \\
\hline
\end{tabular}




\begin{tabular}{|c|c|}
\hline $1=$ No $\quad 2=$ Somewhat $3=Y e$ & definitely \\
\hline $\begin{array}{l}\text { 10. Was learning the importance of encouraging parents to arrange and attend a follow-up } \\
\text { eye exam a necessary part of this workshop? } \\
\text { Comments/suggestions: }\end{array}$ & 123 \\
\hline $\begin{array}{l}\text { 11. Was the theory about the importance of screening the vision of preschoolers a necessary } \\
\text { part of this workshop? } \\
\text { Comments/suggestions: }\end{array}$ & $\begin{array}{lll}1 & 2 & 3\end{array}$ \\
\hline $\begin{array}{l}\text { 12. Do you understand what you were supposed to learn today? } \\
\text { Comments/suggestions: }\end{array}$ & $\begin{array}{lll} & 2 & 3\end{array}$ \\
\hline $\begin{array}{l}\text { 13. Now that you have practiced using the tests, do you feel ready to screen vision? } \\
\text { Comments/suggestions: }\end{array}$ & 123 \\
\hline $\begin{array}{l}\text { 14. Think about how you learn new material. Did the workshop meet your learning style? } \\
\text { Comments/suggestions: }\end{array}$ & $\begin{array}{lll}1 & 2 & 3\end{array}$ \\
\hline $\begin{array}{l}\text { 15. Was the content too difficult to learn? } \\
\text { Comments/suggestions: }\end{array}$ & $\begin{array}{lll}1 & 2 & 3\end{array}$ \\
\hline $\begin{array}{l}\text { 16. If you thought the instructor was humorous and you laughed during the workshop, did the } \\
\text { humor and laugher help you learn? } \\
\text { Comments/suggestions: }\end{array}$ & $\begin{array}{lll}1 & 2 & 3\end{array}$ \\
\hline $\begin{array}{l}\text { 17. Should we delete the dancing chicken from the PowerPoint presentation? } \\
\text { Comments/suggestions: }\end{array}$ & 123 \\
\hline \multicolumn{2}{|l|}{ Part 2: Instructor Skills } \\
\hline $\begin{array}{l}\text { 1. Was the instructor enthusiastic? } \\
\text { Comments/suggestions: }\end{array}$ & 123 \\
\hline $\begin{array}{l}\text { 2. Did the instructor use high-quality teaching materials? } \\
\text { Comments/suggestions: }\end{array}$ & $\begin{array}{lll}1 & 2 & 3\end{array}$ \\
\hline $\begin{array}{l}\text { 3. Did the instructor have expert knowledge of the content? } \\
\text { Comments/suggestions: }\end{array}$ & $\begin{array}{lll}1 & 2 & 3\end{array}$ \\
\hline $\begin{array}{l}\text { 4. Did the instructor make an effort to help you feel comfortable? } \\
\text { Comments/suggestions: }\end{array}$ & 123 \\
\hline $\begin{array}{l}\text { 5. Did the instructor provide you with adequate help in learning the new material? } \\
\text { Comments/suggestions: }\end{array}$ & 123 \\
\hline $\begin{array}{l}\text { 6. Did the instructor hold your interest? } \\
\text { Comments/suggestions: }\end{array}$ & 123 \\
\hline
\end{tabular}




\begin{tabular}{|c|c|}
\hline $1=$ No $\quad 2=$ Somewhat & $3=$ Yes, definitely \\
\hline $\begin{array}{l}\text { 7. Did the instructor use humor appropriately? } \\
\text { Comments/suggestions: }\end{array}$ & 123 \\
\hline $\begin{array}{l}\text { 8. Was the instructor's pace appropriate (i.e., not too slow, not too fast)? } \\
\text { Comments/suggestions: }\end{array}$ & 123 \\
\hline $\begin{array}{l}\text { 9. Did the instructor focus the training on the workshop objectives? } \\
\text { Comments/suggestions: }\end{array}$ & 123 \\
\hline $\begin{array}{l}\text { 10. Was knowing what topics had been covered and what topics were to be covered a } \\
\text { necessary part of the workshop? } \\
\text { Comments/suggestions: }\end{array}$ & 123 \\
\hline $\begin{array}{l}\text { 11. Did the instructor answer your questions and address your concerns? } \\
\text { Comments/suggestions: }\end{array}$ & 123 \\
\hline $\begin{array}{l}\text { 12. Did the instructor use the training time effectively? } \\
\text { Comments/suggestions: }\end{array}$ & 123 \\
\hline $\begin{array}{l}\text { 13. Did the instructor provide sufficient feedback on your practice exercises? } \\
\text { Comments/suggestions: }\end{array}$ & 123 \\
\hline $\begin{array}{l}\text { 14. Is the instructor a good teacher? } \\
\text { Comments/suggestions: }\end{array}$ & 123 \\
\hline $\begin{array}{l}\text { 15. Did the instructor provide too much repetition or review? } \\
\text { Comments/suggestions: }\end{array}$ & 123 \\
\hline \multicolumn{2}{|l|}{ Part 3: Logistical Arrangements } \\
\hline $\begin{array}{l}\text { 1. Were the refreshments fresh and tasty? } \\
\text { Comments/suggestions: }\end{array}$ & 123 \\
\hline $\begin{array}{l}\text { 2. Were the beverages appropriately hot or cold and ready on time? } \\
\text { Comments/suggestions: }\end{array}$ & 123 \\
\hline $\begin{array}{l}\text { 3. Was the room the right temperature? } \\
\text { Comments/suggestions: }\end{array}$ & 123 \\
\hline $\begin{array}{l}\text { 4. Were the chairs comfortable? } \\
\text { Comments/suggestions: }\end{array}$ & 123 \\
\hline $\begin{array}{l}\text { 5. Was the workshop schedule planned well (i.e., breaks in a timely manner)? } \\
\text { Comments/suggestions: }\end{array}$ & 123 \\
\hline
\end{tabular}




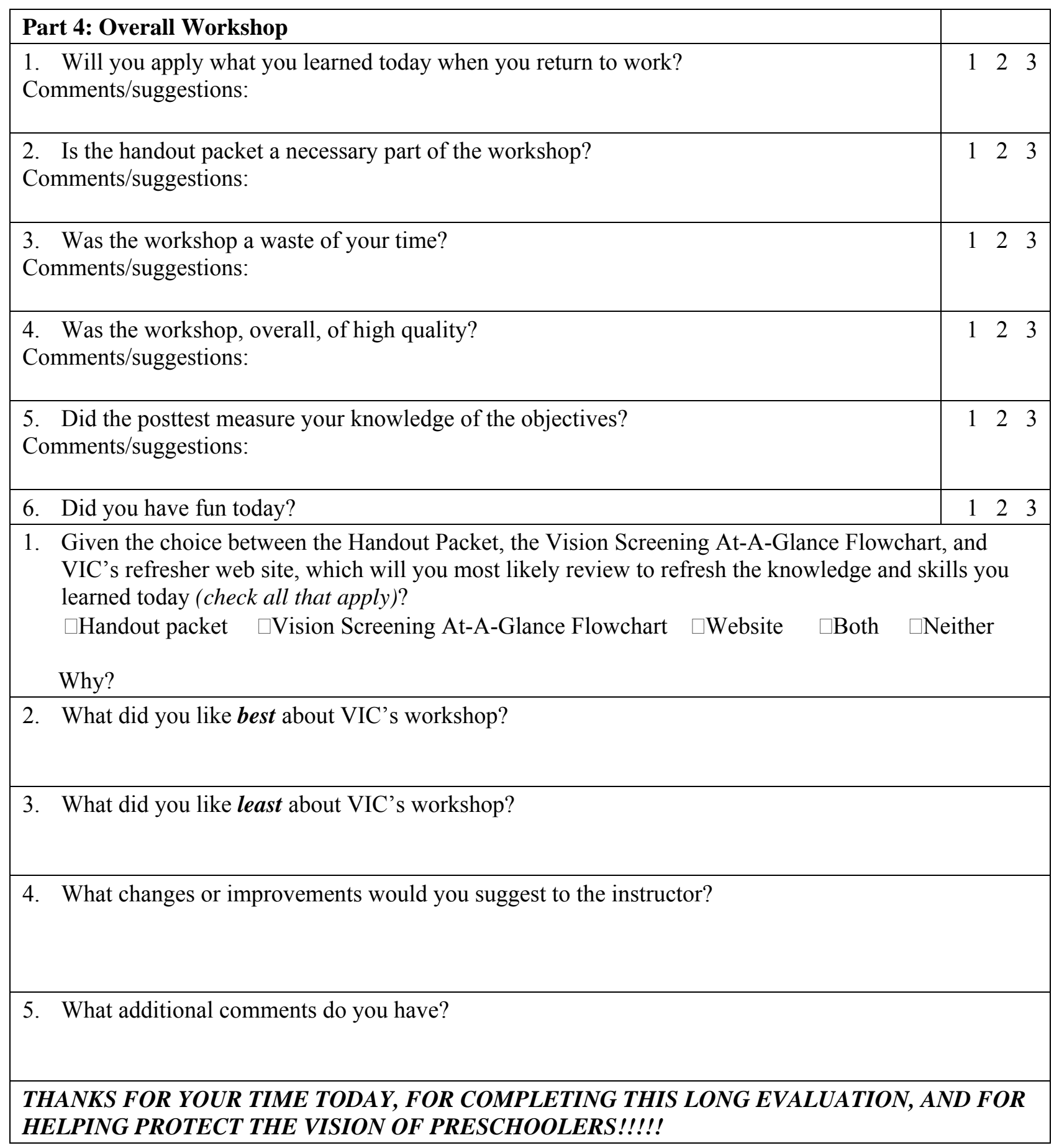

Questionnaire created with guidance from:

Caffarella, R. S. (2002). Planning programs for adult learners: A practical guide for educators, trainers, and staff developers ( $2^{\text {nd }}$ ed.). San Francisco: Jossey-Bass.

Dick, W., Carey, L., \& Carey, J. O. (2001). The systematic design of instruction (5 ${ }^{\text {th }}$ ed.). New York: Addison-Wesley Educational Publishers, Inc.

Guskey, T. R. (2000). Evaluating professional development. Thousand Oaks, CA: Corwin Press, Inc. 


\section{Appendix H}

Postworkshop Evaluation

Name:

Date:

Vision Initiative for Children's Follow-Up Questionnaire

to

Preschool Vision Screening Training Workshop

Directions: Now that you have conducted preschool vision screening, please complete all sections of questionnaire. Your responses after using skills and knowledge learned during VIC's workshop will help VIC provide more effective future workshops.

1. When you think about VIC's preschool vision screening workshop, list 3 components that you remember most vividly:

a.

Why?

b.

Why?

c.

Why?

2. Now that you have completed preschool vision screening after attending VIC's workshop:

a. What occurred during preschool vision screening that was not discussed in the workshop?

b. How could VIC's workshop have better prepared you for screening vision?

c. What parts of VIC's workshop were most helpful? 
d. What parts of VIC's workshop were least helpful?

e. What should be added to the workshop to better prepare future screeners?

f. What should be deleted from the workshop that you considered a waste of time?

3. Use of Job Aids as Follow-Up Support to the Workshop:

Please indicate which job aids you used by marking the box. Then, please how well the job aid(s) helped you refresh knowledge and skills learned at the workshop. If you have not reviewed job aids, skip this section and move to the next section.

\begin{tabular}{|l|c|c|c|}
\hline Job Aides & $\begin{array}{l}\text { Not } \\
\text { Helpful }\end{array}$ & $\begin{array}{l}\text { Sort of } \\
\text { Helpful }\end{array}$ & $\begin{array}{l}\text { Extremely } \\
\text { Helpful }\end{array}$ \\
\hline$\square$ Hand-Out Packet & 1 & 2 & 3 \\
\hline$\square$ Password-Protected Web Site & 1 & 2 & 3 \\
\hline$\square$ Vision Screening At-A-Glance Flowchart & 1 & 2 & 3 \\
\hline
\end{tabular}

a. Which job aid was the most helpful and why?

b. What items did you review in the job aids you chose? (Answer all that apply.)

$\square$ I reviewed this information in the Hand-Out Packet:

$\square$ I reviewed this information in the Password-Protected Web Site:

$\square$ I reviewed this information it the Vision Screening At-A-Glance Flowchart:

c. When did you review the job aids you checked in the table? (Check all that apply.)

$\square$ Within the week after the workshop

$\square$ During the week before screening

$\square$ Between a week after the workshop and the week of screening

$\square$ Other:

4. What material have you printed from VIC's Password-Protected Web Site?

a. To whom did you give the printed material?

5. Have you visited VIC's public web site?

$\square$ Yes $\square$ No 


\begin{tabular}{|l|c|c|c|}
\hline $\begin{array}{l}\text { INSTRUCTIONS: Now that you have screened the vision of } \\
\text { preschoolers, please circle the number that best represents your } \\
\text { view for Questions 6 through 12: }\end{array}$ & No & Somewhat & $\begin{array}{c}\text { Yes, } \\
\text { definitely }\end{array}$ \\
\hline $\begin{array}{l}\text { 6. Were the job aids (Hand-Out Packet and/or the Password- } \\
\text { Protected Web Site and/or the Vision Screening At-A-Glance } \\
\text { Flowchart) enough follow-up support to the workshop? }\end{array}$ & 1 & 2 & 3 \\
\hline $\begin{array}{l}\text { 7. If you have encouraged parents of children who did not pass } \\
\text { vision screening to arrange a comprehensive eye exam for their } \\
\text { children, did VIC's workshop provide enough information to } \\
\text { share with parents? }\end{array}$ & 1 & 2 & 3 \\
\hline $\begin{array}{l}\text { 8. Was the instructor's modeling and demonstration of the tests } \\
\text { helpful? }\end{array}$ & 1 & 2 & 3 \\
\hline $\begin{array}{l}\text { 9. Was practicing the tests with a partner helpful? } \\
\text { 10. Did the lecture at the workshop help prepare you for screening } \\
\text { the vision of preschoolers? }\end{array}$ & 1 & 2 & 3 \\
\hline $\begin{array}{l}\text { 11. Did the PowerPoint that accompanied the lecture at the } \\
\text { workshop help prepare you for screening the vision of } \\
\text { preschoolers? }\end{array}$ & 1 & 2 & 3 \\
\hline $\begin{array}{l}\text { 12. Was the overall workshop effective in preparing you to screen } \\
\text { vision? }\end{array}$ & 1 & 2 & 3 \\
\hline
\end{tabular}

13. Would you recommend VIC's training workshop to your colleagues?

$\square$ Yes $\quad \square$ No $\quad \square$ Undecided

14. What additional comments do you have about VIC's Partners in Preschool Vision Screening System and/or its training model?

15. What support do you need from VIC to screen the vision of preschoolers that you are not receiving?

Thank you for completing this questionnaire!

Questionnaire created with guidance from:

Caffarella, R. S. (2002). Planning programs for adult learners: A practical guide for educators, trainers, and staff developers ( $2^{\text {nd }}$ ed.). San Francisco: Jossey-Bass.

Dick, W., Carey, L., \& Carey, J. O. (2001). The systematic design of instruction (5 ${ }^{\text {th }}$ ed.). New York: AddisonWesley Educational Publishers, Inc.

Guskey, T. R. (2000). Evaluating professional development. Thousand Oaks, CA: Corwin Press, Inc. 


\section{Appendix I}

Visual Representation of Research Questions, Instruments, and Data Analysis

\section{Procedures for Analyzing Data}

Began data analysis by conducting Cronbach's alpha on Workshop Evaluation to determine internal consistency

\begin{tabular}{|c|c|c|}
\hline Research question & $\begin{array}{l}\text { Instruments from which data } \\
\text { were collected }\end{array}$ & How data were analyzed \\
\hline $\begin{array}{l}\text { 1. Overarching question: } \\
\text { What do participants report } \\
\text { about VIC's workshop? }\end{array}$ & $\begin{array}{l}\text { Data were collected from the } \\
\text { Instructional Content and Delivery } \\
\text { subscale of the Workshop } \\
\text { Evaluation }\end{array}$ & $\begin{array}{l}\text { This question was not } \\
\text { explicitly answered. } \\
\text { Responses to subquestions } \\
\text { were used to answer this } \\
\text { question. }\end{array}$ \\
\hline $\begin{array}{l}\text { 1. a. Across all } \\
\text { participants, what do } \\
\text { participants report about } \\
\text { the instructional content } \\
\text { and delivery system of } \\
\text { VIC's preschool vision } \\
\text { screening workshop? }\end{array}$ & $\begin{array}{l}\text { Data were collected from the } \\
\text { Instructional Content and Delivery } \\
\text { System subscale of the Workshop } \\
\text { Evaluation }\end{array}$ & $\begin{array}{l}\text { Scores were totaled for each } \\
\text { individual participant and } \\
\text { compared with a possible } \\
\text { score. Frequencies and } \\
\text { percentages were reported. } \\
\text { Negative Items } 15 \text { and } 17 \\
\text { were reversed. }\end{array}$ \\
\hline $\begin{array}{l}\text { 1. b. (1) Is there a } \\
\text { significant difference in } \\
\text { means on participants' } \\
\text { scores in instructor skills } \\
\text { due to education? }\end{array}$ & $\begin{array}{l}\text { Responses to Item } 17 \text { from } \\
\text { Attendance/Demographics Record; } \\
\text { Responses from the Instructor } \\
\text { Skills subscale within the } \\
\text { Workshop Evaluation were totaled } \\
\text { with negative Item } 15 \text { reversed }\end{array}$ & $\begin{array}{l}\text { Between groups ANOVA } \\
\text { using } \alpha=.05 \text { significance } \\
\text { level for Instructor Skills } \\
\text { subscale in Workshop } \\
\text { Evaluation ( } 3 \text { levels: } 1=\text { no } \\
\text { college degree; } 2=\text { currently } \\
\text { working toward degree; } \\
3=\text { college degree). }\end{array}$ \\
\hline $\begin{array}{l}\text { 1. c. Across all } \\
\text { participants, what do } \\
\text { participants report about } \\
\text { the logistical arrangements } \\
\text { of VIC's preschool vision } \\
\text { screening workshop? }\end{array}$ & $\begin{array}{l}\text { Data were collected from the } \\
\text { Logistical Arrangements subscale } \\
\text { of the Workshop Evaluation }\end{array}$ & $\begin{array}{l}\text { Scores were totaled for each } \\
\text { individual participant and } \\
\text { compared with a possible } \\
\text { score. Frequencies and } \\
\text { percentages were reported. }\end{array}$ \\
\hline
\end{tabular}


Research question

1. c. (1) Is there a significant difference in means on participants' scores in logistical arrangements due to education?

2. Overarching question: What do participants report about VIC's workshop after they screen vision?

\section{2. a. Across all} participants, do participants report that the overall workshop was effective in preparing them to screen vision?

\section{2. b. Across all} participants, what additional support do participants report they need from VIC to screen the vision of preschoolers?

3. Do participants learn new preschool vision screening knowledge at VIC's workshop?
Instruments from which data were collected

Responses from Item 17 of the Attendance/Demographics Record; Responses from the Logistical Arrangements subscale within the Workshop Evaluation

Data were collected from the Postworkshop Evaluation to answer subquestions, which were used to answer Research Question 2

Item 12 of Postworkshop Evaluation

Open-ended responses to Item 15 of Postworkshop Evaluation

Scores from workshop pretest and posttest
How data were analyzed Between groups ANOVA using $\alpha=.05$ significance level for Logistical Arrangements subscale in Workshop Evaluation (3 levels: $1=$ no college degree; $2=$ currently working toward degree; $3=$ college degree).

This question was not directly answered. Responses to subquestions were used to answer this question.

Scores were totaled for each individual participant. Frequencies and percentages were reported.

Responses were categorized and described by categories, frequencies, and percentages.
Compared scores of all participants as a group on pretest and posttest, reported the number and percentages of participants that scored lower, the same as, or higher on the posttest when compared to the pretest. 
Research question

3. Is there a significant

difference in means on

participants' scores

between the pretest and

posttest?

3. b. Is there a significant difference in means on participants' scores between the pretest and posttest due to education?

4. Do participants maintain knowledge learned at VIC's workshop?
Instruments from which data were collected

Scores from workshop pretest and posttest

Responses to Item 17 on the Attendance/Demographics Record and scores from workshop pretest and posttest
Scores from workshop posttest and the 3-month posttest

How data were analyzed

Repeated measures $t$ test using $\alpha=.05$ significance level with two groups of scores: workshop pretest and posttest. The repeated measure was scores on the workshop pretest and posttest.

Repeated measures ANOVA using $\alpha=.05$ significance level for pretest and posttest scores: ( 3 levels: $1=$ no college degree; $2=$ currently working toward degree; $3=$ college degree). The repeated measure was scores on the workshop pretest and posttest.

Compared scores of all participants on the workshop posttest and the 3-month posttest; reported the number and percentages of participants that scored lower, the same as, or higher on the 3-month posttest than they scored on the workshop posttest.

4. a. Is there a significant Scores from workshop posttest and difference in means on 3-month posttest participants' scores between the workshop posttest and the 3-month posttest?

Repeated measures $t$ test using $\alpha=.05$ significance level with two groups of scores: workshop posttest and 3-month posttest. The repeated measure was scores. 
Research question

b. Is there a significant difference in means on participants' scores between the workshop posttest and the 3-most posttest due to education?
Instruments from which data were collected

Information pulled from Item 17 of Attendance/Demographics Record; scores on posttest and 3-month posttest

How data were analyzed

Repeated measures ANOVA using $\alpha=.05$ significance level for 2 time periods: $1=$ posttest scores and 2=3month posttest scores and 3 education levels: $1=$ no college degree, $2=$ currently working toward a degree, $3=$ college degree. The repeated measure was scores. When significant $F$ test results occurred, post hoc tests were conducted.

Responses were categorized and described according to frequencies and percentages for all participants.

Responses were categorized and described according to categories, frequencies, and percentages.

discussed in VIC's workshop?

Item 2.a. on Postworkshop

Evaluation during preschool vision

screening that was not 
Curriculum Vita

\section{P. Kay Nottingham Chaplin}

304-598-6968 (work)

304-292-7976 (home)

304-216-2035 (cell)

chaplinp@rcbhsc.wvu.edu

pknc@commpluswv.net 


\section{PROFESSIONAL EMPLOYMENT}

WEST VIRGINIA UNIVERSITY

Morgantown, WV

1/1/05 - Present

Adjunct Instructor - Special Education - Department of Educational Theory \& Practice

College of Human Resources and Education - Teaching a class on

collaboration/consultation for special and regular educators.

UNIVERSITY HEALTH ASSOCIATES Morgantown, WV 2/15/01 - Present

Program Director - Vision Initiative for Children - WVU Eye Institute

Collaborating with pediatric ophthalmologist to create and refine pilot preschool vision screening model, design training workshop and train vision screeners (nearly 1,000 in more than 80 workshops to date); creating train-the-trainer model; writing grant proposals; creating and monitoring budget for various grant sources; presenting at state and local conferences, university classes, and organizational functions; creating job descriptions and hiring staff, assisting in creating database, and creating web site.

\section{VALLEY HEALTHCARE SYSTEM}

Morgantown, WV

$2 / 15 / 01-8 / 1 / 02$

Part-Time Program Director - WV Birth to Three Early Intervention at Valley

Managed 4-county component of WV Birth to Three for infants and toddlers with, or at risk of, disabilities or developmental delays and their families; hired and supervised staff of nearly 30 early intervention specialists, paraprofessionals, and contracted speech, physical, and occupational therapists; developed and supervised budget for state and federal dollars, wrote procedures to meet state policies, ensured accountability with Medicaid and Part C of IDEA federal and state mandates; conducted in-home intake procedures with new families; carried a caseload; and helped develop a parent advisory council.

\section{VALLEY HEALTHCARE SYSTEM \\ Morgantown, WV \\ $1 / 6 / 94-2 / 15 / 01$}

Program Director - WV Birth to Three Early Intervention at Valley

Same as above.

KINDER HAUS CHILD CARE CENTER

Morgantown, WV 9/14/92-1/6/94 Program Coordinator/On-Site Valley/Kinder Haus Integrated Project Supervisor

JACKSON \& KELLY Law Firm Position:
Morgantown, WV

Legal Secretary (litigation)

$7 / 90$ to $9 / 14 / 92$

HAYNSWORTH, BALDWIN, JOHNSON \& GREAVES Law Firm Position:

Greenville, SC

$10 / 88$ to $7 / 90$

Legal Secretary (litigation)

DOMINION POST

Morgantown, WV

$9 / 84$ to $6 / 88$

Regional newspaper - daily distribution

Positions: $\quad$ Section Editor, Columnist, Features Writer, and Health and General Assignment Reporter

BECKLEY NEWSPAPERS, INC. Beckley, WV

$11 / 83$ to $9 / 84$

Regional newspaper - daily distribution

Position: Health and Medical Reporter

BRAXTON CITIZENS' NEWS Sutton, WV

$10 / 82$ to $11 / 83$

Community newspaper - weekly distribution

Position: Reporter 
BECKLEY NEWSPAPERS, INC. Beckley, WV

$8 / 79$ to $3 / 81$

Regional newspaper - daily distribution

Position: $\quad$ Police Reporter

BRAXTON DEMOCRAT Sutton, WV 12/78 to 8/79

Community newspaper - weekly distribution

Position: Editor

\section{EDUCATION}

BS, Journalism, News/Editorial, WVU, 1978

MA, Early Intervention Special Education, WVU, 1998

Ed.D., WVU - with anticipated graduation in May 2006

\section{GRANT WRITING}

Helped write a partnership federal grant proposal to create a model for Early Head Start in Monongalia County with the Monongalia County School System and West Virginia University. We were awarded funding and was one of the first 60 selected from a pool of 580 nationwide.

\$ 95,000 Co-investigator - Claude Worthington Benedum Foundation - 7/1/026/30/03

\$ 30,000 Co-investigator - Sisters of St. Joseph Charitable Fund - 7/1/02-6/30/04

$\$ 100,000 \quad$ Co-writer - federal Child Care and Development Block Grant Plan to expand Kinder Haus Child Care Center's before/after school program.

\section{WRITING/PUBLISHING/EDITING}

Hartmann, E. E., Bradford, G. E., Chaplin, P. K., Johnson, T., Kemper, A. R., Kim, S., et al. (2006). Project universal preschool vision screening: A demonstration project [Abstract]. Journal of Pediatrics, 117(2), e226-237.

Nottingham Chaplin, P. K., \& Bradford, G. E. (2005, Summer). Child care providers to learn how to screen the vision of preschoolers this summer. West Virginia Early Childhood Provider Quarterly, (6)3, 25.

Nottingham Chaplin, P. K., \& Bradford, G. E. (2004, March). Partnering with Head Start to protect the vision of preschoolers in West Virginia. WVHSA Newsletter, (4)3, p. 2 .

Bradford, G. E. \& Nottingham Chaplin, P. K. (2003). Vision screening guidelines: Birth to 21 years. Unpublished manuscript for West Virginia Department of Health and Human Resources, West Virginia University. 
Nottingham Chaplin, P. K. \& Bradford, G. E. (2003). Mobilizing West Virginia Preschool Vision Screening, West Virginia Early Childhood Provider Quarterly, (4)2, $23-25$.

Thesis--"What West Virginia Families Think About Transition from Part C Early Intervention: A Retrospective Survey," March 31, 1998. Created and distributed a statewide survey (quantitative) and conducted interviews (qualitative) to: 1) Determine, through the caregiver perspective in West Virginia, the extent to which the 12 Birth to Three Early Intervention programs comply with federal regulations and state policies related to transition; 2) Help identify effective transition practices in West Virginia; and 3) Ascertain what aspects of transition could be better accomplished to ensure a smooth transition from Part C Birth to Three Early Intervention for future West Virginia families.

Cisar, C. L., Raab, M. M., \& Nottingham-Chaplin, P. K. (1995). Including Children with Disabilities in Community Settings: Administrative and Classroom Supports. Early Childhood Report, 3-4, 8.

Reviewing articles in a peer-reviewed journal: Journal of Optics.

Editing/proofreading project involving 15 technical training manuals for Training Consultants Incorporated, based in Morgantown.

Published a book through Charlie \& Chaplin Communications, a joint venture between my Red Pen Proofing, Etc., and Charlie Gilmore of NextPrint. Conducted typesetting and editing portion of publication.

\section{TEACHING/WORKSHOPS/POSTERS/PRESENTATIONS}

Teaching

87 Workshops

Workshop
SPED 663, a weekly, semester-long course on collaboration/consultation in the special education at West Virginia University, summer semester 2005.

SPED 663, a weekly, semester-long course on collaboration/consultation in the special education at West Virginia University, spring semester 2005.

Co-taught a culminating projects class at West Virginia University where students completed culminating projects to achieve master's degrees in special education - Summer 2004.

"Vision Initiative for Children, Preschool Vision Screening" throughout the state from $9 / 10 / 2001$ to the present - have trained more than 1,000 individuals, including representatives of Head Start, child care, nurses, physicians, Even Start, Early Head Start, preschool special needs teachers, Parents as Teachers, Child Care Resource \& Referral agencies, WVU Nursery School, Starting Points, Family Resource Networks, and WV Birth to Three.

"Building Relationships" for West Virginia Birth to Three Early Intervention - August 16, 2005 
Workshop

Poster

Poster

Poster

Poster

Poster

Poster

Round Table

Presentation

Presentation

Presentation

Presentation

Presentation
Quality child care for community and family day care providers as Monongalia County Facilitator for the West Virginia University Extension Services' Fundamentals, Ideas for Child Care Providers, program.

"Initial Results of a Statewide Preschool Vision Screening Program Based on the PUPVS Screening Recommendations" Bradford, G. E., \& Nottingham Chaplin, P. K. ARVO Annual Meeting, May 1, 2005.

"Preschool Vision Screening: A Survey of University-Based Primary Care Physicians" - Bradford, G. E., Wadia, J. T., \& Nottingham Chaplin, P. ARVO Annual Meeting, April 27, 2004.

"Preschool Vision screening Practices by Primary Care Physicians in West Virginia"-Bradford, GE, Nottingham Chaplin, PK, Odom, JV. ARVO annual meeting, May 8, 2003.

"A New, Modified Lea Symbols Chart Simplifies Preschool Visual Acuity Screening"-Bradford, G, Nottingham Chaplin, PK, Odom, JV, Schwartz, T. American Association of Pediatric Ophthalmology and Strabismus annual meeting, Kona, Hawaii, March 26, 2003.

"Transition in West Virginia: Retrospectives About the Gap"-(from master's thesis) with Dr. Gretchen Butera at Zero to Three in Washington, D.C., December 3-5, 1998.

"Transition in West Virginia: Retrospectives About the Gap"-(from master's thesis) with Dr. Gretchen Butera at DEC International Early Childhood Conference on Children with Special Needs in Chicago, IL, December 6-9, 1998.

"Evaluating Transition From Part C Birth to Three: How Well Are You Doing?"--Celebrating Connections, Charleston, February 26, 1999.

"Want to Protect Those Preschool Peepers? Screen Vision" with Geoffrey E. Bradford, MD, and Sueann Solomon, Parent, Celebrating Connections - 2/26/04

"Updates Regarding Vision Screening of Pre-K and Kindergarten Students", with Geoffrey E. Bradford, MD, West Virginia Association of School Nurses - Lakeview - 11/13/03

"WVU Vision Initiative for Children, Preschool Vision Screening" Lions Club Zone Meeting, Weirton, WV - 7/1/2002

"WVU Vision Initiative for Children, Preschool Vision Screening" WVU Ophthalmology Residents - 7/4/2003

"WVU Vision Initiative for Children, Preschool Vision Screening" Dr. Bobbi Warash's class - WVU - 2/23/2003 


\section{Presentation}

Presentation

Presentation

Presentation

Presentation

Presentation

Presentation

Presentation

Presentation

Presentation

Presentation

Presentation

Presentation

Presentation

Presentation
"WVU Vision Initiative for Children, Preschool Vision Screening" WV Head Start Association Meeting, Beckley, WV - 11/14/2002

"WVU Vision Initiative for Children, Preschool Vision Screening" Dr. Bobbi Warash's class - WVU - 10/2/2002

"WVU Vision Initiative for Children, Preschool Vision Screening" with Dr. Geoffrey E. Bradford, MD, - West Virginia Department of Health and Human Resources Leadership Team for EPSDT 9/20/2002

"WVU Vision Initiative for Children, Preschool Vision Screening" with Dr. Geoffrey E. Bradford, MD - Central West Virginia Medical Society - 8/10/2002

"WVU Vision Initiative for Children, Preschool Vision Screening" WVU Ophthalmology Residents - 7/1/2002

"WVU Vision Initiative for Children, Preschool Vision Screening" West Virginia Department of Health and Human Resources Leadership Team for family and children services - 6/10/2002

"WVU Vision Initiative for Children, Preschool Vision Screening" Dr. Bobbi Warash's class - WVU - 2/27/2002

"WVU Vision Initiative for Children, Preschool Vision Screening" Monongalia County Preschool Special Needs Teachers - 2/15/2002

"WVU Vision Initiative for Children, Preschool Vision Screening" Dr. Gretchen Butera's class - WVU - 11/13/2001

"WVU Vision Initiative for Children, Preschool Vision Screening" Dr. Bobbi Warash's class - WVU - 10/3/2001

"WVU Preschool Vision Screening Program"--WV Community Voices Partnership Third Annual Retreat, March 22, 2001.

"Hands-On and How To: Vision Screening for Infants and Toddlers"--with Dr. Geoffrey Bradford, pediatric ophthalmologist at WVU, Celebrating Connections, Charleston, February 22, 2001.

"Litigation or Negotiation? . . . Enhancing Win/Win ProblemSolving Negotiation Skills for Families and Professionals"-Celebrating Connections, Charleston, February 27, 1999.

"Transition: What Families Tell Us"--(from master's thesis) at Celebrating Connections in Charleston, WV, March 5-7, 1998.

"Young Children with Autism in the Classroom - What do we Know?"--with Diane Michael, CSPD Coordinator with the Office of Maternal and Child Health, at the West Virginia Association for Young Children State Conference October 18, 1997. 
Presentation

Presentation
"Nutrition As A Component of Part H"--with Pam Roush, Director of Early Intervention with the Office of Maternal and Child Health, at the state conference on Nutrition and Developmental

Disabilities: A Closer Look at Working with Individuals with Special Needs in May 1997.

Quality child care in group settings--with Diane Michael, CSPD Coordinator with the Office of Maternal and Child Health, at West Virginia University for state branch of National Association for the Education of Young Children.

\section{INTERNATIONAL, STATE, AND LOCAL COMMITTEE MEMBERSHIP}

International Level:

Member of Council for Exceptional Children: Divisions of Early Childhood and

Research

\section{State Level:}

Invited to participate as a stakeholder in the West Virginia Making A Difference Initiative, a joint undertaking between WV Birth to Three Early Intervention and the WV Department of Education's Preschool Special Needs program to develop a family and child outcomes system for early childhood.

Member of child wellness subcommittee of PIECES, a statewide advisory council to lead early care and education activities in West Virginia, including the state's new WV-PreK program.

Member of the Steering Committee and the General Supervision Subcommittee for the West Virginia Self-Assessment Monitoring Process for the West Virginia Departments of Education and Health and Human Resources.

Member of the Editorial Board for a state journal entitled, "West Virginia Early Childhood Provider Quarterly".

Governor-appointed consumer representative on the West Virginia Early Intervention Coordinating Council (WVEICC).

WVEICC consumer representative on the Task Force for Birth To Three Systems Evaluation in West Virginia.

Autism Task Force to establish guidelines for assisting children and families in West Virginia.

EQUIP subcommittee to create guidelines and a self-assessment for child care agencies serving families in West Virginia (represented the early intervention special education perspective).

Early Intervention Nutrition Task Team--Assisted in developing and implementing a nutrition screening form for statewide use in ensuring children are appropriately targeted for nutritional needs. 
Early Childhood Transportation Committee--Assisted in reviewing current research on the safest ways to transport young children in school buses and other vehicles and developing recommendations for a state guideline to assure safe practices for West Virginia children during transportation.

REIP (Recruitment for the Early Intervention Program) Advisory Committee-Assisted in establishing a program for recruiting and retaining therapists to serve children and families West Virginia.

West Virginia Early Childhood Transition Steering Committee Stakeholders-Assisted in giving guidance and direction to Transition Steering Committee.

\section{Local Level:}

Invited to assist the special education department in the Monongalia County School System with an on-site monitoring project.

Board of Directors for Monongalia County Family Resource Network.

Collaborative Council for Monongalia County Starting Points Center.

Co-chair of Early Childhood Committee for Monongalia County Family Resource Network.

Operation TADPOLE committees in Monongalia, Marion, Preston, and Taylor counties.

\section{MEETINGS/CONFERENCES ATTENDED}

\section{International Level:}

$20^{\text {th }}$ Annual DEC International Early Childhood Conference on Children and Special Needs, Chicago, IL, December 2004.

14th Annual DEC International Early Childhood Conference on Children with Special Needs, Chicago, IL, December 6-9, 1998.

Division for Early Childhood's International Early Childhood Conference on Children with Special Needs, San Diego, California, December 11-15, 1993.

\section{National Level:}

Zero to Three 13th National Training Institute, Washington, D.C., December 3-5, 1998.

Interactive video-teleconference - "Natural Environments Part 2: Implementation in the Community," November 12, 1998.

National interactive video-teleconference - "Natural Environments: Linking to the Community," May 21, 1998. 
"Developing State and Local Services for Young Children with Autism Spectrum Disorders and their Families," Clearwater Beach, FL, November 2-4, 1997.

"The Team Approach to Services for Children with Special Health Care Needs: Nutrition Makes a Difference," Chapel Hill, North Carolina, May 19-22, 1996.

"NEC*TAS Marketing Partnerships Between Early Childhood Services and Managed Care Meeting," San Antonio, Texas, March 4-6, 1996.

Invited to attend a national-level Leadership Forum on Including Children with Disabilities in Child Care Settings: Connections for Quality Care, sponsored by Child Care Bureau, Administration on Children, Youth, and Families, Washington, D.C., June 27, 1995.

\section{State Level:}

Celebrating Connections - Connecting Communities Through Early Care and Education, West Virginia's Second Annual Early Childhood Conference Charleston - February 24-27, 1999.

"Facilitative Leadership III" sponsored by the Part C Early Intervention Office and the Training Calendar and led by Peggy Hayden, October 21 and 22, 1998.

"Making it Happen: The IFSP - Part 1" interactive video-teleconference with Mary Beth Bruder, July 17, 1998.

The 1998 Statewide Early Intervention Conference for Pennsylvania: Building Communities Where All Children Belong, Hershey, PA, June 17-19, 1998.

"Outcomes \& Objectives: The Steps in the IFSP Process" with Mary Beth Bruder, Charleston, WV, June 4-5, 1998.

Interactive video-teleconference - "Changes and Updates in IDEA - Why Natural Environments?" with Ann Haggart, AGA Associates; Diane D. Michael; and Pam Roush, May 1, 1998.

Celebrating Connections: Connecting Communities through Early Care and Education, West Virginia's First Annual Early Childhood Conference, Charleston, WV, March 5-7, 1998.

"Assuring the Family's Role on the Early Intervention Team--Explaining Rights and Safeguards" sponsored by the Part C Early Intervention Office and presented by Joicey Hurth, Associate Director, NEC*TAS, University of North Carolina, and Paula Goff, Director of Early Childhood Programs, Missouri Department of Education, September 25-26, 1997. 
"Facilitative Leadership II" sponsored by the Part C Early Intervention Office and the Training Calendar and led by Peggy Hayden, August 13 and 14, 1997.

Service Coordination/mentorship, 1997.

"Tadpole Follow-up Training" sponsored by Part H Early Intervention Program/Office Maternal \& Child Health and Office of Special Education and Program Assurances/West Virginia Department of Education, December 15, 1995.

"Group Facilitation Training" (Facilitative Leadership I) sponsored by Part H Early Intervention Program and led by Peggy Stephens Hayden, October 19 and 20, 1995.

"An Introduction to Genetics: Syndromes and Conditions" sponsored by Part H Early Intervention Program/Office of Maternal \& Child Health and Office of Special Education and Program Assurances/West Virginia Department of Education, September 13, 1995.

"Empowerment of Families" sponsored by Part H Early Intervention Program/Office of Maternal \& Child Health and Office of Special Education and Program Assurances/West Virginia Department of Education, August 21, 1995.

"Nutritional Needs of Infants, Toddlers, and Preschoolers," May 3, 1995.

Early Intervention Conference, Olgebay Park, Wheeling, July 24-26, 1994.

First Annual PATHS (Partnerships in Assistive TecHnologieS) Conference, Charleston, May 19-20, 1994.

Tenth Annual Chapter 1 Early Intervention Conference, Canaan Valley Resort, July 28-30, 1993.

\section{Regional Level:}

"Criticism \& Discipline Skills for Managers," A CareerTrack seminar, April 24, 1998.

"Maximizing West Virginia's Brain Power: We Need to Use it or Lose it," Morgantown, WV, November 9, 1998.

"Writing an Interagency Agreement," Fairmont, WV, December 12, 1997.

Five-day "Grantsmanship Training Program" through The Grantsmanship Center, Los Angeles, CA, June 23-27, 1997. 
"Meeting Family Needs in Classroom-Based Settings: What Does It Take of Staff?" presented by Melinda Raab, Ph.D.; Connie Cisar, M.A., CCC-SLP; and Holly Shields, M.S., M.Ed. of Project SUNRISE, Child and Family Studies Program, Allegheny-Singer Research Institute, Pittsburgh, PA, December 4, 1995.

"Promoting Staff Performance: Using Effective Management Practices in Early Childhood Programs" presented by Melinda Raab, Ph.D. and Connie Cisar, M.A., CCC-SLP, Project SUNRISE, Child and Family Studies Program, AlleghenySinger Research Institute, Pittsburgh, PA, December 4, 1995.

"Self-Directed Work Teams" presented by Fred Pryor Seminars, August 14, 1995.

"Operation Tadpole" sponsored by The Early Intervention Program and the West Virginia Department of Education, November 30-December 2, 1994.

"Communication and Language Intervention for Preschool Children" presented by Amy Wetherby, Ph.D., CCC-SLP, October 28, 1994.

"If Only They Could Talk? Replacing Behavior Problems with Communication" presented by V. Mark Durand, October 27, 1994.

"Follow-up to Growing: Birth to Three" sponsored by The Early Intervention Program, June 29, 1994.

"Emotional/Developmental Delays and Disorders in Infants and Children" presented by Dr. Stanley I. Greenspan through the 5th Annual Issues in Infancy conference sponsored by the Department of Pediatrics at Allegheny General Hospital in Pittsburgh, October 13, 1993. 